\title{
WestVirginiaUniversity
}

THE RESEARCH REPOSITORY @ WVU

Graduate Theses, Dissertations, and Problem Reports

2007

\section{Solidification modeling of iron castings using SOLIDCast}

Piyapong Muenprasertdee
West Virginia University

Follow this and additional works at: https://researchrepository.wvu.edu/etd

\section{Recommended Citation}

Muenprasertdee, Piyapong, "Solidification modeling of iron castings using SOLIDCast" (2007). Graduate Theses, Dissertations, and Problem Reports. 1805.

https://researchrepository.wvu.edu/etd/1805

This Thesis is protected by copyright and/or related rights. It has been brought to you by the The Research Repository @ WVU with permission from the rights-holder(s). You are free to use this Thesis in any way that is permitted by the copyright and related rights legislation that applies to your use. For other uses you must obtain permission from the rights-holder(s) directly, unless additional rights are indicated by a Creative Commons license in the record and/ or on the work itself. This Thesis has been accepted for inclusion in WVU Graduate Theses, Dissertations, and Problem Reports collection by an authorized administrator of The Research Repository @ WVU. For more information, please contact researchrepository@mail.wvu.edu. 


\title{
Solidification Modeling of Iron Castings Using SOLIDCast
}

\author{
Piyapong Muenprasertdee
}

Thesis submitted to

The College of Engineering and Mineral Resources

at West Virginia University

in partial fulfillment of the requirements

for the degree of

Master of Science

in

Industrial and Management Systems Engineering

\author{
R. C. Creese, Ph.D., Co-Chair \\ B. Gopalakrishnan, Ph.D., Co-Chair \\ X. B. Liu, Ph.D. \\ Department of Industrial and Management Systems Engineering \\ Morgantown, West Virginia \\ 2007
}

Keywords: Casting, Simulation, SOLIDCast, Finite Difference Method, Cast Iron Copyright 2007 Piyapong Muenprasertdee 


\section{ABSTRACT \\ Solidification Modeling of Iron Castings Using SOLIDCast \\ Piyapong Muenprasertdee}

SOLIDCast is a casting simulation software program which can simulate thermal changes and heat transfer in the solidification process of a casting. It assists the user to visualize the solidification process of a particular casting. The program offers functions to help guide a user in producing gating and riser designs and also have functions which produce visual outputs showing possible problem areas and defects which may occur in a casting. It can help shorten the lead time and reduce the loss in the trial casting stage.

This thesis consists of studies to determine the important capabilities and limitations of the software, the usefulness of the riser and gating design wizard programs offered in SOLIDCast to help a user design the riser and gating system, and the simulation results and analysis of a casting design of a locomotive piston made from gray iron. 


\section{ACKNOWLEDGEMENTS}

I would like to sincerely thank Dr. R. C. Creese and Dr. B. Gopalakrishnan, both of my co-chairs of for teaching, advising and taking care of me throughout my three years at West Virginia University. Dr. Creese was my graduate advisor and teacher and Dr. Gopalahrishnan was my research advisor and teacher as well. My life in West Virginia University has become easier because of both of them.

I would like to thank Dr. X. B. Liu for being in the committee and offering his help in my thesis.

I thank Mr. J. D. Schmidt, manager of the HK Engine Components Casting Division, HK Engine Components, LLC. for letting me use one of their products as a case study and also for helping me with what I needed for the thesis. I would also like to thank Mr. Brandon Lamoncha, CNC programmer from Humtown Products for helping me with the CAD designs of the casting design.

I thank Mr. David Schmidt of Finite Solutions Inc. for helping me and giving me valuable advices about SOLIDCast.

I would like to thank Mr. Sawai and everyone from BIS Pipe Fitting Industry Co., Ltd., Thailand for letting me study the casting processes at your company along with all the help for writing my thesis.

I would like to thank Mr. Navin Vongchankit and family, and everyone at Thai Alloy and Associates Co., Ltd., Thailand, for helping me learn the casting process and the use of casting simulations in your company.

I would like to specially thank Dr. Sombun Charoenvilaisiri from King Mongkut's University of Technology Thonburi, Thailand, and Dr. Suwanchai Pongsukijwat from Chulalongkorn University, Thailand for teaching me about casting simulations and advising me about my thesis.

I would also like to thank Siam Castech Co. and its sister company for letting me study the casting process at their facilities. 


\section{TABLE OF CONTENTS}

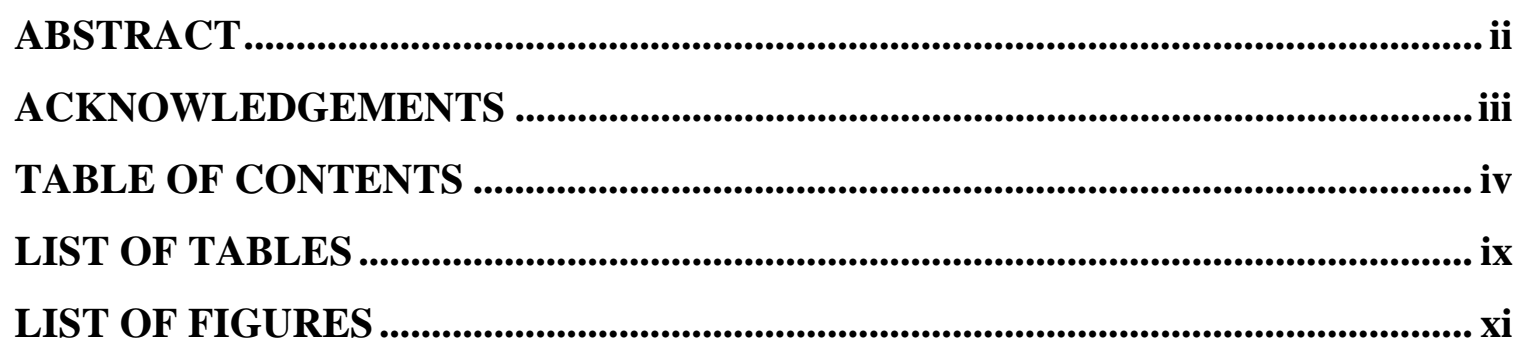

Chapter 1: Introduction .......................................................................................................... 1

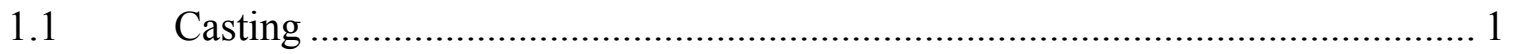

1.2 Advantages and disadvantages of casting ................................................... 1

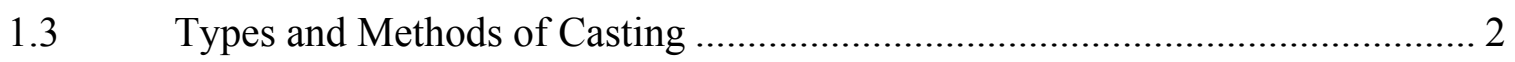

The Casting Process .................................................................................... 4

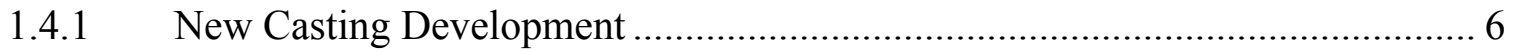

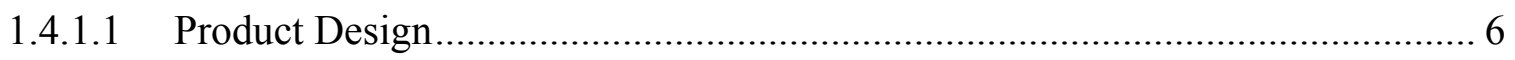

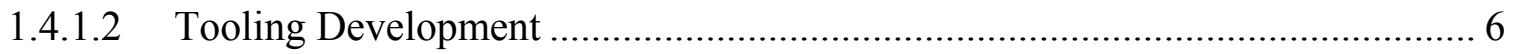

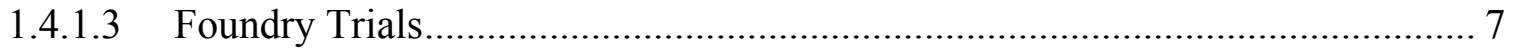

1.4.2 The Next Step in Casting Development........................................................ 8

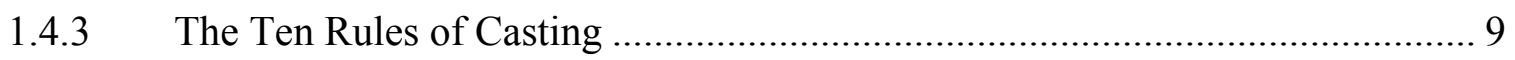

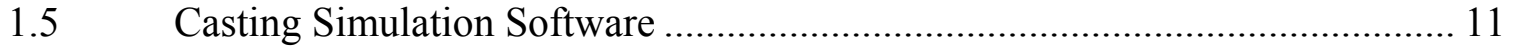

1.5.1 The Usefulness of Casting Simulation Software ....................................... 12

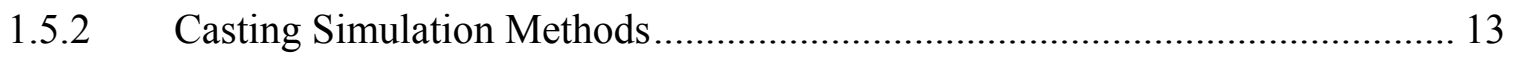

1.5.3 Finite Difference Method (FDM) and Finite Element Method (FEM)............ 13

1.5.4 Limitations of Casting Simulation Software .............................................. 15

1.5.5 Depths in Casting Simulation Involvement ............................................. 15

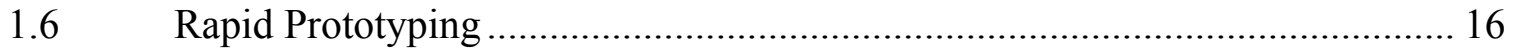

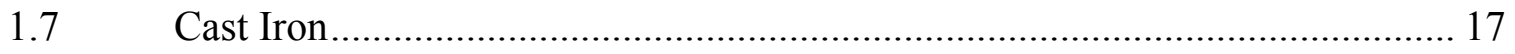

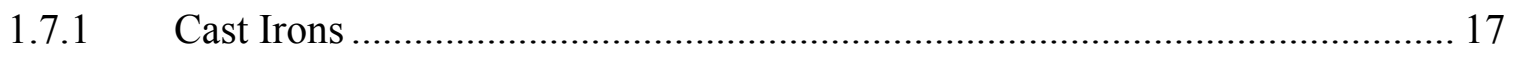

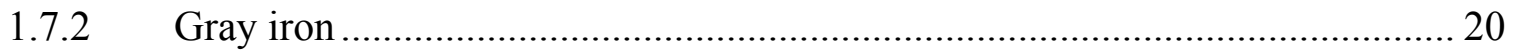

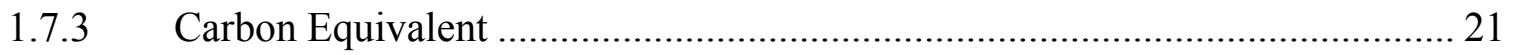

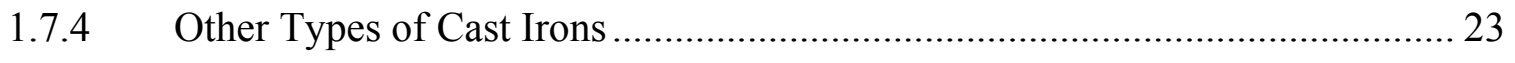

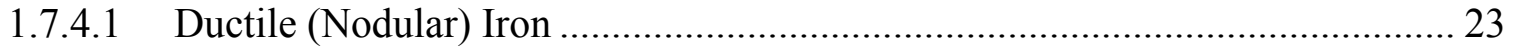




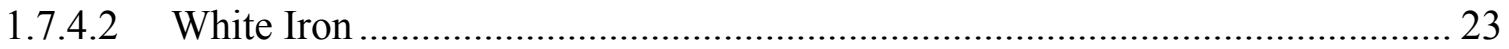

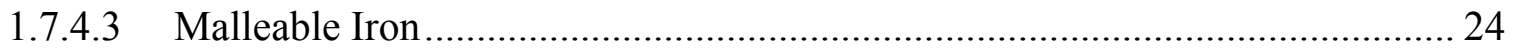

1.7.4.4 Compacted Graphite Iron.............................................................................. 24

$1.8 \quad$ Cast Iron Alloys Appearing in SOLIDCast .................................................. 27

$1.9 \quad$ Problems Occurred in Casting .................................................................... 28

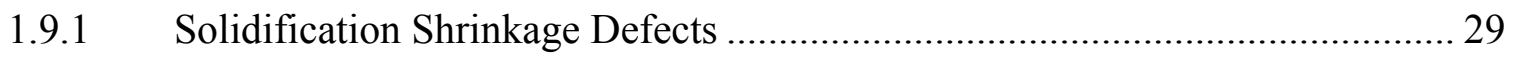

1.9.2 Defects Occurred in Cast Iron..................................................................... 30

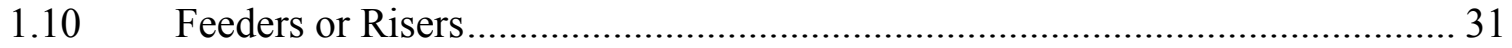

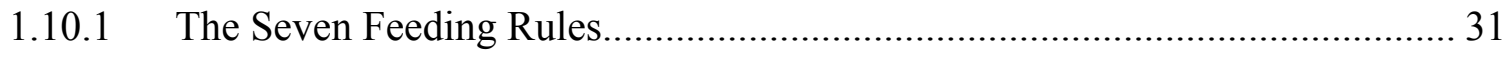

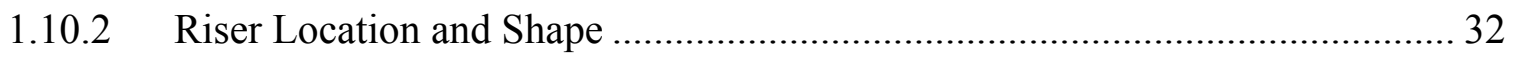

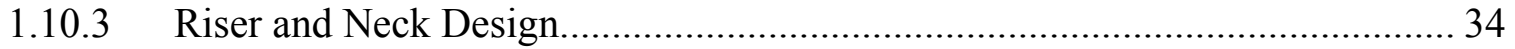

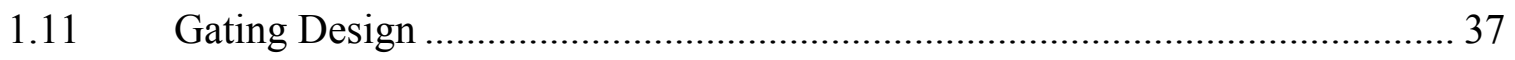

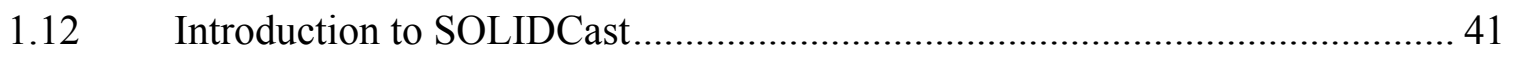

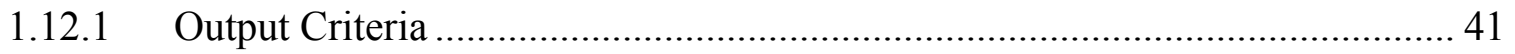

1.12.2 Plotting the Results of Output Criteria........................................................... 47

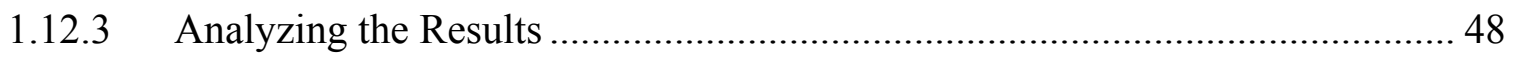

1.12.4 Limitations in Predicting Defects in SOLIDCast .......................................... 48

1.13 The Basic Steps and Functions in SOLIDCast for Sand Casting Cast Irons .... 49

1.14 Extension Programs of SOLIDCast ............................................................. 50

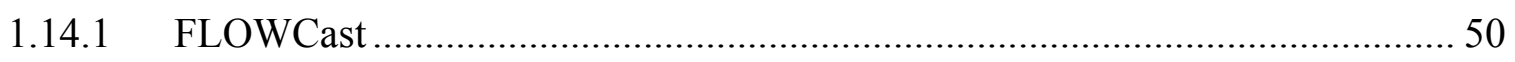

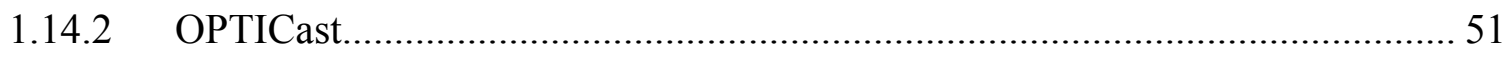

1.15 Commercial Software for Computer Simulation in Metal Casting ……….......52

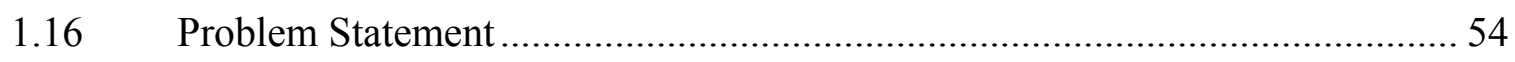

Chapter 2: Literature Review.................................................................................................. 56

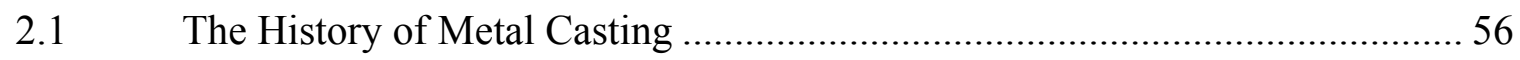

2.2 Studies of Casting Technology and Simulation Software for Casting ............. 57

2.2.1 Casting Techniques and Technologies............................................................. 57

2.2.2 Studies Useful for Casting Simulation Software …………………................58

2.2.3 Studies About Casting Simulation Software....................................................... 60

2.2.4 Implemented Casting Simulation Software Case-studies ................................... 61 
Chapter 3: The Use of SOLIDCast................................................................................ 63

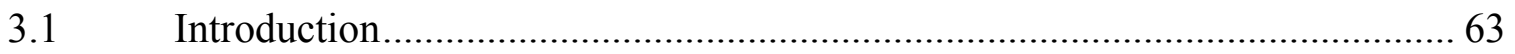

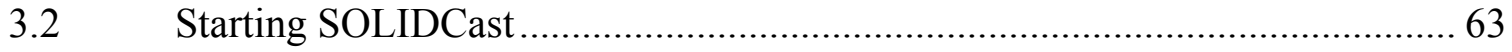

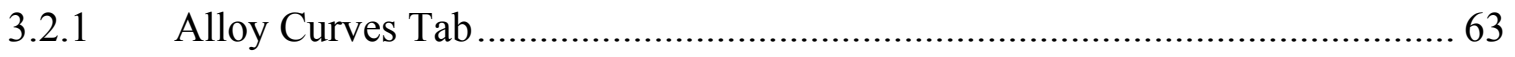

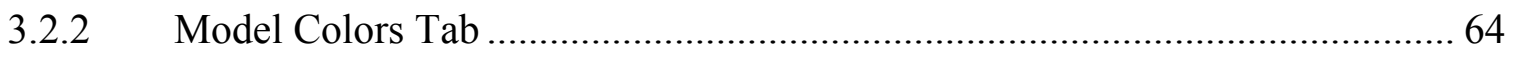

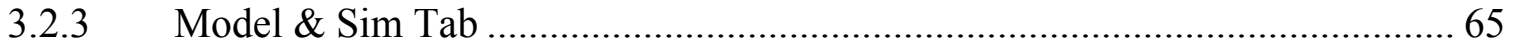

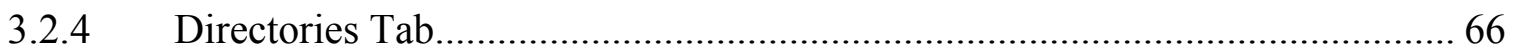

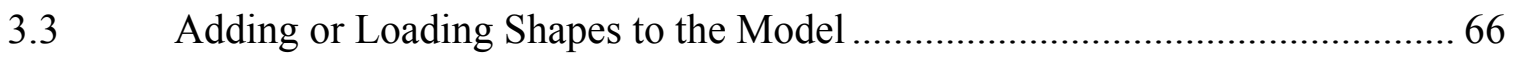

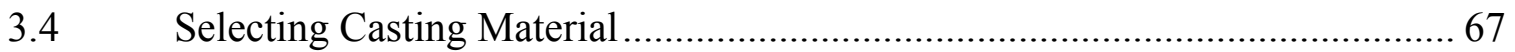

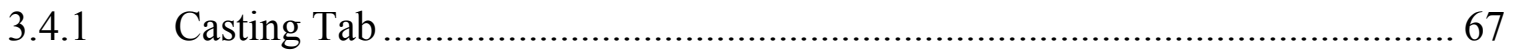

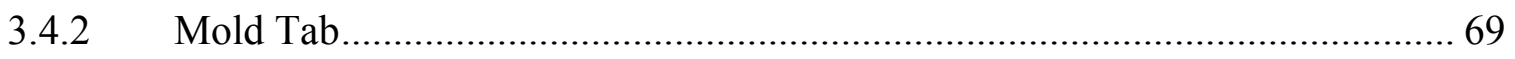

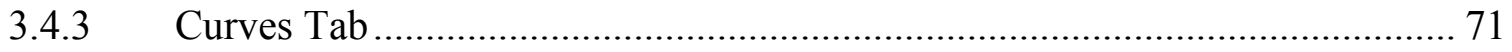

3.4.4 Heat Transfer Coefficients Tab.................................................................. 76

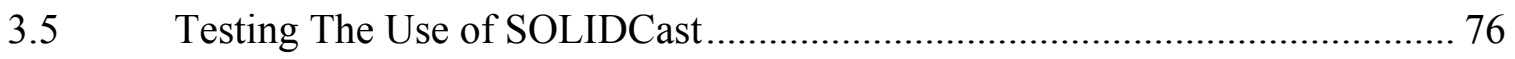

3.5.1 Basic Functions for Simulating Cast Irons …………………........................ 77

3.5.1.1 The Casting Tab and the Curves Tab............................................................. 77

3.5.1.2 The Gray Iron and Ductile Iron Calculator Buttons ........................................ 77

3.5.1.3 The VDG Iron Properties Calculator .............................................................. 79

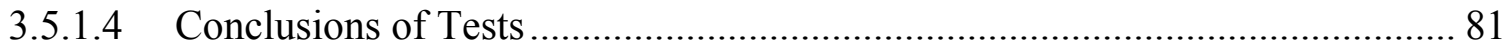

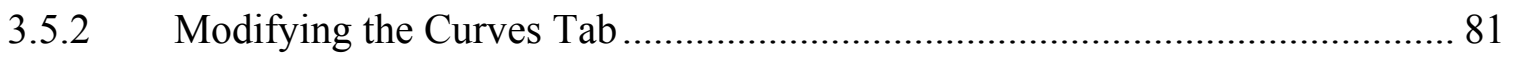

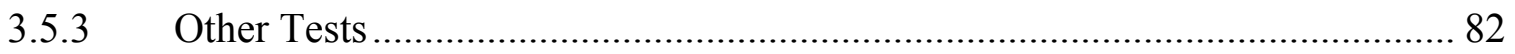

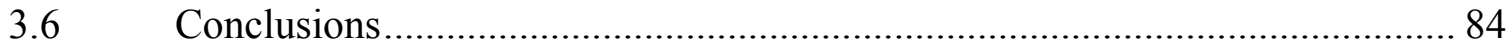

Chapter 4: Using SOLIDCast: Simple Model.................................................................... 85

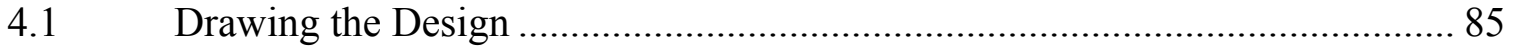

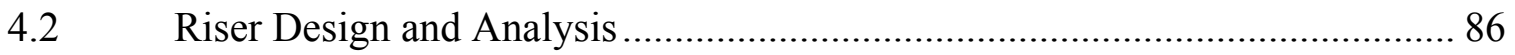

4.2.1 Analysis of the Riser Design Wizard Input Values ......................................... 91

4.2.2 Analysis of the Riser Design Wizard Output Values........................................... 93

4.2.3 The Results of the Riser Design................................................................... 98 


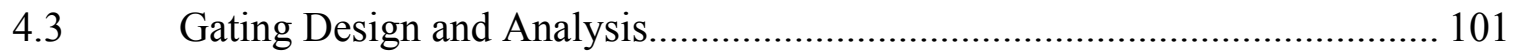

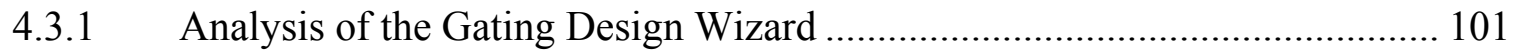

4.3.2 The Results of the Gating Design .............................................................. 111

4.4 The Resulting Dimensions for the Simple Casting Design ........................... 114

4.4.1 Dimensions from Riser Design Wizard ................................................. 115

4.4.2 Dimensions from Gating Design Wizard................................................. 116

4.5 Simulation Results and Analysis of Simple Casting Design ........................ 117

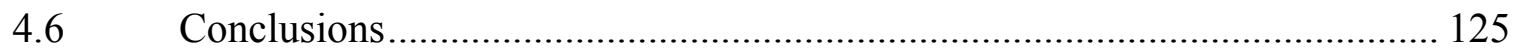

Chapter 5: Using SOLIDCast: Case Study ......................................................... 127

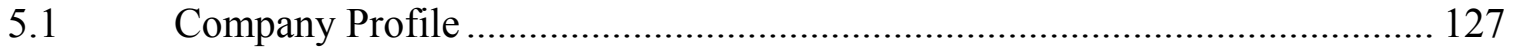

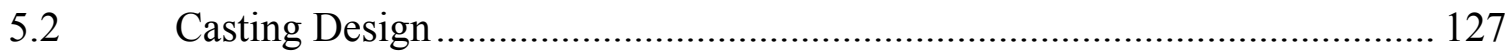

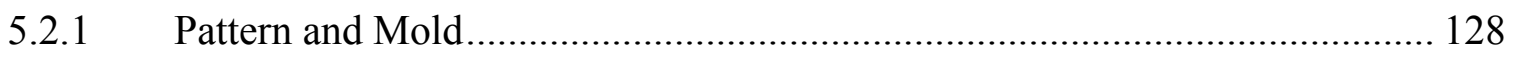

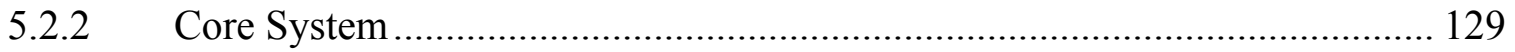

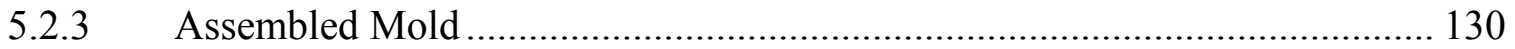

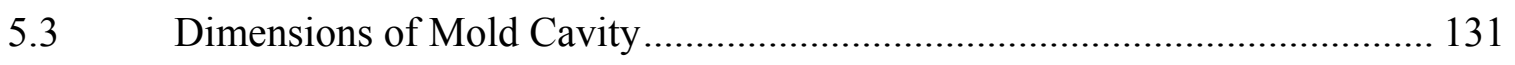

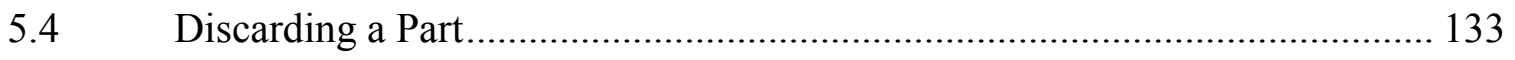

5.5 Modeling the Casting Design in SOLIDCast.............................................. 134

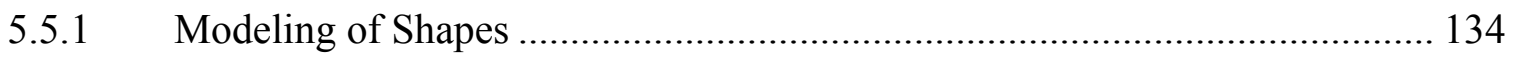

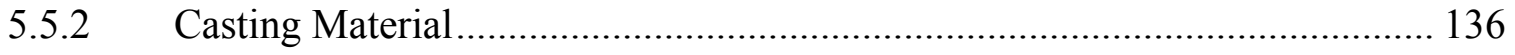

5.5.3 Setting Up the Materials List Window .................................................... 139

5.6 Verifying the Simulation Results with the Casting..................................... 142

5.6.1 Simulation Results of Base Case .......................................................... 143

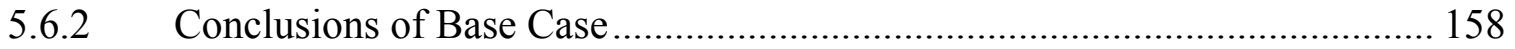

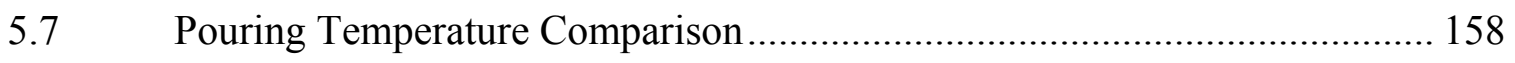

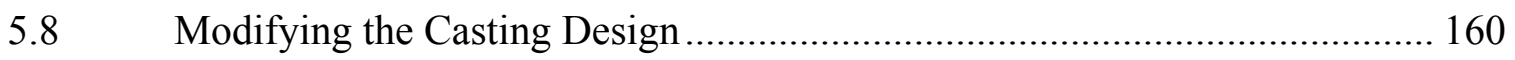

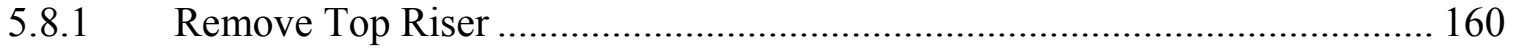

5.8.2 Reduce Size of Neck of Top Riser........................................................ 162

5.8.3 Add a Circular Fin Around Outer Surface of Upper Ring Hot Spot ............. 162

5.8.4 Add Circular Fins Around Outer and Inner Surface of Upper Ring Hot Spot 164

5.8.5 Add Fin at Outer Surface of Upper Ring Hot Spot Across from Top Riser... 165 
5.8.6 Comparing 3.975 and 3.70 Percent Carbon Equivalent to Base Case ............ 166

5.8.7 Add Hemispheric Bottoms to Side Risers .................................................... 168

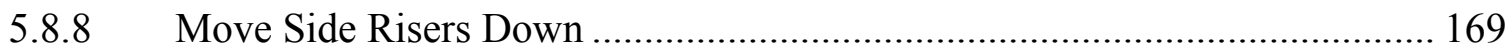

5.8.9 Conclusions of Modifying the Casting Design .............................................. 169

5.9 Using the Riser and Gating Design Wizard Programs.................................... 170

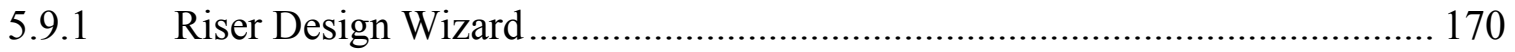

5.9.1.1 Riser Design Wizard: Simulation Tab ........................................................ 170

5.9.1.2 Riser Design Wizard: VDG Iron Properties Calculator.................................. 183

5.9.2 Gating Design Wizard......................................................................... 190

5.10 Simulation Results of Re-designed Casting Design ........................................ 195

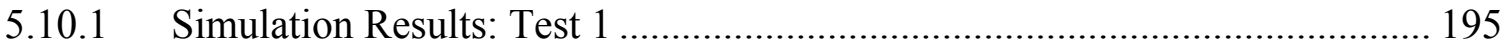

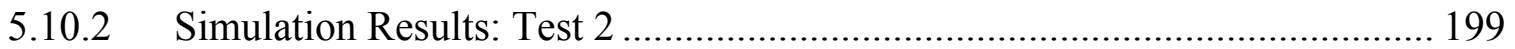

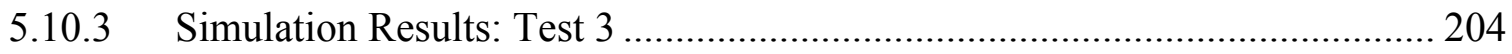

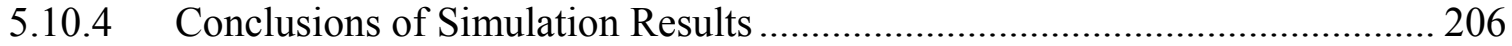

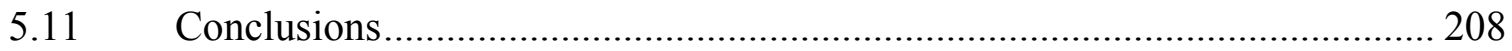

Chapter 6: Summary and Conclusions ............................................................................... 209

6.1 Basic Capabilities and Limitations of the Simulation Function ..................... 209

6.2 Usefulness of the Riser Design Wizard and Gating Design Wizard Programs 213

6.3 Further Capabilities and Limitations Found from the Case Study ................. 217

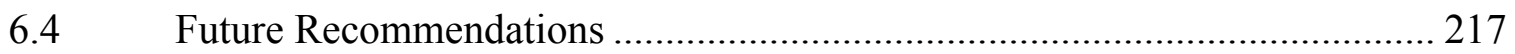

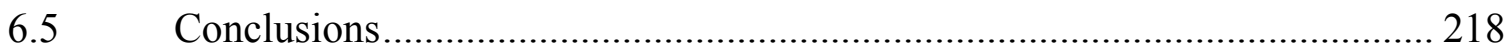

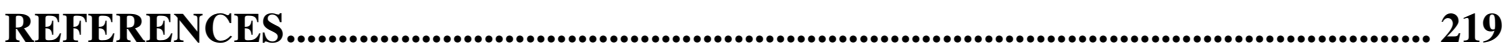




\section{LIST OF TABLES}

\section{Chapter 1: Introduction}

Table 1.1: The typical chemical composition of each type of cast iron (Prasertsakul).... 25

Table 1.2: Selected sprue-runner-gate area ratios (Heine, 1995)....................................... 40

Table 1.3: Different types of materials and their critical Niyama value........................... 44

\section{Chapter 3: The Use of SOLIDCast}

Table 3.1: The weight percent carbon and silicon and mold wall movement of each cast

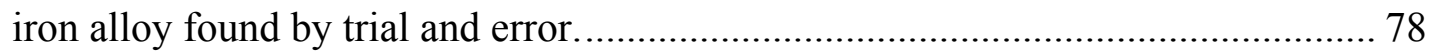

Table 3.2: The relationships of the input and output values in the VDG Iron Properties

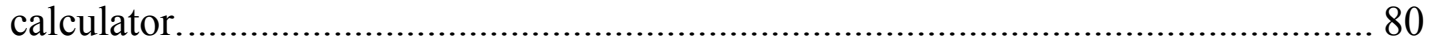

\section{Chapter 4: Using SOLIDCast: Simple Model}

Table 4.1: Resulting values when type of sleeve and option of gating through the riser is selected in the Sleeve Type box.

\section{Chapter 5: Using SOLIDCast: Case Study}

Table 5.1: Default values of each attribute of each gray iron alloy in the Casting tab... 137

Table 5.2: The results from the VDG Iron Properties Calculator of each pouring

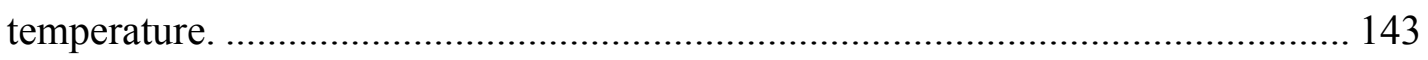

Table 5.3: Values retrieved from the Simulation Status windows................................. 158

Table 5.4: Comparing the severity of the problems predicted by each criterion of the three pouring temperatures.

Table 5.5: Comparing the results from the VDG Iron Properties Calculator of 3.70, 3.85 and 3.975 percent Carbon Equivalent.

Table 5.6: Comparing the results from the Simulation Status window of 3.70, 3.85 and 3.975 percent Carbon Equivalent.

Table 5.7: The inputs needed and outputs provided by each calculator button in the calculator box

Table 5.8: Riser efficiency factor values resulting from different casting modulus values.. 
Table 5.9: Comparing the actual riser volumes and the calculated riser volume required

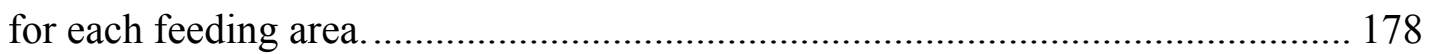

Table 5.10: The actual and calculated surface areas of the necks connecting the three

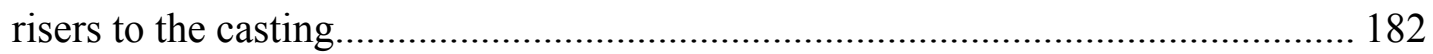

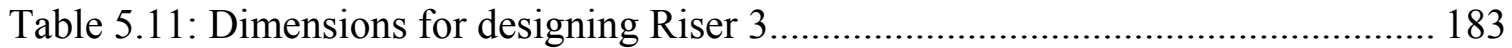

Table 5.12: The modulus and volumes of the three feeding areas of the casting.......... 184

Table 5.13: The calculated diameters, heights and volumes of the risers and the neck

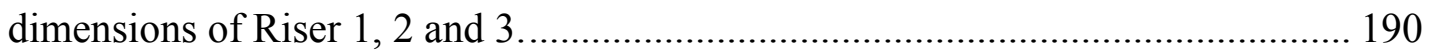

Table 5.14: Dimensions of the current gating system and the proposed gating system. 194 Table 5.15: The percent decrease in casting material weight compared to the base

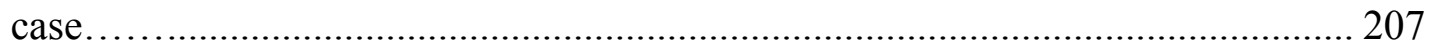

Table 5.16: The casting yield of each case including the base case. .............................. 207 


\section{LIST OF FIGURES}

\section{Chapter 1: Introduction}

Figure 1.1: Main procedures of casting, modified from the casting process procedure of the Thai Alloy and Associates Co., Ltd. and Creese (1999)...................................... 5

Figure 1.2: Cost and impact of product development phases (modified from Ravi, 2005).8

Figure 1.3: Iron-carbon phase diagram................................................................... 18

Figure 1.4: Iron-iron carbide (dotted lines) and true equilibrium phase diagram (bold lines).

Figure 1.5: The relationships between the thickness or diameter of the casting, mechanical properties and the liquidus temperature of the cast iron with the percent Carbon Equivalent (Reproduced from Prasertsakul)

Figure 1.6: Types of cast iron which result from different carbon composition ranges and schematic microstructures which result from a variety of heat treatments............... 26

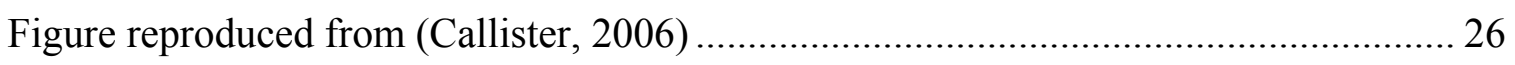

Figure 1.7: Simple guidelines in designing a side riser and a top riser with a height per diameter ratio of 1.0 (Modified from Heine (1995)). 36

\section{Chapter 3: The Use of SOLIDCast}

Figure 3.1: The Alloy Curves tab in the Systems Parameters window. 64

Figure 3.2: The Model Colors in the System Parameters window. .................................. 65

Figure 3.3: The Model \& Sim tab in the System Parameters window. ............................ 65

Figure 3.4: The Directories tab in the System Parameters window................................... 66

Figure 3.5: The Casting tab in the Materials List window. ................................................ 69

Figure 3.6: The Mold tab in the Materials List window................................................ 70

Figure 3.7: The Curves tab in the Materials List window. .............................................. 72

Figure 3.8: The iron properties calculator from pressing the Gray Iron or Ductile Iron button. 73

Figure 3.9: The VDG Iron Properties Calculator located in the Tools menu. 75

Figure 3.10: The corresponding shrinkage curve (black line) using the results from Figure 3.9 . 75

Figure 3.11: The Materials List window showing the HT Coefficients tab. 76 
Figure 3.12: Temperature curve developed by the Ductile Iron calculator button.......... 79

Figure 3.13: Temperature curve developed by the Gray Iron calculator button.............. 79

Figure 3.14: An example of the VDG nomograms from the German Iron Society using

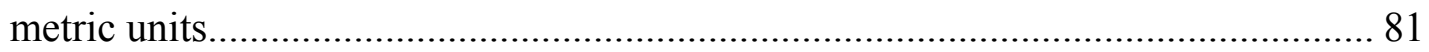

\section{Chapter 4: Using SOLIDCast: Simple Model}

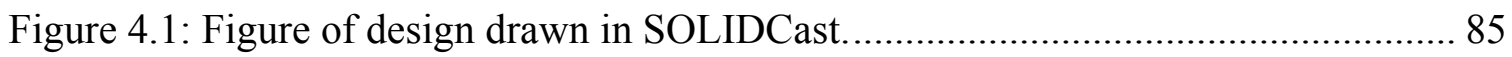

Figure 4.2: Casting tab with properties of material used in test. ................................. 86

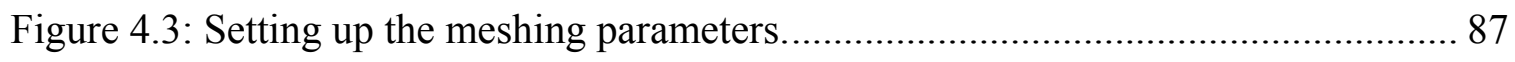

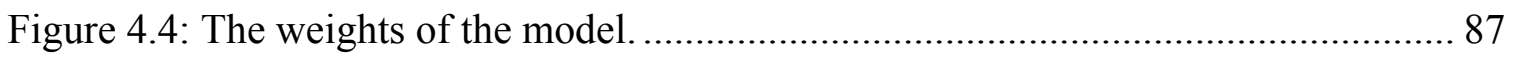

Figure 4.5: Finding the casting modulus from the Riser Design Wizard. ....................... 88

Figure 4.6: Modulus plot showing one feeding area plotted with the suggested value,

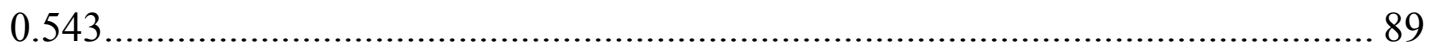

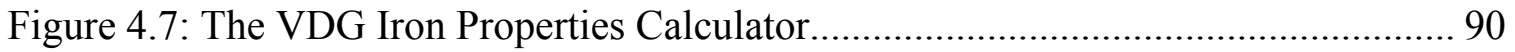

Figure 4.8: The Riser Design Wizard window accessed from the VDG Iron Properties

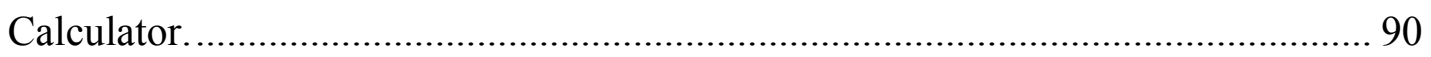

Figure 4.10: The final calculation of the Riser Design Wizard .................................... 98

Figure 4.11: Calculated dimensions of the riser from the Riser Design Wizard............. 99

Figure 4.12: Modulus plot showing one feeding area plotted with the neck modulus,

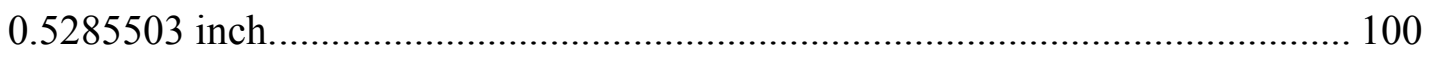

Figure 4.13: Calculating the optimal fill time for the casting.................................. 102

Figure 4.14: Gate Position window for top gating system...................................... 103

Figure 4.15: Gate Position window for bottom gating system. .................................. 104

Figure 4.16: Gate Position window for parting line gating system. ............................ 104

Figure 4.17: Calculated sprue data window, continued from Figure 4.15 ................... 106

Figure 4.18: The "step down" calculation of the runner......................................... 109

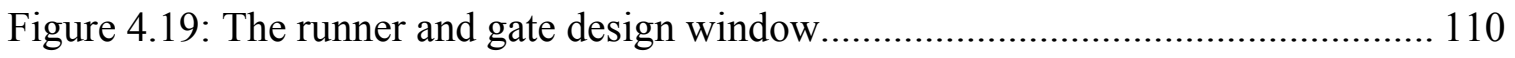

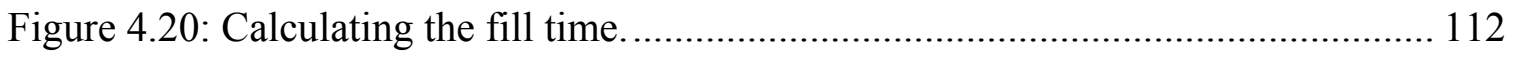

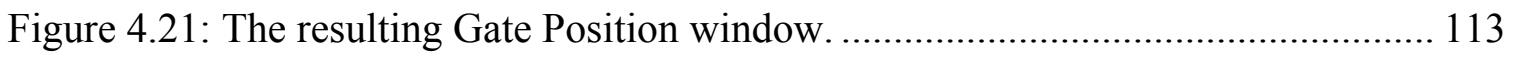

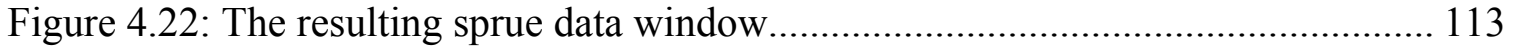

Figure 4.23: The resulting runner and gate design window..................................... 114 
Figure 4.24: The sequence of how liquid metal poured from the ladle enters the mold. 115

Figure 4.25: Casting model in SOLIDCast using all calculated and user-defined

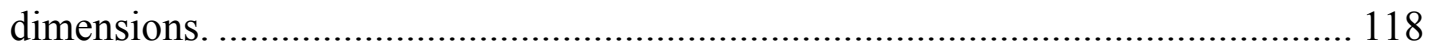

Figure 4.26: The Casting tab set with values representing the casting model............... 119

Figure 4.27: The Curves tab set with values representing the casting model................ 119

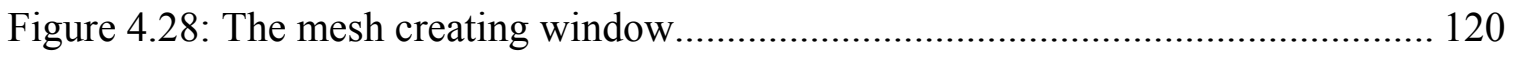

Figure 4.29: The calculated weights of the materials in the model after meshing. ........ 121

Figure 4.30: Critical Fraction Solid Time plots plotted at 10, 10.5, 11, 11.5, 12 and 12.5

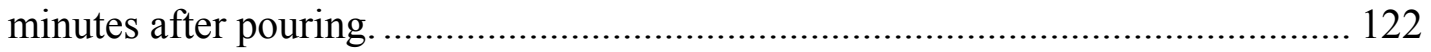

Figure 4.31: Cut-plane plots of the Critical Fraction Solid Time criterion. .................. 123

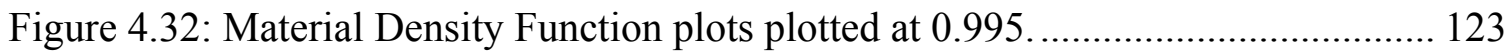

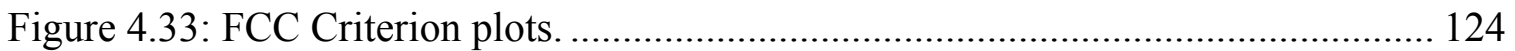

Figure 4.34: Hot Spot Criterion calculated from Critical Fraction Solid Time............. 124

Figure 4.35: Hot Spot Criterion calculated from Solidification Time.......................... 125

\section{Chapter 5: Using SOLIDCast: Case Study}

Figure 5.1: Locomotive piston produced by HKEC. .............................................. 128

Figure 5.2: The cope pattern (left) and drag pattern (right)................................... 128

Figure 5.3: The cope mold (left) and drag mold (right).......................................... 129

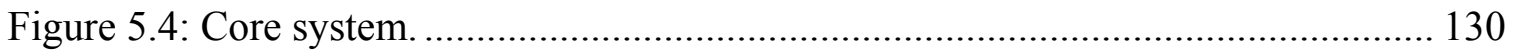

Figure 5.5: Assembled mold with liquid metal and magnesium based insulators covering

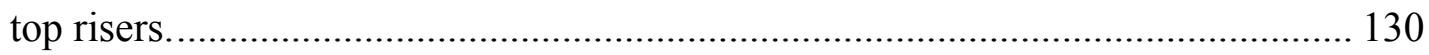

Figure 5.6: Dimensions of top and side risers of casting....................................... 131

Figure 5.7: Dimensions of the mold cavity and gating system.................................. 132

Figure 5.8: Half of the model created in SOLIDCast with Plane of Symmetry

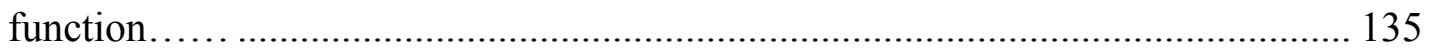

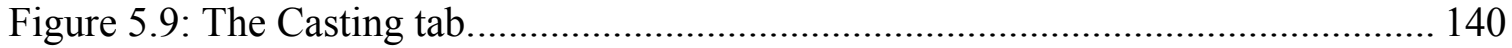

Figure 5.10: The Mold tab showing the attributes of the magnesium based exothermic

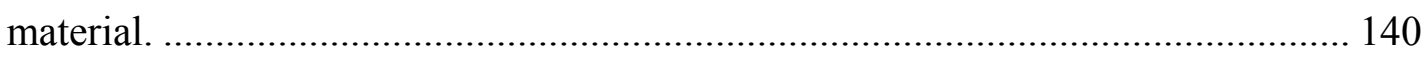

Figure 5.11: The VDG Iron Properties Calculator.................................................. 141

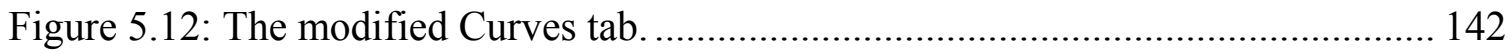


Figure 5.13: Left: Progress of solidification before model re-alignment. Right: Progress of solidification after model re-alignment. ..................................................... 145

Figure 5.14: A shaken out casting placed upside-down. ............................................ 146

Figure 5.15: Critical Fraction Solid Time criterion plotted at 0, 1.0, 1.5 and 2 minutes after mold is filled. 146

Figure 5.16: Critical Fraction Solid Time criterion plotted at 0, 1.0, 1.5, 2.0, 2.5, 3.0, 3.5, 4.0, 4.5, 5.0, 5.5 and 6.0 minutes after mold is filled.

Figure 5.17: Critical Fraction Solid Time criterion plotted at 6.5, 7.0, 7.5, 8.0, 8.5, 9.0, 9.5 and 10.0 minutes after mold is filled. 148

Figure 5.18: Material Density Function plots plotted at 1.0, 0.995 and 0.99 respectively from top to bottom. 150

Figure 5.19: Front view of casting before fettling or knock-off. 151

Figure 5.20: Top view of casting before fettling or knock-off. 151

Figure 5.21: Left; blind single riser. Right; blind shared riser. 152

Figure 5.22: Material Density Function cut-plane plot plotting areas with density values from 0 to 1 152

Figure 5.23: FCC Criterion plots. 153

Figure 5.24: Hot Spot Criterion (Solidification Time) plotted at 1.1. 154

Figure 5.25: Hot Spot Criterion (Critical Fraction Solid Time) plotted at 1.1. 155

Figure 5.26: Hot Spot (Solidification Time) cut-planes plot plotted between 1.0 and 1.1. 155

Figure 5.27: Hot Spot (Critical Fraction Solid Time) cut-planes plot plotted between 1.0

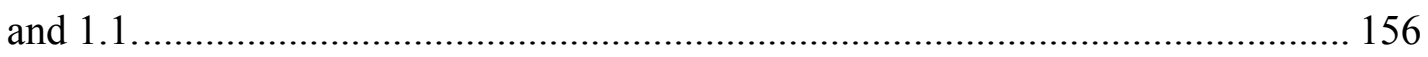

Figure 5.28: Hot Spot (Solidification Time) plotted with 1.0.................................... 156

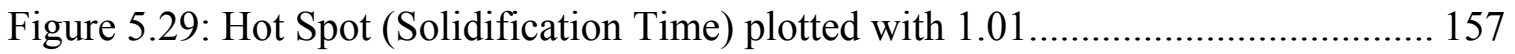

Figure 5.30: Hot Spot (Critical Fraction Solid Time) plotted with 1.0........................ 157

Figure 5.31: Hot Spot (Critical Fraction Solid Time) plotted with 1.01....................... 157

Figure 5.32: Iso-surface plots of the Material Density Function plotted at $0.995 \ldots \ldots \ldots . .161$

Figure 5.33: Cut-plane plots of the Material Density Function plotted from 0 to 1 ...... 161

Figure 5.34: Solidification Time plot plotted at 0 minute. ........................................ 163

Figure 5.35: Cut-plane plots of Hot Spot (Solidification Time) Criterion. .................... 164 
Figure 5.36: Cut-plane plots of Hot Spot (Solidification Time) Criterion. ................... 165

Figure 5.37: Material Density Function plots plotted at 0.995 .................................. 166

Figure 5.38: Options of "Calculate and Display Casting Modulus" and "Design

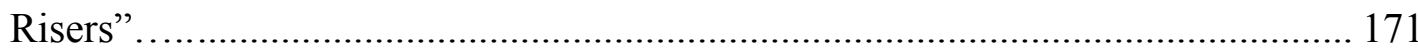

Figure 5.39: Modulus plot set up window. ............................................................... 171

Figure 5.40: The resulting plots from the modulus plot set up window in Figure 5.39. 172

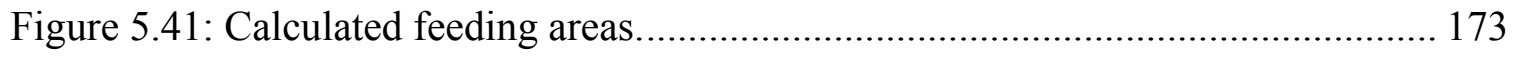

Figure 5.42: Plotted feeding areas; from left to right, Feed Area 1, Feed Area 2 and Feed Area 3.

Figure 5.43: Plots plotted from feeding area identification modulus value of 0.39 showing 3 feeding areas. 174

Figure 5.44: Riser calculator for Feed Area 1........................................................ 175

Figure 5.45: Riser calculator for Feed Area 2 ................................................... 175

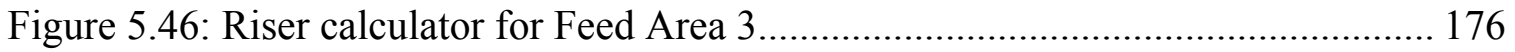

Figure 5.47: Calculated dimensions for Riser 3; the top riser. ................................... 179

Figure 5.48: Resulting calculations for Riser 1 in Riser Design Wizard....................... 185

Figure 5.49: Resulting calculations for Riser 2 in Riser Design Wizard...................... 186

Figure 5.50: Resulting calculations for Riser 2 feeding two feeding areas in Riser Design Wizard.

Figure 5.51: Resulting calculations for Riser 3 in Riser Design Wizard with normal neck.

Figure 5.52: Resulting calculations for Riser 3 in Riser Design Wizard with short

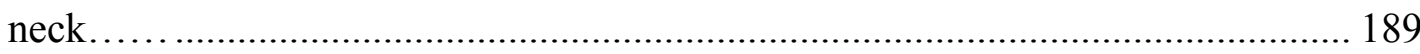

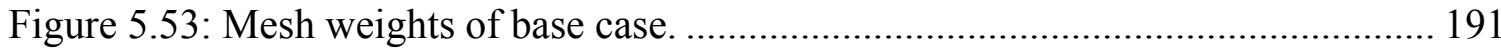

Figure 5.54: Entering the pour weight and fill time................................................ 191

Figure 5.55: The Gate Position window. ............................................................ 192

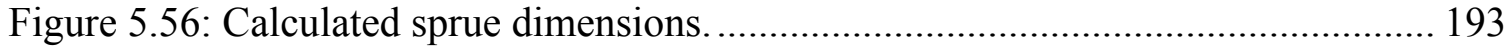

Figure 5.57: Calculated gate and runner areas and dimensions................................ 193

Figure 5.58: Critical Fraction Solid Time plots plotted at 4.5 minutes show possible isolated areas. 197

Figure 5.59: Material Density Function plots plotted at 0.995. 197 
Figure 5.60: FCC Criterion plots showing no highlighted areas. ................................ 197

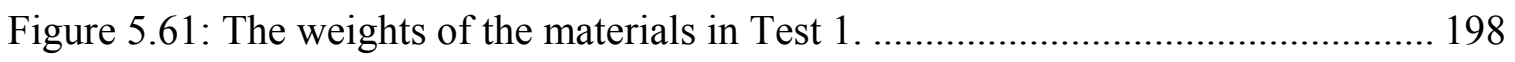

Figure 5.62: Casting model built from calculated dimensions for Test 2.................... 200

Figure 5.63: The weights of the materials in Test 2. ................................................ 201

Figure 5.64: Critical Fraction Solid Time plot plotted at 7.5 minutes.......................... 201

Figure 5.65: Material Density Function plots plotted at 0.995 ................................. 202

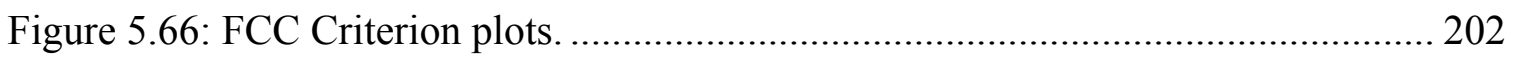

Figure 5.67: Hot Spot (Solidification Time) plotted at 1.1........................................ 203

Figure 5.68: Hot Spot (Critical Fraction Solid Time) plotted at 1.1........................... 203

Figure 5.69: Casting model built from calculated dimensions for Test 3.................... 204

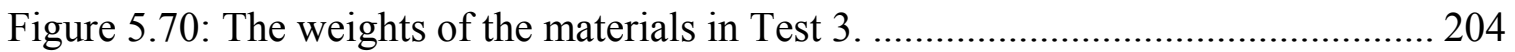

Figure 5.71: Material Density Function plots plotted at 1.0 ..................................... 205

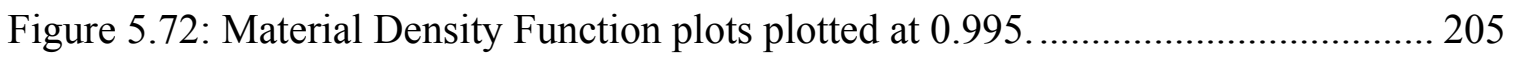

Figure 5.73: Hot Spot (Solidification Time) plotted at 1.1 ....................................... 206

Figure 5.74: Hot Spot (Critical Fraction Solid Time) plotted at 1.1............................ 206 


\section{Chapter 1}

Introduction

\subsection{Casting}

Casting is the process of producing metal into a determined shape by melting solid metal into liquid form, pouring it into a mold and letting it solidify into the desired shape. The mold is a negative copy of the shape of the casting. There are many other methods of shaping metals, such as machining, forging, welding, stamping and hot working. Casting has many advantages over the other methods of metal shaping for producing some particular shapes of metal and types of metal.

\subsection{Advantages and disadvantages of casting}

Casting can simplify production by casting a single complex shape piece instead of manufacturing a product that requires assembling several pieces together. Mass production of products can be done by casting; a large number of products in a single mold or in other cases by reusing the mold. Very large heavy objects can be cast which would be extremely difficult or economically impossible to produce by other methods. Some engineering properties in casting are better than objects produced by other methods. For example, uniform properties throughout the casting can be achieved if properly cast. Casting can give an economic advantage resulting from one or more of the advantages shown which may help in the competition against other types of manufacturing. (Heine et. al., 1995)

There are situations where other shaping methods are more suitable. For example, machining can achieve better surface finish and dimensional accuracy not achievable by casting; welding can join metal objects which may be produced by wrought or casting into more complex structures, stamping produces light weight sheet metal parts; and forging helps improve the strength and toughness of steel, etc. An engineer with knowledge of the possibilities of each shaping method may select a method or a combination of methods which best suits his or her work achieving high quality, low priced products (Heine et. al., 1995). 


\subsection{Types and Methods of Casting}

There are many processes for producing a casting depending on size, type of metal, complexity, dimensional allowance, quality and whatsoever. One of the oldest methods known is sand casting. Sand is mixed with binders and water so the sand grains hold shape, compacted in a flask which can be separated into two or more pieces with a pattern in the middle. This pattern will have approximately the same shape and size (or may be slightly different depending on the dimensional tolerance, shrinkage/expansion of the metal or machining allowances) of the desired casting. The mold is then parted, the pattern is removed and the compacted sand will have a negative shape of the pattern. The mold may be assembled with cores to give the casting hollow shapes, and the gating system, including runners, ingates, risers, sprues, etc., will be made in the mold. The liquid metal would then be poured into the mold. After the casting has cooled down, the mold is broken to remove the casting. The casting's gating system and risers would be broken off, the casting cleaned and then machined into the desired product.

Sand casting may be separated into green-sand mold casting, no-bake sand mold casting and shell-mold casting. Green-sand mold casting is silica sand and clay mixed with water, no-bake sand mold is silica sand mixed with resin that hardens within minutes after shaping and shell-mold casting is silica sand mixed with resin, shaped and baked to form the wanted mold shape (Society of Manufacturing Engineers).

Sand casting may be classified as Expendable Mold/Reusable Pattern process. Other Expendable Mold/Reusable Pattern process casting methods are the plaster-mold casting process, and ceramic-mold casting process (Society of Manufacturing Engineers).

The lost wax casting method or investment casting process was used by Asian Indians to make sculptures of gods and goddesses for hundreds of years. The wax models were carved and carefully pasted over and covered with natural clay obtained from river banks, after wetting with water. After being sun dried for 3 to 4 weeks, the wax was melted with heat, forming a hollow mold. Molten metal was poured into the mold to make the casting (Ravi, 2005). The modern lost wax casting method is called investment casting. Wax is injected into a metal mold to make patterns, which are connected to a common sprue to form a tree. The tree is repeatedly dipped in ceramic slurry and dried. The wax is removed by heat leaving a mold. The ceramic shell is 
preheated and filled with molten metal, then broken after the casting has cooled down. This method is suitable for casting any metal with small to medium intricate shapes and thin walls.

Full mold casting or evaporative-foam casting is done by packing loose silica sand around an expanded polystyrene (EPS) pattern. Molten metal is then poured into the mold through the gating system, burning out the foam pattern as it fills the mold. It is called full mold casting because the pattern is not removed, hence the name full mold. This method is suitable for even intricate castings and requires less labor and skill compared to sand casting. A mold must be used to make the EPS patterns and the mold should properly vent out the gases generated from burning the foam. The replicast process is a method similar to wax investment casting except EPS is used instead of wax. Another variation is vacuum casting, which also uses loose sand but held between two thin plastic sheets by vacuum applied to a pattern with a number of vent holes (Ravi, 2005).

Investment casting and evaporative-foam casting can be classified as Expendable Mold/Expendable Patterns Process. Another classification of casting process is Permanent Mold/No Patterns Process. The casting processes in this classification are permanent mold casting, die casting and centrifugal casting (Society of Manufacturing Engineers).

Gravity die casting (also called the permanent mold process) is a method which molten metal is poured into a cast iron mold coated with a ceramic mold wash. Cores can be made from sand or metal. After the casting has cooled down, the mold is parted and the casting is removed. This method is suitable for non-ferrous metals with medium sizes and moderate complexity and thickness (Ravi, 2005).

Pressure die casting is a process which molten metal is injected into a hardened steel die under pressure. Usually this type of die is water-cooled and metal cores must be used instead of sand cores. The casting is removed by parting one half of the die and the casting is removed by ejector pins. This process is suitable for non-ferrous castings with small to medium size, varying complexity and thin walls (Ravi, 2005).

Centrifugal casting is a process which molten metal is poured into a horizontal rotating mold where the centrifugal force would push the molten metal to the mold wall. 
This method can produce pipes of tubes without using cores (Ravi, 2005) and the thickness of the casting wall depends on the amount of molten metal poured into the mold (Society of Manufacturing Engineers). An alternative to this process is the semicentrifugal casting process which axis-symmetrical castings, like pulleys, gears and rotors can be produced while rotating about a vertical axis rotating mold. Another variation called the centrifuge casting is a process which mold cavities are arranged around a central axis. This method uses the rotation of the mold to get better filling characteristics (Ravi, 2005).

Squeeze casting or semi-solid casting is a process which semi-solid metal is forced under pressure into a metal mold. This method would give a casting fine microstructure free from dendrites. The mechanical properties of these castings are close to those of forgings. This method is useful for non-ferrous metals and composites and is also applied for aerospace and automotive parts (Ravi, 2005).

\subsection{The Casting Process}

The casting process starts from receiving an order from a customer which may include the design, dimension, physical properties, etc., then the foundry must plan how to make the castings, what methods must be used, then produce a prototype of the casting, modify the casting methods to get rid of the defects, produce the product, and last of all, the send the final product to the customer. Figure 1.1 shows the main procedures of a casting process, but the procedures in each casting facility may differ in detail. 


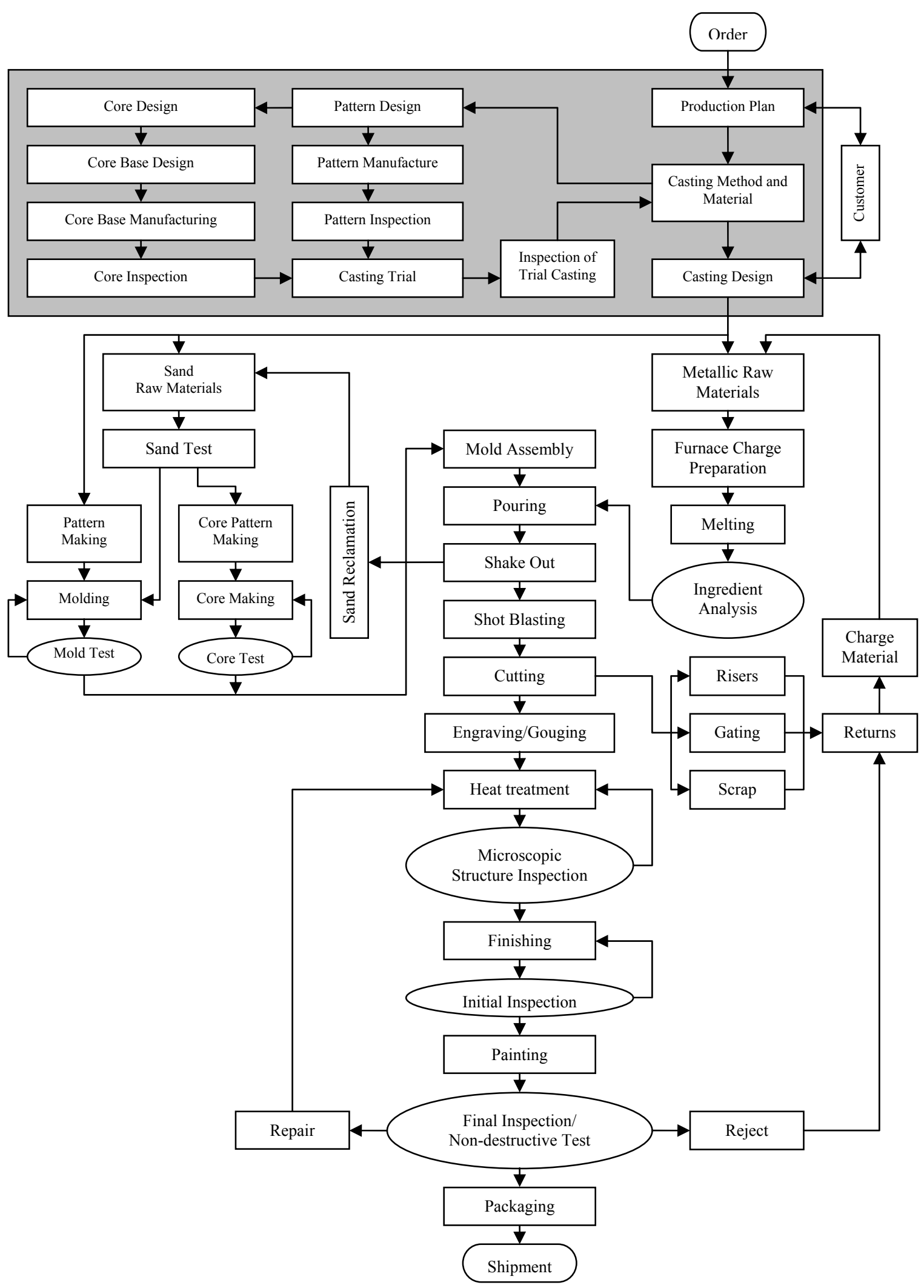

Figure 1.1: Main procedures of casting, modified from the casting process procedure of the Thai Alloy and Associates Co., Ltd. and Creese (1999). 


\subsubsection{New Casting Development}

From Figure 1.1, the area in the shaded box could be called the development of a new casting, which in detail, might be separated into three stages, product design, tooling development and foundry trials (Ravi, 2005).

\subsubsection{Product Design}

This first stage is the most essential because it virtually influences all other decisions and activities in the product life cycle, and eventually the technical and economical value of the product.

This stage consists of three types of requirements. First is the functional requirements, driven by geometry, dimensions, relative location and orientation. The next type of requirements is property requirements, including thermal-physical properties, mechanical, and chemical properties of the product. These properties are mainly driven by the material composition and structure. The third type is production and quality requirements, which include surface finish, tolerance, internal soundness, order quantity and lead time, etc.

The above requirements are developed through three steps of the product design, which are conceptual design which focuses on the geometries of the product to achieve the required functions, detailed design involves selecting the material(s), defining the geometry and its tolerances and prototyping which basically is producing a prototype to test the form, fit and function of the product. Iterations may be done to these production design steps to achieve optimality of functional requirements, quality and cost (Ravi, 2005).

\subsubsection{Tooling Development}

Tooling consists of patterns and core boxes for sand casting or dies for die casting or investment casting. It can also be further classified as design of cavity or the pattern for producing the cavity or cavities and its accessories.

This stage involves setting the best orientation of the casting and the determination of the parting line or parting lines if there has to be more than two segments of molds to produce the casting. Also, some castings might have multiple 
cavities instead of just one. It also involves the internal cavities such as holes and undercuts produced by cores. This require identification of core features, design of cores, which also includes their supports, called prints in sand casting, and core boxes for producing the cores.

Proper allowances must be incorporated in the mold cavity and cores considering part shrinkage, distortion and machining which may be done later in the process. The cores or dies must be easy to remove from the part. Other cavities include feeders or risers (number, location, shape, and dimensions), sprues, runners, the gating system which leads the molten metal into the mold. Other accessories include cooling, guiding and ejection systems (for die casting). The method for manufacturing the tooling depends on its material, complexity, quality and time/cost considerations (Ravi, 2005).

\subsubsection{Foundry Trials}

Trial castings are made to observe the flaws and defects that might happen in a casting which may occur from the two previous stages. Castings are inspected using destructive and non-destructive methods for finding external and internal defects. The most common destructive method is to section the casting in the places of interest and find if defects are present. Macroporosities and shrinkages may be seen by the naked eye while microporosities and microstructural defects would require seeing through a microscope. Non-destructive methods include radiography, ultrasound, magnetic partical, dye penetrant, and eddy current testing. Based on the results, the tooling, usually the gating and riser system may be modified, and the process parameters, usually the pouring temperature, pouring time (and pressure variation in the case of die casting), etc., may also be modified to improve the casting to a desirable level of quality. If the defects cannot be eliminated by modifying the process parameters or tooling design, it is necessary that the product design be modified, which is very expensive and time consuming at this late stage. Figure 1.2 shows the relationships of management time spent, the ability to influence the production process, the cost of rectifying mistakes in the process and the accumulated costs to each product development phase (modified from Ravi, 2005). 


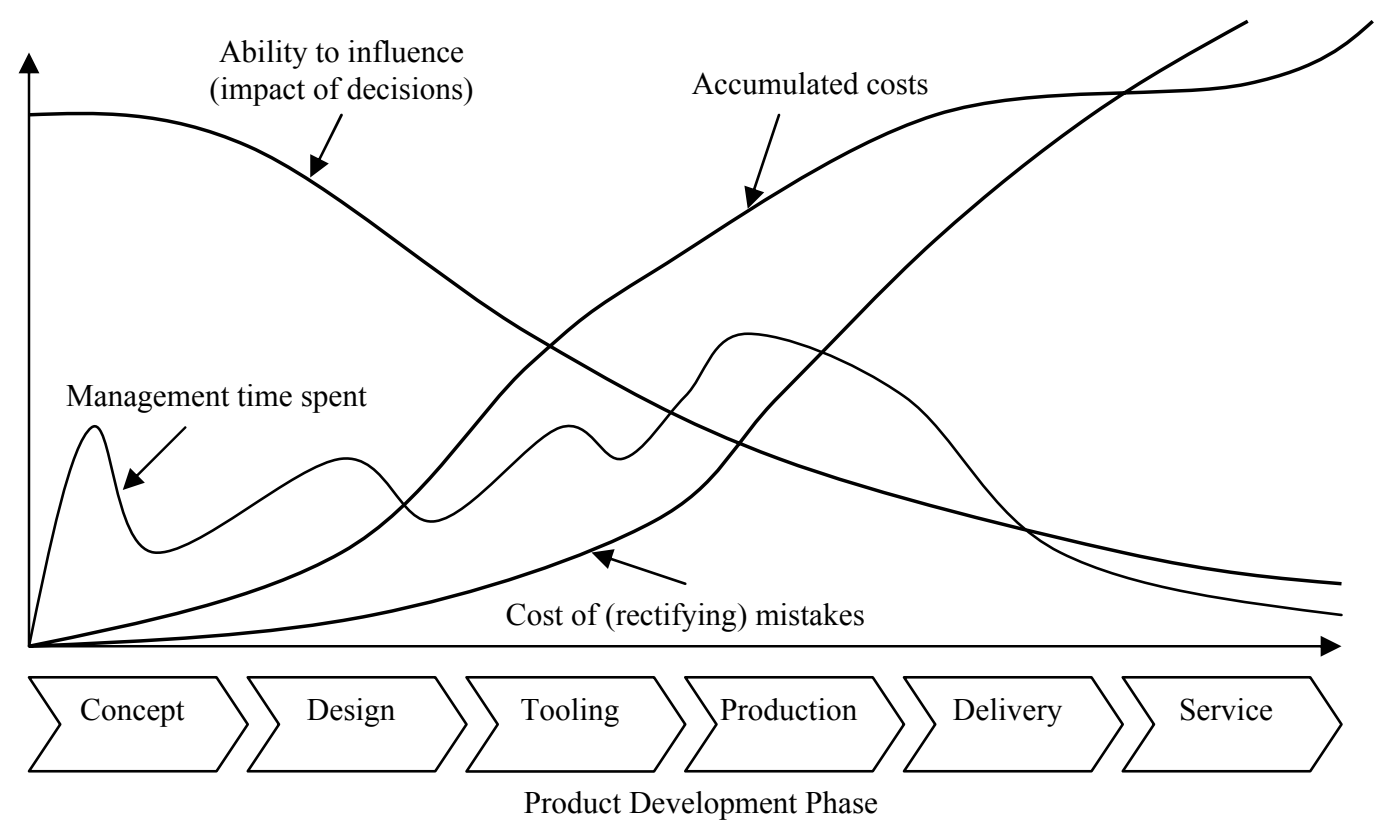

Figure 1.2: Cost and impact of product development phases (modified from Ravi, 2005).

\subsubsection{The Next Step in Casting Development}

Over the last decade, many casting buyers and assemblers adopted the Just-InTime philosophy to reduce their inventory costs, which requires foundries to deliver smaller lots and more frequently, while maintaining a strict schedule. There has been a steady increase in the requirements in terms of quality assurance, shorter lead-time, smaller lot sizes and competitive pricing. Assemblers also are eliminating inspection of incoming goods and expect the suppliers to be responsible for casting quality and want the foundries to continuously reduce their costs by adopting better technologies and methodologies. There is also pressure from energy conservation, environment and operational safety regulations.

Casting buyers, especially in the automotive industry, are moving towards longterm partnerships with a few foundries instead of short-term cost-based purchasing agreements with a number of foundries as in the past. This is also one of the methods in the Just-In-Time methodology. For a foundry to survive and compete in the market, it must produce dimensionally stable and sound castings (Quality), have reliable on-time small-lot delivery (Delivery) and continuously lower their prices (Cost) (Ravi, 2005 and Pongsukijwat, 2006). 
Usually, the average lead time for developing a new casting might take several weeks and tooling development and foundry trials account for nearly 70 percent of that time. The lead-times can be reduced more than half, especially for intricate castings when using computer-aided systems for product design, tooling development and process optimization. Casting simulation software can help predict internal defects and the process parameters, tooling design and part model can be modified and verified to achieve the desired quality before pouring a trial casting for physical verification. Rapid prototyping can greatly reduce the lead time by eliminating the tooling design and requirements.

\subsubsection{The Ten Rules of Casting}

A good casting is a casting that meets or exceeds a customer's specification. Campbell (2004) has laid out ten rules, which if followed, will produce good and near defect-free castings.

\section{1) Rule 1}

A good quality melt is very significant to the quality of the casting. The liquid metal should be prepared, checked and treated to achieve an acceptable minimum standard for casting a certain product.

\section{2) Rule 2}

Avoid turbulent entrainment of the surface file on the liquid. The liquid metal should not go too fast or fall more than the critical height.

\section{3) Rule 3}

Avoid laminar entrainment of the surface film on the liquid. No part of the liquid metal front should come to a stop before the mold cavity is completely filled. The filling should progress only uphill in a continuous uninterrupted upward advance. 


\section{4) Rule 4}

No bubbles of air entrainment should be allowed to pass through the liquid metal into the mold cavity. Using a properly designed sprue, avoiding the use of sprue wells or other volume-increasing systems, using small volume runners, using ceramic filters close to the sprue or runner junctions and bubble traps, etc., are some ways of preventing bubbles entering the casting. Also, the pouring should not be interrupted.

\section{5) Rule 5}

Core blows or bubbles from the out-gassing of cores must be avoided. Cores must have low gas content or must be vented to prevent the bubbles from the cores entering the casting. Clay-based cores or mold repair pastes should be fully dried before use.

\section{6) Rule 6}

Avoid shrinkages by not feeding uphill in larger section thickness castings because of unreliable pressure gradients and complications which are occurs from

convection. Feeders or risers should be used for counteracting the shrinkages. A riser with appropriate dimensions should be added to the casting at the appropriate position. The rules for designing a good riser will be explained later. Also, the level of flash at the mold and core joints, the mold coat thickness, if any, and the temperatures of the metal and mold should be controlled.

\section{7) Rule 7}

Avoid convection damage. Convection is a flow phenomenon resulting from density differences in a fluid. The density differences may result from temperature differences. The time needed for a convection to start may be between one and two minutes. By three or more minutes, convection can become well established, causing extensive re-melting and a major redistribution of heat in a casting. Thin castings which take less than one minute to solidify or thick castings which may take more than perhaps ten minutes to solidify would not have convection problems because in thin castings, the viscous restraint of the walls make convection difficult and the rapid cooling allows less 
time for convection to develop. For thick castings, the liquid metal would have plenty of time to convect and re-organized itself. Intermediate size castings are most prone to convection damage. The problem may be taken care by redesigning the casting and rigging system, avoid feeding uphill or by using the tilt casting process.

\section{8) Rule 8}

At regions of the casting which local cooling rates change, either from section change or at a chill or a riser, the change in composition of the casting will occur. This problem is called segregation. Sometimes they are unavoidable, so, there should be a specification limit agreement with the customer.

\section{9) Rule 9}

Reduce residual stress by not quenching into water.

\section{0) Rule 10}

All castings should be provided with agreed location points so the dimensions may be measured accurately and the work done by the toolmaker to the foundryman down to the machining operator could be smooth.

\subsection{Casting Simulation Software}

In this day and age, customers, especially in the automotive industry, would be more likely to request castings with high quality (Q), quick delivery (D) and at a low cost (C). A tool that foundries may use to achieve the three goals previously mentioned is to apply Computer Aided Engineering into their process, in this case is by using computer simulation software for casting.

The procedure of using casting simulation software may be explained as follows (Pongsukijwat, 2006):

1) Build a model of the casting design including the gating system and all other material used with the casting, such as chills, cores, sleeves, etc. This step may be done by using a CAD (Computer Aided Design) system. 
2) Input required data needed for computation, such as the physical, mechanical and heat properties of the metal, properties of the mold or die, pouring temperature, pouring time, pressure, etc.

3) Computation of the simulation, which different casting simulation programs may have different approaches in simulating the results. Some well known approaches, for example are, the numerical simulation approaches (Finite Element and Finite Difference Methods), the geometrical approach (Sarfaraz, 1988), the meshless method (Lewis et. al., 2004), etc.

4) Simulated results and interpretation of results. The results from the simulation program may be shown in the form of graphs or colored figures with numerical results depending on what criterion is used, such as the temperatures in each section of the casting at a given time, solidification times, hot spots, material density, etc. These results must be translated into useful information to evaluate if a casting is sound or not, or what must be done to improve the casting design and start from step 1 once again.

\subsubsection{The Usefulness of Casting Simulation Software}

In the past the foundryman have strived for ways to improve the casting process and eliminate the defects that occurred in the castings by trial and error and past experiences. The time needed to produce a particular product is a time-consuming process. Problems occurred in the casting may only be solved through trial and error.

Scientists throughout the years have studied the science of casting and metallurgy and developed theories and mathematical models to explain the properties of metals while going through the solidification process. Simulation programs were developed from these methods which are useful in predicting how the casting will come out. Defects and problems can be discovered before the actual casting is cast avoiding costly tests to prevent the problems.

The process of manufacturing a new casting design in a foundry starts from receiving a design from a customer, which would include all dimensions and tolerances, what kind of material and additives, and may also include the strength, hardness or surface finish, etc. Then the foundryman or the foundry engineer would design the gating 
and risering system for the casting. The time used in designing and re-designing the gating and risering system might take a few days or up to several weeks before good castings can be made (as mentioned earlier in section 1.4.1 and 1.4.2) depending on the casting complexity and the skill of the foundryman or the engineer. Casting simulation software can predict where and what defects might occur in a casting and the time and material used in the trial stage may be reduced significantly.

\subsubsection{Casting Simulation Methods}

The casting simulation programs have different approaches in calculating and predicting the outcome of a casting. Each method hold advantages and disadvantages compared to another. Some casting simulation methods may be shown below:

1) Numerical Approach

- Finite Element Method (FEM)

- $\quad$ Finite Difference Method (FDM)

2) Geometrical Approach

- $\quad$ K-Contour Method (Safaraz, 1988)

3) Computer Wave Front Analysis

- Pour-out Method

- Cubic Spine Functions

4) Meshless Method (Lewis, 2004)

5) Grid-based simulation system (Pan et. al., 2004)

This study used one program, SOLIDCast, which uses the Finite Difference Method.

\subsubsection{Finite Difference Method (FDM) and Finite Element Method (FEM)}

The Finite Difference Method and Finite Element Method are the two most common methods used by casting simulation software developers. The differences between these two methods from a user's point of view are presented.

If a three dimensional picture of a casting model mesh in a casting simulation program is composed of several small cubic boxes or blocks or cells, the simulation program used uses the Finite Difference Method. This method would take a three 
dimensional casting design and break it into small elements, small square boxes along the $\mathrm{X}, \mathrm{Y}$ and $\mathrm{Z}$ axes. The calculation method has each box be uniform throughout itself and have interaction with the adjacent boxes. The calculations are made to the closest $d x, d y$, $\mathrm{dz}$ values and calculated at nodes which are located at the centers of the elements. The smaller the boxes, the smoother the picture of the mesh becomes and the more accurate the calculations are. But the smaller the boxes, the more boxes are needed and more memory space on the computer is needed.

The Finite Element Method mesh would look like small triangles joined together. Actually they are nodes connected with lines. The skin of the three dimensional picture would look smoother than the mesh from Finite Difference Method.

Comparing these two methods, the meshing of Finite Difference Method is easier, because when a user orders the program to mesh the design with Finite Element Method, some nodes may not be properly connected. The user must check thoroughly throughout the design to see that all nodes are connected, which is a very stressful job. If there is a gap, the simulation may not be done and errors would occur which the user must find the gap and re-mesh the design again with a different node size. The temperatures are calculated at nodes which are located at the corners of the elements. The Finite Element Method uses more computer memory and takes more time in calculating results, but the primary advantage of Finite Element Method over Finite Difference Method is that it gives more accurate results.

If there are thin sections in the casting, the Finite Element Method user can assign smaller meshes to the thin sections and larger meshes in thicker sections to save memory usage for calculation. For Finite Difference Method, there can only be one size of cells throughout the casting. The size of the cells must be appropriate compared to the smallest section of the casting or the calculations will become inaccurate. Less intricate castings can be calculated quite accurately with larger cells resulting in less computer memory usage in calculating for results.

The biggest difference in the two methods regards the axis alignment of the model. Finite Difference Method breaks down the model into small boxes aligned to the $\mathrm{X}, \mathrm{Y}$ and $\mathrm{Z}$ axes and the simulation results would differ if aligned differently, but the results would be the same in any direction using the Finite Element Method. 


\subsubsection{Limitations of Casting Simulation Software}

Even though casting simulation software may sound like a savior from casting heaven, it may not solve every problem. The limitations of each casting simulation software program are different.

The most accurate simulation results require that all input parameters be set carefully to match the real casting, including material, chemical composition, mold material, pouring temperature, pouring time, heat transfer coefficient values, cooling curves, expansion and shrinkage rates, etc. Casting simulation software cannot predict all types of defects that may occur in a casting, such as processing defects, human error, additional chemical elements added to the molten metal, etc. A foundry engineer must be able to notice what kinds of defects occur and what causes them to occur so the problem can be treated as casting simulation software can only simulate the solidification process.

\subsubsection{Depths in Casting Simulation Involvement}

After visiting foundries to interview the foundry managers and engineers and from interviewing a few professors in the field of metal casting in Thailand, it was found that the involvements in casting simulation software, if any, are different in each foundry.

The depths in the simulation of castings may be separated into four levels, as follows:

1) The foundry engineer designs all gating system, runners, risers, sprues, tooling, process, etc., and starts the trial casting stage without using casting simulation software. This is what most foundries still practice. It really depends on the experience of the engineer in getting a good casting in a short period of time.

2) The foundry engineer designs and verifies the casting design with a casting simulation software program himself/herself.

3) The foundry engineer would send the design (along with the tooling design if needed) and information about the casting to a casting simulation specialist and the specialist would design all gating system, runners, risers, sprues, etc., with the simulation program. The specialist would send back the results along with suggestions about the casting design. The engineer may start the trial castings or make some modifications if required before starting the trial castings. 
4) The foundry engineer designs all of the gating system, including runners, risers, sprues and tooling and writes the model into a 3D CAD program. The engineer then sends the design along with all needed information, such as material name, material grade, additives, chemical composition, process parameters, etc., to a simulation specialist to verify the design. The specialist may suggest how the design should be changed and then sends back the results of the simulation. If no problems occur in the simulation, the engineer may start the trial castings, but if there are any, the engineer would re-design the casting before starting the trial castings. The engineer may re-design the casting on the $3 \mathrm{D} \mathrm{CAD}$ program and verify the design once more with the specialist. This is starting to be more common in the Thai foundry society because the Ministry of Industry of Thailand is supporting and encouraging Thai foundries to learn and make use of casting simulation software to improve their efficiencies in order to compete in the modern market.

\subsection{Rapid Prototyping}

Rapid prototyping is the automatic construction of physical objects using solid freeform fabrication (SFF) (http://en.wikipedia.org/wiki/Rapid_prototyping) which is a technique for manufacturing solid objects by the sequential delivery of energy and/or material to specified points in space to produce that solid (http://en.wikipedia.org/wiki/Solid_freeform_fabrication).

Basically, rapid prototyping takes virtual designs from a Computer Aided Design (CAD) model and creates a physical model of the design. The object created would become a prototype so it may be analyzed by the designer to check for the form and functions of the product. It would be easier for a designer to find ways of improvement in the design of the product when there is a physical object. Rapid prototyping can greatly reduce the lead time by reducing or eliminating the tooling design time in producing a new product.

The physical properties of a prototype produced by rapid prototyping may or may not be the same as a real product from a casting process. The rapid prototyping process can produce sand molds for casting, but metal molds are usually not made by rapid prototyping. 


\subsection{Cast Iron}

The interest of this study focuses is on sand casting and cast irons which are included in the SOLIDCast program's list of materials. A review of cast irons is presented in the following sections.

\subsubsection{Cast Irons}

Cast irons are a class of ferrous alloys with carbon contents above 2.0 weight percent, but in practice, most cast irons contain between 3.0 to 4.5 weight percent carbon. In some exceptional cases, alloys with less than 2.0 weight percent carbon may be considered in the cast iron family because silicon and some other alloying elements may change the maximum solubility of carbon in austenite resulting in solidifying with a eutectic structure (http://www.key-to-steel.com/Articles/Art63.htm). It can be seen in the iron-carbon phase diagram Figure 1.3 how close they are to the eutectic composition. This equilibrium diagram actually represents the metastable equilibrium between iron and iron carbide (cementite or $\mathrm{Fe}_{3} \mathrm{C}$ ). At 6.67 weight percent carbon, there is 100 percent iron carbide $\left(\mathrm{Fe}_{3} \mathrm{C}\right)$ (Callister, 2006).

Iron carbide, also called cementite $\left(\mathrm{Fe}_{3} \mathrm{C}\right)$, is a metastable compound. It can decompose to form alpha $(\alpha)$ ferrite and graphite if heated over long time periods (decades) according to the reaction in equation (1.1) (Callister, 2006):

$$
\mathrm{Fe}_{3} \mathrm{C} \rightarrow 3 \mathrm{Fe}(\alpha)+\mathrm{C} \text { (graphite) }
$$




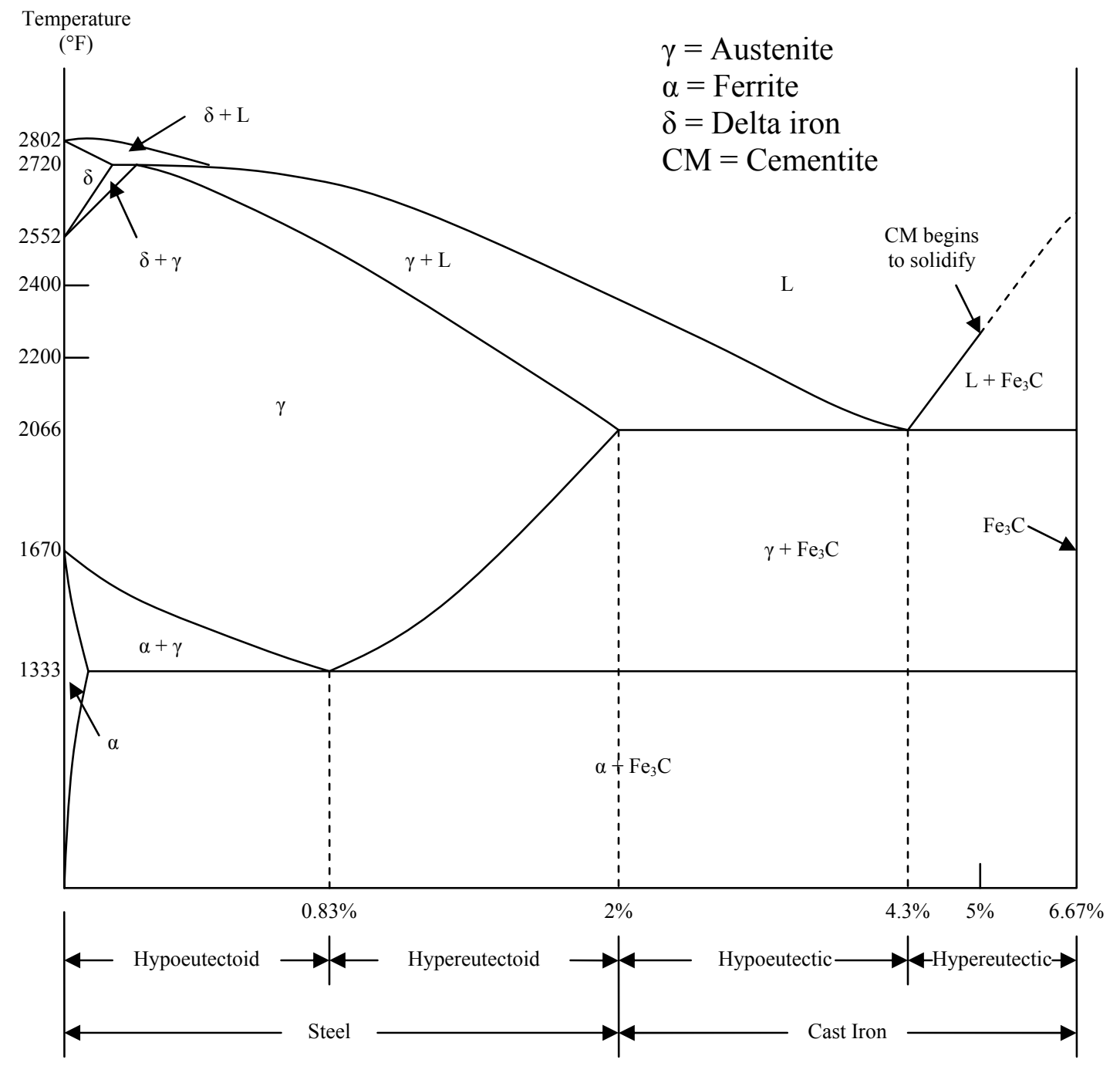

Figure 1.3: Iron-carbon phase diagram.

Modified from http://www.msm.cam.ac.uk/phase-trans/2001/adi/cast.iron.html

Figure 1.4 shows the iron-iron carbide phase diagram (dotted lines) and the true equilibrium iron-carbon phase diagram (bold line) with graphite instead of cementite as a stable phase together. Because the decomposition rate of cementite into graphite is extremely slow, virtually all the carbon formed at the eutectoid temperatures will be in the form of $\mathrm{Fe}_{3} \mathrm{C}$. The carbon formed between the eutectic and eutectoid temperatures will tend to be in the form of graphite flakes or nodules. So, the iron-iron carbide phase diagram can be used practically. But if silicon is added to cast irons, normally more than one weight percent (Callister, 2006), it will slow the cooling rate of the casting and accelerate the cementite decomposition reaction to form graphite. Slower cooling rates 
during solidification also help the formation of graphite. Mostly, cast irons will have carbon in the form of graphite which affects the microstructures and mechanical properties.

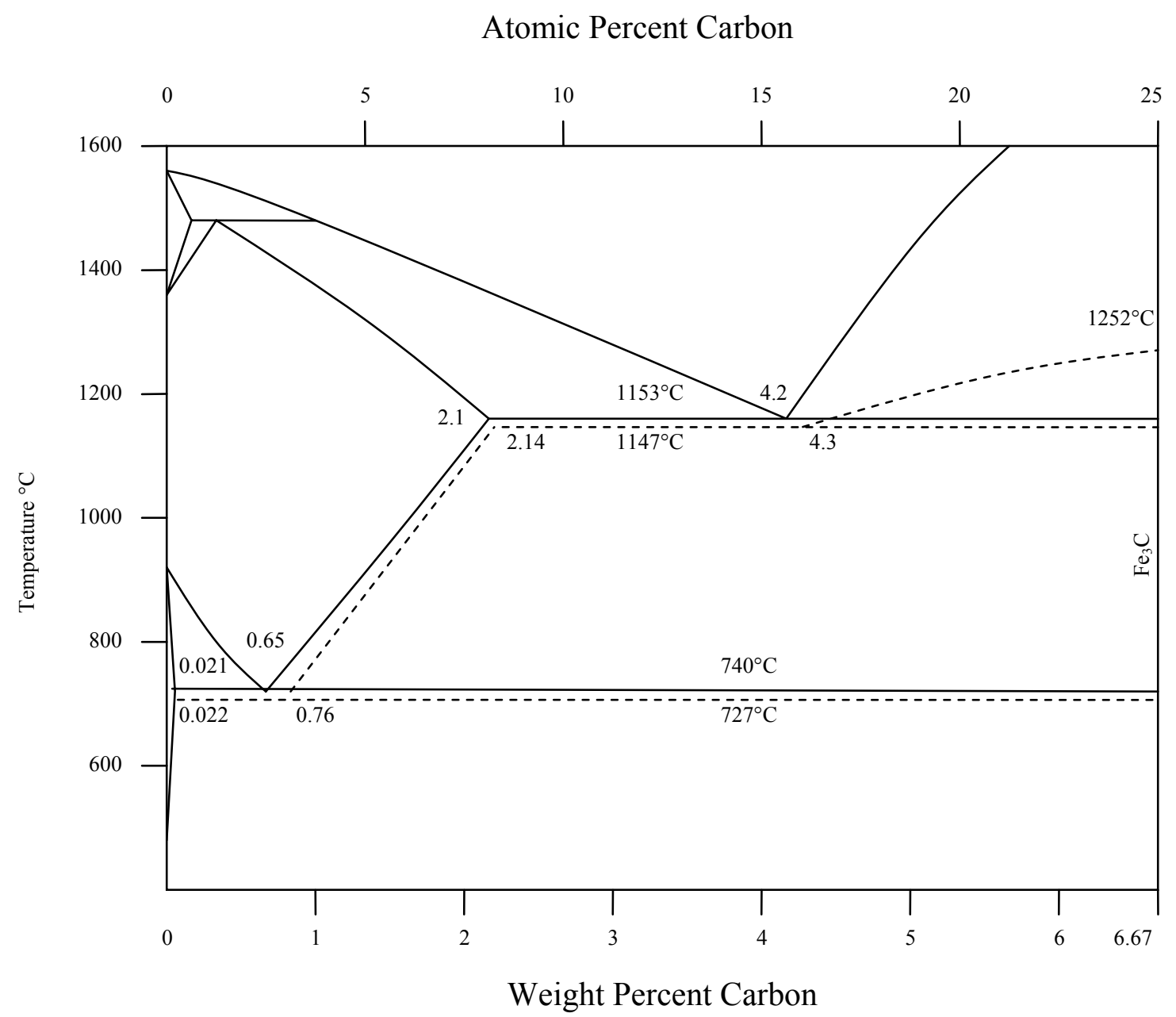

Figure 1.4: Iron-iron carbide (dotted lines) and true equilibrium phase diagram (bold lines)

Modified from:

http://www.mrl.ucsb.edu/ edkramer/LectureVGsMat100B/99Lecture14VGs/FeCPhaseDi agramVG.html 
Sulfur in cast irons is known to favor the formation of the graphite flakes. Adding a small quantity of calcium carbide can help remove the sulfur from the melt which will encourage graphite growing into a spheroidal shape. This is followed by a minute addition of cerium or magnesium in the form of an alloy with iron and silicon rather than pure magnesium will result in spheroids of graphite. Spheroidal graphite cast iron, known as ductile iron or nodular iron, has excellent toughness and is used widely (http://www.msm.cam.ac.uk/phase-trans/2001/adi/cast.iron.html).

Cast irons alloys become completely liquid at temperatures between approximately 2,100 and 2,350 degrees Fahrenheit, and are easier to melt and cast than steel. The most common known cast irons are gray iron, nodular or ductile iron, white iron, malleable iron and compacted graphite iron (Callister, 2006). This thesis has focused on gray iron as the type of material used in all examples and in the case study.

\subsubsection{Gray iron}

Gray iron has a carbon content varying between 2.5 to 4.0 weight percent and a silicon content of around 1.0 to 3.0 weight percent. The graphite in gray iron would exist in the form of flakes, similar to the shape of a corn flake, normally surrounded by alpha ( $\alpha$-ferrite or pearlite matrix. These graphite flakes make the surface appear gray, hence its name (Callister, 2006).

The flakes of graphite cause good machinability, because the graphite acts as a chip-breaker and lubricates the cutting tools. In applications involving wear, the graphite is beneficial because it helps retain lubricants. But on the other hand, the graphite flakes are also stress concentrators which lead to poor toughness and low strength. Gray iron is considered weak and brittle in tension because of its microstructure. The tips of the graphite flakes are sharp and pointed which serve as points of stress concentration when

there is external tensile strength applied, but it has higher strength and ductility under compressive loads (Callister, 2006).

Gray iron also has the ability to damp mechanical and sound vibrations, so it is used as base structures for machines and heavy equipment. It has high fluidity and castability at casting temperature, makes it easy to cast complicated detailed shapes, has 
little casting shrinkage and is among the least expensive of all metallic materials (Callister, 2006).

Chemical elements other than Fe, $\mathrm{C}$ and Si may be added in order for gray iron to improve its mechanical properties. Gray iron castings may be used as-cast without any treatment, may be annealed for better machinability, or hardened for better corrosion resistance or to improve strength and ductility.

The metal expands slightly on solidifying as the graphite precipitates. The amount, size and shape of graphite during the solidification of the liquid metal are affected by the chemical composition, how the liquid metal is treated and the solidification rate of the casting in the mold. The matrix structure is affected by the cooling rate after the casting has solidified until it reaches the room temperature. So, the mechanical properties of gray iron are affected by the chemical composition, by the thickness and solidification rate of the casting and by the cooling rate after solidifying.

Specific mechanical properties of the casting can be estimated by determining the chemical composition. The applications of a type of gray iron must consider its mechanical properties, which may be tested from pouring liquid metal into a standard mold apart from the product (Prasertsakul).

\subsubsection{Carbon Equivalent}

If there were only carbon in the cast irons, there would be very little chance that graphite would form. But if there were 0.05 to 3.5 weight percent of silicon in the liquid metal, the graphite is able to form while the liquid metal solidifies. There may also be phosphorus in the liquid metal up to about 1.0 weight percent which will be in the form of impurities. Normally, gray irons that require high strength will allow less than 0.12 weight percent phosphorus and also 0.06 to 0.12 weight percent sulfur. If the cast iron is melted with a cupola, both the sulfur and phosphorus will come from the coke burned. Manganese is added to the liquid metal to lessen the effect of sulfur. Usually, manganese would be added at a level of five times the amount of sulfur that is to be removed from the melt. The manganese left over in the cast iron after solidification will be around 0.05 to 1.5 weight percent, which will help enforce the matrix's strength (Prasertsakul). 
The Carbon Equivalent (CE) is a way of measuring the effects of silicon and phosphorus in the liquid metal which tells the qualities of the liquid metal and the mechanical properties of the metal after it has solidified. The formula for finding the percent Carbon Equivalent is shown in equations (1.2) and (1.3):

$$
\begin{aligned}
& \% \mathrm{CE}=\% \mathrm{C}+1 / 4 \% \mathrm{Si}+1 / 2 \% \mathrm{P} \quad \text { (Prasertsakul) } \\
& \text { or } \\
& \% \mathrm{CE}=\% \mathrm{C}+1 / 3(\% \mathrm{Si}+\% \mathrm{P}) \quad \text { which is more widely used }
\end{aligned}
$$

The closer the percent Carbon Equivalent gets the metal composition to reach the eutectic point, the lower the liquidus temperature will become, fluidity will increase and will have less tensile strength when solidified. The relationships between the thickness or diameter of the casting, mechanical properties and the liquidus temperature of the cast iron with the percent Carbon Equivalent is shown in Figure 1.5.

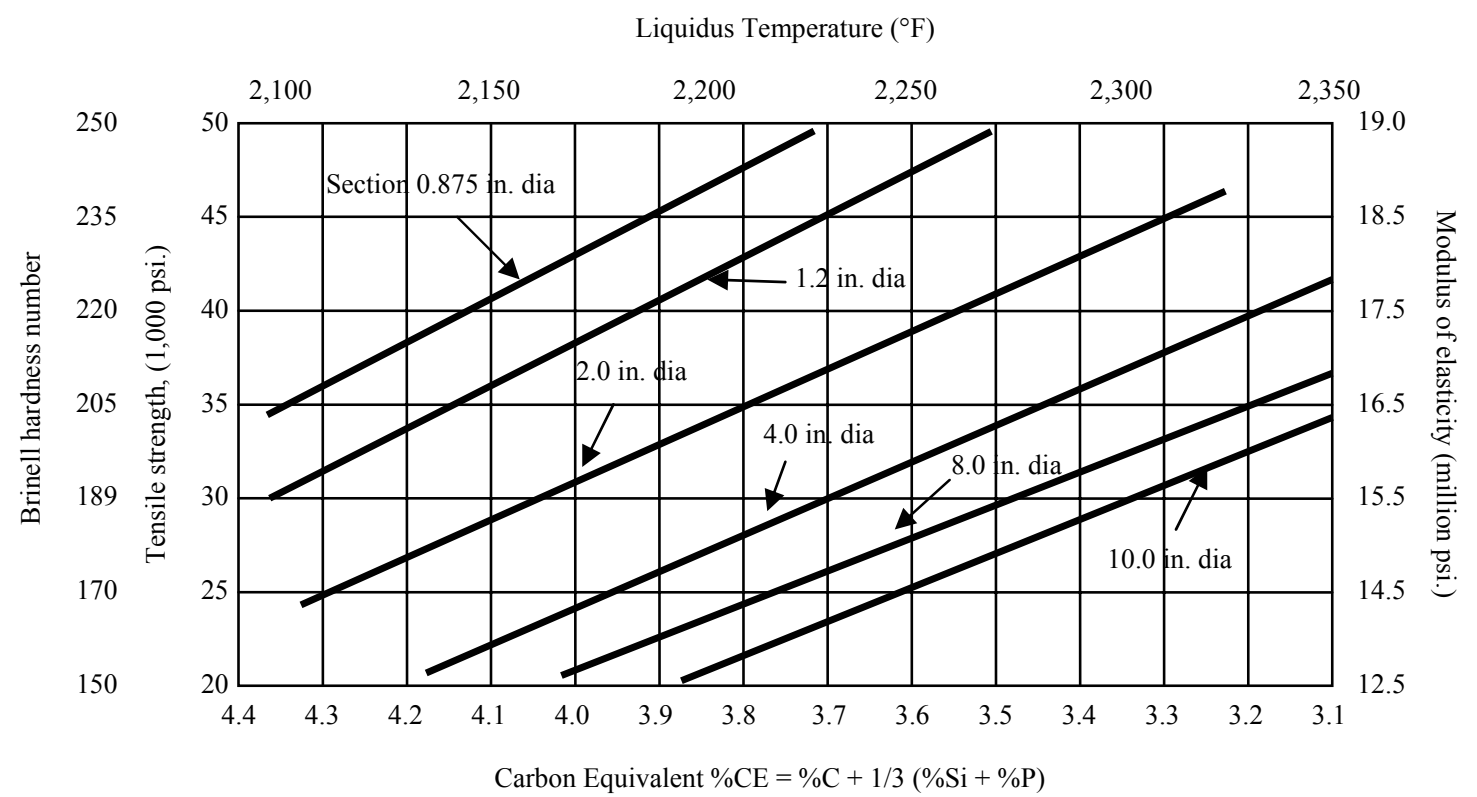

Figure 1.5: The relationships between the thickness or diameter of the casting, mechanical properties and the liquidus temperature of the cast iron with the percent Carbon Equivalent (Reproduced from Prasertsakul).

The liquidus temperature is very sensitive to the percent Carbon Equivalent. The cooling curve is a method to find the liquidus temperature, which is used to find the 
percent Carbon Equivalent value. The wedge test and the chill test can also find the percent Carbon Equivalent of the liquid metal but are less accurate (Prasertsakul).

The Carbon Equivalent of cast irons helps to distinguish the gray irons which cool into a microstructure containing graphite from the white irons where the carbon is normally in the cementite form. A high cooling rate and low Carbon Equivalent favors the formation of white iron whereas a low cooling rate and a high Carbon Equivalent promotes gray iron.

\subsubsection{Other Types of Cast Irons}

\subsubsection{Ductile (Nodular) Iron}

Ductile iron is made by adding a small amount of magnesium and/or cerium to the gray iron before casting. This produces different microstructure and mechanical properties. Graphite forms in nodular or sphere-like particles instead of flakes and is called nodular or ductile iron. Depending on heat treatment and alloy composition, the matrix phase surrounding the graphite is either pearlite, ferrite, austenite or martensite. Normally the matrix is pearlite for an as-cast piece. Heat treating at 1,300 degrees Fahrenheit for several hours will yield a ferrite matrix. The ferrite or pearlite types have mechanical characteristics very close to steel (Callister, 2006).

\subsubsection{White Iron}

Most of the carbons in low-silicon cast irons (irons which contain less than 1.0 weight percent $\mathrm{Si}$ ) and have rapid cooling rates exists as cementite or martensite instead of graphite. White iron exhibits a white, crystalline fracture surface because fracture occurs along the iron carbide pallets giving the surface a white appearance, hence its name. White iron is extremely hard but very brittle and is virtually un-machinable (Callister, 2006). Normally white iron occurs from rapid cooling; either from being a very thin casting or the chemical composition may help accelerate the cooling rate. Thick castings may have a surface layer of white iron while gray iron may form in the interior. This is called "chilled casting", which benefits are having a hard surface and a somewhat tougher interior. 
White iron can also be made by mixing a high percentage of chromium into the iron. $\mathrm{Cr}$ is a strong carbide-forming element, so if the percentage of $\mathrm{Cr}$ is high, the precipitation of graphite out of the iron may be suppressed, so even a large white iron casting can be achieved. But this type of white iron is not able to be heat treated in order to decompose the $\mathrm{Cr}_{27} \mathrm{C}_{3}$ at all (Prasertsakul).

\subsubsection{Malleable Iron}

White iron, if heated at temperatures between 1,470 and 1,650 degrees Fahrenheit for a prolonged period of time in a neutral atmosphere (to prevent oxidation) would cause the cementite to decompose and form graphite, which will exist in the form of clusters or rosettes surrounded by a ferrite or pearlite matrix depending on the cooling rate (Callister, 2006). This is called "graphitization annealing". This would make this cast iron machinable and more ductile (Prasertsakul). The microstructure of malleable iron is very close to of ductile iron, which accounts for higher strength, appreciable ductility or malleability (Callister, 2006).

\subsubsection{Compacted Graphite Iron}

This type of cast iron is actually new to the family. The same as gray, ductile and malleable irons, carbon in compacted graphite iron (CGI) exists in the form of graphite, which formation is promoted by the existence of silicon. Silicon ranges between 1.7 and 3.0 weight percent and carbon ranges between 3.1 and 4.0 weight percent.

The microstructure of graphite in compacted graphite iron is worm-like or vermicular shaped. In a sense, this microstructure has a look in-between flake shape of gray iron and nodular shape of ductile iron and a small amount (less than 20 percent of the graphite) may be nodular shaped. Fracture and fatigue resistance has improved as the sharp edges of the flakes are reduced. Magnesium and/or cerium is also added but in a lesser amount than of ductile iron (Callister, 2006). Figure 1.6 shows the types of cast iron which result from different carbon composition ranges and schematic microstructures which result from a variety of heat treatments. Table 1.1 shows the typical chemical composition of each type of cast iron (Prasertsakul). 
Table 1.1: The typical chemical composition of each type of cast iron (Prasertsakul).

\begin{tabular}{|c|c|c|c|c|c|c|}
\hline Type of Cast Iron & wt\% C & wt\% Si & wt \% Mn & wt \% P & wt\% S & wt\% Cr \\
\hline Gray cast iron & $2.5-4.0$ & $3.0-1.0$ & $0.5-1.4$ & $0.05-0.20$ & $<0.2$ & - \\
\hline $\begin{array}{l}\text { Ductile (nodular) } \\
\text { cast iron }\end{array}$ & $2.5-4.5$ & $4.0-1.2$ & $0.3-0.8$ & $<0.05$ & $<0.03$ & $\begin{array}{c}\mathrm{Mg} \\
0.02-0.07\end{array}$ \\
\hline $\begin{array}{l}\text { Blackheart } \\
\text { malleable cast iron }\end{array}$ & $2.0-2.9$ & $1.5-0.8$ & $<0.4$ & $<0.2$ & $<0.2$ & - \\
\hline $\begin{array}{l}\text { Whiteheart } \\
\text { malleable cast iron }\end{array}$ & $2.8-3.2$ & $1.11-0.60$ & $<0.5$ & $<0.2$ & $<0.3$ & $<0.15$ \\
\hline $\begin{array}{l}\text { Pearlitic malleable } \\
\text { cast iron }\end{array}$ & $2.0-2.6$ & $1.5-1.0$ & $0.2-1.1$ & $<0.2$ & $<0.2$ & $<0.08$ \\
\hline
\end{tabular}

The effects of each element in the chemical composition of cast iron may be explained as follows:

Carbon - mostly found in the form of graphite in cast irons, it would give a cast iron different qualities, mechanical properties, strength, ductility, etc., depending on its structure, which are different in each kind of casting. Hypoeutectic alloys when solidifying, after reaching its eutectic point, the graphite would begin to participate and causes the alloy to expand. Hypereutectic alloys would expand immediately upon solidification or when reaching its liquidus point.

Silicon - would help the graphite formation by accelerating the cementite decomposition reaction and slowing down the cooling rate.

Magnesium or Cerium - would help graphite form in a nodular shape. They may be added to gray iron to produce ductile iron by reacting with the sulfur. Magnesium tends to encourage the precipitation of cementite, so normally silicon will be added as an inoculant to ensure the formation of graphite. 




Figure 1.6: Types of cast iron which result from different carbon composition ranges and schematic microstructures which result from a variety of heat treatments.

Figure reproduced from (Callister, 2006) 
Phosphorus - is one of the elements apart from carbon and silicon that helps the cast iron solidify closer to the eutectic point in the Carbon Equivalent (CE) formula.

Sulfur - favors the formation of graphite flakes. Calcium carbide can be added to get rid of the sulfur in the melt. Manganese can also be added to lessen the effect of sulfur.

Chromium - can be added at a high percentage to suppress the precipitation of graphite to be able to cast a large white iron casting. This type of white iron may not be treated to eliminate $\mathrm{Cr}_{27} \mathrm{C}_{3}$ at all.

\subsection{Cast Iron Alloys Appearing in SOLIDCast}

From the previous section, in could be said that there are many types of cast irons in the cast iron industry. There are also some types of cast iron that were not mentioned as well. In the casting industry, alloys may be separated further into different types and classes. Only the alloys appeared in SOLIDCast will be mentioned.

In the following, a list of cast iron alloys in SOLIDCast is shown:

1) CI A532 IA

2) CI A532 IB

3) CI A532 IC

4) CI A532 ID

5) CI A532 IIA

6) CI A532 IIB

7) CI A532 IIC

8) CI A532 IID

9) CI A532 IIE

10) CI A532 IIIA

11) CI DI Ferr

12) CI DI Pearl

13) CI GI $3.5 \mathrm{CE}$

14) $\mathrm{CI}$ GI $4.0 \mathrm{CE}$

15) CI GI $4.4 \mathrm{CE}$ 


\section{6) CI Malleable}

List numbers 1 through 10 are wear-resistant cast iron alloys or white irons which are classified by the American Society for Testing and Materials (ASTM). List numbers 11 and 12 are ductile irons with ferritic and pearlitic matrices respectively. List numbers 13, 14 and 15 are gray irons with 3.5, 4.0 and 4.4 Carbon Equivalent respectively. The program would let the user adjust the parameter values in the Materials List for these gray iron alloys. List number 16 is malleable iron which actually solidifies as white iron.

\subsection{Problems Occurred in Casting}

Before one may use a casting simulation program, he/she should know what defects may occur in a casting and also the cause of each kind of defect, because casting simulation programs may only forecast defects that occur from the solidification process. Simulation cannot forecast defects that occur from human error or errors in the production process. The details in using simulation software will be explained later on in this thesis.

A casting that does not fulfill the requirements of a customer is an unacceptable one. It either becomes scrap or is repaired and becomes a good casting (Pearce, 2001). Generally, what customers look for in a good casting are its;

1) Physical features, which are the dimensional tolerances, the surface condition and integrity.

2) Mechanical properties and other properties, including machineability, which may depend on its:

- Chemical composition

- Macrostructure and microstructure

- Segregation

- Inclusions

Defects that occur in castings may be separated into;

1) Overall shape defects

- Oversized, distortion and misruns

2) Surface defects

- Burn-ons and scabs 


\section{3) Internal defects}

- Shrinkages, sub-surface holes, pores and cracks

4) Structural defects

- Undesirable microstructural constituents

- Excess inclusion level and oversized eutectic grains or cells, etc.

The overall shape defects and surface defects are the simplest defects to notice. They may be found after knockout, after cutting or breaking off the gating system (fettling) or after cleaning the casting. These defects mostly are caused from the mold and/or while filling the molten metal. Internal defects can be found by using an appropriate non-destructive test method or may be found after the machining process. These defects are hard to detect and also hard to prevent. Structural defects mostly can be found through mechanical tests, such as hardness or tensile strength or can be seen through a microscope (Pearce, 2001).

Because one kind of defect may be called by many names, the International Committee of Foundry Technical Associations (CIATF) has standardized how each casting defect can be grouped and named, as follows:

1) Metallic projections - such as flashes, excess metal on surface, mold material, erosions, core misplacement, etc.

2) Cavities and porosities - such as blow holes, macro or micro-porosities, pores, centerline shrinkage, corner shrinkage, etc.

3) Discontinuities - such as hot tearing, cold tearing, cold shuts, cold breakage, etc.

4) Defective surface

5) Incomplete casting

6) Incorrect dimensions and shapes

7) Inclusions or structural anomalies - such as alien objects which may accidentally enter the mold, such as loose sand, inoculants, inoculant products, etc.

\subsubsection{Solidification Shrinkage Defects}

Shrinkage in castings may be separated roughly according to size, macroporosity and microporosity shrinkages. 
Macroporosity may appear as an area consisting of many shrinkage holes or a single cavity with a rough surface. Macroporosity mostly occurs at isolated hot spots in short freezing range alloys, which typical locations are the middle of thick sections, junctions, corners and areas between two or more cores. Macroporosity could be detected by cutting open the area or by using non-destructive tests, such as X-ray, ultrasound and magnetic methods (Ravi, 2005). It is named macroporosity because this type of porosity is large enough for the naked eye to see.

Microporosity appears as small holes of rough surface and usually detected during machining. It mostly occurs in castings of long freezing range alloys and sometimes in thick sections of short freezing alloys. They may be hardly seen with the naked eye, hence its name, but it affects the strength of critical sections. In long thick sections, it may appear as a dotted line called as centerline shrinkage (Ravi, 2005).

Areas in a casting most prone to shrinkage defects would be characterized by high temperature, coupled with low gradient and high cooling rate. High temperatures indicate fewer directions from where liquid metal can flow in to fill up an area where shrinkage occurs. Low gradient would imply that even if liquid metal is available at a neighboring region, there may be insufficient thermal pressure for the flow to actually take place. For high cooling rate, it would imply that even though there is sufficient liquid metal and gradients, the metal may freeze too quickly before reaching the hot spot (Ravi, 2005).

Cracks or hot tears may occur in locations with high temperature, high gradient and high cooling rate, coupled with a sharp corner. High temperature would contribute to low strength while high gradient and high cooling rate would contribute to stress. A sharp corner would contribute to crack initiation (Ravi, 2005).

\subsubsection{Defects Occurred in Cast Iron}

Many types and kinds of defects may occur in cast irons. Physical defects that could be found in cast iron may occur from shrinkage, chemical composition, inclusions or from the process. This thesis would only focus on the defects that can be detected by SOLIDCast; defects occurred from the solidification process. 


\section{$1.10 \quad$ Feeders or Risers}

Feeders or risers are designed to compensate the shrinkage in the solidification of castings to eliminate porosities (Ravi, 2005). A feeder or riser would act like a reservoir of liquid metal which would feed into an area of a casting which needs extra metal. Since its action is to feed the casting, it seems to be more appropriate to call it a feeder than a riser. Actually, the word "riser" is an American term which is not descriptive in a helpful way (Campbell, 2003). It probably comes from the fact that feeders are located on the surface or above the casting; that is they "rise" above the casting surface (Creese, 2007). But since SOLIDCast uses the term "riser", it shall be used throughout the thesis.

\subsubsection{The Seven Feeding Rules}

It can be considered very difficult adding a riser or multiple risers at the right positions and with the right dimensions. There are seven rules that could be used to help in the systematic approach to a solution (Campbell, 2003), which are explained in the following:

\section{1) Rule 1}

"Do not feed (unless absolutely necessary)" (Campbell, 2003). There are several reasons why risers should not be placed on a casting. One of the most obvious ones is cost. It needs extra money to add a riser and more in removing it after the casting is done. Some castings do not necessarily need risers, such as in some small and medium size castings. Gray iron is a material which would expand from graphite growth that would counteract shrinkage and may not need any feeding in many cases (Webster, 1980). Many castings may be impaired from inappropriate placement of the riser and from using an appropriate riser size (Campbell, 2003).

\section{2) Rule 2}

The riser must solidify at the same time as or later than the casting. 


\section{3) Rule 3}

The riser must contain sufficient amount of liquid to compensate the shrinkage in the casting.

\section{4) Rule 4}

The neck connecting the riser to the casting should not contain a hot spot or should not solidify later than either the casting or the riser.

\section{5) Rule 5}

There must be a path for the liquid metal from the riser to be able to reach the regions in the casting which need it.

\section{6) Rule 6}

There must be sufficient pressure from the riser to push the liquid metal to flow into the requiring areas.

\section{7) Rule 7}

There must be a sufficient amount of pressure in all points of the casting to help suppress the growth of porosities and prevent them from forming.

All rules must be fulfilled in order to achieve a sound casting. Also, there may be other methods that would eliminate the use of risers and still achieve a sound casting, for example, applying chills and cooling fins, etc. Also, Rules 2, 3 and 4 can be gathered together into one criterion that the thermal center of the total casting, including all risers should be in the risers. Or it can be simply said that the thermal hot spots should be in the risers only (Campbell, 2003).

\subsubsection{Riser Location and Shape}

The direction of solidification inside a casting would start from an end region and then to the intermediate regions into the region where metal would solidify last. The feed metal would flow in an opposite direction from the hottest region to the regions which 
solidify first. A feed path is the entire path starting from a local hot spot to an end region. Any intermediate point on a feed path should have only one adjacent point with a higher temperature. The hot spot should feed all regions along the feed path effectively, so it should be located in the riser or risers for the casting to be defect free (Ravi, 2005).

If there is only one major hot spot in a casting, the riser should be located on the face closest to the hot spot. If there is more than one isolated hot spot, multiple risers may be required for each hot spot. For isolated hot spots with different solidification times, the riser for the hotter hot spot should be designed and analyzed first, and then verified if the same riser could feed any other hot spot or not to reduce the number of risers. Then another riser should be designed for the next largest hot spot and so on. For minor hot spots, chills may be used instead (Ravi, 2005).

Risers may be classified as top and side, hence their names, top risers are placed above a hot spot while side risers are placed at the side of the hot spot, usually at the parting line. Top risers are more effective because of the additional effect of gravity. Side risers can be fed with liquid metal directly from the ingates, which would keep the riser hotter for longer, implying that a smaller riser can be used (Ravi, 2005). Risers may also be classified as open and blind. Open risers have their tops exposed to the atmosphere showing the liquid metal rising as the mold is filled, while blind risers are hidden inside the mold. For sand castings, open risers would lose heat faster than blind risers, but on other hand, blind risers in metal molds would lose heat faster than open risers since heat transfer by conduction through the metal mold is greater than heat transfer by convection and radiation through air (Ravi, 2005).

A spherical shape would have the lowest surface area compared to its volume or the highest modulus compared to any other shape, therefore would have the longest solidification time and would be ideal for a riser, but in practice, other shapes are used because of how the formation of shrinkage pipe (which may extend into the casting) and molding constraints (mainly undercuts) (Ravi, 2005). Cylindrical shape side risers have a height per diameter ratio of 2 or more for steel castings, about 1.5 for iron castings and 3 to 4 for aluminum castings. Cylindrical risers are widely used with small castings. For larger castings, cylindrical risers with a spherical bottoms for side risers or spherical tops for top risers are widely used (Ravi, 2005). 


\subsubsection{Riser and Neck Design}

The most widely used neck shapes are rectangular for side risers and cylindrical for top risers. The neck may be tapered down to the casting which would help in fettling or knocking off the risers from the casting. This would not affect the neck modulus or its solidification time because of low heat transfer from the sharp reentrant corner. A riser designed for a given hot spot must satisfy three major requirements, which are the solidification time, feed path and feed metal volume requirements.

The riser must solidify later, or have more solidification time than the nearest hot spot, so, it must have a higher modulus compared to the casting region around the hot spot. This may be represented by equation (1.4) shown below:

$$
\mathrm{M}_{\mathrm{r}} \quad=\mathrm{k}_{\mathrm{r}} \mathrm{M}_{\mathrm{h}}
$$

Where,

$$
\begin{array}{ll}
M_{\mathrm{r}} & =\text { Modulus of riser } \\
\mathrm{M}_{\mathrm{h}} & =\text { Modulus around hot spot } \\
\mathrm{k}_{\mathrm{r}} & =\text { Riser design factor }
\end{array}
$$

The riser design factor is usually set at more than 1.0. It may be over 1.1 for ductile iron castings and over 1.2 for aluminum and steel castings. If there is an intermediate portion of the casting between the riser and the hot spot, the riser design factor may be raised up to 1.4 or more (Ravi, 2005).

A clear feed path should be available between the riser and the hot spot. This means that there should be sufficient thermal gradients for the liquid metal to flow from the riser into the thermal hot spot. So, in order to achieve this, the modulus must gradually increase from the hot spot to the intermediate section to the neck to the riser, which should have the highest value. Similar to equation (1.4), the equations may be represented by equations (1.5) shown below:

$$
\begin{array}{ll}
\mathrm{M}_{\mathrm{r}} & =\mathrm{k}_{1} \mathrm{M}_{\mathrm{n}} \\
\mathrm{M}_{\mathrm{n}} & =\mathrm{k}_{2} \mathrm{M}_{\mathrm{i}} \\
\mathrm{M}_{\mathrm{i}} & =\mathrm{k}_{3} \mathrm{M}_{\mathrm{h}}
\end{array}
$$


Where,

$$
\begin{array}{ll}
\mathrm{M}_{\mathrm{r}} & =\text { Modulus of riser } \\
\mathrm{M}_{\mathrm{n}} & =\text { Modulus of neck } \\
\mathrm{M}_{\mathrm{i}} & =\text { Modulus of intermediate section } \\
\mathrm{M}_{\mathrm{h}} & =\text { Modulus around hot spot } \\
\mathrm{k}_{\mathrm{n}=1,2,3} & =\text { Design factors }
\end{array}
$$

For metals which exhibit volumetric shrinkage during solidification, all $\mathrm{k}_{\mathrm{n}}$ should be more than 1, such as aluminum and steel castings should have a minimum value of $\mathrm{k}_{\mathrm{n}}$ of 1.1. So, the resulting modulus can be arranged as $M_{r}>M_{n}>M_{i}>M_{h}$. However, in the cases of some gray irons and low grade ductile iron which would expand towards the end of solidification, the value of $\mathrm{k}_{2}$ should be less than 1.0 to prevent reverse feeding of liquid metal from the casting into the riser through the neck (Ravi, 2005).

The third requirement, the riser volume must be able to compensate the shrinkage of the hot spot. Equation (1.6) shown below may represent this criterion:

$$
\eta_{\mathrm{r}} \mathrm{V}_{\mathrm{f}}=\alpha\left(\mathrm{V}_{\mathrm{h}}+\mathrm{V}_{\mathrm{r}}\right)
$$

Where,

$$
\begin{array}{ll}
\eta_{\mathrm{r}} & =\text { Riser efficiency } \\
\alpha & =\text { Volumetric shrinkage of the casting material } \\
\mathrm{V}_{\mathrm{f}} & =\text { Riser volume } \\
\mathrm{V}_{\mathrm{h}} & =\text { Volume of the region around the hot spot }
\end{array}
$$

The riser efficiency depends on the feeder shape, type (open or blind) and application feed-aids, such as insulators or exothermic sleeves. It has to be considered because the riser itself is also solidifying as it is feeding liquid metal to the casting. For an open riser with a height per diameter ratio of 1.5, the efficiency is around 14 percent. It can be increased to about 50 percent if insulated with sleeves or exothermic sleeves. The net volumetric shrinkage may range from 1 to 2 percent for gray irons, 3 to 4 percent for steel, 4 to 6 percent for copper and 5 to 7 percent for aluminum alloys. This equation 
may fail in the cases of large castings with thin sections and molds with risers connected to more than one casting (Ravi, 2005). Figure 1.7 shows simple guidelines in designing a side riser and a top riser with a height per diameter ratio of 1.0 (Heine, 1995).

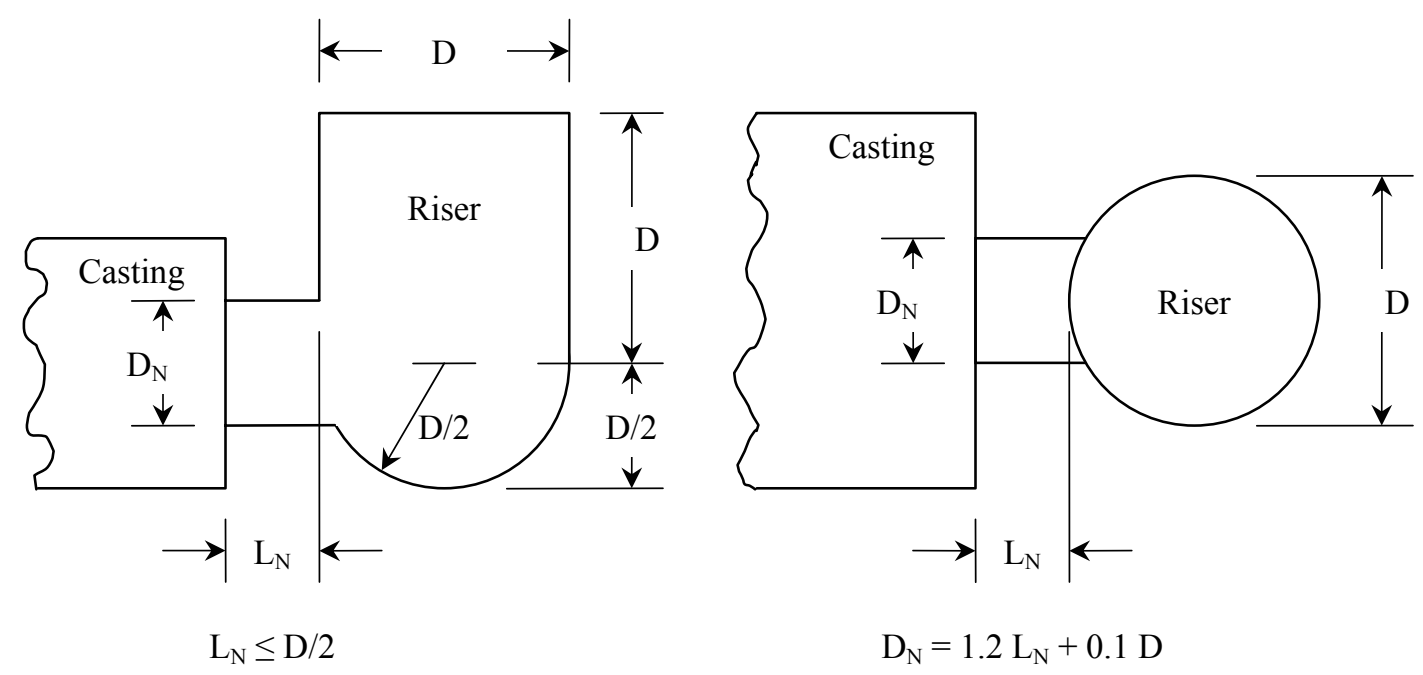

a) Side riser
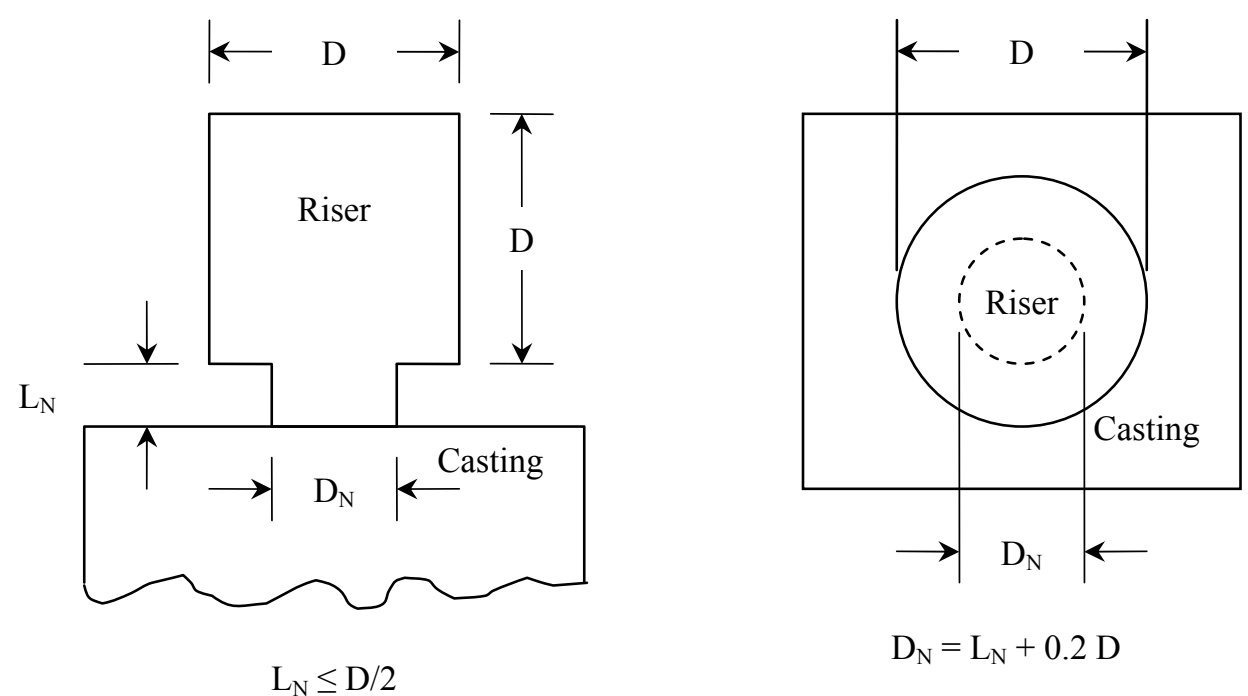

b) Top riser

Figure 1.7: Simple guidelines in designing a side riser and a top riser with a height per diameter ratio of 1.0 (Modified from Heine (1995)). 
The size of a riser should not be too large or too small. A riser too large would be a waste of casting material, and being large, it would have a slow cooling rate and might keep the area of the casting connected to it a hot spot which may be the cause of porosities. A riser too small would not be able to feed enough molten metal into the casting and shrinkage would occur. Also, the size of a neck should not be too large or too small as well. A neck too large would result in a high modulus and the neck would cool down too slowly causing it to be a hot spot. A neck too small would result in low modulus and it may cool down too rapidly preventing enough liquid metal to be fed into the casting.

\subsection{Gating Design}

A well-designed gating system would ensure smooth, uniform and complete filling of liquid metal into the mold cavity resulting in a clean casting free of discontinuities, solid inclusions and voids. Clean metal implies no slag or inclusions entering the mold and with minimal surface turbulence, smooth filling implies minimal bulk turbulence, uniform filling would mean that all portions of the casting are filled at the same time and complete filling would mean that the liquid metal is led to the end and thin sections with minimal resistance (Ravi, 2005).

The first step of designing the gating system is selecting the type of gating system and the layout of the gating channels, which are the orientation and position of the sprue, the runner and the ingate or ingates into the casting. There are also occasions when a riser or risers may be positioned in the gating system, for example, the ingate from the runner is led into a riser, then into the casting cavity through its neck. The major elements of the gating system are the pouring basin, the sprue, the sprue well, the runner or runners and the ingate or ingates.

The gating systems can be classified as horizontal and vertical gating systems. Horizontal gating systems are those with a horizontal parting plane containing the runners and ingates with a vertical sprue perpendicular to the parting plane. This type of gating system is suitable for flat castings filled under gravity, such as green sand and gravity die casting. Vertical gating systems are those with a vertical parting plane containing the runners and ingates. For gravity filling processes, such as high pressure sand molding, 
shell molding and gravity die casting, the sprue is vertical, which is suitable for tall castings. For pressure die casting, the sprue may be horizontal, perpendicular to the parting plane.

Also, depending on the position of the ingate or ingates, the gating system may also be classified as top, bottom and parting line gating systems. Top gating systems are for identifying gating systems with an ingate or ingates entering from the top of the casting cavity, promoting directional solidification from the bottom to the top of the casting. This type of gating system is suitable for flat castings to limit the damage occurred from the liquid metal free falling into the mold during initial filling. Bottom gating systems would have the ingate or ingates entering the mold from the bottom minimizing turbulence. It is recommended for tall castings which free falling of molten metal should be avoided. Parting line gating systems would have the ingate or ingates at the parting line, usually at the middle, combining the characteristics of both top and bottom gating systems. They are also easier to produce and to modify during trial runs (Ravi, 2005).

The most critical design decision is finding the ideal filling time which is based on how the gating channels are designed. A casting that is filled too slowly can have discontinuities, such as cold shuts and misruns, and premature freezing in thin sections before completion of filling. But if it is filled too fast, inclusions and blow holes may occur from surface turbulence. The correct filling time would lie somewhere in between, and is a function of cast metal, weight, minimum section thickness and pouring temperature (Ravi, 2005). Several empirical equations for determining the appropriate filling time were developed by many researchers. Equations (1.7) (Ravi, 2005), (1.8) and (1.9) (Heine, 1995) are some examples of equations used for calculating the optimal filling time.

$$
\mathrm{t}_{\mathrm{f}}=\mathrm{K}_{0}\left(\mathrm{~K}_{\mathrm{f}} \mathrm{L}_{\mathrm{f}} / 1,000\right) \times\left(\mathrm{K}_{\mathrm{s}}+\mathrm{K}_{\mathrm{t}} \mathrm{t} / 20\right) \times\left(\mathrm{K}_{\mathrm{w}} \mathrm{W}\right)^{\mathrm{P}}
$$

Where,

$\mathrm{t}_{\mathrm{f}}=$ Optimal filling time, seconds

$\mathrm{K}_{0} \quad=$ Overall coefficient

$\mathrm{K}_{\mathrm{f}} \quad=$ Coefficient for fluidity 


$$
\begin{array}{ll}
\mathrm{L}_{\mathrm{f}} & =\text { Fluidity, millimeters } \\
\mathrm{K}_{\mathrm{s}} & =\text { Coefficient for size } \\
\mathrm{K}_{\mathrm{t}} & =\text { Coefficient for thickness } \\
\mathrm{t} & =\text { Thickness, millimeters } \\
\mathrm{K}_{\mathrm{w}} & =\text { Coefficient in weight } \\
\mathrm{W} & =\text { Weight, kilograms } \\
\mathrm{P} & =\text { Coefficient of pouring temperature }
\end{array}
$$

For gray iron castings with sizes between 100 and 1,000 millimeters and wall thicknesses up to 10 millimeters, the following values may be used:

$$
\begin{array}{ll}
\mathrm{K}_{0} & =1.0 \\
\mathrm{~K}_{\mathrm{f}} & =1.0 \\
\mathrm{~K}_{\mathrm{s}} & =1.1 \\
\mathrm{~K}_{\mathrm{t}} & =1.4 \\
\mathrm{~K}_{\mathrm{w}} & =1.0 \\
\mathrm{P} & =0.4
\end{array}
$$

Equations (1.8) and (1.9) are for calculating the optimal filling times for gray iron castings weighing no more than 1,000 pounds and weighing more than 1,000 pounds respectively (Heine, 1995).

$$
\begin{array}{lll}
\mathrm{t}_{\mathrm{f}} & =(\mathrm{F} / 40) \times(0.95+\mathrm{T} / 0.853) \times \sqrt{\mathrm{W}} & \text { where } \mathrm{W} \leq 1,000 \\
\mathrm{t}_{\mathrm{f}} & =(\mathrm{F} / 40) \times(0.95+\mathrm{T} / 0.853) \times{ }^{3} \sqrt{\mathrm{W}} & \text { where } \mathrm{W}>1,000
\end{array}
$$

Where,

$$
\begin{array}{ll}
\mathrm{t}_{\mathrm{f}} & =\text { Optimal filling time, seconds } \\
\mathrm{F} & =\text { Fluidity of iron, inches } \\
\mathrm{T} & =\text { Average thickness, inches } \\
\mathrm{W} & =\text { Weight, pounds }
\end{array}
$$


There are several ways to calculate this filling time. The method SOLIDCast uses in calculating the optimal filling time is different from the shown equations and shall be mentioned later in Chapter 4.

Table 1.2: Selected sprue-runner-gate area ratios (Heine, 1995).

\begin{tabular}{|c|c|}
\hline Casting & Sprue : Runner : Gate ratio \\
\hline Steel & $1: 2: 1.5$ \\
\hline & $1: 3: 3$ \\
\hline & $1: 1: 0.7$ \\
\hline & $1: 2: 2$ \\
\hline - Fin-gated & $1: 1: 1$ \\
\hline Gray cast iron & $1: 4: 4$ \\
\hline - Pressurized system & 1:1.3:1.1 \\
\hline Ductile iron, dry sand molds & 10:9:8 \\
\hline - Shell molded, vertical pouring & $1: 2: 2$ \\
\hline - Pressure system & $4: 8: 3$ \\
\hline - Reverse choke & $1.2: 1: 2$ \\
\hline Aluminum & $1: 2: 4$ \\
\hline - Pressurized system & $1: 2: 1$ \\
\hline - Un-pressurized system & $1: 3: 3$ \\
\hline Brass & $1: 1: 1-1: 1: 3$ \\
\hline
\end{tabular}

The sprue well should be designed to minimize turbulence as the liquid metal free falls down the sprue. The recommended shape of a sprue well is cylindrical with a diameter twice the diameter of the sprue exit and a depth of 1.5 times the depth of the runner (Ravi, 2005) or twice the depth of the runner (Campbell, 2004). For the runner, its main function is to slow down the liquid metal as it speeds up falling down the sprue and take it to the ingates. The runners must fill completely before letting the molten metal enter the ingates. The cross-sectional area of the runner should be reduced by the crosssectional area of the ingate it passes to ensure uniform flow through the ingates. The ingates would lead the molten metal from the runners into the mold cavity. They should 
be easy to fettle or knock off, should not lead to a local hot spot and its cross-sectional area must be proportional to the volume of the connected casting region it is feeding.

The gating ratio is given by the cross-sectional area ratio of the sprue exit per runner(s) per ingate(s). In the case of multiple runners and ingates, their total crosssectional areas are considered. A larger cross-sectional area would affect the velocity of liquid metal to slow down as it passes. Different ratios may be used for different cast metals and systems. Table 1.2 shows some ratios used in different casting situations. The smallest value in the gating ratio is considered to be the choke, which controls the flow rate of molten metal.

\subsection{Introduction to SOLIDCast}

SOLIDcast is a computer simulation software program for castings created and owned by the Finite Solutions Inc. of USA. The version used in this thesis is Version 6.3.39. It is capable of simulating sand casting, investment casting and permanent mold casting models with many types of metal.

SOLIDCast is a program which helps a user in predicting defects that might occur in a casting from the solidification process of a casting. It uses the Finite Difference Method (FDM) in calculating the thermodynamics of each element in the casting and records the temperature changes. The temperature changes collected will be used in plotting graphs of different criterions in predicting different types of defects in a casting.

This program has many functions and features, but only the topics of interest will be presented.

\subsubsection{Output Criteria}

The output criteria which can be displayed in SOLIDCast for users to analyze are as follows:

\section{1) Solidification Time}

Solidification time shows the time in minutes for each part of the casting to become completely solid, i.e., to cool down to the solidus point from the time the pouring ends. The solidification time plots shows the progressions of solidification through the 
casting, which can help locate isolated areas of molten metal within the casting and get a general idea of progressive solidification in various areas of the casting.

\section{2) Critical Fraction Solid Time}

Critical fraction solid time is the time in minutes for a part of the casting to reach the critical fraction solid point, the point at which the molten metal loses its ability to flow liquid feed metal from the time the pouring ends. It is a better indicator for looking at progressive solidification than solidification time. It also helps find if there are any isolated areas formed in the casting that cannot be fed by risers. It gives a good indication of whether any contraction that forms will be able to be fed by liquid feed metal with the risers or feeders. This plot is interpreted in the same manner as solidification time, that is, a casting should show a good progressive cooling, from the edges of the casting towards the risers.

\section{3) Material Density Function}

This criterion is a result of a calculation in which the contraction of the casting and resulting flow of liquid metal is taken into account during solidification. Areas having metal removed due to feeding liquid metal to other areas of the casting will have lower material density numbers. In this way, potential shrinkage can be predicted.

The material density function is a number varying between 0 and 1; 0 meaning that the metal has been completely drained from that part of the casting while 1 indicates completely sound metal. It is found that, in general, values in the range between 0.995 or 0.990 and below are areas of detectable shrinkage porosity in castings.

The material density function is a measure of macroporosity and is most useful in ferrous castings. In non-ferrous alloys, especially aluminum, it can be used to predict gross macroporosity, but structural microporosity due to poor or stagnant solidification can best be predicted by other criteria such as the Niyama or the FCC custom criterion.

In ferrous castings, if the Material Density Function is plotted at 1, the plot would highlight any area that may experience any loss of density. This would overstate the shape and size of a hole, but would indicate all the locations that might lose any density whatsoever (David Schmidt of Finite Solutions Inc.). 


\section{4) Temperature Gradient}

Temperature gradient is a measure of how much change in temperature there is as you go from point to point within a casting. A high temperature gradient means there is a large temperature change within a short distance within the casting while a low temperature gradient means there is a small change in temperature from one point to the next.

The temperature gradient is calculated at each node within the casting as that point reaches the Niyama point on the cooling curve. The temperature gradient is always calculated in degrees Celsius per centimeter.

It can be used to get an idea of whether there is good or poor directional solidification or not. Usually, higher temperature gradients are good, as steeper temperature gradients mean a greater driving force for solidification.

\section{5) Cooling Rate}

The cooling rate is a measure of how quickly a casting cools down in degrees Celsius per minute which is measured at each point in the casting as it reaches the Niyama point on the cooling curve. Cooling rate can be an indication of material quality, because areas of a casting that cools down rapidly generally has a more favorable grain structure.

\section{6) The Niyama Criterion}

The Niyama criterion is a function based on the temperature gradient and cooling rate criterions. This criterion is developed by Dr. Niyama, a Japanese researcher studying shrinkage prediction in steel. He found that the temperature gradient divided by the square root of the cooling rate, as shown in equation (1.10) corresponded to the presence of shrinkage porosity in steel castings, which the lower the value, the higher probability of shrinkage.

$$
\text { Niyama Criterion } \quad=\text { Temperature Gradient } \div \sqrt{ } \text { Cooling Rate }
$$


The Niyama criterion is basically a prediction of directional solidification. Also, it can be used to identify potentiality for centerline shrinkage. But Niyama plots need interpretation, because they give low values in many areas where temperature gradients are low but shrinkage might not be likely, such as the centerline of thin-wall areas and the dividing line between the feeding areas of two risers. Also, Niyama is based only on heat transfer and does not take the effect of gravity into account, which the Material Density Function does and is a better indicator than Niyama for most ferrous materials. However, the Niyama criterion is still used heavily in many non-ferrous applications, typically in aluminum alloys, but rarely used in ferrous alloys anymore according to Mr. David Schmidt of Finite Solutions Inc.

For plotted values, 0 represents poor directional solidification, good directional solidification by higher values. The values that are critical values separating between poor and good directional for each type of material are different. Table 1.3 shows the critical Niyama values which would be used for plotting Niyama plots recommended by the SOLIDCast manual (Finite Solutions Inc., 2005).

Table 1.3: Different types of materials and their critical Niyama value.

\begin{tabular}{|c|c|}
\hline Material & Critical Niyama Value \\
\hline Steels & 1 \\
\hline Cast Irons & 0.75 \\
\hline Aluminum & 0.30 \\
\hline Copper Base & 1.30 \\
\hline
\end{tabular}

It could be said that the Niyama Criterion is a shrinkage 'potential' plot. The lower the value plotted or the closer to 0 , the higher the potential for shrinkage actually being present. It is not a definite indication of shrinkage, nor does it show the size and shape of shrinkage (David Schmidt of Finite Solutions Inc.).

\section{7) Hot Spots}

Hot spot plotting is a function in SOLIDCast that locates thermal centers or hot spots within the casting by comparing the solidification times or critical fraction solid 
times of each metal node to its neighbors. If it froze later than its neighbors, it is an isolated area, or a hot spot. The range of values is between 0 to 10 which 0 means the area is most isolated, 1 is stagnant, that is, froze at the same time as its neighbors and 10 is most directional. The method of calculation is to divide a node's neighbors solidification time or critical fraction solid time with its own and use the highest value to represent its hot spot value. To see the hot spots in the casting clearly, plotting at 1.1 or 1.2 would cover a greater volume. 1.1 shall be the value used as the critical plotting value for the Hot Spot Criterions in all simulation tests in this thesis.

The hot spot plots do not give an indication of the severity of the defect, as it does not take the contraction or expansion into account, but it does give a good indication of which areas are prone to have problems.

\section{8) Custom Criterion}

The custom criterion is a function that allows the user to plot data from standalone programs in SOLIDCast, which are available from Finite Solutions Inc. (2005), or the user can develop custom criteria functions using one of the standalone utilities in the program.

One custom function called the FCC Criterion is built-in the SOLIDCast software. It calculates the FCC criterion, which was developed by Franco Chiesa of the Collège de Trois-Rivières in Quebec (Finite Solutions Inc., 2005). The FCC criterion function was developed as an indicator of the total evolved microporosity in aluminum castings, which has also been some success applying to other alloys as well. It also has been proven useful in identifying thermal centers within castings, for example, the location of possible secondary shrinkage in iron castings might be displayed.

The FCC criterion can be calculated in the program from selecting the FCC calculation tab in the menu tab. To display the results, the user must use the CustomHigh criterion to plot.

This FCC criterion is based on the solidus wavefront velocity, meaning the speed of which the solidus wavefront moves through the casting at each point of the casting, and the local solidification time, which is the time to cool from liquidus to solidus. 
The range of numbers of the FCC criterion developed for any given casting depends on the alloy and the geometry of the casting, the higher the number, the more probability of microporosity formation. But it has been suggested to use a 40 percent of the total range generated by the program as the critical value in starting a plot. Numbers higher than this will indicate more severe areas and numbers lower indicate less severe areas.

SOLIDCast allows the user to create a customized formula for plotting a calculated output from the results of a simulation. The formula can be created with the form shown in equation (1.11):

$$
\text { Result }=\mathrm{Kx} \mathrm{T}^{\mathrm{e} 1} \times \mathrm{ST}^{\mathrm{e} 2} \times \mathrm{CFS}^{\mathrm{e} 3} \mathrm{xG}^{\mathrm{e} 4} \mathrm{x} \mathrm{r}^{\mathrm{e} 5} \times \operatorname{LT}^{\mathrm{e} 6} \times \operatorname{LST}^{\mathrm{e} 7} \times \mathrm{V}^{\mathrm{e} 8}
$$

Where

$$
\begin{array}{ll}
\mathrm{K} & =\text { Constant } \\
\mathrm{T} & =\text { Temperature } \\
\mathrm{ST} & =\text { Solidification Time (min.) } \\
\mathrm{CFS} & =\text { Critical Fraction Solid Time (min.) } \\
\mathrm{G} & =\text { Temperature Gradient }\left({ }^{\circ} \mathrm{C} / \mathrm{cm}\right) \\
\mathrm{r} & =\text { Cooling Rate }\left({ }^{\circ} \mathrm{C} / \mathrm{min} .\right) \\
\mathrm{LT} & =\text { Liquidus Time }(\min .) \\
\mathrm{LST} & =\text { Local Solidification Time }(\mathrm{ST}-\mathrm{LT}) \\
\mathrm{V} & =\text { Solidus Velocity }(\mathrm{cm} / \mathrm{min} .)
\end{array}
$$

e1 through e $8=$ exponents applied to each of the above factors $=0$ means that that factor has no significance to the interested output

For example, a formula which has been developed for DAS (Dendrite Arm Spacing) (Finite Solutions Inc., 2005) in steel is shown in equation (1.12):

$$
\text { DAS }=100 \times \operatorname{LST}^{0.41}
$$

This can be evaluated for a simulation by entering the constant and exponents as shown in equation (1.13): 


$$
\text { Result }=100 \times \mathrm{T}^{0} \times \mathrm{ST}^{0} \times \mathrm{CFS}^{0} \times \mathrm{G}^{0} \times \mathrm{rr}^{0} \times \operatorname{LT}^{0} \mathrm{xLST}^{0.41} \times \mathrm{V}^{0}
$$

After evaluating the equation, the user could then plot the results in SOLIDCast to see the calculated DAS in the casting.

\section{9) Other Criterions}

Other than the 8 criterions above, there are also other criterions that the user may use to analyze the simulation, such as the "Temperature" criterion which the user can select either the temperature throughout the whole model, the casting and riser(s) only or the mold only at the time the pouring is finished. And the "Liquidus" criterion can be used for seeing how much time until a particular area reaches the liquidus point from the time the pouring is finished.

\subsubsection{Plotting the Results of Output Criteria}

From all output criteria mentioned, there are three methods to plot for results:

\section{1) Plotting Results Using Iso-surfaces}

An iso-surface plot is a three dimensional model with transparent surface which displays highlighted areas with a particular value. Only one value entered by the user can be plotted at a time.

\section{2) Plotting Results Using Cut Planes}

Cut plane plotting shows simulation results on a two dimensional plane cut through the casting. The plot would consist of shades of color representing the values of simulation results. Only three plane orientations can be observed; XY-plane, XZ-plane and YZ plane. The planes could not be tilted into any other orientation.

\section{3) Plotting Results Using CastPic}

CastPic is a function in SOLIDCast that can create a detailed three dimensional image of the casting with shades of color representing the values of 
simulation results. A plane could be cut through the model to reveal the simulation results under the surface of the casting. It can be said it is a combination of iso-surfaces and cut planes. The plane orientations are the same as the cut plane plots.

\subsubsection{Analyzing the Results}

As already discussed in section 1.12.1 and 1.12.2 about each output criteria and what kind of defects or results may happen in a casting by interpreting the results from the plots, a typical sequence for analyzing a casting may be done as shown in the following:

1) Observe the sequence of solidification using the Critical Fraction Solid Time or Solidification Time Criterion to check for directional solidification and locate isolated freezing areas. Isolated freezing areas are most prone to casting defects.

2) Next, the Material Density Function is used for finding areas of potential macroporosity shrinkage.

3) The FCC Criterion is used for finding the areas prone to microporosity in the casting.

4) The Hot Spot Criterions are used for finding potential hot spot areas.

5) The Niyama Criterion is used for checking the possibility of centerline shrinkage.

The Niyama Criterion is used widely for non-ferrous castings but not a good criterion for ferrous castings. So, the Niyama Criterion would not be needed for analyzing a ferrous casting.

These steps may use any method of plotting from section 1.12.2 depending on whichever plots gives out the most useful information to the user. By following these steps, the user would learn about the typical characteristics of the simulated casting design. The user then may also analyze the casting simulation results further with other output criterions in order to help predict the outcome of the casting design.

\subsubsection{Limitations in Predicting Defects in SOLIDCast}

SOLIDCast simulates a casting from the pouring of molten metal into the mold. The program calculates an approximate flow and heat loss during the flow but it cannot 
calculate the turbulence from the flow. The program simulates and collects only temperature and time data, starting from when the metal is poured until the last node of casting material is completely solidified.

Casting simulation software currently do not predict the porosities occurred from first principles, i.e., the pressure drop which may occur in various parts of the casting. But many researchers found that there are other parameters which are easier to calculate and can be used for assessing the porosity formation (Campbell, 2003). From all criterions available in SOLIDCast and the custom criterion, it was found that all output criterions are functions of temperature, time and distance, except for the Material Density Function that also takes gravity into consideration. SOLIDCast only simulates these values during the solidification.

There are many types of defects that may occur in a casting but there are limited methods to detect those defects in a casting simulation program. For SOLIDCast, the predictions of the outcome of a casting design are limited to the output criterions mentioned earlier, but the user may also create custom criterions to predict certain defects. However, the formula created for that custom criterion must consist only of functions of temperature, time and distance.

Also, the time plots, such as the Critical Fraction Solid Time Criterion or Solidification Time Criterion, etc., the particles may drop under the critical fraction solid point or solidus point before the pouring is finished causing areas with no highlights at time zero. It is because the plotting time starts from when the pouring is finished, so in some occasions, the user may not be able to see the solidification process in some certain areas.

\subsection{The Basic Steps and Functions in SOLIDCast for Sand Casting Cast Irons}

This study is interested in the use of SOLIDCast in cast irons cast by the sand casting method. This section shall show the basic steps of using the program, along with explanations of the program's functions associated with cast iron casting. The detailed procedure of using SOLIDCast with cast irons will be shown in Chapters 3, 4 and 5.

The first step is building the model. The casting design can be created by using SOLIDCast but it can not produce complicated geometrical shapes. A model can be 
created in other 3D CAD programs and converted into a ".stl" file format which is the type of file SOLIDCast is able to read and use.

The next step is to select the casting material, the mold material and other materials which will be used in or with the mold, such as cores, chills, sleeves, etc. The default characteristic values of the materials are included in the program, but can be adjusted if needed. Those characteristics may include thermodynamic characteristics, densities, cooling curves, etc.

There are also special functions to adjust the temperature curve and the shrinkage curve of a cast iron. As mentioned in section 1.7, cast irons with different Carbon Equivalent values would have different liquidus and solidus temperatures according to the phase diagram. The temperature and shrinkage curves can be adjusted automatically or semi-automatic by entering the weight percent of carbon, silicon and phosphorus values to make the simulation as accurate as possible.

There are also functions that may help the user design risers, runners and gating system, called the "Riser Design Wizard" and the "Gating Design Wizard", so, the user may design risers, runners and the gating system in a shorter time.

The weight of the casting, risers and gating system can be calculated to help the user calculate the yield. The optimal filling time for the casting can also be calculated.

When the simulation is done, the user can analyze the results using the different output criteria and plots. If there are problems in the casting, the user may re-design the model and re-simulate the model again.

\subsection{Extension Programs of SOLIDCast}

There are two extensional programs or modules for SOLIDCast created by Finite Solutions Inc., which are FLOWCast and OPTICast. Even though they are not in the focus of this thesis, a brief explanation of the two modules shall be explained in the following:

\subsubsection{FLOWCast}

FLOWCast is an extensional program that covers up the limitations of calculating the speeds of the liquid metal particles which may result in defects occurred from 
turbulence in SOLIDCast. It is a flow simulation module which models the filling of the gating and mold cavity. It models progressive temperature and velocity of the liquid metal.

The module can show flow pathlines, or particle trace lines which helps the user visualize the flow of the metal and determine whether any excessive vortexing or turbulence may be occurring. This can also be used to predict the likely end location of foreign particles (oxides or dirt) entrained in the metal stream. Also, the velocity of the liquid metal at any point can be shown as well.

This module can help the user visualize how the gating system will function and how the mold will fill. Flow-related defects such as misruns or cold shuts can be identified as well. It also provides a more realistic temperature distribution in the casting and mold for a subsequent solidification analysis. The user using only SOLIDCast must design a gating design which will create minimal turbulence in the pouring of liquid metal.

\subsubsection{OPTICast}

This module will help the user optimize the casting, riser and gating system designs, which shall mean a design that will result in better yield, lower costs, lower production time, etc.

Optimization is a mathematical method for finding the best solution to a given problem. It automates the search for a design solution, frees the engineer's time and provides a more thorough and repeatable design process.

The basic steps required for optimization may start from developing an initial design, defining design variables, constraints and the objective function then launch the optimization. The design variables are the elements allowed to vary for finding the optimized design, such as the height and diameter of a riser, the size of a feature of a casting, pouring temperature, etc. Constraints are aspects of a design whether that design is acceptable or not. Typical constraints may be the macroporosity level, microporosity level, yield percentage, minimum cooling rate, minimum thermal gradient, etc. And the objective function would be the single result which the user would want to either maximize or minimize. For example, maximize yield percentage, minimize 
macroporosity level, minimize microporosity level, maximize the cooling rate, maximize directional solidification, etc.

An experienced foundry engineer would know how to optimize or improve a casting design. He or she may use SOLIDCast in verifying the improved design if it would meet the required qualifications. But having OPTICast may help the user to reduce the time used in optimizing the casting design.

\subsection{Commercial Software for Computer Simulation in Metal Casting}

There are many casting simulation software programs in the market today. Each program may have different approaches in creating the model or calculation and may have different advantages and disadvantages. Some programs shall be reviewed in the following:

CastCAE is a casting simulation program which uses the Finite Difference Method approach created by CASTech, Inc., Finland. It claims to be the first in the world to bring simulation to the Windows environment. It can simulate mold filling, solidification, iron properties and casting defects for steel, iron, light alloys, copper alloys, superalloys and precious metals, and casting methods of sand casting, replicast, investment casting, croning process, gravity die casting, low-pressure and high-pressure die casting. (www.castech.fi)

CAPCAST was created by EKK, Inc., founded in 1991 and based in Michigan, USA. The CAPCAST software package includes mesh generation tools, solidification simulation, porosity simulation, flow simulation and stress simulation, which all of the tools are based on the Finite Element Method. CAPCAST could model high-pressure die casting with or without a vacuum, high-pressure die castings with shot sleeve analysis, various low pressure processes, semi-solid, thixomolding processes, permanent and semipermanent casting processes, squeeze castings, green sand castings, hard sand castings, centrifugal castings, structural investment castings and many other options. It can also simulate various cast alloys and mold materials. Even though it uses the Finite Element Method as its approach, it claims to simulate at a very good speed and with high accuracy and efficiency. (www.ekkinc.com) 
MAGMASOFT was created by MAGMA, a German company founded in 1988. This Finite Element Method program may help the user avoid gating and feeding problems, predict casting quality, aids permanent mold design and reduces fettling costs. It contains many modules for calculating specific processes, such as high-pressure die casting, low-pressure die casting, lost foam, low-pressure die casting for wheel castings, etc., optimization modules, and modules that could predict thermoelastic/thermoplastic stresses, residual stresses and strain in castings and molds, modules that can predict the solidification sequence of cast iron alloys using microscopic kinetic growth models, heat treatment modules, etc. (www.magmasoft.com)

MAVIS-FLOW is a software program for simulating the mold filling and solidification of cast alloys, developed by Eidawn Software Limited at the University of Wales Swansea, UK. It uses the Finite Difference Method approach and includes a Navier-Stokes mold filling simulator. It includes a database of commonly used casting alloys and mold materials and the user can also edit and create their own material properties data files if wished. It can simulate any conventional gravity process, lowpressure and high-pressure die casting. It has been successfully applied to steel, gray iron, SG iron or ductile iron, aluminum, copper, zinc and brass alloys. It also has program for simulating grain growth as an aid to understanding grain structure evolution. (www.alphacast-software.co.uk)

NovaFlow \& Solid was created by NovaCast Technologies founded in 1981 in southern Sweden. It is a complete mold filling and solidification simulation package based on advanced fluid flow and heat transfer theories. It also has an add-on program called NovaStress that calculates the stresses that occur in the casting during solidification of the material. It uses the Finite Difference Method approach. (www.novacast.se)

PASSAGE/PowerCast was created by Technalysis, Inc. which is based in Indianapolis, Indiana, USA. This casting simulation software can be applied to sand castings, permanent mold castings, die castings, lost foam castings, automotive parts and appliances. Technalysis, Inc. also developed many other flow and heat transfer simulation programs apart from casting simulation. (www.technalysis.com) 
ProCast was created by Calcom ESI, founded in 1991, an engineering company located in Lausanne Switzerland, which is also involved in the development and marketing of the metallurgical simulation software PAM-QUIKCAST and CALCOSOFT. ProCast is based on the Finite Element Method approach. It covers a wide range of casting processes and alloy systems, including, high and low-pressure die casting, sand casting, gravity die casting and tilt pouring, investment casting, shell casting, lost foam and centrifugal casting. CALCOSOFT is dedicated to the simulation of continuous casting processes, including, horizontal and vertical continuous and semi-continuous casting, direct chill casting, strip casting, twin-roll casting and Hazlett process. PAMQUIKCAST is a software package which allows the user to simulate the entire casting process from filling to solidification including defects prediction. It uses the Finite Difference Method approach. (www.calcom.ch)

SIMTEC was founded under the parent company, RWP of Germany founded in 1984. SIMTEC USA opened its first office in Michigan in 1996. Its mission is to supply engineering teams with simulation software that enables them to develop processes that produces the highest quality castings in the shortest time at the lowest possible cost. It was the first leader in Finite Element Method simulation. SIMTEC software provides a full range of casting simulations. SIMTEC's Finite Element Method approached simulation enables computer-aided calculation of mold filling and solidification for a full range of casting types, including, common casting processes, such as high and lowpressure die casting, sand casting, lost foam, permanent mold (conventional/tilt pour), investment casting, shell casting, and special casting processes, such as, continuous casting, centrifugal casting, squeeze casting, semi-solid casting. It can also calculate thermal stress and distortion and strength. (www.simtec-inc.com)

\subsection{Problem Statement}

There are various types of defects that may occur in a casting. There are also many casting simulation software programs in the market nowadays. Different casting simulation software programs and modules may predict some types of defects that may occur in the casting. The accuracy of the simulation depends both on the program and the input values it receives from the user. The user must also know how to interpret the 
results from the simulation in order to know what defects may occur and where they might take place.

SOLIDCast is one of the most popular PC-based casting simulation systems in the market (http://www.moderncasting.com/MoreInfo/0804/MoreInfo_06_0804.pdf), and is also the focus of this thesis. The reasons why SOLIDCast was chosen are, first of all, the Department of Industrial and Management Systems Engineering of West Virginia University has already purchased this program for educating their students, so it was already available for use. This program is based on the Finite Difference Method, so it is considered to be rather faster than the Finite Element Method and easier to use as it would not produce meshing gaps as mentioned earlier in section 1.5.3. Also, the user interface is easy to understand and user-friendly.

Next, SOLIDCast has a built-in flow calculation module which would calculate the temperature drop during the filling of the mold. Although it does not calculate the speed of the particles and the turbulence of the flow, it is considered to be very useful as many other casting simulation programs might not be able to do the same. A separate program or an extension program is needed to calculate the flow and to transfer the data to the main casting solidification program. If the user would want detailed calculations of the filling of the mold, FLOWCast, which is an extension program of SOLIDCast, can be added. Another extension program for SOLIDCast is OPTICast which can help the user optimize a casting design.

The focus of this thesis is to study the capabilities and limitations of the program by going through simple models and the usefulness of SOLIDCast in a real casting environment with a case study. 


\section{Chapter 2}

\section{Literature Review}

\subsection{The History of Metal Casting}

Casting technology dates back to around 5,500 B.C. Gold was the first metal prehistoric man used because of how shiny it was and how easy to be shaped. Then silver was found and treated similarly. Later mankind found copper appearing in the ashes of camp fires from copper-bearing ore that lined the fire pits. It was found that copper was a lot harder than gold and silver and couldn't be bent easily. Copper products were used as tools and weaponry.

Pottery, made from clay, was found earlier than metal. Man learned how to make pottery by shaping clay into bowls and hardening by fire. Food was cooked in these pots. Man learned that gold could be melted with heat in clay pots, and if there was sufficient heat, copper could be melted, too. These were the beginnings of the "Casting Industry" (Danzur).

The oldest known casting in existence probably made around 3,200 B.C. is a copper frog cast in Mesopotamia, today's modern Iraq (www.metal-technologies.com and Ravi, 2005). The frog's complexity indicates that it was preceded by other simpler casting efforts. In Eurasia, copper and bronze tools, decorations and weapons became common around 3,000 B.C. Bronze refers to a broad range of copper alloys, with tin as the main additive which makes it stronger and tougher than copper.

Because at that period of time, bronze was the most advanced metal working technique, it has become the name of that period, "The Bronze Age". The Bronze Age may have started around 3,500 B.C. in the Near East area, or around modern Turkey and around the Middle East. The Indian Bronze Age began around 3,300 B.C. while China's Bronze Age started around 2,100 B.C. There are many areas in the world which Bronze Ages starts and ends at different periods (Pernicka, 2003).

The Iron Age was the last period of the three-age system for classifying prehistoric societies (Stone Age, Bronze Age and Iron Age). The Iron Age corresponds to the stage at which iron production was the most advanced form of metal working. The first use of iron probably came from the Sumerians and Egyptians around 4,000 B.C. (Wikipedia). China started to have iron castings around 1,000 B.C. India made steel 
around 500 B.C. (Danzur). The casting technology went to Europe from India and the Middle East through Portuguese explorers in the $14^{\text {th }}$ century (Ravi, 2005).

\subsection{Studies of Casting Technology and Simulation Software for Casting}

Metal casting has evolved throughout the ages. The techniques have been passed on and improved through generations. Metal casting, although having a history of thousands of years, still hasn't stopped evolving. The developments and findings of new casting techniques and technologies are made everyday.

\subsubsection{Casting Techniques and Technologies}

The casting techniques and technologies are continuously improved, whether they be casting materials, mold materials or tooling, etc. Zanchuk (2006) has done a study about a permanent graphite mold that may become an economical alternative to $\mathrm{CNC}$ (Computer Numerically Controlled) machining, die casting, sand casting and investment casting for producing parts from ZA-12, a zinc-aluminum alloy that is harder, stronger and more durable than aluminum, brass, bronze or plastic. Furthermore, the surface finish of ZA-12 parts virtually eliminates additional finishing steps required with other casting techniques due to high accuracy and fine, shiny surface, which will result in the reduction of overall production times and costs.

Other than direct techniques in casting, there may be indirect techniques and methods in improvement in the casting field, such as, casting management. Apart from the managements of planning, leading, organizing and controlling, another critical factor to a die-caster's survival in a highly competitive industry is the ability to manage the simple basics of the casting process. Because each of the casting alloys and die casting dies behave differently towards temperature, planning should also be applied to temperature management to optimize die casting quality and throughput (Andersen, 2006).

Herman (2004) has done a study that in die casting, solidification and cooling rates can be forced by the design of the die cast. If the water lines are properly placed and at the correct length and the die operated at the correct cycle rate, the maximization 
of the casting cycle rate could be achieved and the casting production could be maximized as well.

Guharaja et. al. (2006) have done a study about obtaining the optimal settings of green sand casting to yield the optimum quality characteristics of spheroidal or ductile cast iron by using Taguchi's method. The process parameters considered were green strength, moisture content, permeability and mold hardness. The effect of the selected process parameters and its levels on the casting defects and the subsequent optimal settings of the parameters were accomplished using Taguchi's parameter design approach and verified by confirming with practical experiments.

\subsubsection{Studies Useful for Casting Simulation Software}

In order for a casting simulation software program to predict the results of a casting, there must be studies and researches about the characteristics of each component in each process. Liu et. al. (2005) studied the influences of casting pressure, the loading time and the piston position of pressure intensification on the variation of pressure and the quality of casting because casting pressure conditions in die casting have great influences on the casting defects, such as gas porosity, shrinkage porosity and gas holes. It was found that casting pressure, the loading time and the piston position of pressure intensification have great influences on the pressure variations in the mold, the quality and the performance of casting.

Normally metals shrink when they lose heat, which is the same as a casting would shrink when it solidifies in a mold, but sometimes the casting may start to expand after it cools down to a certain temperature according to what material it is made of. The heat transfer rate would depend on the heat transfer coefficient (h) between two types of surface, in the case of casting are the casting and the mold, but since a casting may shrink in the solidification process, the $\mathrm{h}$ value may change because of the gap of air formed by the shrinkage of the casting. Wang et. al. (2003) has conducted a study to measure the interfacial heat transfer coefficient (h) between high temperature casting alloys and molds during the casting due to gap formation. It was found that a high value of interfacial heat transfer coefficient is generally obtained at the start of the casting, then the value drops abruptly and then rises to a certain value, and then the value gradually decreases. It was 
also observed that the heat transfer coefficient (h) value is not considerably affected by the casting alloys but rather by the mold material; castings with ceramic molds would have an $\mathrm{h}$ value between $22 \mathrm{~W} / \mathrm{m}^{2}-\mathrm{K}$ and $350 \mathrm{~W} / \mathrm{m}^{2}-\mathrm{K}$ while sand molds are between $40 \mathrm{~W} / \mathrm{m}^{2}-\mathrm{K}$ and $90 \mathrm{~W} / \mathrm{m}^{2}-\mathrm{K}$.

De Looze (2005) studied how the operating parameters of a low pressure die cast (LPDC) machine and the quality level of the aluminum melt affected the casting cooling rate and/or the microstructure of the aluminum. The formation and distribution of microporosity in the castings was used as an indicator of casting quality and solidification conditions, and experimental evidence for the operation of burst feeding in low pressure die casting was detected. There were significant improvements to the directional solidification and microstructural refinement were achieved with die cooling.

Wong (2004) has done research on applying Campbell's 10 casting rules (Campbell, 2004) to develop high quality aluminum castings. Campbell's rules were adopted to design the runner and gating system which the proper designs of runner and gating system included bottom filling, low filling rate and good design of pouring basin, riser and venting. The CAE software was then used to confirm the designs. In this research, three castings were made and tested by X-ray examinations and fluorescent penetrant inspections and all passed. The castings were a CVD heater cast by sand casting, a gate valve body cast by permanent mold die casting and an aerospace housing cast by the Quickcast process.

Yang (2003) studied the effect of casting temperature on the properties of gravity casting and squeeze cast of aluminum alloy with 13.5 percent silicon and zinc alloy with 4.6 percent aluminum and found out that casting temperature had an effect on the mechanical properties of both the types of casting. The aluminum alloy was tested at temperatures 660, 690 and 720 degrees Celsius while the zinc alloy was tested at temperatures of 440, 460 and 480 degrees Celsius. A top-loading crucible furnace was used to melt the alloys and the die-preheating temperatures used were 200 to 220 degrees Celsius for the aluminum alloy and 150 to 165 degrees Celsius for the zinc alloy. It was found that the best temperature to gravity cast the aluminum alloy was 720 degrees Celsius and for zinc alloy was 460 degrees Celsius. For squeeze casting the aluminum alloy, either 690 or 660 degrees Celsius would be the best temperature for which the 
former would give better property at the top of the casting while the latter, at the bottom. However, the best temperature for squeeze casting the zinc alloy was again 460 degrees Celsius.

Filipic (2004) has done a study about implementing an optimization tool consisting in an optimization algorithm and casting process simulator. It was applied to an industrial casting machine where spray coolant flows were optimized. The manual setting of coolant flows were significantly improved.

\subsubsection{Studies About Casting Simulation Software}

Many a casting and casting related simulation software programs are created in order to achieve the most accurate predictions. Some may have more strength in some areas than the other. Jakumeit (2003) has done a study of coupling two simulation programs, the CFD (Computational Fluid Dynamics) program FLUENT and casting simulation tool CASTS, for simulating a mold filling and solidification for an aerospace investment casting. It is because of the various physical processes and the geometry. It is a combination of the expertise of FLUENT's flow simulation and the strength of CASTS for casting simulation in order to achieve an accurate prediction of this complexity level of casting.

Also, a paper by Moreira and Ribeiro (2003) discusses the advantages and limitations of the use of two software packages, FLOW-3D based upon the Finite Element Method and SOLIDCast based upon the Finite Difference Method. Both software packages were applied to a specific need for the development of a feeding system of a real casting produced into a Portuguese sand foundry using equivalent sets of thermo and physical constants. The conclusion was the development of feeding systems applied to sand castings are equally powerful for both the programs, but SOLIDCast retrieved the results in a much shorter time for the same amount of cells.

The Finite Difference and Finite Difference Methods are the two most well known approaches in casting simulation software. Both methods are meshed based simulation programs which may have some disadvantages in predicting hot spots and simulating the jetting/splashing effects during mold filling (Lewis, 2004). From discussions with experienced foundrymen, Lewis (2004) found alternative techniques for 
predicting hot spots by using a technique which uses a geometric transformation method known as the medial axis transformation and a technique based on meshless methods used for simulating the mold filling process. The medial axis transformation reduces the dimensionality of the problem by unity, e.g. the medial object of a three-dimensional object is a two-dimensional surface whereas the medial axis for a two-dimensional object is simply a curve. The saving in computational time becomes significant if the analysis is coupled with optimization techniques. Finite Element based optimization techniques are inherently computationally expensive and hence the objective of this research was to develop techniques which can speed up the optimization process without significant loss of accuracy. For the meshless methods, they do not need meshes or grids in their formulation. Since these particle methods involve only a number of nodal points, or particles, they are totally free from mesh entanglement and distortion, which may occur in the computational simulation of large deformation problems using traditional meshbased methods. Hence, the advent of mesh-free methods has led to the opening of new avenues in the numerical computational field. Particle-based methods have emerged as an attractive alternative for modeling mold filling simulation in casting processes.

\subsubsection{Implemented Casting Simulation Software Case-studies}

Many casting manufacturers have implemented casting simulation software to their production and have been successful. Wright (2004) conducted two successful case studies of implementing casting simulation technology within the company, Walker Die Casting, which is a producer of complex aluminum castings.

In 1995, a foundry named Raahen Teräsvalimo Oy in Finland was casting various valve components for Neles Controls. The foundry was experiencing some defects in a particular stainless steel that resulted in repair welding. The foundry considered investing in casting simulation software and this component was selected as a test case. The foundry used CastCAE to simulate the test model and the defects were predicted exactly as what the foundry experienced. A circular chill and insulating sleeves were added in the system and resulted in a sound casting. Later, the real casting was made according to the new design and resulted in sound castings (www.castech.fi/). 


\subsubsection{Studies of SOLIDCast}

A paper by Moreira (2003) discusses the comparison of two sets of software; one based upon the Finite Element Method, FLOW-3D, and the other based on the Finite Difference Method, SOLIDCast. FLOW-3D is considered much more powerful than SOLIDCast but more complicated to be used. Both packages were applied in developing a feeding system of a real casting produced in a Portuguese sand foundry. It was found that for developing feeding systems applied to sand castings, SOLIDCast was equally powerful and quicker in retrieving results.

A research by Alonso and Franco (2005) used SOLIDCast along with OPTICast to increase the yield of vertical gating systems in the investment casting process of a jewelry workshop to improve productivity, quality and promote new product designs. SOLIDCast was used for verifying the casting models while OPTICast was used for optimizing the simulation of the vertical gating system for this investment casting of this jewelry workshop. It was found that these two modules showed a great potential from improving the design of the filling systems. 


\section{Chapter 3 \\ The Use of SOLIDCast}

\subsection{Introduction}

The SOLIDCast program is able to simulate numerous types of casting alloys, but cast iron seems to be the only type of material which has special functions to calculate and predict the characteristics of a certain cast iron alloy. For example, the Gray Iron and Ductile Iron calculator buttons in the Curves tab for adjusting the temperature curve, the VDG Iron Properties Calculator for adjusting the shrinkage curve and the set points for the critical fraction solid point and Niyama point. Even an additional Riser Design Wizard program was built into the VDG Iron Properties Calculator for designing risers for a cast iron casting.

This thesis is interested in modeling cast iron sand castings using SOLIDCast. Sand casting is one of the simplest methods in casting and cast iron is one of the most popular casting alloys in the casting industry. Sand casting needs the least effort in setting up for simulation compared to other casting methods. The casting design chosen for the case study is a locomotive piston made from gray iron by sand casting.

\subsection{Starting SOLIDCast}

Before drawing or loading any shape into the program, the user must set the system parameters in order to get the correct results and prevent any problems which may occur from these settings. The system parameter setting is located in the Tools menu. There are 5 tabs, which are; "Alloys Curves", "Model Colors", "Model \& Sim", "Directories" and "FLOWCast".

\subsubsection{Alloy Curves Tab}

In the Alloy Curves tab, the user would set the default values for the default critical fraction solid percentage, usually at 60 percent, default Niyama point percentage, usually at 65 percent (the percentages in both cases mean the percent of solidification in the curves graph) and default solidification shrinkage, usually at -7 percent. The negative sign means volumetric contraction of the metal. This value is actually the net expansion/contraction of the metal. In the curves graph, the volumetric shrinkage line 
would linearly incline or decline from 0 percent to the net value at 100 percent of solidification.

The critical fraction solid point is the point assumed to be the end of feeding or metal movement for a cast alloy. It means if liquid metal reaches this point, it will no longer have the ability to flow anymore even though it has not completely solidified. The Niyama point in the program is the point which the Niyama value is calculated. The Niyama value of a single node is the temperature gradient divided by the square root of the cooling rate when it reaches its Niyama point in the cooling curve. It is a value used as an indicator of the degree of directional solidification and the likelihood of shrinkage formation; the lower the value, the greater potential for shrinkage formation. It is normally set at 5 percent after the critical fraction solid point. Figure 3.1 shows the Alloy Curves tab in the Systems Parameters window.

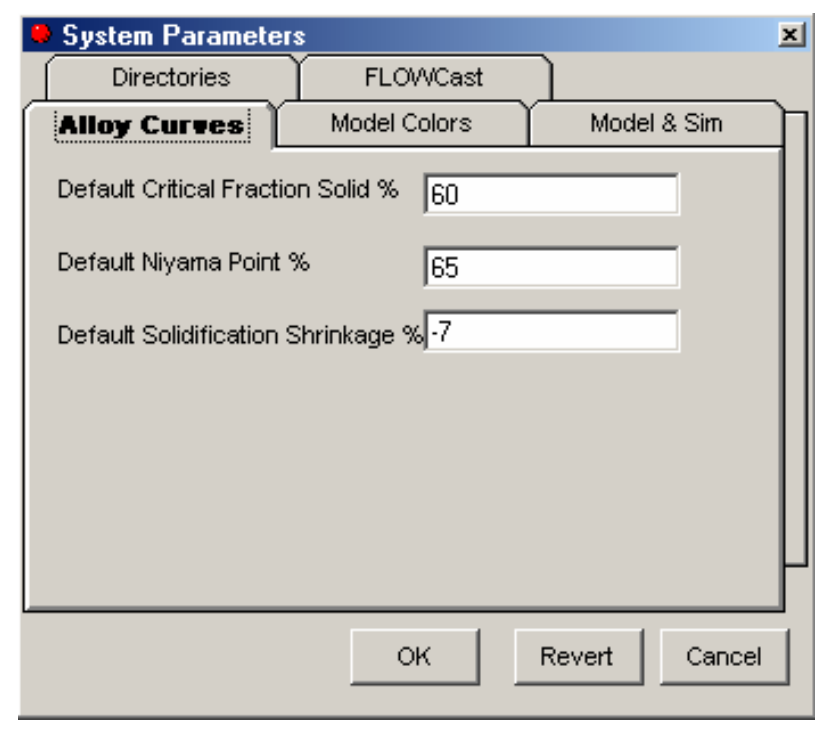

Figure 3.1: The Alloy Curves tab in the Systems Parameters window.

\subsubsection{Model Colors Tab}

The Model Colors tab lets the user set up the colors for each material which will be shown in the model, such as the casting, riser, mold, and fill material and the selected shape(s). Figure 3.2 shows the Model Colors tab in the System Parameters window. 


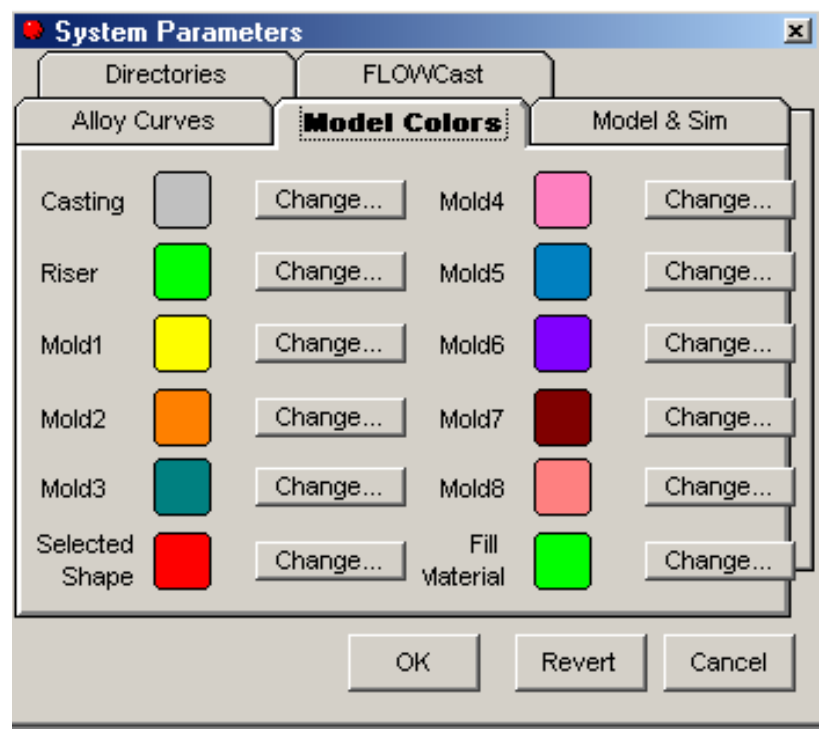

Figure 3.2: The Model Colors in the System Parameters window.

\subsubsection{Model \& Sim Tab}

The Model \& Sim tab contains the defaults for measurement system, snap to grid and the time step interval for volumetric calculations. It also has entries for the maximum number of facets displayed in an iso-surface plot, a toggle for displaying data graphically during simulation, and the redraw interval for the graphic display. Figure 3.3 shows the Model \& Sim tab in the System Parameters window.

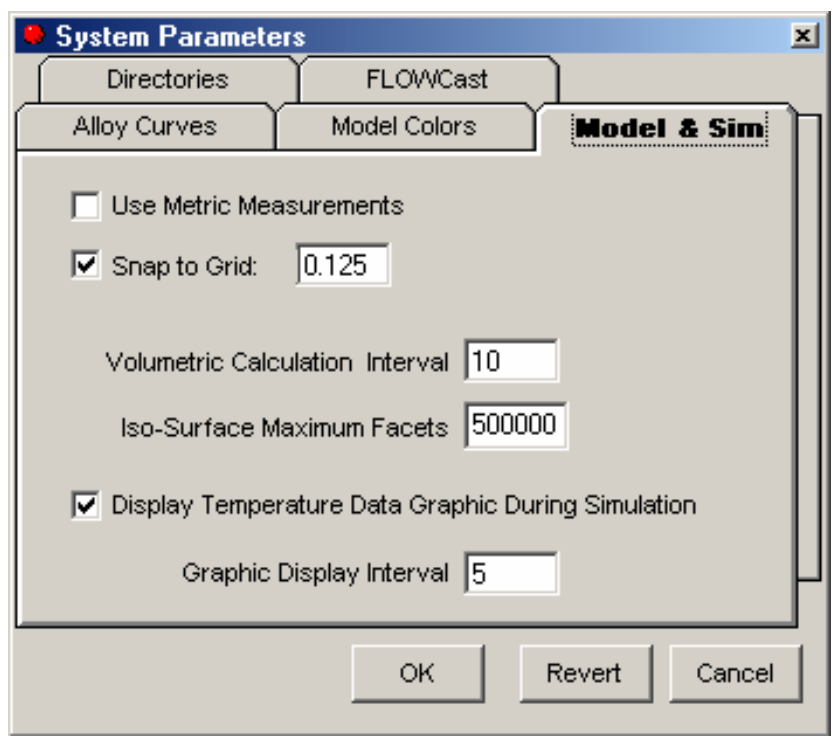

Figure 3.3: The Model \& Sim tab in the System Parameters window. 
The user must be careful to select what unit of measurement shall be used. Normally, the default would use English units (inches, degrees Fahrenheit, etc.), but if the user would want to design or import a model file using Metric measurements (millimeters, degrees Celsius, etc.), he or she must select the Use Metric Measurements checkbox.

\subsubsection{Directories Tab}

The Directories tab lets the user set up the default locations for Projects and Import Files, shown in Figure 3.4. The user should set up the Projects path to an existing directory, such as C: Projects. So, when the user creates a new project, the system would create a new directory underneath this one. The Import Files path is where the user would be keeping the .stl CAD files. This is also where the system would store the avi movie files created by the movie functions in SOLIDCast.

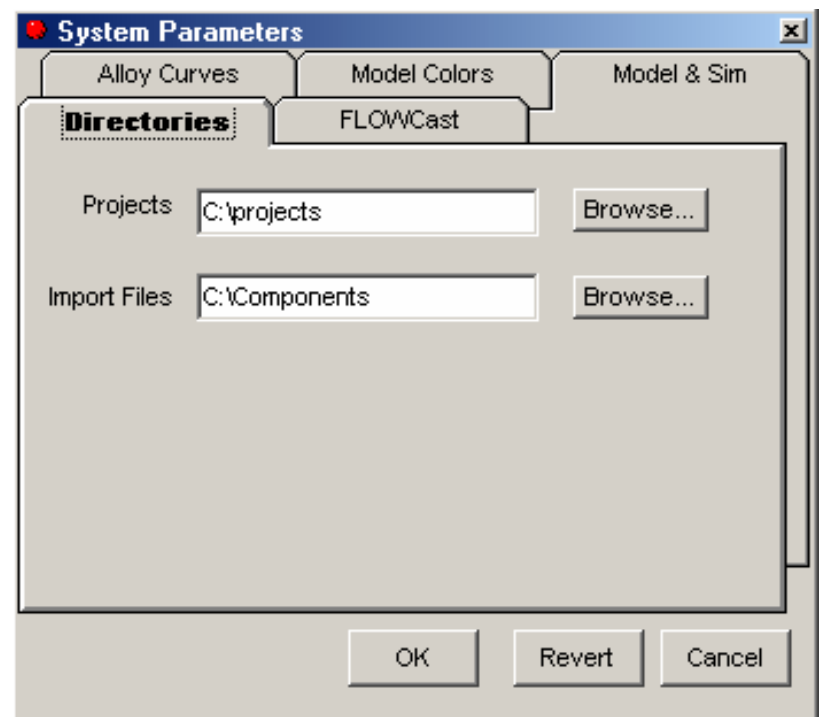

Figure 3.4: The Directories tab in the System Parameters window.

\subsection{Adding or Loading Shapes to the Model}

SOLIDCast allows the user to design and build the model in the program itself or import models from other CAD programs as well. Imported files must be in the stl format. Although most 3D CAD systems can export .stl files of solid models, users may have difficulty exporting the files if the solid model was not combined into one single solid body, etc. 
The user must make sure what unit of measurement was used in the designing of the model and check in the correct box in the "Model \& Sim" tab before loading the imported file. The user may also draw a design in SOLIDCast. The geometric shapes provided in the program are quite basic. If the user would like to draw a more complex design, he or she may use some other 3D CAD program in creating it. The basic geometric shapes provided in SOLIDCast are:

1) Rectangular solid

2) Solid cylinder aligned with the $X$ axis

3) Solid cylinder aligned with the $Y$ axis

4) Solid cylinder aligned with the $Z$ axis

5) Hollow cylinder aligned with the $X$ axis

6) Hollow cylinder aligned with the $Y$ axis

7) Hollow cylinder aligned with the $Z$ axis

8) Sphere

The shapes can be edited and modified by the user, such as moving the shape or modifying the radius of a cylinder or changing an element's properties, etc., also, there are the other commands such as the Revolve and Extrude commands to create more complicated shapes.

\subsection{Selecting Casting Material}

Selecting "Model" and then "Materials List" from the menu tab, a new window would appear on the screen. This window will have four tabs for the user to set the primary parameters for the simulation, which are the Casting Tab, Mold Tab, Curves Tab and Heat Transfer Coefficients Tab.

\subsubsection{Casting Tab}

The user will use this tab to select the casting material along with setting the values of parameters which will be used in the simulation. First, the user may select alloys from the SOLIDCast database by pressing the "From DB..." button. Many grades of alloys may be selected, but the scope of this study would focus only on cast irons. The list of cast irons in SOLIDCast is shown as follows: 
1) CI A532 IA

2) $\mathrm{CI} A 532 \mathrm{IB}$

3) $\mathrm{CI} A 532 \mathrm{IC}$

4) CI A532 ID

5) CI A532 IIA

6) CI A532 IIB

7) CI A532 IIC

8) CI A532 IID

9) CI A532 IIE

10) CI A532 IIIA

11) CI DI Ferr

12) CI DI Pearl

13) CI GI $3.5 \mathrm{CE}$

14) CI GI $4.0 \mathrm{CE}$

15) CI GI $4.4 \mathrm{CE}$

16) CI Malleable

From list number 1 to 10, are cast iron grades defined by the ASTM (American Society for Testing and Materials). List number 11 and 12 are ductile cast irons with ferritic and pearlitic matrices, respectively. List number 13 to 15 would represent gray iron with 3.5, 4.0 and 4.4 percent Carbon Equivalent (CE). List number 16 is malleable cast iron. Figure 3.5 shows the Casting tab in the Materials List window.

The user may select a material and modify values of its attributes or create a new material and save it to the program's database. The attributes of a casting material in the Casting tab along with its units (English units) may be shown in the following:

1) Alloy Name - this is the casting material selected by the user.

2) Thermal Conductivity (Btu/hr-ft- ${ }^{\circ}$ F).

3) Specific Heat (Btu/lbm- $\left.{ }^{\circ} \mathrm{F}\right)$.

4) Density (lbm/cu.ft.).

5) Initial Temperature - normally, this temperature would be the pouring temperature $\left({ }^{\circ} \mathrm{F}\right)$.

6) Solidification Temperature - can also be called the solidus temperature $\left({ }^{\circ} \mathrm{F}\right)$. 
7) Freezing Range - is simply the difference of the liquidus and solidus temperatures $\left({ }^{\circ} \mathrm{F}\right)$.

8) Latent Heat of Fusion (Btu/lbm).

9) Fill Time - is the amount of time used in filling the casting with liquid metal or could be called the pouring time (seconds).

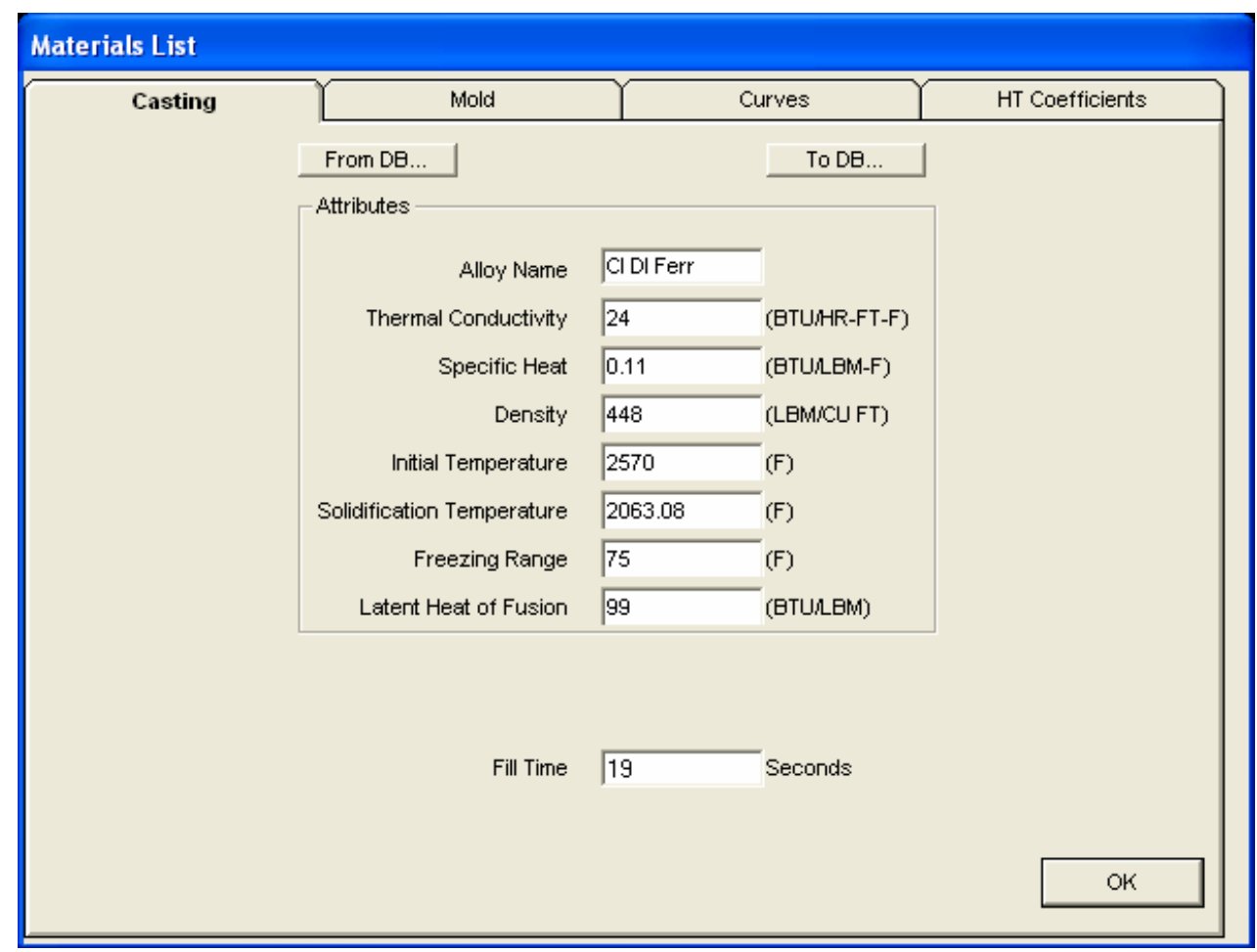

Figure 3.5: The Casting tab in the Materials List window.

\subsubsection{Mold Tab}

In this tab, the user would be able to select the mold material(s) which will be used in the simulation. The mold material in this case does not only mean the material used for making the mold, but would include materials other than the casting used in the mold. It would include different sands, cores, chills and insulator materials that may be added to the model. The list of materials in the database is shown in the following:

1) Air

2) Cast Iron

3) Chromite Sand

4) Copper Chill 

5) Exothermic Sleeve
6) Graphite
7) Insulation Sleeve
8) Investment Shell
9) Iron Chill
10) Olivine Sand
11) Silica Sand
12) Steel
13) Stainless Steel
14) Zircon Sand

These materials may be selected and added to the materials list which will be used in the model. The ambient temperature can also be set in this page.



Figure 3.6: The Mold tab in the Materials List window.

From Figure 3.6, the mold materials attributes are shown and values may be changed by the user. The attributes are as follows: 
1) Name - the name of mold material.

2) Type - the type of mold, which the user can select one of five types of mold materials that can be simulated in SOLIDCast, which are:

a. Normal mold - is a material that changes temperature as the simulation progresses.

b. Exothermic mold - is a material that burns for a period of time at a constant temperature and then changes temperature. It may have an elevated ignition temperature.

c. P.M. core - is a special material used to indicate consumable cores used in permanent mold simulation.

d. Constant temperature - is a material which remains fixed at the given temperature during the simulation.

e. Cooling channel - is a material which activates a cooling (or heating) channel, under the control of either a timer or a thermocouple inserted in the mold.

3) Initial Temperature - of the mold $\left({ }^{\circ} \mathrm{F}\right)$.

4) Thermal Conductivity (Btu/hr-ft- $\left.{ }^{\circ} \mathrm{F}\right)$.

5) Specific Heat $\left(\mathrm{Btu} / \mathrm{lbm}-{ }^{\circ} \mathrm{F}\right)$.

6) Density (lbm/cu.ft.).

7) Burn Temperature - for exothermic molds only $\left({ }^{\circ} \mathrm{F}\right)$.

8) Burn Time - for exothermic molds only (minutes).

9) Ignition Temperature - for exothermic molds only $\left({ }^{\circ} \mathrm{F}\right)$.

\subsubsection{Curves Tab}

This tab shows the temperature and shrinkage curves of the casting material along with the critical fraction solid point line and the Niyama point line.

The Curves tab is shown in Figure 3.7. The white line represents the temperature curve comparing with the values on the left vertical axis while the black line represents the volumetric shrinkage curve comparing with the values on the right vertical axis. The line with $\mathrm{L}$ on top is the liquidus line (100 percent liquid, 0 percent solid) and the line 
with $\mathrm{S}$ on top is the solidus line (100 percent solid, 0 percent liquid). The lines with $\mathrm{C}$ and $\mathrm{N}$ below them are the critical fraction solid and Niyama point lines respectively.

These curves have no relationship with time, so the steepness of the temperature curve does not mean that it has rapid cooling. The information shown in this graph is the relationship between temperature and volumetric shrinkage.

The curves shown in this window come from the default values from the program. On the bottom of this window, there are six buttons which the user may use to modify the curves. The "Set Niyama Pt." and "Set CF Solid Pt." are buttons used for setting the Niyama and critical fraction solid points on the graph respectively while the "Draw Sol. (solidification) Curve" and "Draw Shrk (shrinkage) Curve" buttons can be used for modifying the temperature and shrinkage curves respectively.

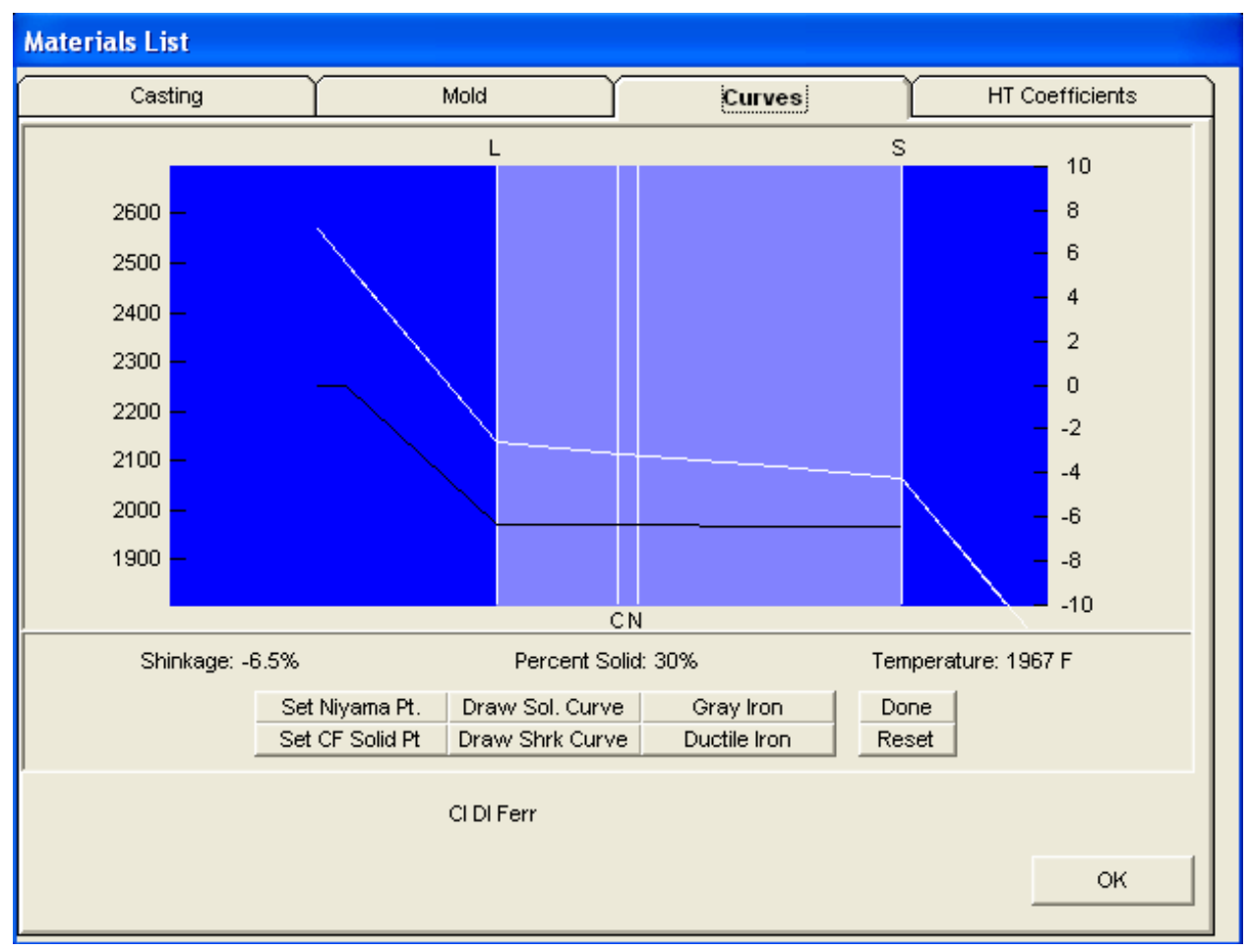

Figure 3.7: The Curves tab in the Materials List window.

For gray and ductile irons, there are two buttons to help the user set the curves automatically. Three inputs are taken from the user, which are the weight percent carbon, weight percent silicon and percent mold wall movement. Lower values for mold wall movement represent more rigid molds, such as high-pressure automatic molding and 
small chemically-bonded sand molds, while higher values represent softer molds such as squeezer or floor-molded green sands. Normally, green sands would have values of one to two percent.

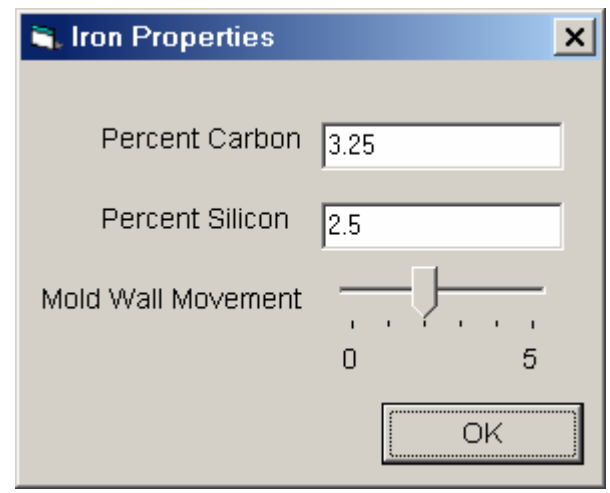

Figure 3.8: The iron properties calculator from pressing the Gray Iron or Ductile Iron button.

Normally, if the shrinkage curve shows hypoeutectic cooling, it is recommended in the SOLIDCast manual (Finite Solutions Inc., 2005) that the critical fraction solid point be reset on the eutectic point (the point where the curve starts to incline again after declining) and the Niyama point set at 5 percent from the critical fraction solid point. But if the shrinkage curve shows hypereutectic cooling, the critical fraction solid point should be reset to the range of 20 to 25 percent solid and the Niyama point set at 5 percent from the critical fraction solid point.

Pressing the reset button would reset the curve back to the default values set in the system parameters mentioned earlier in section 3.2.1, the Alloy Curves tab, which are the values of the critical fraction solid and Niyama points and the net percent shrinkage. Also, the temperature curve would incline linearly from the liquidus line to the solidus line.

The VDG Iron Properties Calculator located in the Tool menu is a new subprogram added to SOLIDCast, called vdg.exe, to modify the shrinkage curve, the critical fraction solid point and Niyama point for cast irons to better represent the characteristics of the alloy. The VDG Iron Properties Calculator is based on the VDG Nomograms as published by the German Iron Society (Finite Solutions Inc., 2005). By setting the 
weight percent carbon, silicon and phosphorus, casting modulus and temperature in the mold, the values for setting up the shrinkage curve and the critical fraction solid point can be found. According to the SOLIDCast manual, the temperature in the mold would mean the average temperature of the metal in the mold after pouring is finished, not the pouring temperature. This temperature is difficult to measure. So, considering that the metal does not lose much heat in the process of pouring, the pouring temperature may be used instead.

When all five inputs in the calculator are set, pressing the "Calculate Iron Properties" button would give the results of the shrinkage time in percent of solidification time and the net expansion or contraction. The shrinkage curve would be modified to start shrinking from the pouring temperature linearly to the point equal to the calculated shrinkage time in percent of solidification time with a net shrinkage of the calculated contraction (or expansion) added the percent mold wall movement. After this point, 0.5 percent expansion would be added for every ten percent of solidification time. This point where contraction ends and expansion begins could also be called the eutectic point. The critical fraction solid point should be set at five percent of solidification time beyond the eutectic point and the Niyama point set at five percent of solidification time beyond the critical fraction solid point.

Figure 3.9 is an example of the VDG Iron Properties Calculator and Figure 3.10 shows the corresponding shrinkage curve using the results from the calculator in Figure 3.9 with a mold wall movement of 1.5 percent. As could be seen in Figure 3.10, the eutectic point is set at 90 percent of solidification time with a net shrinkage of 5.6 percent $(4.1+1.5=5.6)$. On the bottom of Figure 3.9 , there is a button called "Riser Design" which may be used for helping the user design riser systems. The Riser Design button shall be mentioned in detail in Chapter 4.

Regarding an e-mail from Mr. David Schmidt of the Finite Solutions Inc., the method in generating the shrinkage curve mentioned above is for a good quality cast iron. For poorer quality cast irons, he recommended that the critical fraction solid point should be moved more to the left to represent the less amount of expansion to counteract the shrinkage of the cast iron. 


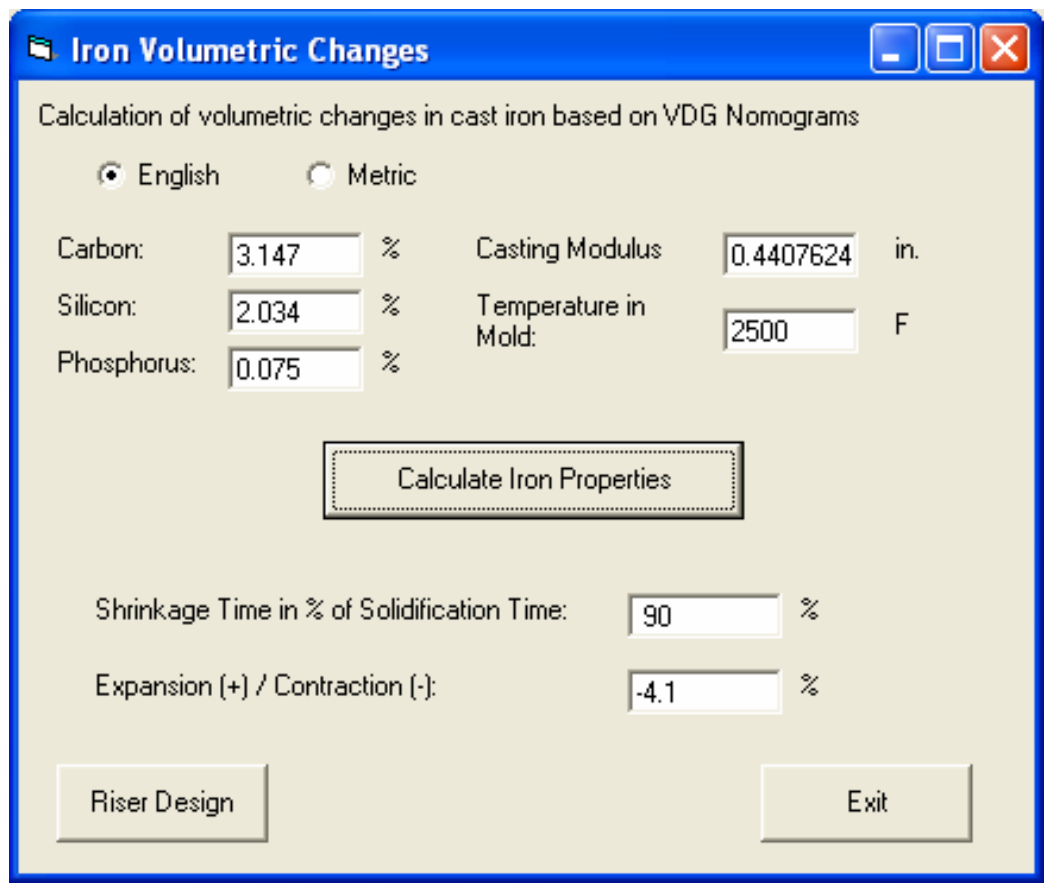

Figure 3.9: The VDG Iron Properties Calculator located in the Tools menu.

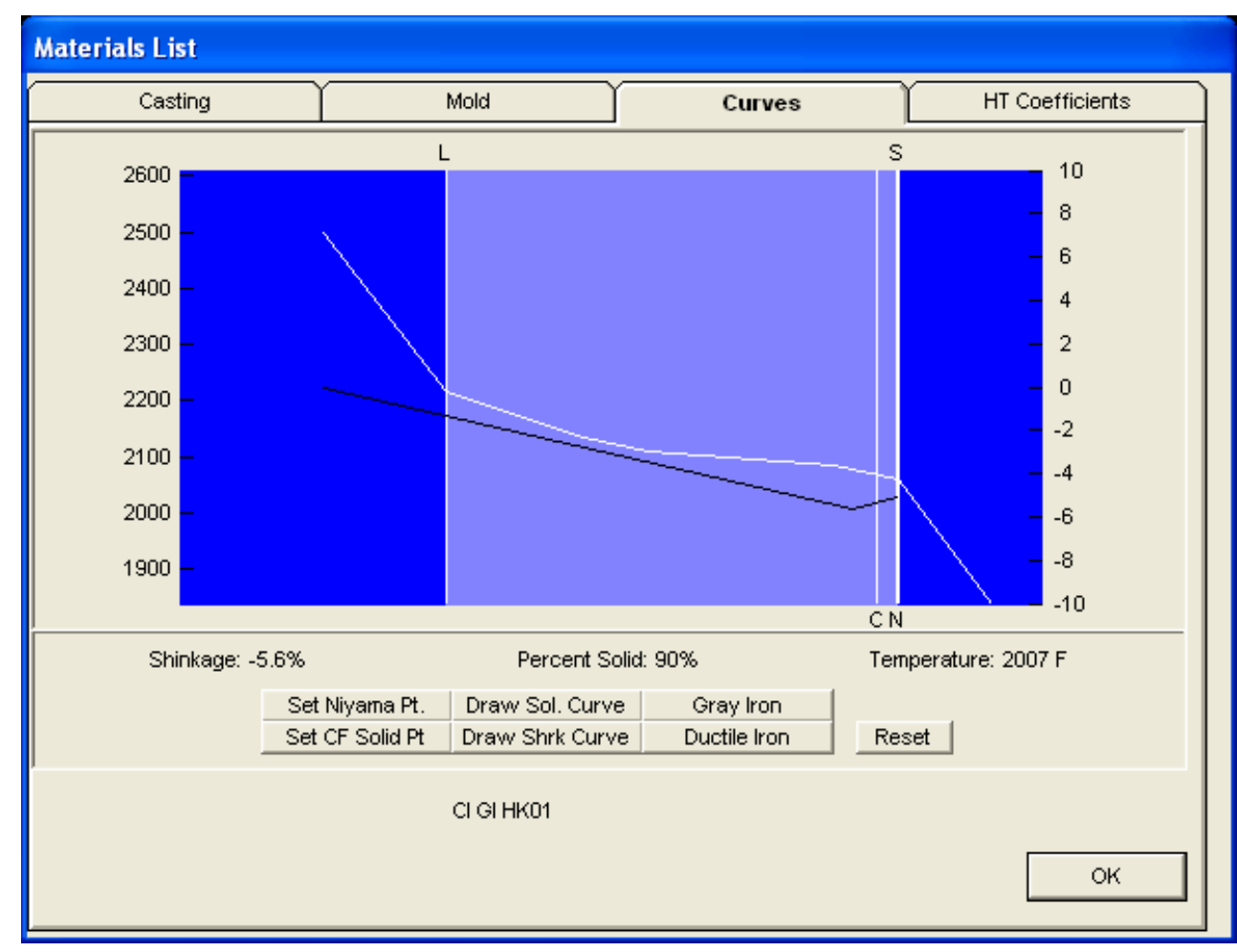

Figure 3.10: The corresponding shrinkage curve (black line) using the results from Figure 3.9 . 


\subsubsection{Heat Transfer Coefficients Tab}

Heat transfer coefficients indicate how well or how poorly heat is transferred between two surfaces. Normally in sand casting, the "Use Internal HT Coefficients" checkbox as shown in Figure 3.11 would be left unchecked for the system to consider only external surface heat transfer coefficients which would normally be set at $1.5 \mathrm{Btu} / \mathrm{hr}$ sqft-F. But in cases, for example, in permanent mold applications, the Use Internal HT Coefficients checkbox would be checked and the heat transfer coefficients between all materials in the model must be specified.

\subsection{Testing The Use of SOLIDCast}

Tests were conducted to study some of the basic functions in the SOLIDCast program that are used for simulating a cast iron casting model. Several capabilities and limitations of the program were found in these tests. The tests and observations were conducted and the results are summarized.

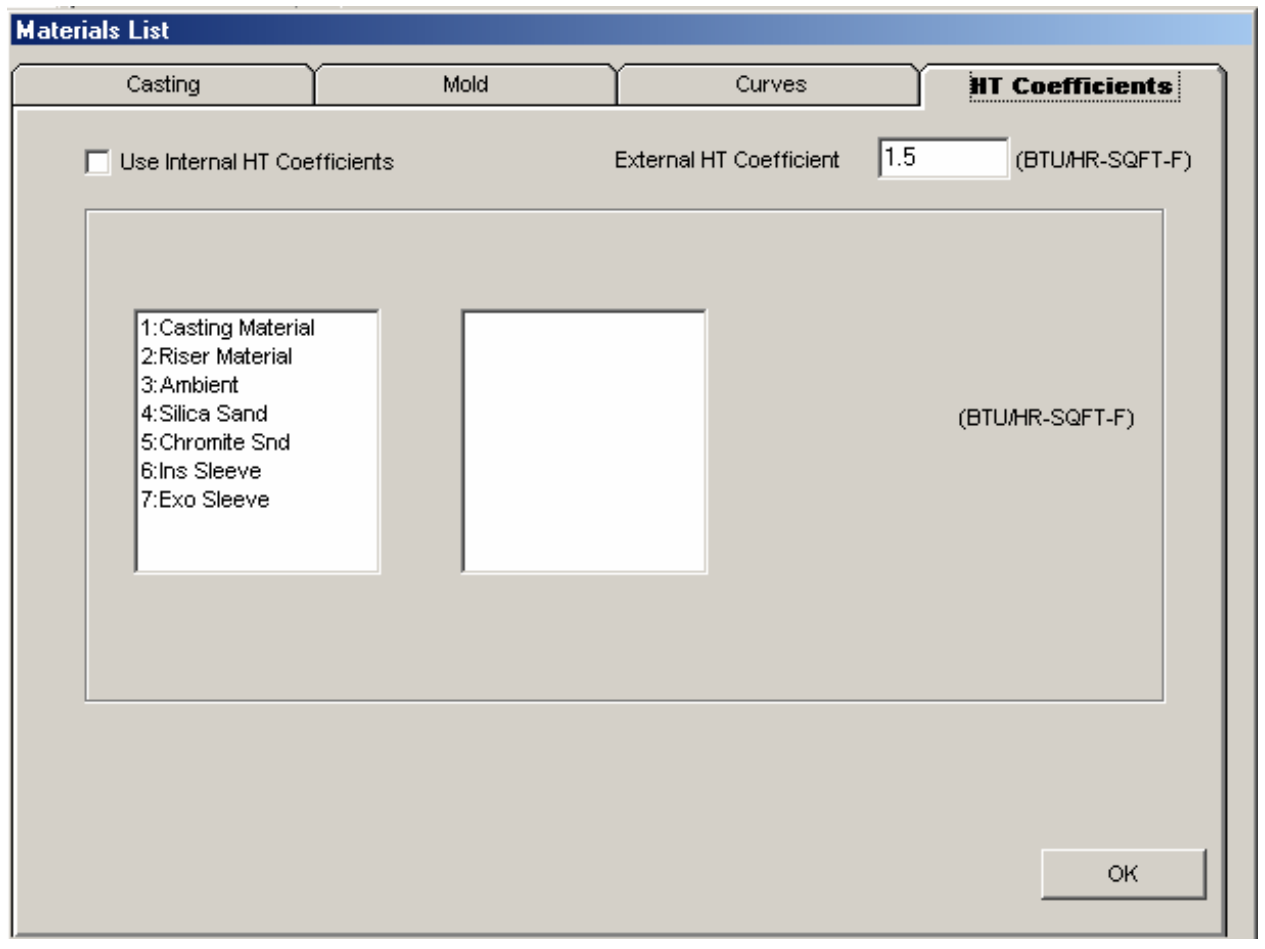

Figure 3.11: The Materials List window showing the HT Coefficients tab. 


\subsubsection{Basic Functions for Simulating Cast Irons}

This set of tests was conducted to observe the input settings in the Materials List window along with the VDG Iron Properties Calculator. The tests and their brief conclusions are presented.

\subsubsection{The Casting Tab and the Curves Tab}

First, the cast irons listed in the program and their default values in the Casting tab and the default graphs in the Curves Tab were observed. Next, a test was conducted to find the relationships between the each tab in the Materials list window. It was found that only the Casting tab and the Curves tab have some relationships between each other. The Mold tab and the Heat Transfer Coefficient tab did not affect any values of the other tabs in the Material List window when their input parameters were altered.

The input parameters in the Casting tab that affected the graph in the Curves tab were the specific heat, the initial temperature, the solidification temperature, the freezing range and the latent heat of fusion. These parameters mentioned would only affect the temperature curve in the Curves tab. The input parameters in the Casting tab which did not affect the graph in the Curves tab were the thermal conductivity and the density values.

\subsubsection{The Gray Iron and Ductile Iron Calculator Buttons}

In the Curves tab, there are buttons labeled "Gray Iron" and "Ductile Iron". These buttons are used for modifying the graph in the Curves tab in the cases which the casting used in the model was either made of gray iron or ductile iron respectively. The input values for these calculators are the weight percent carbon and silicon and the percent mold wall movement. A test was conducted by observing the graph in the Curves tab while altering the values of the three input parameters in the Ductile Iron calculator button using CI DI Ferr or ductile iron with a ferrite matrix from the SOLIDcast database as the subject.

The main findings in this test was that the relationship between the Carbon Equivalent (CE) values calculated from the weight percent carbon and silicon and the liquidus temperatures follows an iron-carbon phase diagram quite accurately. For 
example, the liquidus temperature would decrease as the Carbon Equivalent value increases closer to the eutectic point and increase as it passes the eutectic point in an ironcarbon phase diagram. Also, the test showed hypoeutectic and hypereutectic cooling as the Carbon Equivalent value increased to the eutectic point and passed it respectively. The conclusion to this test is that the resulting graph in the Curves tab from using the calculator buttons were derived from metallurgy knowledge applied into the program.

It was also found in another test that the weight percent carbon and silicon and the mold wall movement of each ductile and gray iron from the SOLIDCast database could be found. By trial and error, the weight percent carbon and silicon and the mold wall movement were adjusted until the graph in the Curves tab would match the default graph given by the program of a selected material, shown in Table 3.1.

Table 3.1: The weight percent carbon and silicon and mold wall movement of each cast iron alloy found by trial and error.

\begin{tabular}{|c|c|c|c|c|}
\hline No. & Name & $\mathbf{\% C}$ & $\mathbf{\% S i}$ & $\begin{array}{c}\text { \%Mold Wall } \\
\text { Movement }\end{array}$ \\
\hline 1 & CI DI Ferr & 3.5 & 2.6 & 2 \\
\hline 2 & CI DI Pearl & 3.5 & 2.6 & 2 \\
\hline 3 & CI GI 3.5 CE & 2.9 & 1.5 & 2 \\
\hline 4 & CI GI 4.0 CE & 3.45 & 1.4 & 2 \\
\hline 5 & CI GI 4.4 CE & 3.85 & 1.4 & 2 \\
\hline
\end{tabular}

A test was conducted to find the differences between the Gray Iron and Ductile Iron calculator buttons. It was found that no matter which gray iron or ductile iron was selected from the database, the same graph would result in the Curves tab. But if observed closely, the temperature curve from using the Gray Iron calculator button, as it inclines, would be curved as the steepness of the curve changes, similar to an "S" shape. The temperature curve resulted from using the Ductile Iron calculator button would not curve as the steepness of the temperature curve changes, so the shape of the curve can be compared similar to a "Z" shape. Figures 3.12 and 3.13 shows examples of a temperature curve developed by the Ductile Iron and Gray Iron calculator buttons respectively. 


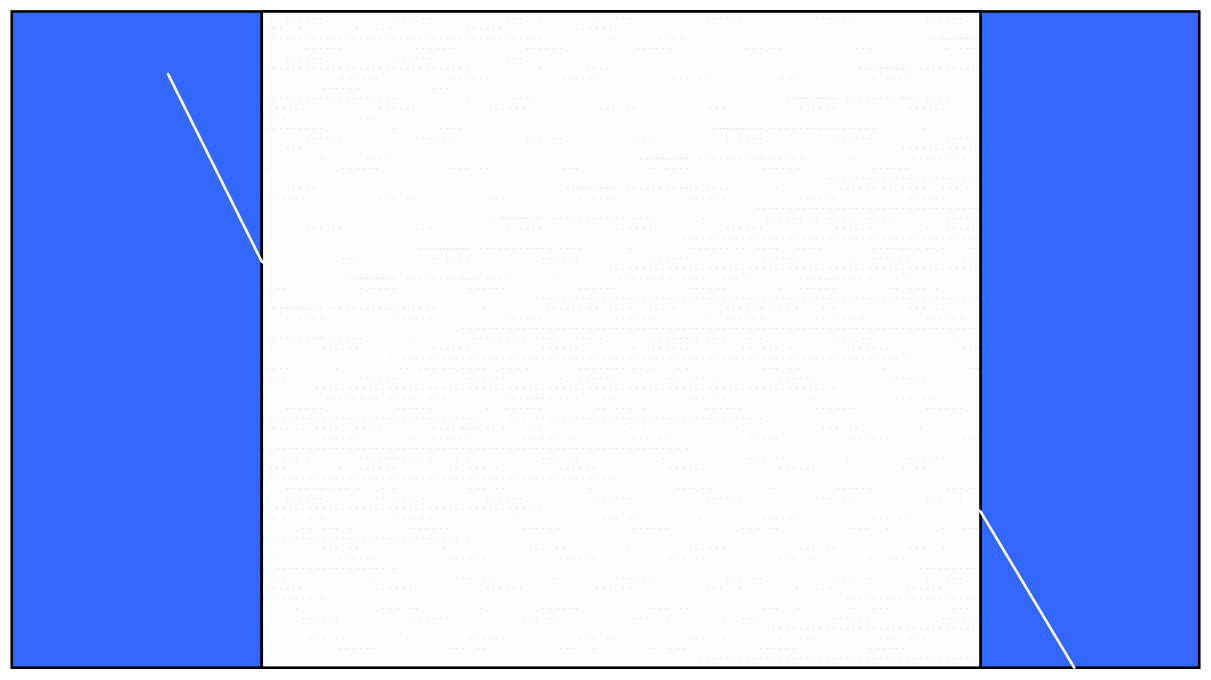

Figure 3.12: Sketch of temperature curve developed by the Ductile Iron calculator button.

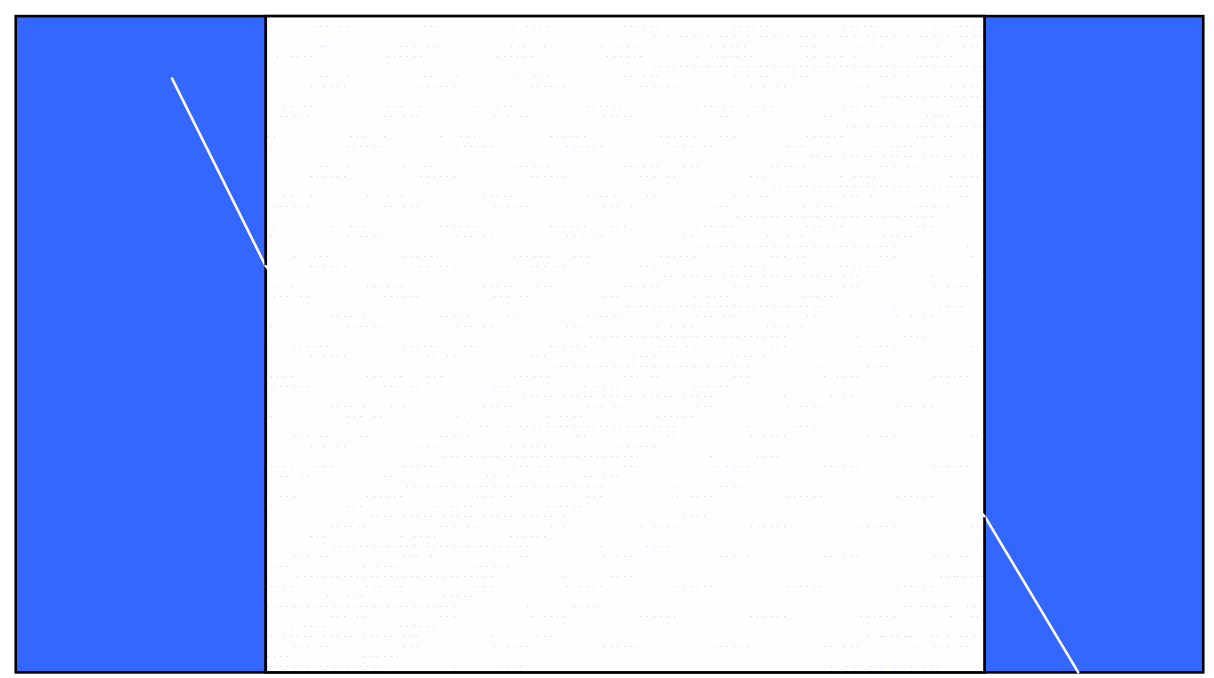

Figure 3.13: Sketch of temperature curve developed by the Gray Iron calculator button.

\subsubsection{The VDG Iron Properties Calculator}

As mentioned earlier in section 3.4.3 about the Curves tab, the VDG Iron Properties calculator in the Tools menu would take five inputs; the weight percent carbon, silicon and phosphorus, casting modulus and temperature in the mold and give two outputs; the shrinkage time in percent of solidification time and the expansion or contraction percentage for the user to modify the shrinkage curve and set the critical fraction solid line and the Niyama line. It does not automatically modify the graph in the 
Curves tab like the Ductile Iron and Gray Iron calculator buttons do. This calculator is a stand-alone program that has no relationship with any other functions in the program.

A test was conducted to find the relationships between the input and output values of the VDG Iron Properties calculator. Table 3.2 shows how the each output value varied when an input value was increased and decreased.

From the SOLIDCast manual (Finite Solutions Inc., 2005), this VDG Iron Properties calculator is a stand-alone program in SOLIDCast called vdg.exe which is a program that gives an estimate of the total amount of contraction (or expansion) for a cast iron and the point at which this contraction (or expansion) ends based on the VDG nomograms as published by the German Iron Society. An example of this VDG nomogram is shown in Figure 3.14 and a test was conducted and proved that the values calculated by the VDG Iron Properties calculator matches the VDG nomograms. It is assumed that SOLIDCast has a database of the nomograms for retrieving results when values are entered into the VDG Iron Properties calculator.

Table 3.2: The relationships of the input and output values in the VDG Iron Properties calculator.

\begin{tabular}{|c|c|c|c|}
\hline \multicolumn{2}{|c|}{ Outputs } & $\begin{array}{c}\text { Shrinkage Time in Percent } \\
\text { of Solidification Time }\end{array}$ & Percent shrinkage \\
\hline \multirow{2}{*}{ Inputs } & Increase & Decrease & Decrease \\
\cline { 2 - 4 } & Decrease & Increase & Increase \\
\hline \multirow{2}{*}{ Silicon } & Increase & Decrease & Decrease \\
\cline { 2 - 4 } & Decrease & Increase & Increase \\
\hline \multirow{2}{*}{ Phosphorus } & Increase & Decrease & Decrease \\
\cline { 2 - 4 } & Decrease & Increase & Increase \\
\hline \multirow{2}{*}{$\begin{array}{c}\text { Mosting } \\
\text { Medulus }\end{array}$} & Increase & Decrease & Decrease \\
\cline { 2 - 4 } in Mold & Decrease & Increase & Increase \\
\cline { 2 - 4 } & Decrease & Increase & Increase \\
\hline
\end{tabular}



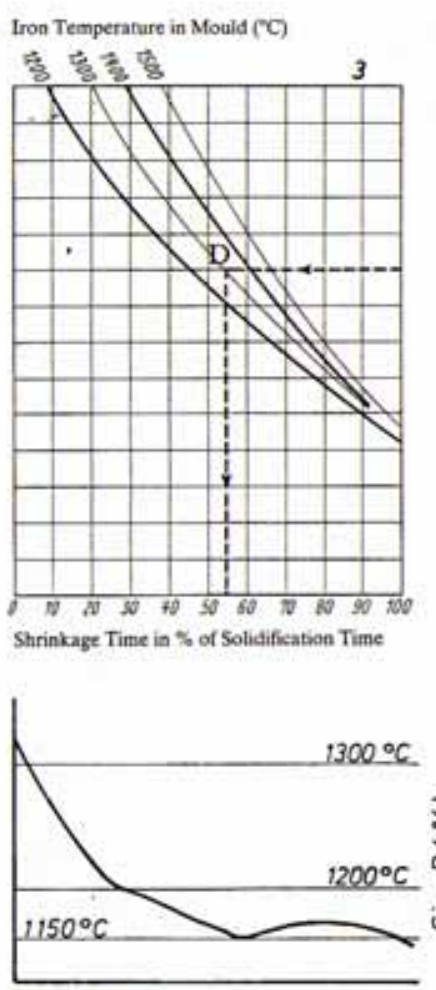

Solidification pattem
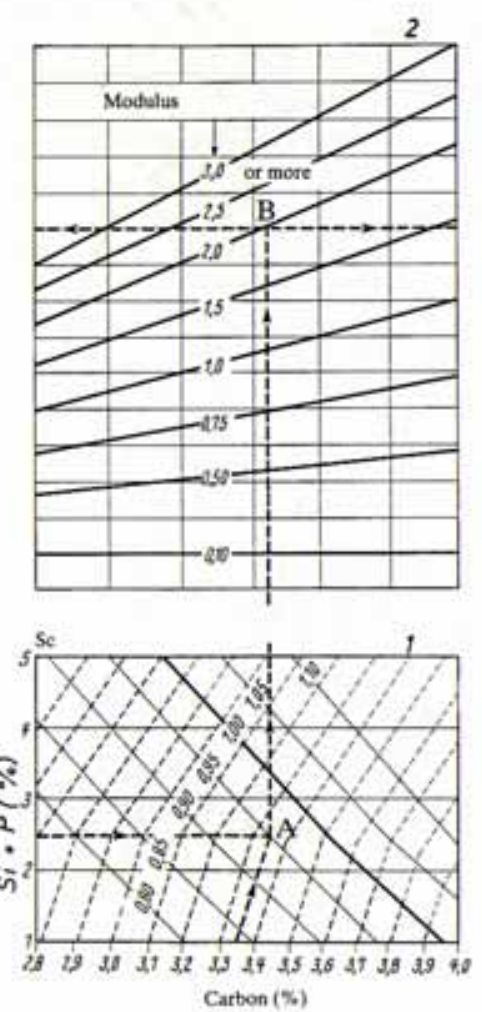

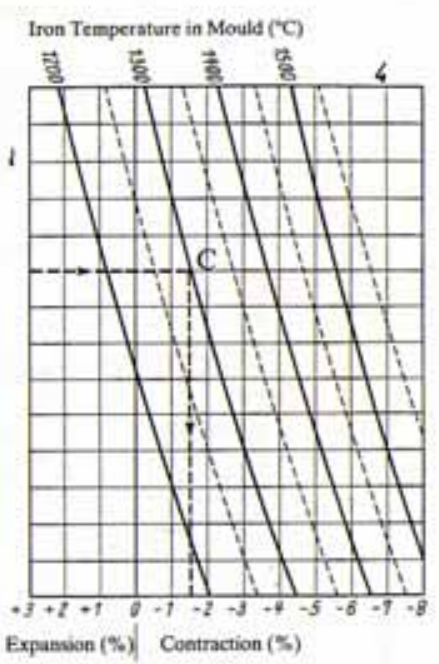

Estimation of shrinkage and shrinkage time from Analysis, Casting Modulus and Metal Temperature

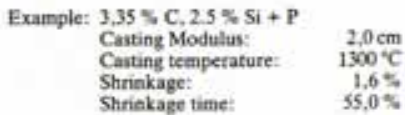

Figure 3.14: An example of the VDG nomograms from the German Iron Society using metric units.

\subsubsection{Conclusions of Tests}

The conclusion to this set of tests is that the information in the database of the SOLIDCast program and the calculators built into the program were derived from metallurgy knowledge which were arranged and applied into the program. So, in order for a simulation to be able to simulate as accurately as possible, the user must enter the correct data collected from the materials used in the casting process, i.e., the weight percent carbon, silicon and phosphorus in the casting material, the pouring temperature, the approximate percent mold wall movement of the mold material used, etc.

\subsubsection{Modifying the Curves Tab}

In SOLIDCast, the amount of shrinkage of metal at any time would equal to the volumetric difference of the mold cavity and casting. So, the shrinkage curve in the 
Curves tab is actually the shrinkage of the metal added the shrinkage occurred from the expansion of the mold or the percent mold wall movement. A test was conducted and was found that modifying the shrinkage curve would not affect the weight of the casting because the weight of the casting is calculated from the size of the nodes, the total number of nodes and the density of the material. The calculation of the weight of a casting could only be found from meshing and not from simulation. It was also found that SOLIDCast does not simulate the dimensional shrinkage or expansion of the casting, including deformations.

It was found in another test that modifying the shrinkage curve would not affect any output criterion except the Material Density Function output plots. It is because all other output criterions would only use temperature data and/or time and/or distance for calculation. It was also found that in a cylindrical shape casting, which in this case is representing a riser, the shrinkage would normally consist of two shapes; an upside-down cone-shape or a funnel shape and a flat cylindrical shape with a diameter slightly smaller than the cylindrical shape casting or the riser. The test showed that the cylindrical shaped shrinkage is the shrinkage which occurs during the time when the liquid metal cools down to its liquidus point and the funnel shape occurs during the time when the metal cools down from its liquidus point to its critical fraction solid point. The size of the shrinkage depends on the degree of the shrinkage slope and where the shrinkage ends or the metal starts expanding. If the shrinkage ends early in the percent of solidification time, the development of the cone-shape shrinkage would stop abruptly showing very little or no growth of the cone-shape shrinkage at all. The shrinkage or expansion may still occur after the metal has reached its critical fraction solid point but in very small volumes. It was also found that modifying the Niyama line would only affect the Niyama Criterion output plots as it will only calculate the Niyama value when a particular node reaches its Niyama point.

\subsubsection{Other Tests}

A test was conducted to find out if the SOLIDCast program would be able to simulate a misrun or not. It was found that in the simulation of the flow of metal, the simulation would allow the molten metal to flow until it reaches its solidification point or 
solidus point, which in reality the molten metal should lose its ability to flow after it reaches its critical fraction solid point. This may conclude that the user must use his or her judgment to interpret where the misrun would actually occur. From this test, it may be assumed that the program would also be able to detect coldshuts as well if they may occur.

The maximum number of nodes which could be created by this version of SOLIDCast is 19,046,664 nodes which could be found from the mesh creating window shown in Figure 4.3. The Planes of Symmetry function is a useful function which can help reduce the use of nodes in a simulation. It can reduce the time used for simulating a casting model using the same node size or achieve more detailed simulation results using a smaller node size for a symmetrical casting design.

The Planes of Symmetry function was tested and the results showed that the results from simulating a symmetrical casting using this function may have results slightly different from simulating a symmetrical casting without using this function. The reason that the results may be different is because the model does not start the mesh from the symmetric plane, so, the size of the casting at that symmetrical parting line may be one node size larger or smaller than the model without using the Planes of Symmetry function. It was also found that if there is no casting material at the symmetrical parting plane, the program would assume that the closest point where the casting material is to the symmetric plane is where the casting model and its symmetrical counter part is connected, instead of considering them as two objects with a distance twice the distance between the casting model and the symmetrical plane.

A test was conducted to observe the meshing function. It was found that the program would start meshing from the edge of mold along the $\mathrm{X}, \mathrm{Y}$ and $\mathrm{Z}$ axes. A portion of a material would be considered a whole node if it is larger than half the size of the node size and neglected if smaller, and it was also found that the node size cannot exceed the size of the thinnest section of any material in the mold. Also, the weights of each material in the model would be calculated from the number of nodes, the node size and the density of the material, so, the weights of a model may be different according to the node size. So, the only situation that the calculated weights of the model would be exactly correct is the model intersects perfectly with the nodes. For intricate shaped 
models, the more detailed the meshes could represent the model or the smaller the nodes could possibly be, the better approximation of the weights of the model. There are also situations which a symmetrical hollow casting may not be symmetrical after meshing with a difference of one node size thickness due to the meshing pattern.

\subsection{Conclusions}

The characteristics of a material in SOLIDCast were derived from metallurgy knowledge, so, a user must input precise data of the actual alloy into the simulation program to receive the most accurate results. Some limitations of SOLIDCast were also found. Being based on the Finite Difference Method, the shape of a meshed model may differ significantly from the original design according to the node size and alignment of the model. Problems that may occur, for example, are the thickness of two areas with the same thickness in a casting design may have a difference in the number of nodes representing those thicknesses, the weights of the model would only be precise if the nodes intersect the design perfectly, and because the nodes are square blocks, weights of casting designs with curves or intricate designs would be more accurate if smaller nodes are used. Misruns and coldshuts cannot be predicted precisely because the program would allow the liquid metal to flow until it reaches the solidification temperature, not the critical fraction temperature which liquid metal should lose the ability to flow. 


\section{Chapter 4 \\ Using SOLIDCast: Simple Model}

A test was conducted to learn how a user would develop a riser and gating system for a simple shaped casting model by using the Riser Design Wizard and the Gating Design Wizard programs built-into the SOLIDCast program. The calculation methods behind the two programs and the simulation results from using the calculated riser and gating dimensions were analyzed.

\subsection{Drawing the Design}

A hollow rectangular box was created in SOLIDCast with outer dimensions of 10 by 15 by 4 inches and inner dimensions of 7 by 12 by 4 inches along the $\mathrm{X}, \mathrm{Y}$ and $\mathrm{Z}$ axes. So, the walls of this box was 1.5 inches thick with a height of 4 inches. A rectangular box with dimensions of the outer dimensions of the hollow box was created first using the casting material as the material. Then, a smaller rectangular box with dimensions of the inner dimensions of the hollow box was created using "void" as the material. This void material is used in SOLIDCast modeling to create a voided shape in any material the user would like to become the primary mold material. This method is also much easier than modeling four rectangular shapes that would form into the final shape of this hollow rectangular box. Figure 4.1 shows how the hollow box appeared in the model.

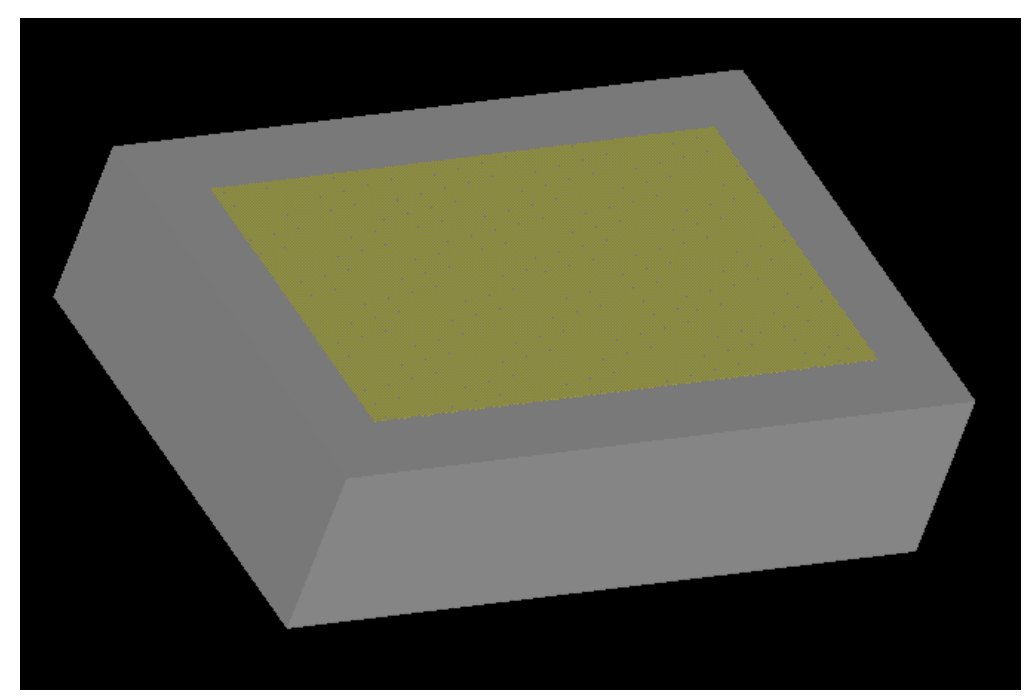

Figure 4.1: Figure of design drawn in SOLIDCast. 


\subsection{Riser Design and Analysis}

The Riser Design Wizard can be accessed from either the Simulation tab in the menu or from the VDG Iron Properties Calculator from the Tools tab in the menu. In this test, the Riser Design Wizard from the VDG Iron Properties Calculator was used because the information calculated from the VDG Iron Properties can be drawn directly to this Riser Design Wizard and used for designing the riser, and it was specially used for designing single risers.

The important information the Riser Design Wizard would need were the casting modulus and the casting weight. The weight could be found from meshing the model using the selected casting material the user would select from the Casting tab in the Materials List window while the casting modulus could be found from simulation. The casting material selected is gray iron with properties similar to the material which will be used in the case study in Chapter 5. Figure 4.2 shows the Casting tab with the properties of the material used in this test.

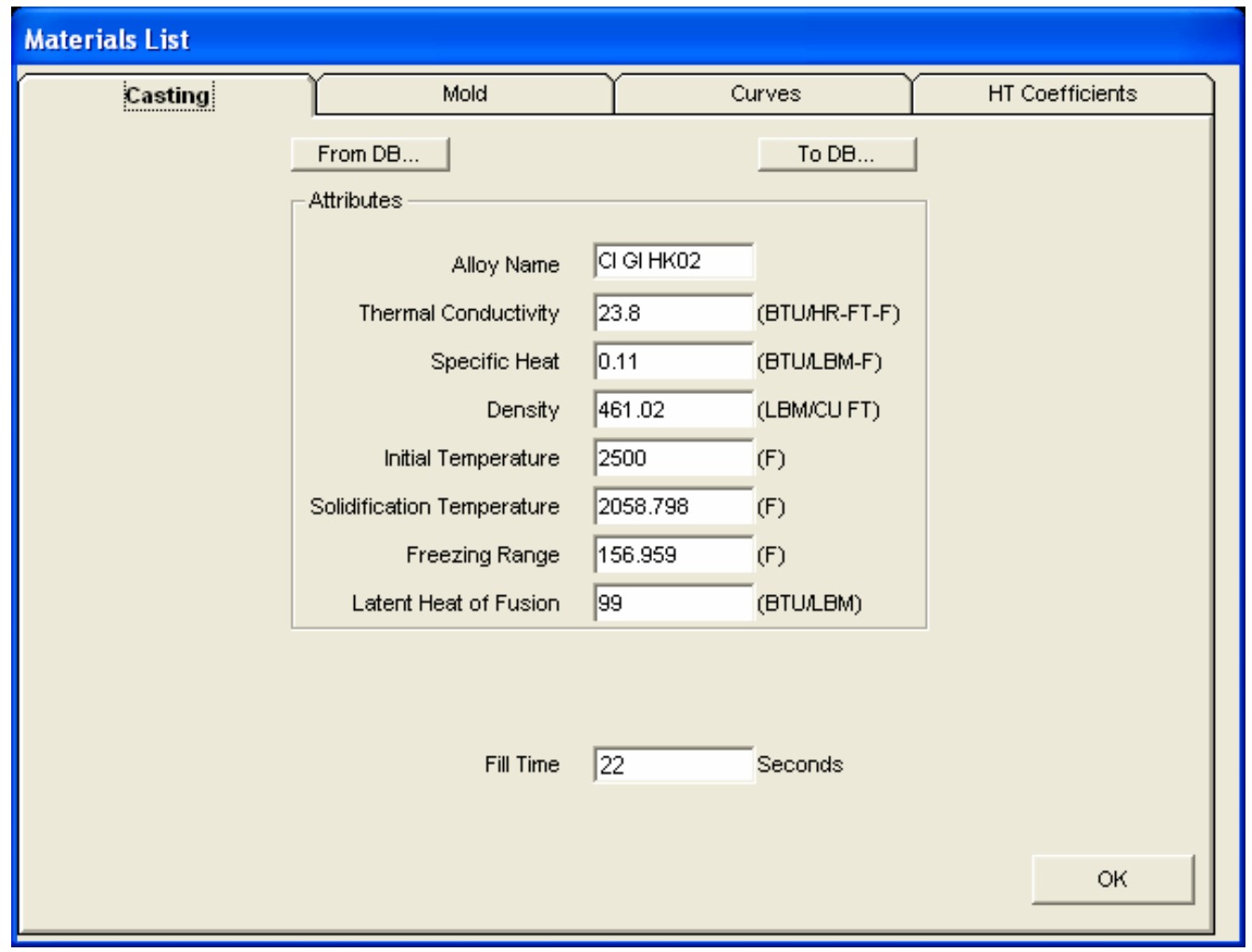

Figure 4.2: Casting tab with properties of material used in test. 
The node size used in the meshing of this model was 0.25 inches, so the nodes would intersect with the model completely and represent the weights of the model and the casting modulus most accurately. A rectangular shaped mold with silica sand used as the mold material with one inch thickness surrounding the casting was set in the meshing function, as shown in Figure 4.3. The weight of the casting material and silica sand was calculated to be 70.434 pounds and 52.778 pounds respectively, as shown in Figure 4.4.

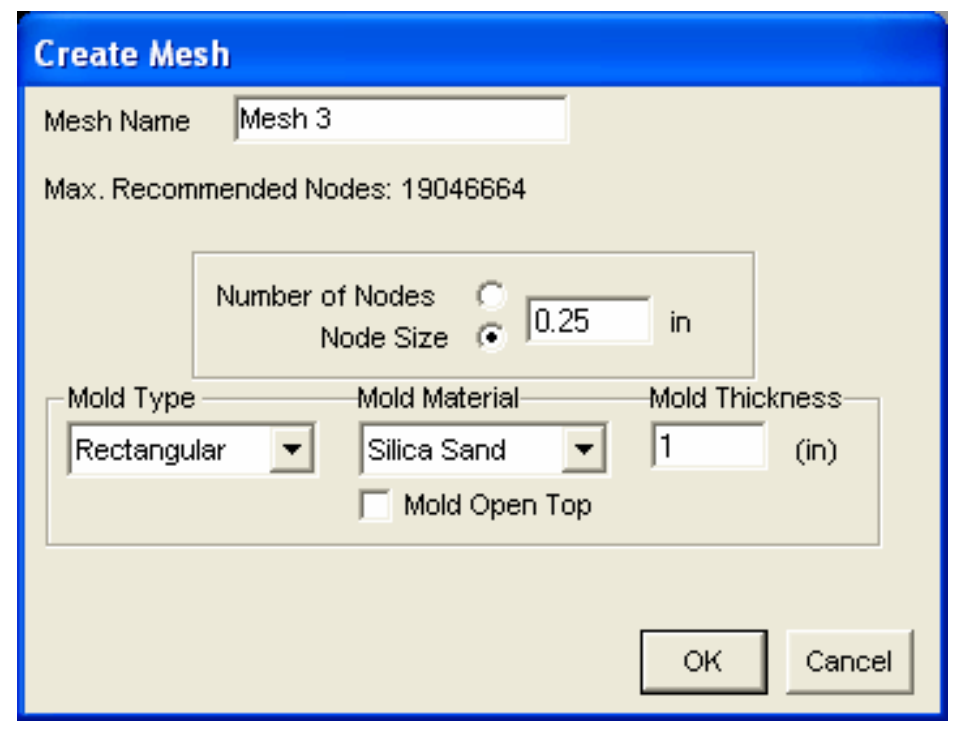

Figure 4.3: Setting up the meshing parameters.

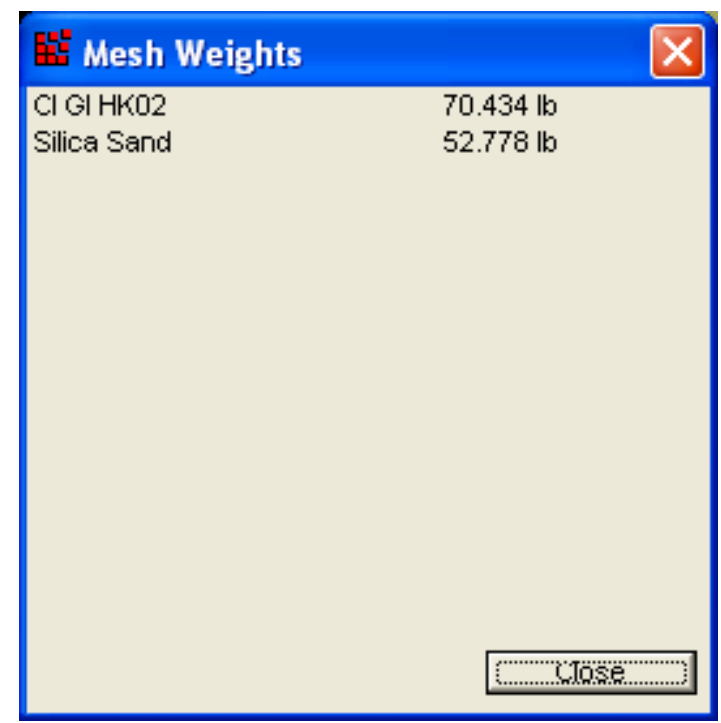

Figure 4.4: The weights of the model. 
Next, the Riser Design Wizard from the Simulation menu was accessed to find the representative modulus of the casting was in the VDG Iron Properties Calculator for modifying the volumetric shrinkage curve in the Curves tab. Selecting the "Calculate and Display Casting Modulus" option, the maximum modulus value of the casting shall be used as the representative casting modulus in the VDG Iron Properties Calculator as recommended by the SOLIDCast manual (Finite Solutions Inc., 2005). The modulus values calculated from the Riser Design Wizard actually represents the solidification rate of a node, not the actual modulus of the whole casting, so, the nodes which have higher modulus values mean that they take more time to solidify. The resulting window showing the calculated range of modulus values is shown in Figure 4.5 and the casting modulus value which will be used in the VDG Iron Properties Calculator is 0.6004735 inch. The actual modulus of the whole casting was calculated and shown in equation (4.1).

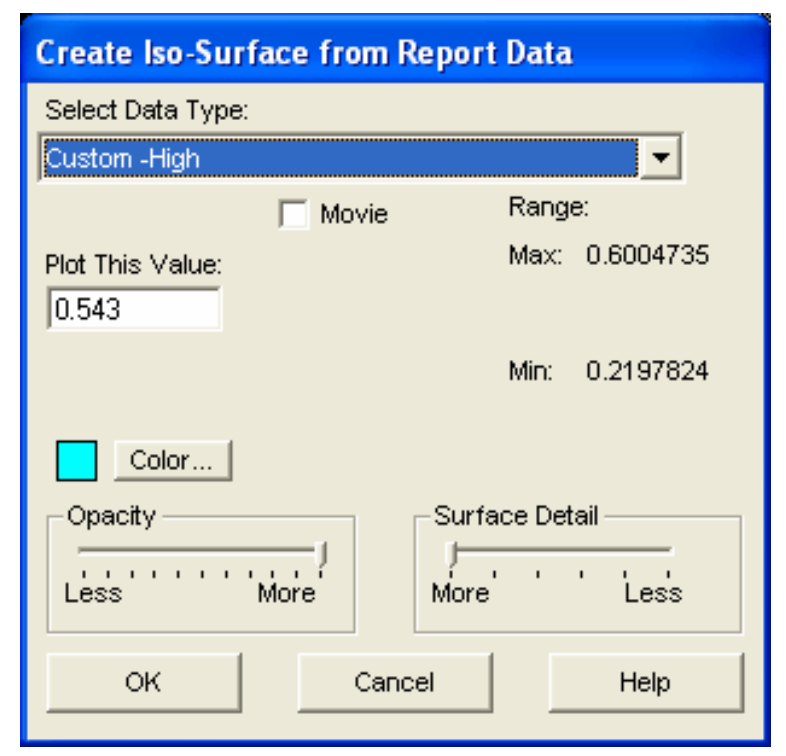

Figure 4.5: Finding the casting modulus from the Riser Design Wizard.

$$
\begin{aligned}
\text { Casting modulus }= & \text { Volume } \div \text { Surface area } \\
= & {[4 \times\{(10 \times 15)-(7 \times 12)\}] \div[2 \times\{(15 \times 4)+(10 \times 4)} \\
& +((10 \times 15)-(7 \times 12))+(12 \times 4)+(7 \times 4)\}] \\
= & 264 \text { cubic inches } \div 484 \text { square inches } \\
= & 0.545 \text { inch }
\end{aligned}
$$


The actual casting modulus is 0.545 inch, which is very close to the value in the box, 0.543, as shown in Figure 4.5. But the value in this box is actually a suggested plotting value for finding approximate feeding areas for the casting, not the actual casting modulus. For a more accurate number of feeding areas, the neck modulus value is needed for plotting instead of this suggested value, which could be found later in the process. Plotting with a larger value would show the areas with higher modulus values or more solidification time. The highlighted areas would be smaller and closer to the centerline of the thickness of the casting as the plotting value is increased, meaning that the centerline of the casting takes a longer time to solidify than the rest of the casting. Figure 4.6 shows the resulting plot using the recommended value which shows one feeding area.

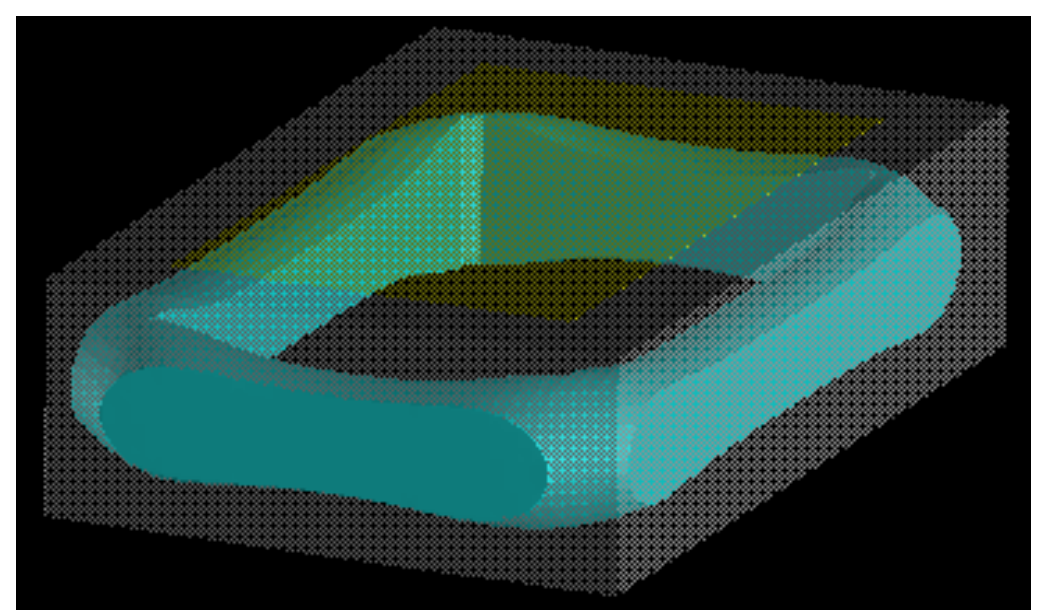

Figure 4.6: Modulus plot showing one feeding area plotted with the suggested value, 0.543 .

Now, the VDG Iron Properties Calculator shall be accessed from the Tools menu. The weight percent carbon, silicon and phosphorus, casting modulus and temperature in mold shall be entered. The weight percent carbon, silicon and phosphorus and temperature in mold information are similar to the case study in chapter 5. Clicking on the "Calculate Iron Properties" button, the shrinkage time in percent of solidification time and the expansion or contraction will be calculated and shown, as in Figure 4.7. The Riser Design Wizard can now be accessed by clicking on the "Riser Design" button, as shown in Figure 4.7, and the Riser Design window would appear, as shown in Figure 4.8. 


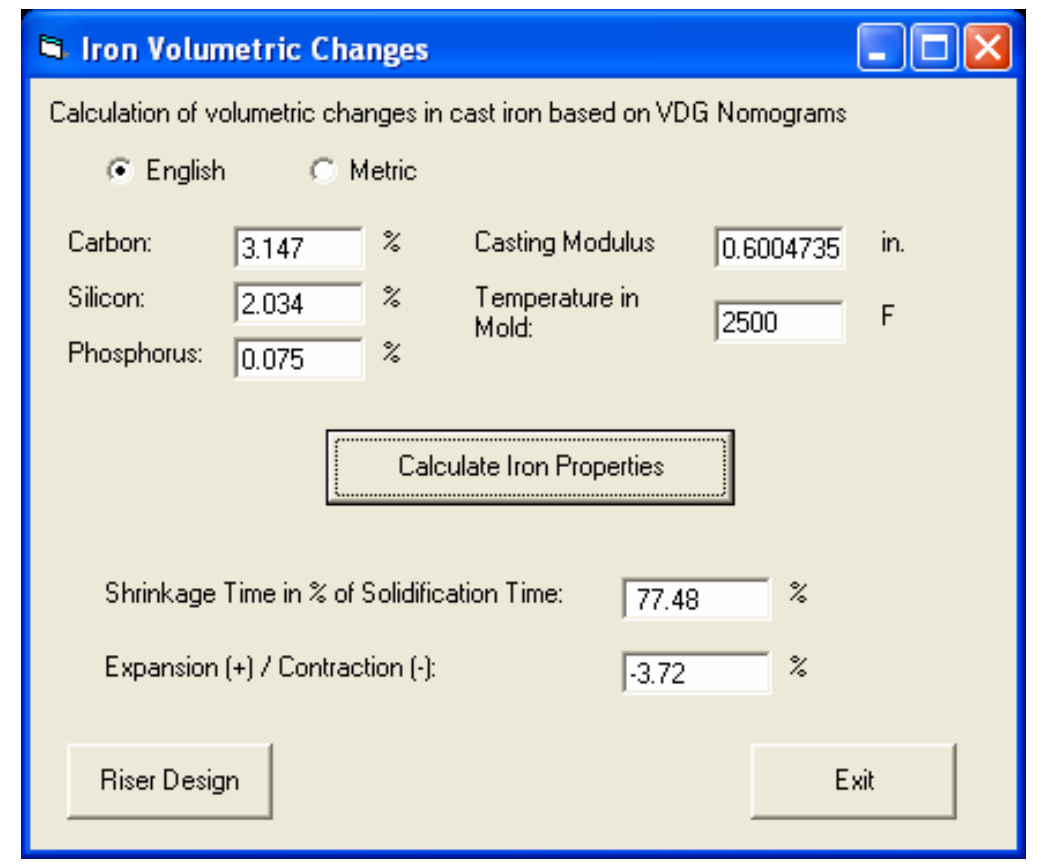

Figure 4.7: The VDG Iron Properties Calculator.

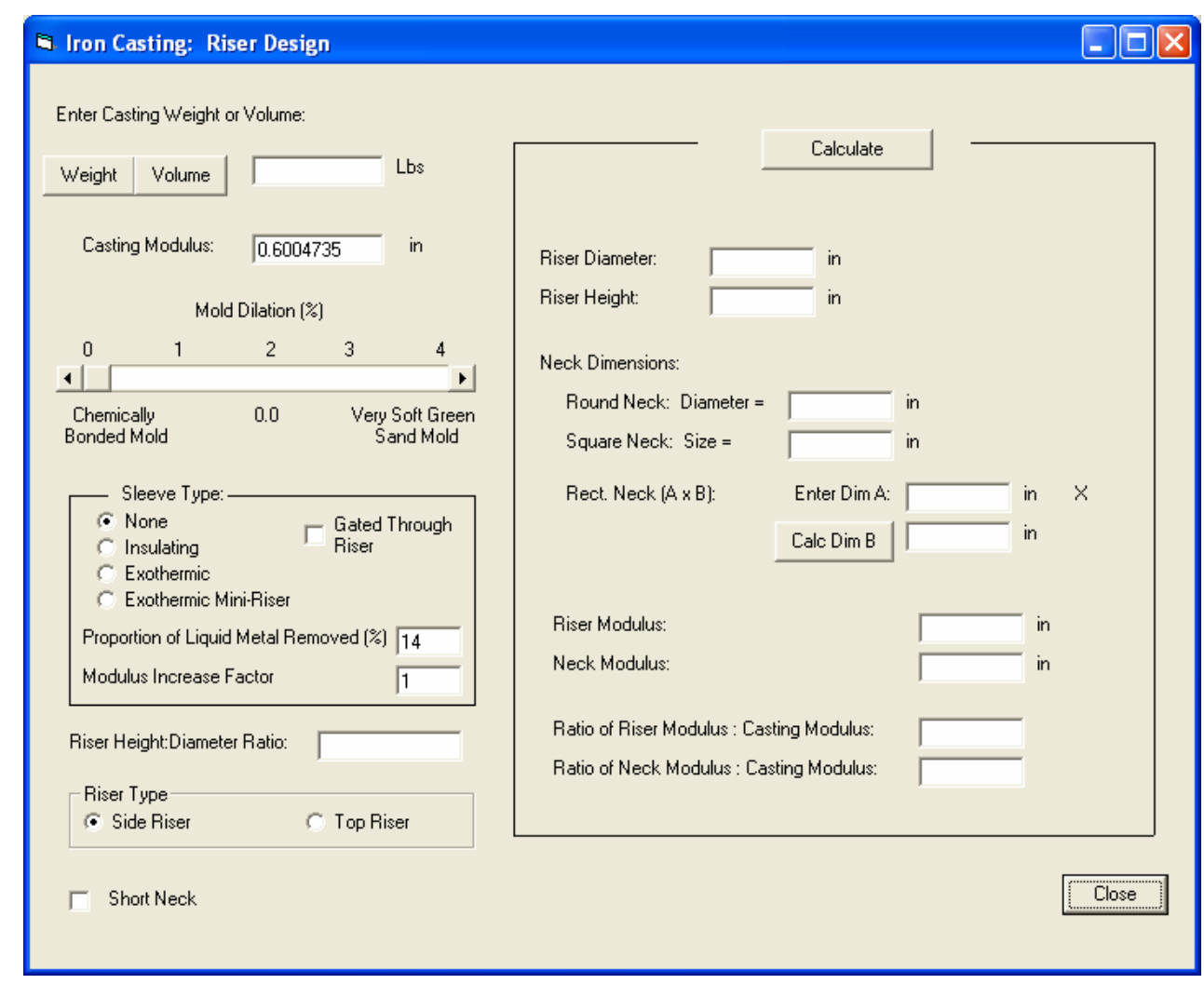

Figure 4.8: The Riser Design Wizard window accessed from the VDG Iron Properties Calculator. 
In the Riser Design Wizard window in Figure 4.8, the casting modulus value will be transferred automatically from the VDG Iron Properties Calculator into this window. This calculation window may only be activated if the weight of volume of the casting and the riser height per diameter ratio are entered. An analysis about the input and calculated values for this Riser Design Wizard was done and could be summarized in the following:

\subsubsection{Analysis of the Riser Design Wizard Input Values 1) Enter Casting Weight or Volume}

Either the casting weight or volume could be entered into this window. But it was found that the density of the cast iron material the program uses to calculate between the weight and volume is constant at around 0.25926 pound per cubic inch or 448 pounds per cubic foot. This sub-program calculator does not take the density of the material set in

the Casting tab nor consider the input values in the VDG Iron Properties Calculator to calculate for a new density. But since the VDG Iron Properties Calculator is only used for cast irons, the weights of cast iron alloys are not significantly different, so, this constant weight may be used as an average weight for cast irons.

\section{2) Percent Mold Dilation}

The mold dilation is the same as percent mold wall movement. In calculating the riser dimensions, the calculated expansion or contraction rate from the VDG Iron Properties Calculator would be taken into account, added with this percent of mold dilation. The percentage value shown under the slider bar has only one decimal, but the actual number used in calculation seems to have more. First of all, one percentage value seems to consist of many snap grids and each snap grid produces slightly different calculated values. Also, clicking on the slider arrows would slightly change the calculated dimensions every time, showing that there are more detailed values in between the snap grid values. But since the dimensions a user would need are just approximated dimensions, and the dimensions of objects in SOLIDCast can only be created to the detailed level of three decimals of a measuring unit, the slight difference of the calculation would not be a significant problem. 


\section{3) Sleeve Type}

There are three types of riser sleeves (SOLIDCast uses the term "sleeve" for both insulating sleeves and exothermic toppings) and the option of having no sleeve, and an option to set the gating through the riser. When the user selects the type of sleeve and gating type, the program would automatically give out the proportion of liquid metal removed from the riser into the casting and the modulus increase factor. It seems that these values are kept in the program database, which were derived from casting and metallurgy knowledge. They could also be modified if needed. Table 4.1 shows the resulting values as the options are chosen.

Table 4.1: Resulting values when type of sleeve and option of gating through the riser is selected in the Sleeve Type box.

\begin{tabular}{|c|c|c|c|c|}
\hline \multirow[b]{2}{*}{ Sleeve type } & \multicolumn{2}{|c|}{ Not gated through riser } & \multicolumn{2}{|c|}{ Gated through riser } \\
\hline & $\begin{array}{l}\text { Proportion of } \\
\text { liquid metal } \\
\text { removed (\%) }\end{array}$ & $\begin{array}{c}\text { Modulus } \\
\text { increase factor }\end{array}$ & $\begin{array}{l}\text { Proportion of } \\
\text { liquid metal } \\
\text { removed (\%) }\end{array}$ & $\begin{array}{c}\text { Modulus } \\
\text { increase factor }\end{array}$ \\
\hline None & 14 & 1 & 20 & 1 \\
\hline Insulating & 32 & 1.25 & 33 & 1.25 \\
\hline Exothermic & 35 & 1.33 & 35 & 1.33 \\
\hline $\begin{array}{c}\text { Exothermic } \\
\text { Mini-Riser }\end{array}$ & 70 & 1.33 & 70 & 1.33 \\
\hline
\end{tabular}

\section{4) Riser Height Per Diameter Ratio}

The user may enter the riser height per diameter ratio of the risers needed for the casting in this space. The user may enter a riser height per diameter of 1.5 for an iron casting (Ravi, 2005). 


\section{5) Riser Type}

The user may select either a side or a top riser for the casting model. The SOLIDCast Training Overview (Finite Solutions Inc., 2005) recommends users to use a "hot" riser, i.e., to design the gate into the riser if using a side riser, so that the amount of heat in the riser and its ability to feed the liquid metal into the casting is maximized. For top risers, it is difficult to design a gate into this type of riser, so, insulating or exothermic sleeves are recommended.

\section{6) Short Neck Check Box}

In the case the user would want to use a short neck for the riser, the short neck check box could be checked so the program may calculate the dimensions of a riser with a short neck. A short neck would be able to cool down slower than a normal length neck because of the heat from the casting and the riser. The modulus of the neck would be reduced by multiplying a factor 0.6 to the normal neck modulus resulting in a smaller neck dimension. In order to be considered as a short neck, the distance between the casting and the riser should be less than the minimum dimension of the connecting surface of the riser neck on the casting. The neck dimensions connected to the riser can be larger and tapered down to the side connected to the casting to allow easier fettling or break off of the riser.

\subsubsection{Analysis of the Riser Design Wizard Output Values}

There are actually two methods in calculating for the riser design; calculation based on volume requirement and calculation based on the riser modulus being 20 percent more than the calculated neck modulus. The latter method of calculation would only be used if the calculation based on volume requirement does not satisfy the rule that the riser modulus has to be at least 20 percent larger than the calculated neck modulus, which from testing would mean the casting size may be too small compared to the casting modulus. In the following shows the calculation methods based on volume requirement. 


\section{1) Riser Diameter and Riser Height}

The diameter and height of the calculated riser dimensions would be shown in this space. They would follow the ratio set in the riser height per diameter ratio input space. For a side riser, the proportion of liquid removed from this cylindrical shaped riser would equal to the total shrunken volume of the casting. Equation (4.2) would explain this calculation.

$$
\begin{aligned}
& \text { Liquid removed from riser }=\text { Total shrunken volume of casting } \\
& {\left[\begin{array}{ll}
\left.\pi \times\left(D^{2} / 4\right) \times(D \times r)\right] \times \% & =V_{c} \times\left(\%{ }_{\mathrm{VDG}}+\% \mathrm{MD}\right)
\end{array}\right.}
\end{aligned}
$$

Where,

$$
\begin{array}{ll}
\mathrm{D} & =\text { Diameter of side riser, inch } \\
\mathrm{r} & =\text { Riser height per diameter ratio, no unit } \\
\mathrm{V}_{\mathrm{c}} & =\text { Volume of casting, cubic inch } \\
\%_{\mathrm{p}} & =\text { Proportion of liquid metal removed from riser in percent } \\
\%_{\mathrm{VDG}} & =\text { Percent shrinkage calculated from the VDG Iron Properties Calculator } \\
\%_{\mathrm{MD}} & =\text { Mold dilation, percent }
\end{array}
$$

For a top riser, it shall show the dimensions of a cylindrical shape with 20 percent more volume than a cylindrical shape with the dimensions calculated for a side riser, as shown in equation (4.3) and Figure 4.9. It is because the program assumes that the side riser would have a hemispheric bottom, so, the true height of the side riser is more than the calculated height. For a height per diameter ratio of 1.5, it is approximated that the volume of the hemispheric bottom is around 20 percent of the cylindrical shape. So, even though the calculated riser diameter and height for both types of risers are different, the total volumes of both riser types are approximately the same, as shown in equation (4.4).

$$
\begin{aligned}
\text { Volume of top riser } & =1.2 \times \text { Volume of cylindrical shape of side riser } \\
\qquad V_{\text {top }} & =1.2 \times\left(\pi \times D_{\text {side }}^{2} \times H_{\text {side }} \div 4\right)
\end{aligned}
$$

Where,

$$
\begin{aligned}
& \mathrm{V}_{\text {top }}=\text { Volume of top riser, cubic inch } \\
& \mathrm{D}_{\text {side }}=\text { Diameter of calculated side riser, inch }
\end{aligned}
$$


$\mathrm{H}_{\text {side }} \quad=$ Height of calculated side riser, inch

$$
\begin{aligned}
\mathrm{V}_{\mathrm{H}} \div \mathrm{V}_{\mathrm{C}} & =\left[(2 / 3) \times \pi \times(\mathrm{D} / 2)^{3}\right] \div\left[\pi \times \mathrm{D}^{2} \times(1.5 \mathrm{D}) \div 4\right] \\
& =0.222 \\
& \approx 20 \%
\end{aligned}
$$

Where,

$$
\begin{array}{ll}
\mathrm{V}_{\mathrm{H}} & =\text { Volume of hemispheric bottom, cubic inch } \\
\mathrm{V}_{\mathrm{C}} & =\text { Volume of cylindrical shape, cubic inch } \\
\mathrm{D} & =\text { Diameter of calculated side riser, inch }
\end{array}
$$

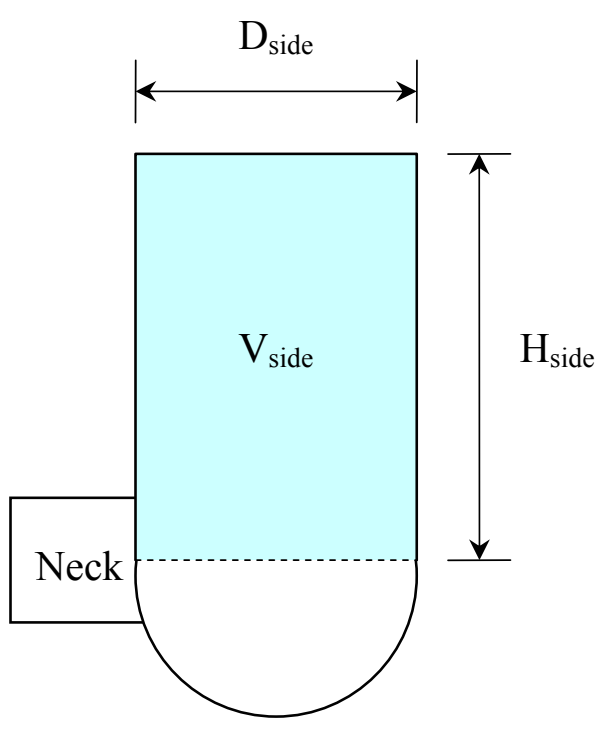

Side Riser

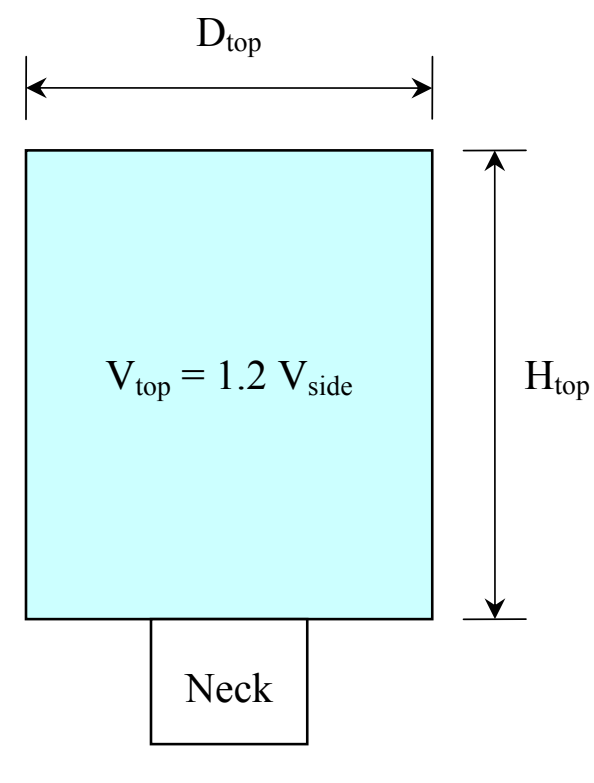

Top Riser

Figure 4.9: Comparing the volumes of a side and top riser.

But in cases which the riser height per diameter ratio is not 1.5 , the rule of 20 percent would not be true. From equation (4.1), it seems that the effective feeding volume is the volume of the cylindrical shape of the side riser, excluding the hemispheric bottom. So, the 20 percent increase in the size of the top riser may be to compensate for heat loss if it is considered as an open top riser. 


\section{2) Neck Dimensions}

The calculated neck dimensions are shown as either the diameter of a round neck, a side of a square neck, or if the user would want to use a rectangular shaped neck, there is a calculator which would calculate the dimensions of a rectangular shaped neck which would have the same cross-sectional area as a square neck.

The neck dimensions calculated in this Riser Design Wizard considers the neck to have a cubic shape with four surfaces excluding the surfaces connected to the riser and casting. The formula for calculating the length of one side of this cubic shaped neck is shown in equation (4.5). The formula for calculating the neck modulus is shown in equation (4.6).

$$
\begin{array}{ll}
\mathrm{M}_{\mathrm{n}} & =\text { Volume of cubic shaped neck } \div \text { Four surface areas } \\
\mathrm{M}_{\mathrm{n}} & =\mathrm{L}^{3} \div\left(4 \times \mathrm{L}^{2}\right) \\
& =\mathrm{L} \div 4 \\
\mathrm{~L} & =4 \mathrm{M}_{\mathrm{n}}
\end{array}
$$

Where,

$\mathrm{M}_{\mathrm{n}} \quad=$ Neck modulus, inches

$\mathrm{L} \quad=$ Length of one side of the cubic neck, inches

Normally, a neck would have a rectangular shape, not a cubic shape. If the user uses the rectangular neck dimensions calculator, the resulting neck would have the same connecting area as a square neck, but the actual neck modulus would decrease. So, if the user would like to have a neck with a modulus equal to the calculated modulus, he or she must recalculate a new neck.

\section{3) Riser Modulus}

The riser modulus value in the "Riser Modulus" box is calculated by multiplying the modulus increase factor with the riser modulus. The modulus is the volume divided by the surface area of an object. The side riser type is assumed to have a cylindrical shape with a diameter and height of the calculated riser diameter and height added a hemisphere shaped bottom which has an equal diameter as the cylindrical shape. The 
volume used for calculating the modulus is the volume of the cylindrical shape added the hemisphere bottom. The area used for calculating the modulus is the total surface area of this riser less the area of the cross-sectional area of the calculated square-shaped neck.

In the case of a top riser, it is assumed to have a cylindrical shape with a diameter and height of the calculated riser diameter and riser height. The volume used for calculating the modulus is the volume of the cylindrical shape. The area used for calculating the modulus is the total surface area of the cylindrical shape less the area of the cross-sectional area of the calculated square-shaped neck.

\section{4) Neck Modulus}

The neck modulus is calculated from the square root of the shrinkage time in percent of solidification time from the VDG Iron Properties Calculator multiplied by the casting modulus. This formula is shown in equation (4.6).

$$
\mathrm{M}_{\mathrm{n}}=\mathrm{M}_{\mathrm{c}} \mathrm{x} \sqrt{ } \%_{\mathrm{ST}}
$$

Where,

$$
\begin{aligned}
M_{n}= & \text { Neck modulus, inch } \\
M_{\mathrm{c}}= & \text { Casting modulus, inch } \\
\%_{\mathrm{ST}}= & \text { Shrinkage time in percent of solidification time from VDG Iron } \\
& \text { Properties Calculator, percent }
\end{aligned}
$$

\section{5) Ratio of Riser Modulus per Casting Modulus}

This is the value of the riser modulus divided by the casting modulus. It should be more than 1 showing that the riser should solidify later than the casting.

\section{6) Ratio of Neck Modulus per Casting Modulus}

This is the value of the neck modulus divided by the casting modulus. It should be less than 1 showing that the neck should solidify before the casting does to prevent liquid metal being pushed back into the riser due to expansion of graphite. 


\subsubsection{The Results of the Riser Design}

The final calculation of the Riser Design Wizard is shown in Figure 4.10. The sample model with a weight of 70.434 pounds and casting modulus of 0.6004735 inch cast in a sand mold with one percent mold dilation having a side riser with a height per diameter ratio of 1.5 without any sleeves and with gating through it would have a calculated diameter of around 3.786 inches, a height of 5.679 inches and a cubic shaped neck with 2.114 inches on all sides. Figure 4.11 shows the calculated dimensions.

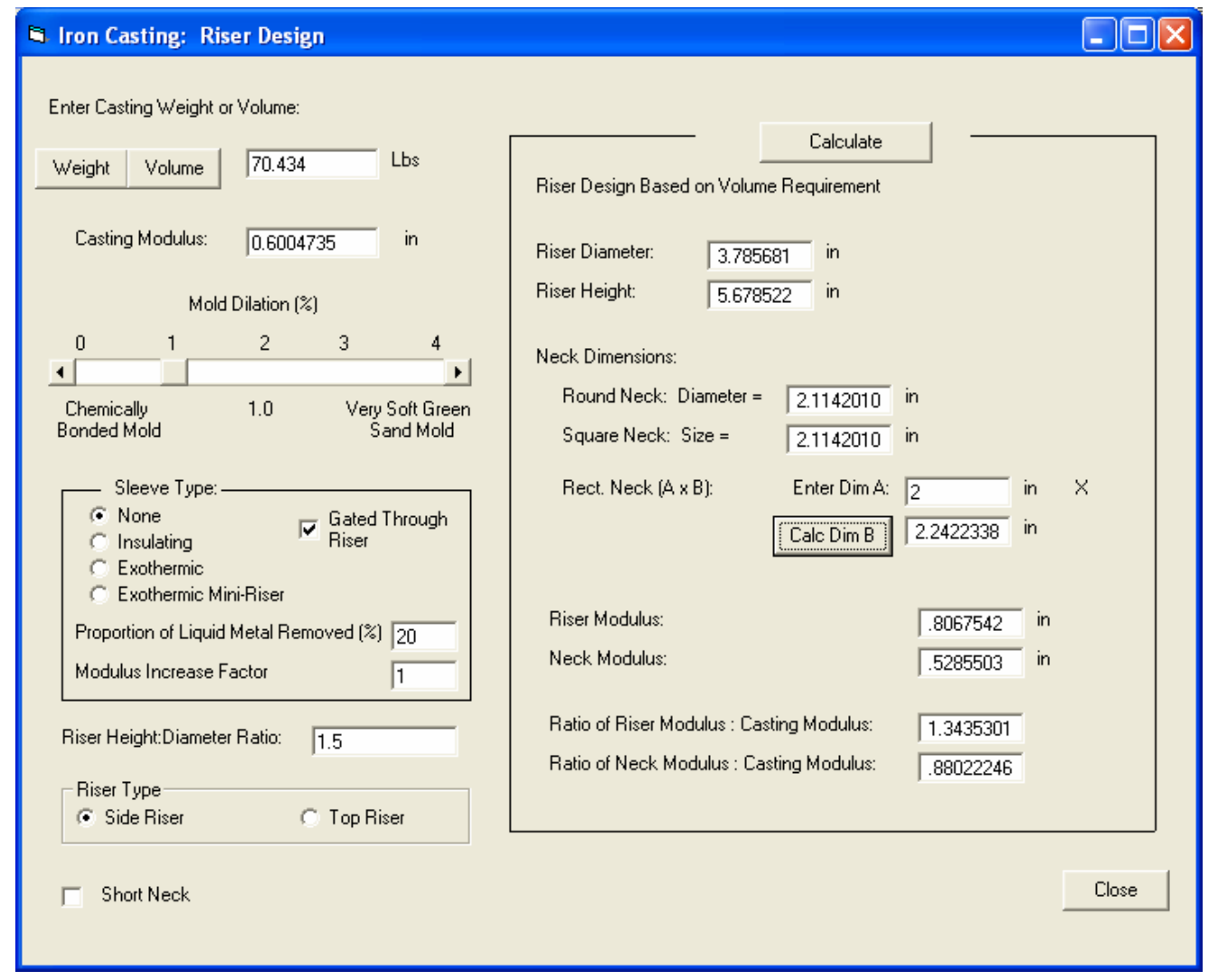

Figure 4.10: The final calculation of the Riser Design Wizard

It could be seen in Figure 4.11 that the total height of the riser divided by the diameter is more than 1.5 due to the calculations behind the program. If a user would like to have a side riser with a true height per diameter ratio of 1.5 , the user must set the riser height per diameter ratio at 1.0 instead. 


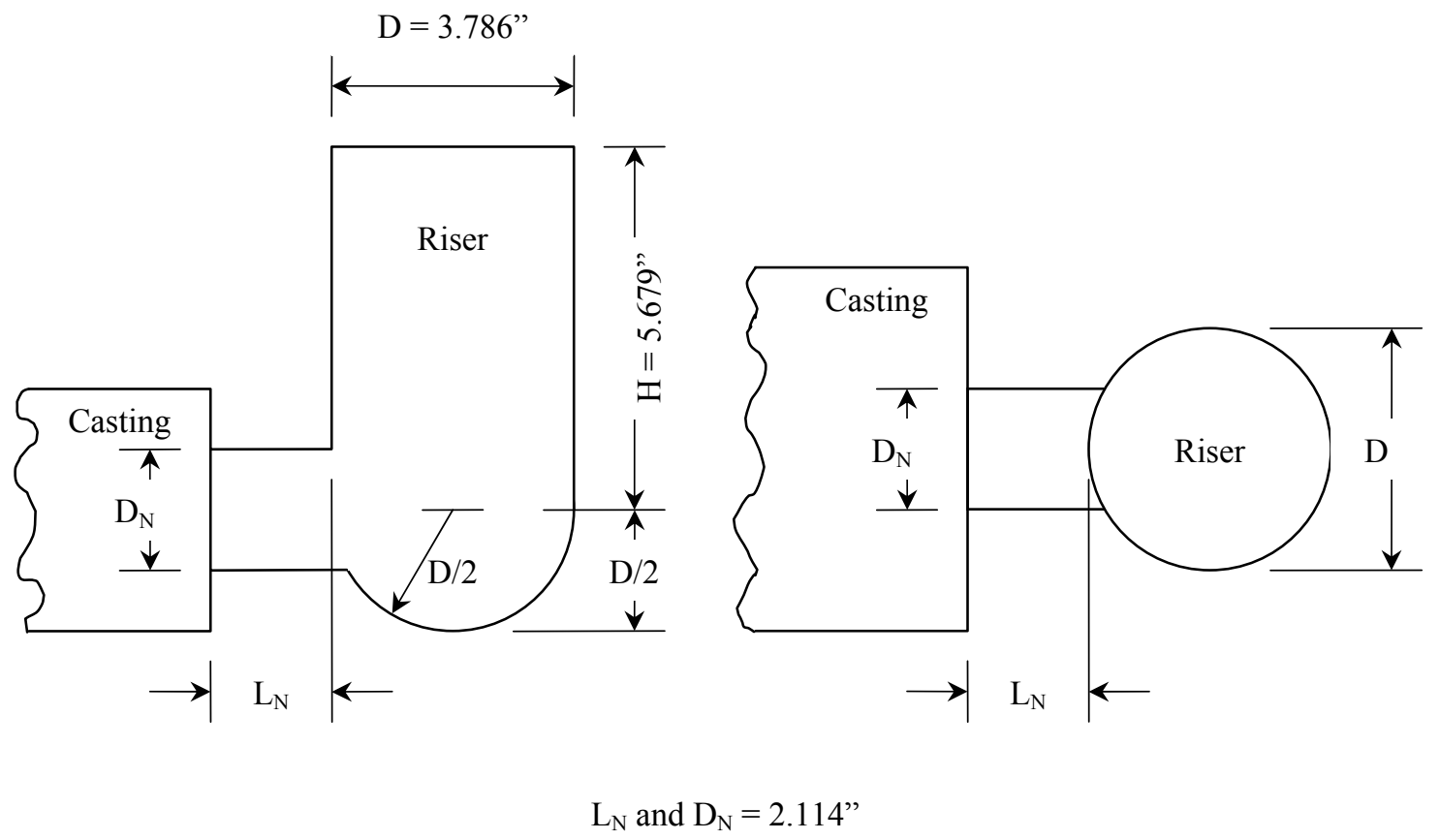

Figure 4.11: Calculated dimensions of the riser from the Riser Design Wizard.

The VDG Iron Properties Calculator's Riser Design Wizard was designed especially for designing risers for cast irons. Designing risers for gray iron and ductile iron castings involves one primary consideration above all else, which is control of expansion pressure (Finite Solutions Inc., 2005). This means allowing a riser neck to remain open long enough to feed liquid metal into the casting but ensuring it would freeze in time to pressure the casting during expansion so the liquid metal would not flow back into the riser causing the formation of shrinkage porosity. As could be seen from Figure 4.10, the riser has the highest modulus, then the casting, and the neck has the least modulus so it may freeze first.

Only one riser should be used for each feed zone or feeding area within a casting (Finite Solutions Inc., 2005). Feed zones can be visualized by plotting the calculated neck modulus in the "Calculate and Display Casting Modulus" option in the Riser Design Wizard from the Tools menu. This neck modulus can also be called the "transfer modulus". If more than one riser is used for a single feed zone, only one riser would pipe and the other riser would create a thermal hot spot which some shrinkage porosity will likely be able to form underneath that riser. Figure 4.12 shows the single feed zone 
which was plotted with the neck modulus. Also, for gray and ductile iron castings, the tops of the risers should be above the highest point of the casting by at least the minimum section thickness of the casting (Finite Solutions Inc., 2005).

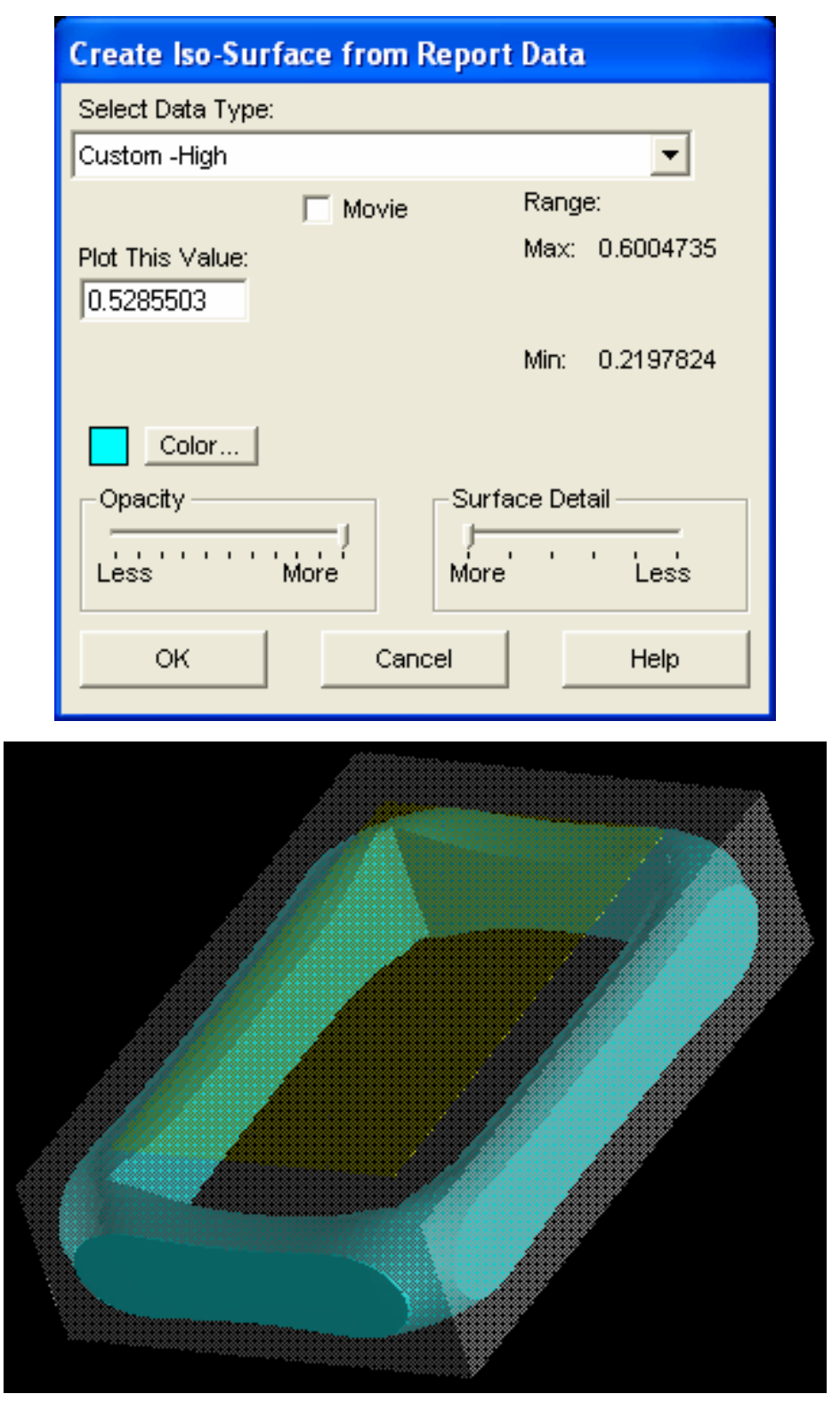

Figure 4.12: Modulus plot showing one feeding area plotted with the neck modulus, 0.5285503 inch. 


\subsection{Gating Design and Analysis}

\subsubsection{Analysis of the Gating Design Wizard}

To start the Gating Design wizard, first double-click the Simulation tab in the Project Tree. The "Simulation Status" window would appear. Next, close the window. This would load the information from the simulation results to the design wizard program. The Gating Design Wizard can be accessed from the Simulation tab in the menu. The Gating Design Wizard window would appear and would let the user choose between designing a horizontal gating system or vertical gating system. In this case, a horizontal gating system is selected for the casting.

Next, the wizard program would let the user select the alloy sensitivity, the pouring weight and the critical section thickness to calculate the optimal fill time for the casting, as shown in Figure 4.13. The alloy sensitivity slider bar refers to the sensitivity of alloys to form oxides during the pouring process. Alloys which are less sensitive (low value of this factor) may be poured more quickly. Alloys which are more sensitive to oxide formation should be poured more slowly to avoid excessive turbulence which may expose more of the metal surface to oxygen, thus forming and entraining the oxides as inclusions in the finished casting (Finite Solutions Inc., 2005).

From Figure 4.13, the pour weight for a horizontal gating system would include the casting along with rigging; the riser and gating system. The pour weight for a vertical gating system would not include the rigging weight. The user may estimate this weight from past experience. The critical section thickness is the minimum thickness in the casting that is most likely to misrun. The calculated fill time or optimal fill time is calculated with the formula shown in equation (4.7), but the user may also manually enter the fill time in the case the fill time is already known or estimated by past experience. The formula used for calculating the optimal fill time was found to neither consider the type nor the density of the casting material.

$$
\mathrm{t} \quad=2.26 \mathrm{x}^{3} \sqrt{\mathrm{W}} \mathrm{x}^{3} \sqrt{\mathrm{T}} \times \mathrm{S}
$$

Where,

$\mathrm{t}=$ Optimal filling time or fill time, second

$\mathrm{W}=$ Weight of casting, pound 
$\mathrm{T}=$ Critical section thickness, inch

$\mathrm{S} \quad=$ Alloy sensitivity number, no unit

Gating Design Wizard

$\square \square$

Horizontal Gating System

Enter values here. When you are satisfied with the values, click "Next".

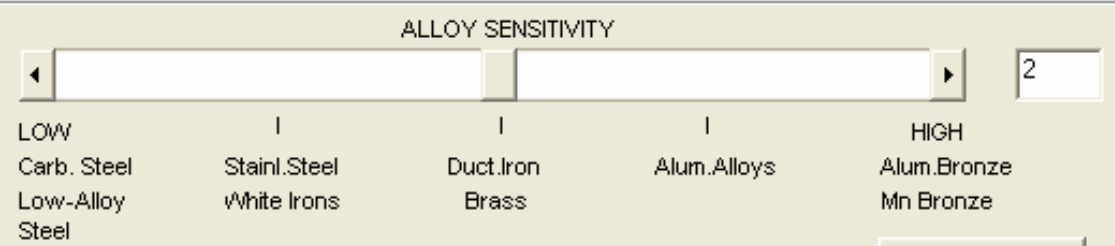

Stee

\begin{tabular}{|c|c|}
\hline Pour Weight: & 70.434 \\
\hline Critical Section Thickness: & 1.5 \\
\hline Fill Time: & 21.4 \\
\hline
\end{tabular}

Get Model Data

Calc. Fill Time

Fill Time:

sec.

Click Cancel to close the wizard without saving, or Close to save your place. (c) 2003 Finite Solutions Inc.

Cancel

\begin{tabular}{l|l|l|} 
<古ack & Next $>$ & Finish \\
\hline
\end{tabular}

Figure 4.13: Calculating the optimal fill time for the casting.

It was found that the material density used for calculating the volume would change whenever the material density information in the Casting tab in the Materials List window was changed. It was assumed that the material density in the Casting tab in the Materials List window would be automatically transferred to the Gating Design Wizard.

Next, the wizard program would let the user select a sprue type between round tapered, round straight and square tapered sprue shape. Each sprue type would have different efficiencies accounting from friction losses associated with flowing through each sprue shape. It was found that a round tapered shape sprue, a round straight shape 
sprue and a square tapered shape sprue would have efficiencies of around 88.2, 47.0 and 74.0 percent respectively. The flow areas calculated would be increased by a factor of the inverse of the efficiency of the sprue type to account for the energy losses associated with flowing through it, as shown in equation (4.11). In this case, a round tapered sprue is chosen as the sprue type as it is the most common type used. Then the user may choose a gating type between top gating, bottom gating and parting line gating. Figure $4.14,4.15$ and 4.16 shows the appearance of the window when top gating, bottom gating and parting line gating are selected respectively.

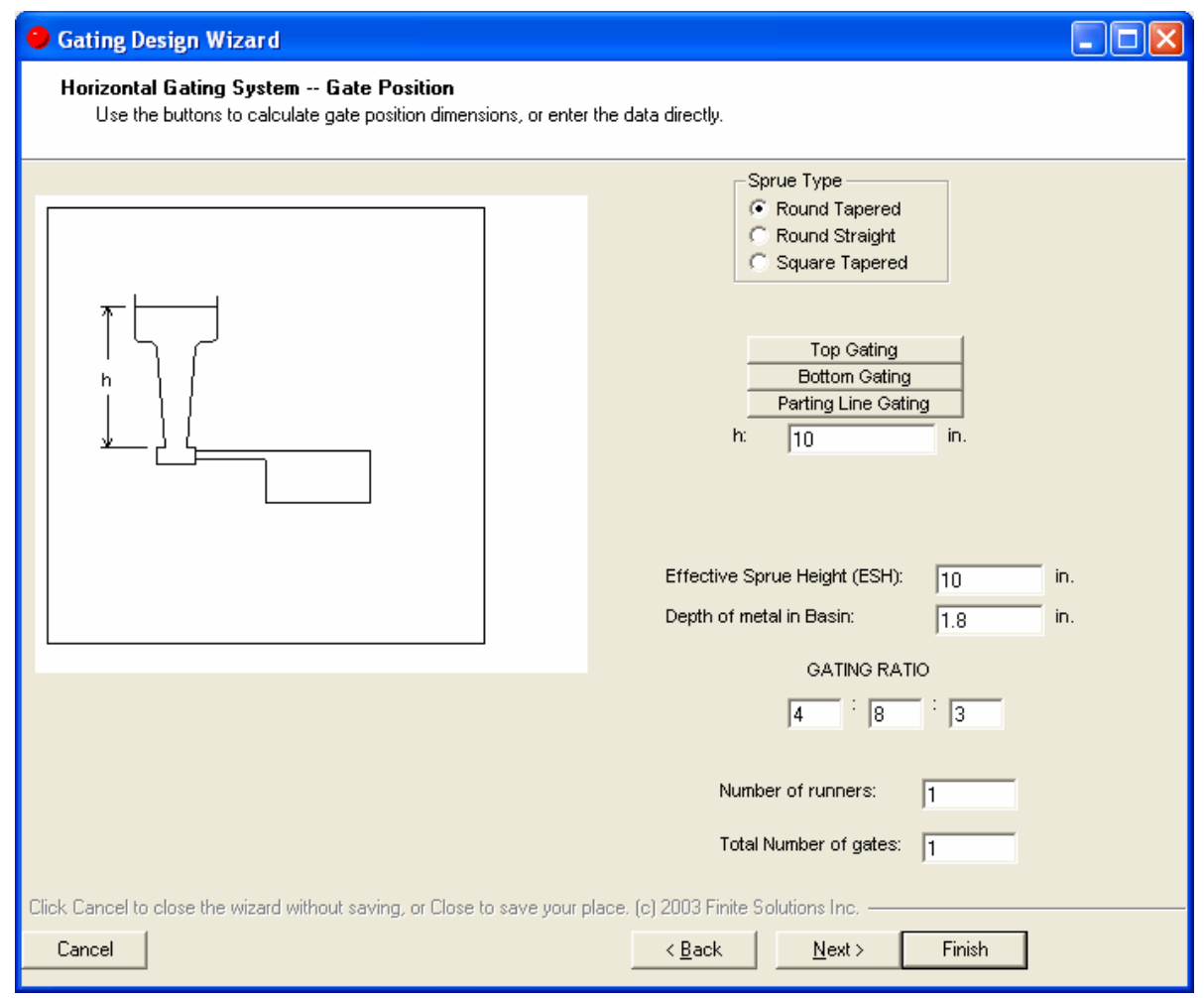

Figure 4.14: Gate Position window for top gating system. 


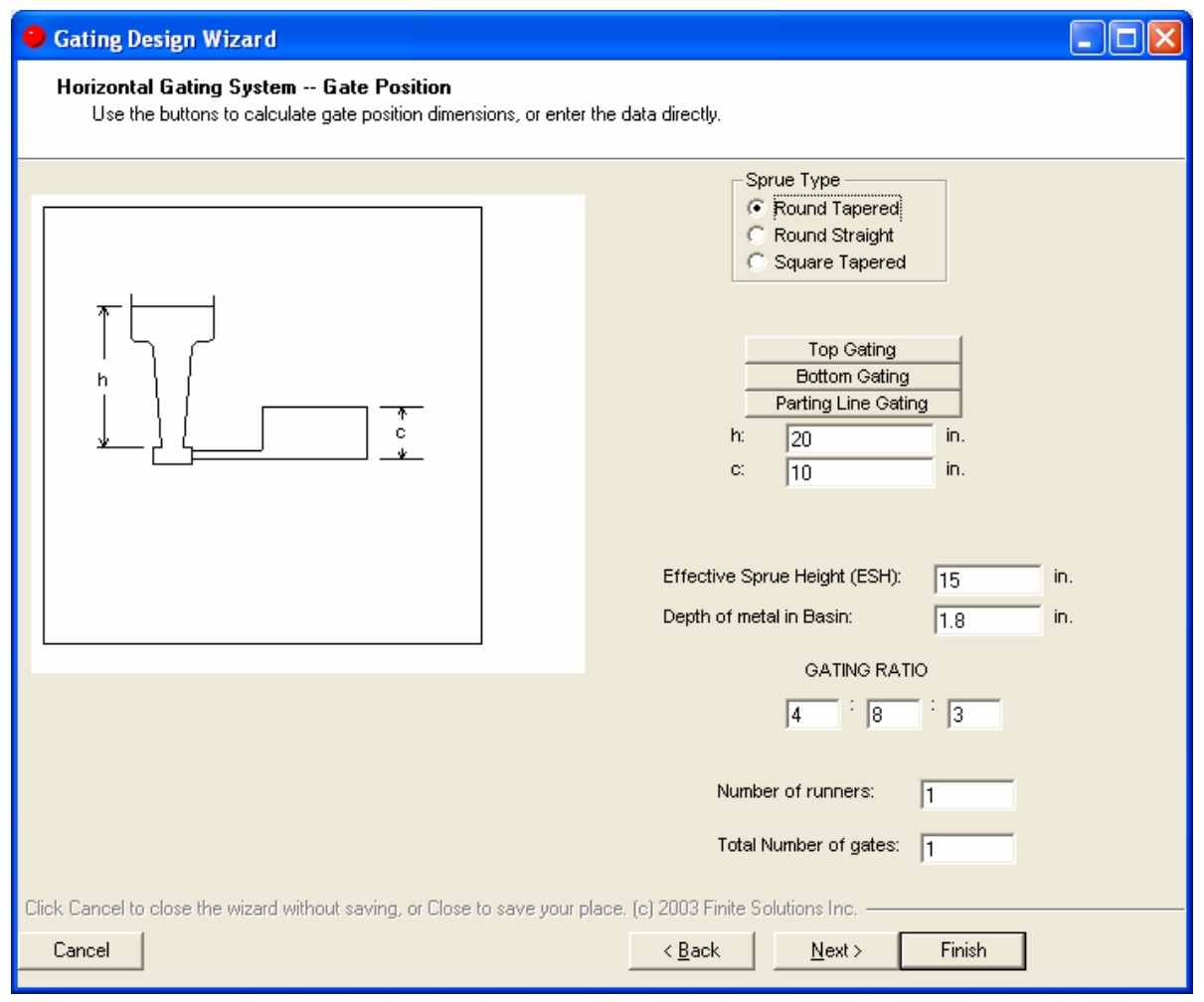

Figure 4.15: Gate Position window for bottom gating system.

Gating Design Wizard

Horizontal Gating System -- Gate Position

Use the buttons to calculate gate position dimensions, or enter the data directly.

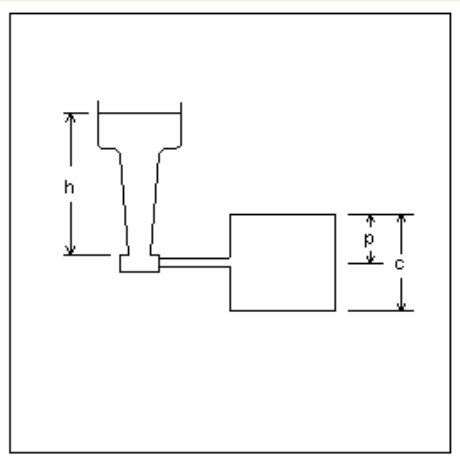

Sprue Type

- Round Tapered

C Round Straight

$C$ Square Tapered

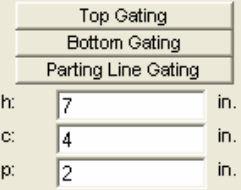

Effective Sprue Height (ESH): $\sqrt{6.5}$ in.

Depth of metal in Basin: $\quad \longdiv { 1 . 8 }$ in

$$
\begin{aligned}
& \text { GATING RATIO } \\
& \sqrt{4}: \sqrt{8}: \sqrt{3}
\end{aligned}
$$

Number of runners: 1

Total Number of gates: 1

Click Cancel to close the wizard without saving, or Close to save your place. (c) 2003 Finite Solutions Inc.

Cancel

〈ㅁack Next> Finish

Figure 4.16: Gate Position window for parting line gating system. 
From Figures 4.14, 4.15 and 4.16, the user must enter the height of liquid metal in the pouring basin from the bottom of the sprue during filling (h) for all three types of gating, the total height of the casting (c) for the bottom and parting line gating, and the height of the casting from the parting line (p) for parting line gating. The depth of the metal in the basin is basically the depth of liquid metal when the metal is poured into the pouring basin, so it may be equal to or less than the depth of the basin. This pouring basin is used for absorbing the initial surge of liquid and minimizes splashing. The effective sprue height (ESH) is a value calculated by formulas shown in equations (4.8), (4.9) and (4.10) for top, bottom and parting line gating respectively. In the case that liquid metal is poured directly into the sprue and not into a pouring basin, the additional height of the ladle above the top of the mold should be added to the calculated effective sprue height (ESH).

$$
\begin{aligned}
\text { ESH } & =\mathrm{h} \\
\text { ESH } & =\mathrm{h}-(\mathrm{c} / 2) \\
\mathrm{ESH} & =\mathrm{h}-\left[(0.5 / \mathrm{c}) \times \mathrm{p}^{2}\right]
\end{aligned}
$$

Where,

ESH = Effective sprue height, inch

$\mathrm{h}=$ Height of liquid metal in pouring basin from bottom of sprue, inch

c $\quad=$ Total height of the casting, inch

$\mathrm{p} \quad=$ Height of the casting from the middle of the gate, inch

Next, the gating ratio, which is the ratio of the area of flow at the sprue, the runner and the gates needs to be defined from the user. For example, a ratio of 4:8:3 is used with pressurized ductile iron casting systems in sand molds, and a ratio of 1:1.3:1.1 is used with pressurized gray iron castings (Heine, 1995). The choke is defined as the location within the gating system of the minimum cross-sectional area. For example, the 4:8:3 ratio would have the choke at the gate and the 1:1.3:1.1 ratio would have the choke at the sprue exit. Last of all, the user must fill in the number of runners and gates. 
Next, the window would show the calculated sprue data. This window is shown in Figure 4.17 and the formulas used for calculating these values are shown in equations (4.11) through (4.15).

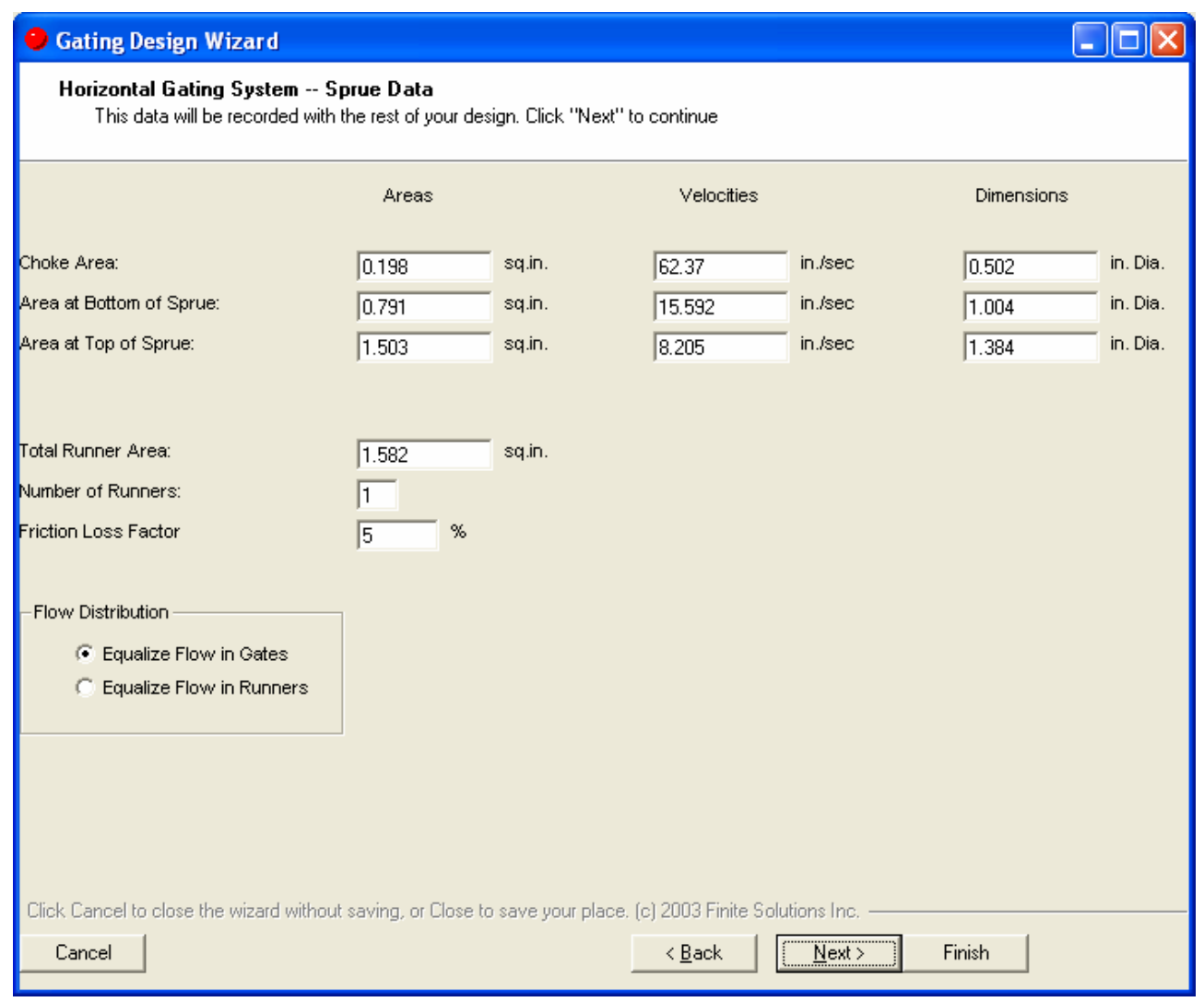

Figure 4.17: Calculated sprue data window, continued from Figure 4.15.

$$
\mathrm{A}_{\mathrm{c}}=\left(1 / \mathrm{Eff}_{\text {sprue }}\right) \times[(\mathrm{W} \div \rho) \div\{\mathrm{t} \times \sqrt{ }(2 \times \mathrm{g} \times \mathrm{ESH})\}]
$$

Where,

$\mathrm{A}_{\mathrm{c}} \quad=$ Choke area, square inch

$\mathrm{Eff}_{\text {sprue }}=$ Efficiency of sprue shape due to friction loss, percent

$\mathrm{W} \quad=$ Weight of casting, pound

$\rho \quad=$ Density of casting, pound per cubic inch

$\mathrm{t} \quad=$ Fill time, second

$\mathrm{g}=$ Acceleration due to gravity, 32.2 feet per second square or 386.4 inches per second square

ESH = Effective sprue height, inch 


$$
\mathrm{V} \quad=\mathrm{W} \div \rho
$$

Where,

$$
\begin{array}{ll}
\mathrm{V} & =\text { Volume of casting, cubic inch } \\
\mathrm{W} & =\text { Weight of casting, } \text { pound } \\
\rho & =\text { Density of casting, pound per cubic inch }
\end{array}
$$

$$
\begin{array}{ll}
\mathrm{A}_{\mathrm{BS}} & =\mathrm{A}_{\mathrm{c}} \times \mathrm{R}_{\mathrm{AS}} \\
\mathrm{A}_{\mathrm{R}} & =\mathrm{A}_{\mathrm{c}} \times \mathrm{R}_{\mathrm{AR}} \\
\mathrm{A}_{\mathrm{G}} & =\mathrm{A}_{\mathrm{c}} \times \mathrm{R}_{\mathrm{AG}}
\end{array}
$$

Where,

$$
\begin{aligned}
& \mathrm{A}_{\mathrm{c}}=\text { Area of calculated choke, square inch } \\
& \mathrm{A}_{\mathrm{BS}} \quad=\text { Area at bottom of sprue, square inch } \\
& \mathrm{A}_{\mathrm{R}} \quad=\text { Total runner area, square inch } \\
& \mathrm{A}_{\mathrm{G}} \quad=\text { Required gate area, square inch }
\end{aligned}
$$

From the gating ratio,

$\mathrm{R}_{\mathrm{AS}} \quad=$ Ratio of the area of flow at the sprue

$\mathrm{R}_{\mathrm{AR}}=$ Ratio of the area of flow at the runner

$\mathrm{R}_{\mathrm{AG}} \quad=$ Ratio of the area of flow at the gates

$$
\mathrm{A}_{\mathrm{TS}} \sqrt{\mathrm{D}_{\mathrm{B}}} \quad=\mathrm{A}_{\mathrm{BS}} \sqrt{\mathrm{ESH}}
$$

Where,

$$
\begin{aligned}
& \mathrm{A}_{\mathrm{TS}}=\text { Area at top of sprue, square inch } \\
& \mathrm{D}_{\mathrm{B}}=\text { Depth of metal in basin, inch } \\
& \mathrm{A}_{\mathrm{BS}}=\text { Area at bottom of sprue, square inch } \\
& \mathrm{ESH}=\text { Effective sprue height, inch } \\
& \mathrm{V} \div \mathrm{t}=\mathrm{A}_{\mathrm{c}} \times v_{\mathrm{c}} \quad=\mathrm{A}_{\mathrm{BS}} \times \mathrm{v}_{\mathrm{BS}}=\mathrm{A}_{\mathrm{TS}} \times \mathrm{v}_{\mathrm{TS}}
\end{aligned}
$$

Where,

$$
\begin{array}{ll}
\mathrm{V} & =\text { Volume of casting } \\
\mathrm{t} & =\text { Fill time, second } \\
\mathrm{A}_{\mathrm{c}} & =\text { Area of calculated choke, square inch }
\end{array}
$$


$v_{c} \quad=$ Velocity of liquid metal through choke area, inch per second

$\mathrm{A}_{\mathrm{BS}}=$ Area at bottom of sprue, square inch

$v_{\mathrm{BS}} \quad=$ Velocity of liquid metal through bottom of sprue, inch per second

$\mathrm{A}_{\mathrm{TS}} \quad=$ Area at top of sprue, square inch

$v_{\mathrm{TS}} \quad=$ Velocity of liquid metal through top of sprue, inch per second

From equation (4.13), the choke area should equal to the lowest section of the gating ratio, but the calculated section areas are multiplications of the choke area by the ratio value. The method for calculating for the gating sections would be wrong if none of the three section ratio values are equal to one, for example, 1:1.3:1.1, etc. If the gating ratio is $4: 8: 3$, the choke area would be at the ingate, but its area would be three times the area of the calculated choke area and the velocity of the liquid metal passing it would be only one third of the calculated choke velocity. The program also does not consider if the velocity of the liquid metal would be too high or not. The recommended limit of velocity of liquid metal is approximately half a meter per second for aluminum (Ravi, 2005) and also for most metals (Campbell, 2004), and one meter per second for iron (Ravi, 2005).

Next, the user may input the required number of runners, the friction loss factor and option of flow distribution. The friction loss factor will default to 5 percent when the program is first run, but may be modified by the user. The user may select the flow distribution to be either to equalize the flow through the gates, meaning all gates have equal flow, or equalize the flow in the runners, meaning all runners have equal flow regardless of the number of gates they feed. The more common practice is to equalize the flow through the gates (Finite Solutions Inc., 2005).

For equalizing the flow through the gates, in the case of multiple runners with one ingate per runner, the cross-sectional area of each runner would be the calculated total runner area $\left(A_{R}\right)$ divided by the number of runners. The required gate area would be the calculated required gate area $\left(\mathrm{A}_{\mathrm{G}}\right)$ divided by the number of runners.

For runners which feed multiple gates, in order to equalize flow in the gates, it is normal to "step down" the runner, which is reducing the cross-sectional area of the runner after reaching each gate by the area of the gate to try to equalize the flow through 
all of the gates fed by the runner. The friction loss factor would be considered in calculating for each runner and ingate section to compensate for friction loss.

The cross-sectional area of the runner before the first ingate is the runner area of a runner with one ingate multiplied by the number of ingates for that runner. The first ingate would have a required gate area of the calculated required gate area $\left(\mathrm{A}_{\mathrm{G}}\right)$ divided by the number of runners. The runner area after passing an ingate would equal to the runner area less the ingate area and added with the friction loss factor. This step down calculation is summarized in Figure 4.18 and equation (4.16). The following window after the window in Figure 4.17 is shown in Figure 4.19, which is the runner and gate design window.

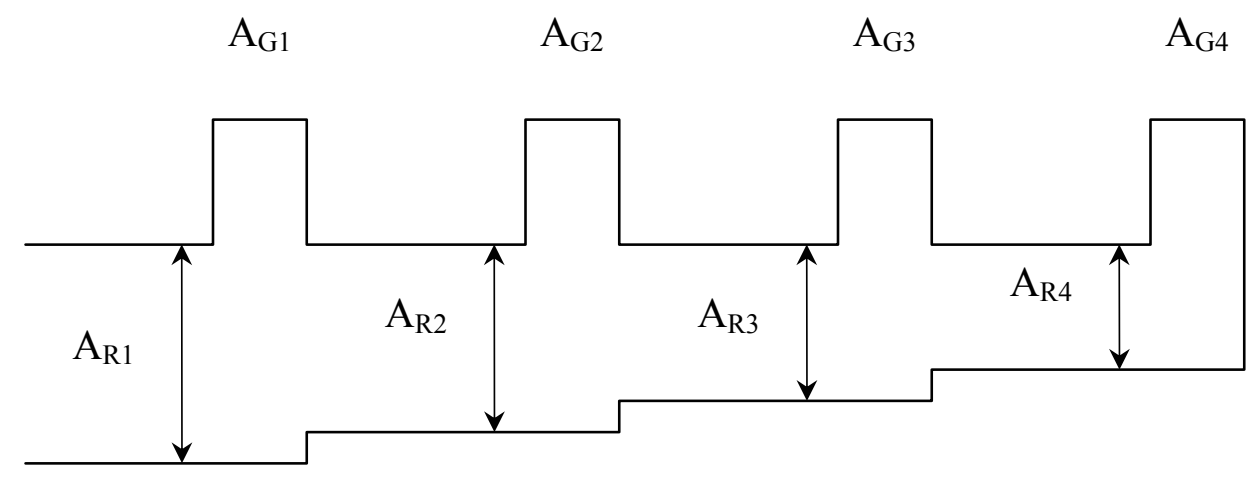

Figure 4.18: The "step down" calculation of the runner.

$$
\begin{aligned}
& A_{R 2}=\left(A_{R 1}-A_{G 1}\right) \times(1+F L F) \\
& A_{G 2}=A_{G 1} \times(1+F L F) \\
& A_{R 3}=\left(A_{R 2}-A_{G 2}\right) \times(1+F L F) \\
& A_{G 3}=A_{G 2} \times(1+F L F) \\
& A_{R 4}=\left(A_{R 3}-A_{G 3}\right) \times(1+F L F) \\
& A_{G 4}=A_{G 3} \times(1+F L F)
\end{aligned}
$$

Where,

FLF $=$ Friction loss factor, percent

$A_{R 1}=$ Cross-sectional area of runner in section number 1, square inch

$A_{R 2}=$ Cross-sectional area of runner in section number 2, square inch

$\mathrm{A}_{\mathrm{R} 3}=$ Cross-sectional area of runner in section number 3 , square inch 
$\mathrm{A}_{\mathrm{R} 4}=$ Cross-sectional area of runner in section number 4 , square inch

$\mathrm{A}_{\mathrm{G} 1}=$ Cross-sectional area of gate number 1, square inch

$\mathrm{A}_{\mathrm{G} 2}=$ Cross-sectional area of gate number 2, square inch

$\mathrm{A}_{\mathrm{G} 3}=$ Cross-sectional area of gate number 3, square inch

$\mathrm{A}_{\mathrm{G} 4}=$ Cross-sectional area of gate number 4 , square inch

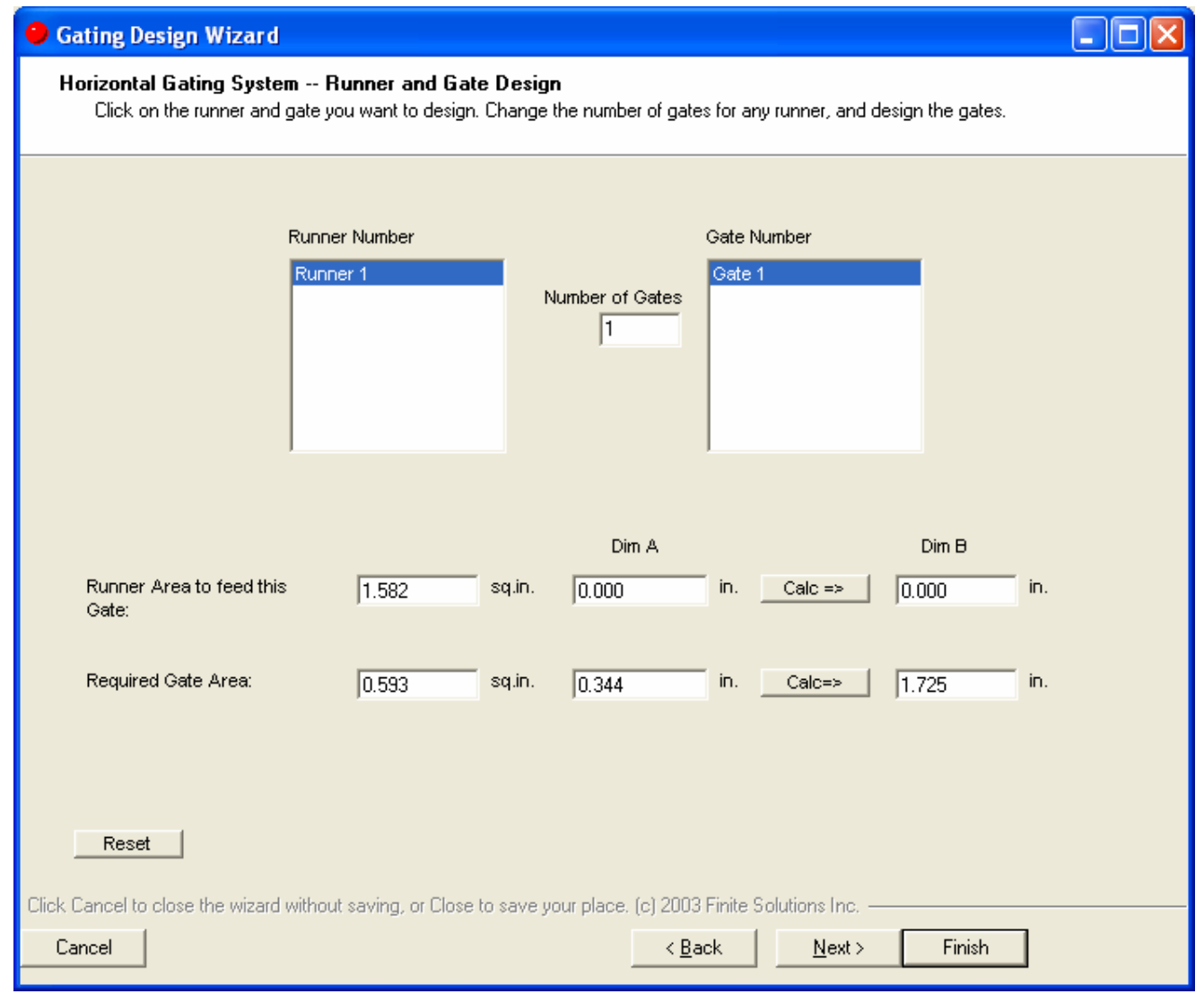

Figure 4.19: The runner and gate design window.

In Figure 4.19, it could be seen that there are two calculator buttons which can be used by the user to calculate a rectangular shaped runner or gate area with the same areas as the runner area to feed this gate and required gate area respectively. Gating should be designed to freeze relatively quickly after the liquid metal has filled the mold cavity. The cross-sectional dimensions of the gate is recommended to have a width per thickness ratio of $5: 1$ to ensure relatively quick freezing so that expansion pressure can be contained (Finite Solutions Inc., 2005). Equation (4.17) shows the formula to calculate the thickness of the gate. 


$$
\mathrm{t} \quad=\sqrt{ }(\mathrm{A} / 5)
$$

Where,

$\mathrm{t}=\quad=$ Thickness of rectangular gate with width per thickness ratio of 5:1, inch

A $\quad=$ Area of gate, square inch

\subsubsection{The Results of the Gating Design}

The weight that shall be entered into the Gating Design Wizard for horizontal gating system must include the weight of the rigging of the casting design. The weight of the calculated riser and its neck can be calculated as shown in equations (4.18) through (4.22) shown below:

$$
\begin{aligned}
\text { Volume of cylindrical shape } & =\left(\pi \times 3.786^{2} \div 4\right) \times 5.679 \\
& =63.933 \text { cubic inches }
\end{aligned}
$$

$$
\begin{aligned}
& \begin{aligned}
\text { Volume of hemispheric shape } & =\left[(4 / 3) \times \pi \times(3.786 / 2)^{3}\right] \div 2 \\
& =14.207 \text { cubic inches } \\
& =2.114^{3} \\
& =9.447 \text { cubic inches } \\
\text { Volume of neck } & =63.933+14.207+9.447 \\
& =87.587 \text { cubic inches }
\end{aligned} \\
& \text { The total volume }
\end{aligned}
$$

$$
\begin{aligned}
\text { The total weight } \quad & =87.587 \text { cubic inches } \mathrm{x} 0.25926 \text { pound per cubic inch } \\
& =22.708 \text { pounds }
\end{aligned}
$$

From the casting weight being 70.434 pounds and the riser with its neck weight being 22.708 pounds, the total weight would equal to 93.142 pounds. But this weight does not include the sprue and gating weight. So, the approximated weight that seems appropriate to be entered into this calculation window may be around 100 pounds. 
In the fill time calculation window, the pour weight was entered as 100 pounds and the critical section thickness was entered as 1.5 inches. Clicking on the "Calculation Fill Time" button, the calculated fill time is 24 seconds, as shown in Figure 4.20.

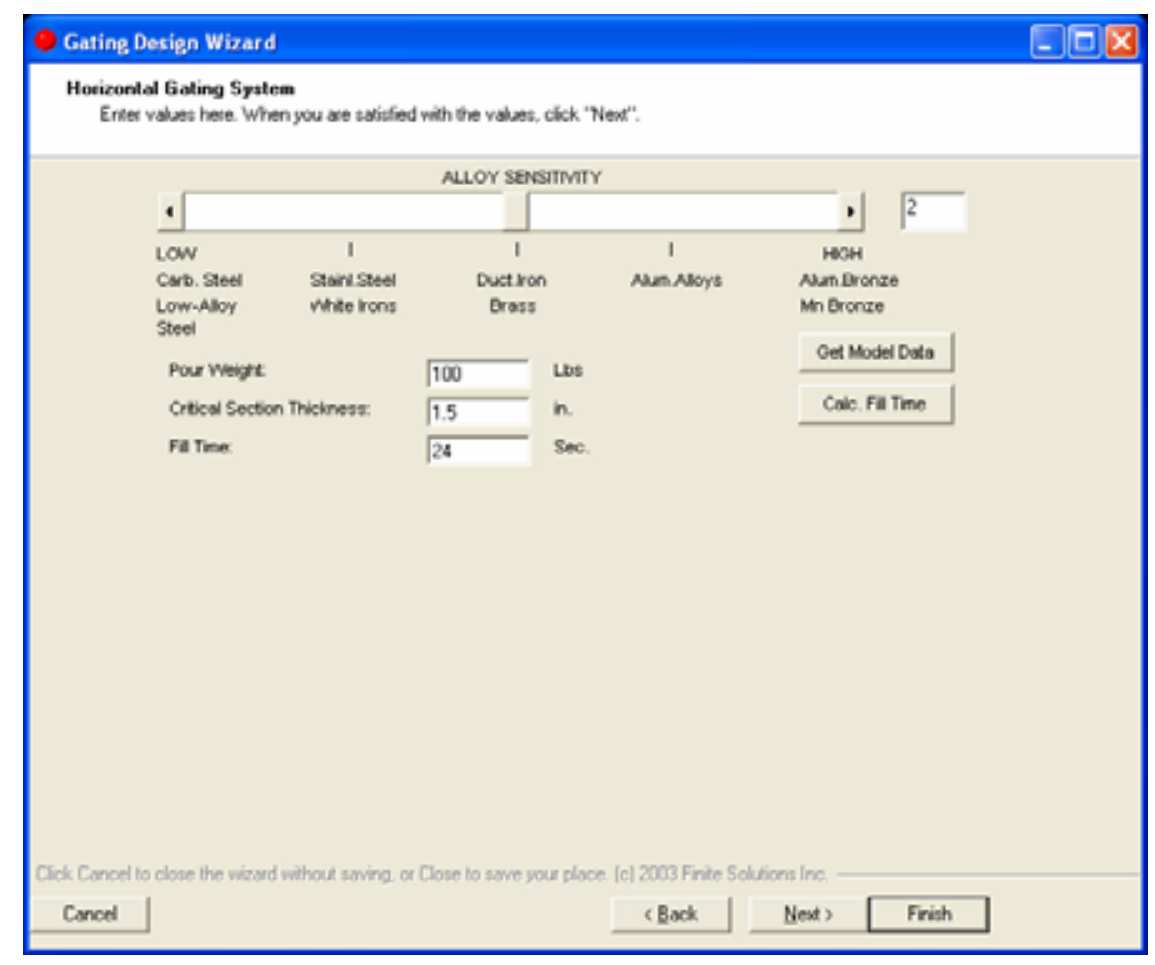

Figure 4.20: Calculating the fill time.

Next, a round tapered sprue with parting line gating was selected in the gate position window. Since the riser height from the middle of the casting was calculated to be 5.679 inches, it seems quite appropriate to have the variable "h" equal to 7 inches, so the riser may be a hidden riser with more than an inch of mold material covering on top of it. The total height of the casting or variable "c" is 4 inches and the height of the casting measured from the center of the gating or variable "p" is 2 inches. The calculated effective sprue height became 6.5. The depth of metal in the basin was approximated to be 1.8 inches for a pouring basin with a depth of 2 inches. The gating ratio was selected to be 1:1.3:1.1 as should be used for a pressurized gray iron casting (Heine, 1995). The number of runners and total number of gates were both set to be equal to one. The resulting "Gate Position" window is shown in Figure 4.21. The resulting sprue data and runner and gate design windows are shown in Figure 4.22 and Figure 4.23 respectively. 


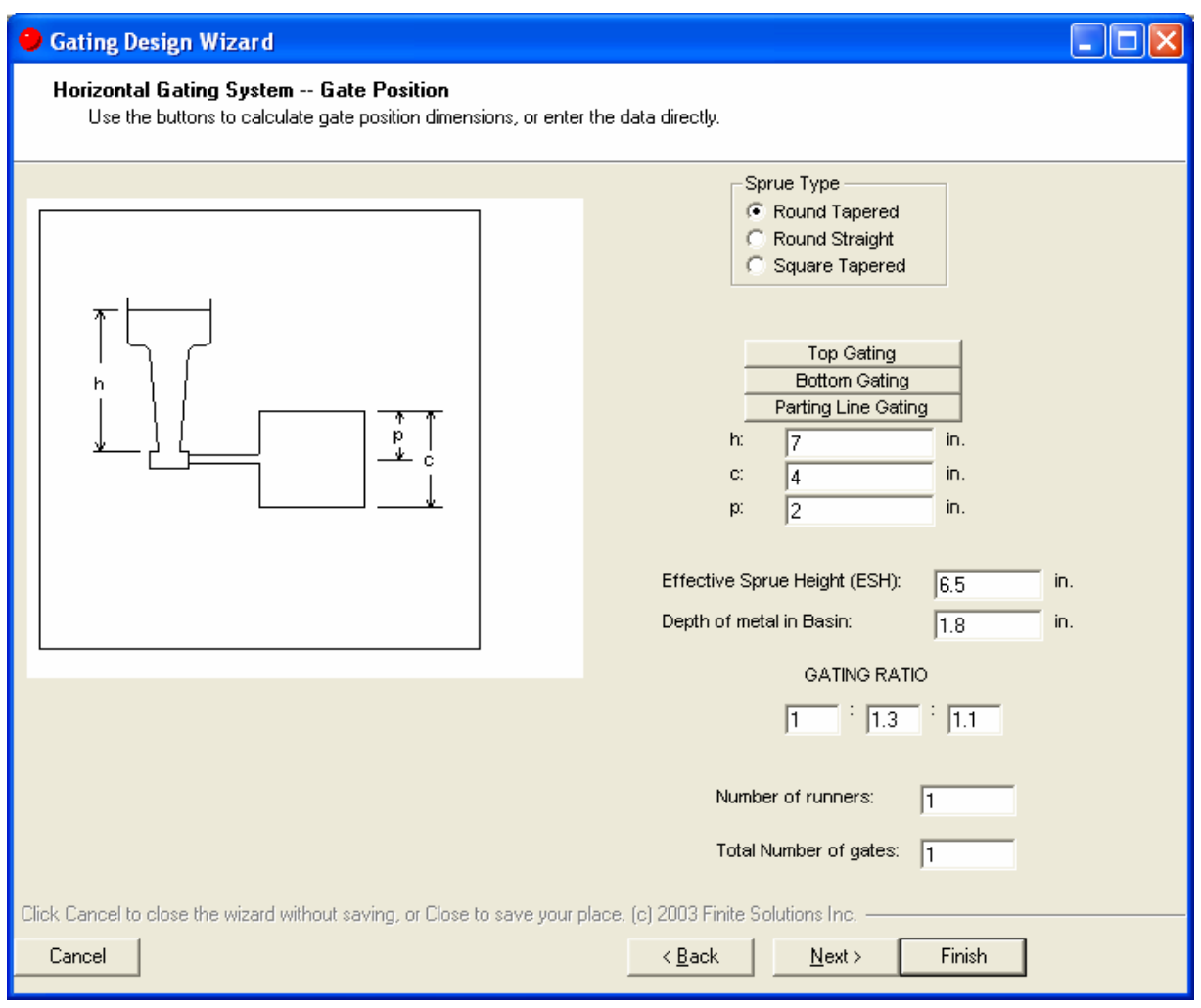

Figure 4.21: The resulting Gate Position window.

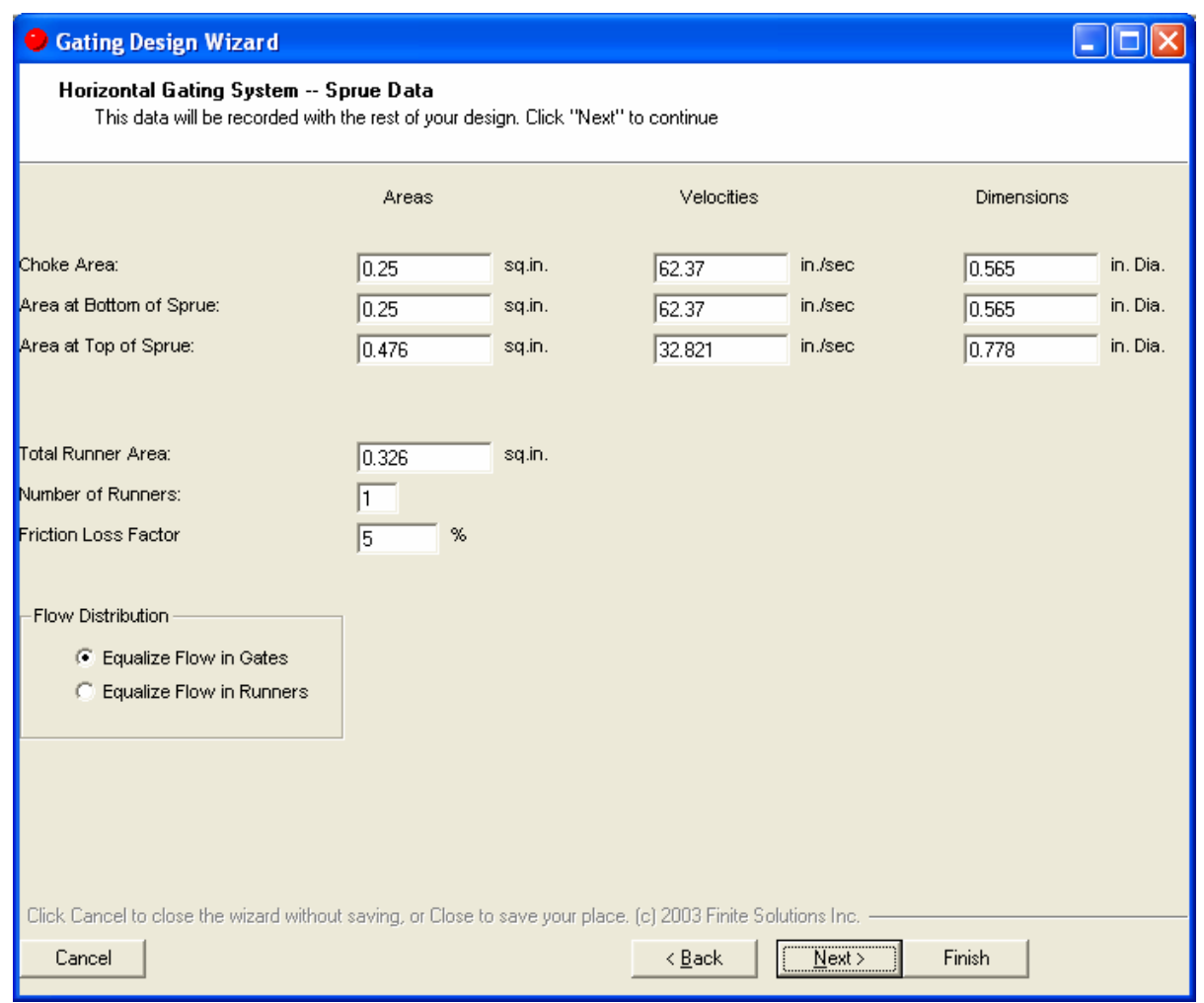

Figure 4.22: The resulting sprue data window. 


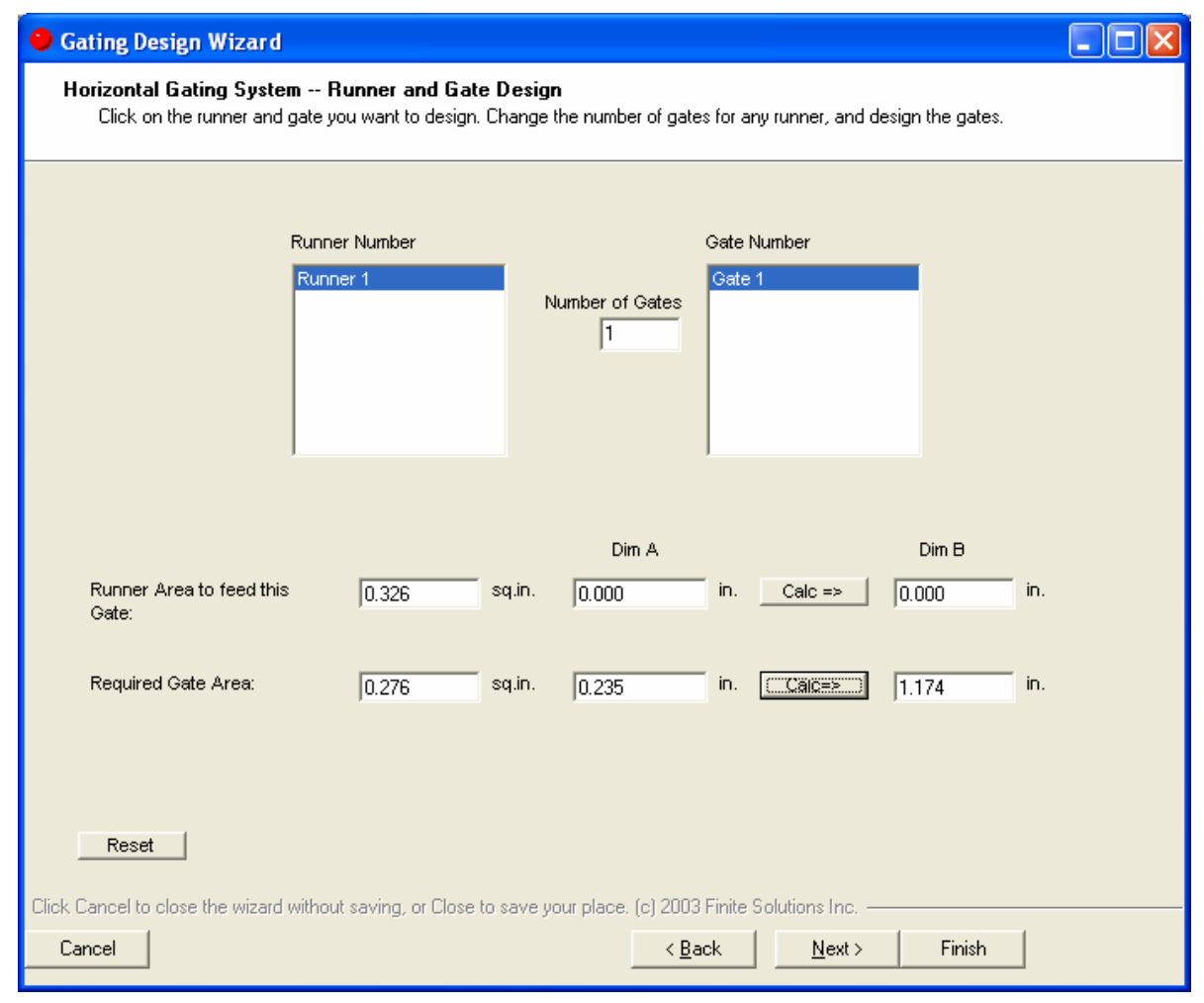

Figure 4.23: The resulting runner and gate design window.

\subsection{The Resulting Dimensions for the Simple Casting Design}

The calculated dimensions for this simple casting design are for a casting design which liquid metal would first enter the mold from the pouring basin down the sprue into the sprue well, into the ingate, into the riser, into the neck and into the casting respectively. The riser was located next to the sprue instead of being located on the opposite end because it was recommended in the SOLIDCast manual (Finite Solutions Inc., 2005) that gating through the riser would increase the proportion of liquid metal that would feed the casting. The program did not define where the neck of the riser shall be placed, so, it was placed on the width side of the casting, which is similar to an example in the SOLIDCast training material (Finite Solutions Inc., 2005). Since the liquid metal will directly enter the riser from the sprue well, a runner is not needed. Figure 4.24 shows the sequence of the liquid metal as it is poured from the ladle into the mold. 


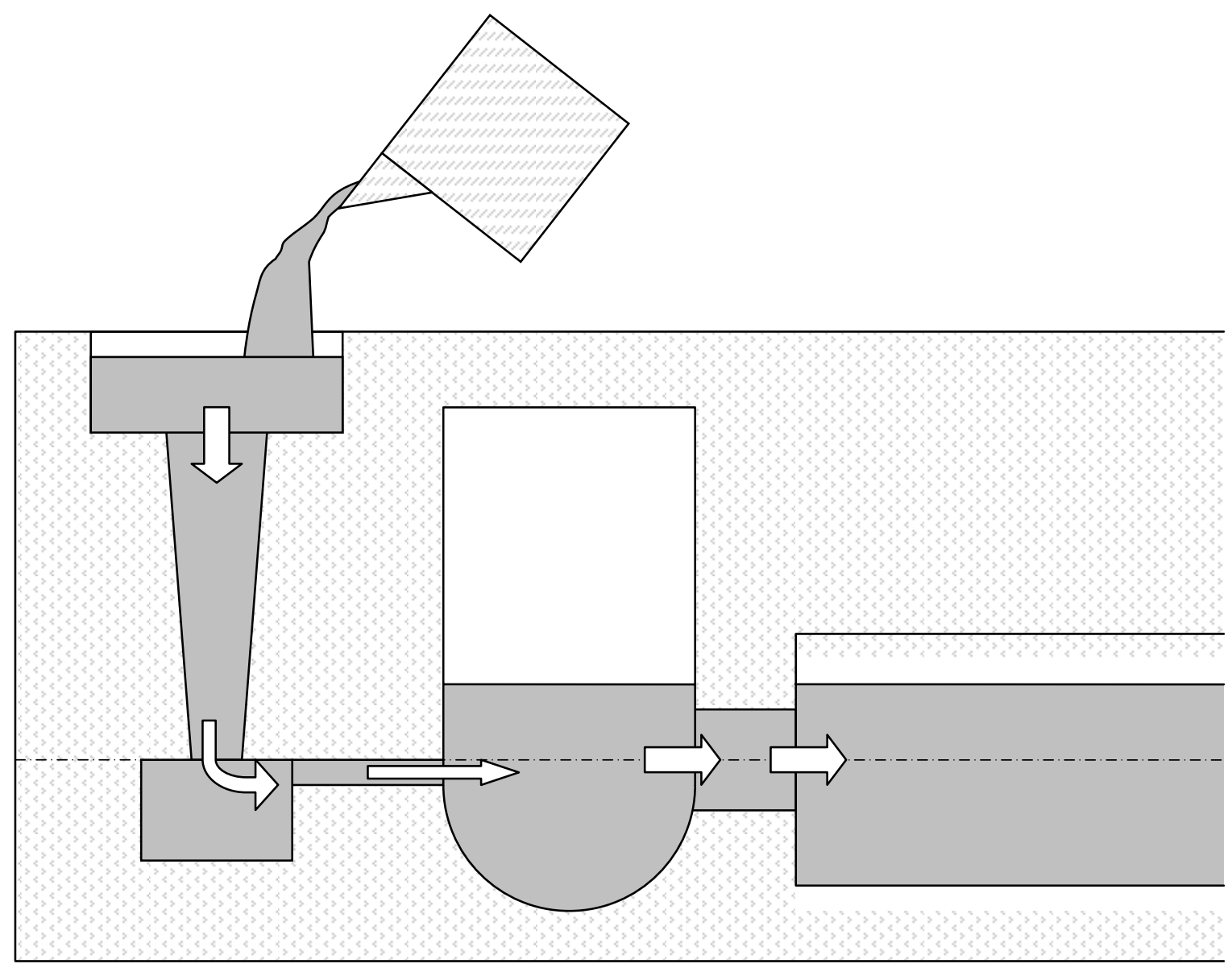

Figure 4.24: Sketch of the sequence of how liquid metal poured from the ladle enters the mold.

Almost all the required dimensions can be calculated by the Riser Design Wizard and the Gating Design Wizard, but there are some dimensions which need to be determined by the user. The following sections show the dimensions calculated and the dimensions determined by the user.

\subsubsection{Dimensions from Riser Design Wizard}

\section{1) Riser Dimensions}

A side riser having a cylindrical shape with a diameter of 3.786 inches and a height of 5.679 inches with a hemispheric bottom with the same diameter as the cylindrical shape. 


\section{2) Neck Dimensions}

A cubic shaped neck with 2.114 inches on each side. But since the surface connecting the riser is not flat, 2.114 inches shall be the length of the neck measured from the casting surface to the closest position of the riser, assuming the modulus would not have significant change. The centerline of the neck would be placed at the centerline of the casting's thickness.

\subsubsection{Dimensions from Gating Design Wizard 1) Pouring Basin Dimensions}

The depth of the metal in the basin during pouring is 1.8 inches assuming that the pouring basin is 2 inches deep. The width and length of the pouring basin must be determined by the user. The width and length of the pouring basin was set at 2 and 3 inches respectively. It was aligned with the length on the $\mathrm{X}$-axis to minimize the total mold size. A rectangular box shape with dimensions 3 by 2 by 1.8 inches was assigned as "fill material" which would represent a full pouring basin at the start of simulation. The term "fill material" in SOLIDCast is basically the same kind of material as the casting material but would be defined in the simulation as the position where the liquid metal enters the mold. In this case, the pouring basin made from fill material would signify the simulation would start with a full pouring basin.

\section{2) Sprue Dimensions}

The calculated diameter for the top of the sprue is 0.778 inch and the calculated diameter for the bottom of the sprue is $0.565 \mathrm{inch}$. The height of the sprue is the height of liquid metal in the pouring basin from the bottom of the sprue during filling less the depth of metal in the pouring basin, which is 5.2 inches ( 7 inch -1.8 inch).

\section{3) Sprue Well}

The dimensions of the sprue well could not be found from the Gating Design Wizard, so, it must be calculated by the user. The recommended shape of a sprue well is cylindrical with a diameter twice the diameter of the sprue exit and a depth of 1.5 times (Ravi, 2005) or twice (Campbell, 2004) the depth of the runner. In this particular case, 
the runner was neglected, so the ingate becomes the runner. The calculated diameter and depth of this sprue well should be 1.13 inch $(2 \times 0.565$ inch $)$ and 0.353 inch $(1.5 \times 0.235$ inch) respectively, but these dimensions do not seem appropriate for this particular casting as the calculated diameter of the sprue well is smaller than the width of the ingate. So, the diameter of the sprue well was adjusted to match the width of the ingate instead, which is 1.174 inch. For the depth of the sprue well, it seems acceptable to use the calculated runner area for calculation. If the runner would have had a square shaped cross-sectional, each side would have measured 0.571 inch $\left(\sqrt{ } 0.326\right.$ square nch $\left.^{1 / 2}\right)$. So, the depth of the sprue well may be calculated as 1.5 times the calculated length of one side of calculated runner area, which is 0.856 inch $(1.5 \times 0.571)$.

\section{4) Ingate to Riser}

The calculated gate connection area has a thickness of 0.235 inch and a width of 1.174 inch. The length of the gate from the sprue well to the riser is unknown and must be determined by the user. Normally, the ingate should have a length of at least the width or thickness whichever side is longer. In this case, the length of the ingate is equal to the calculated width.

\subsection{Simulation Results and Analysis of Simple Casting Design}

After drawing the casting model with the calculated dimensions, both from the Riser Design Wizard and Gating Design Wizard programs and the user-defined dimensions, the finished casting model is shown in Figure 4.25. The pouring basin was made from "fill material" and the risering and gating system were made from "riser material". Fill material is made of casting material indicating the position where liquid metal enters the mold. Riser material indicates shapes made of casting material but not part of the casting. 


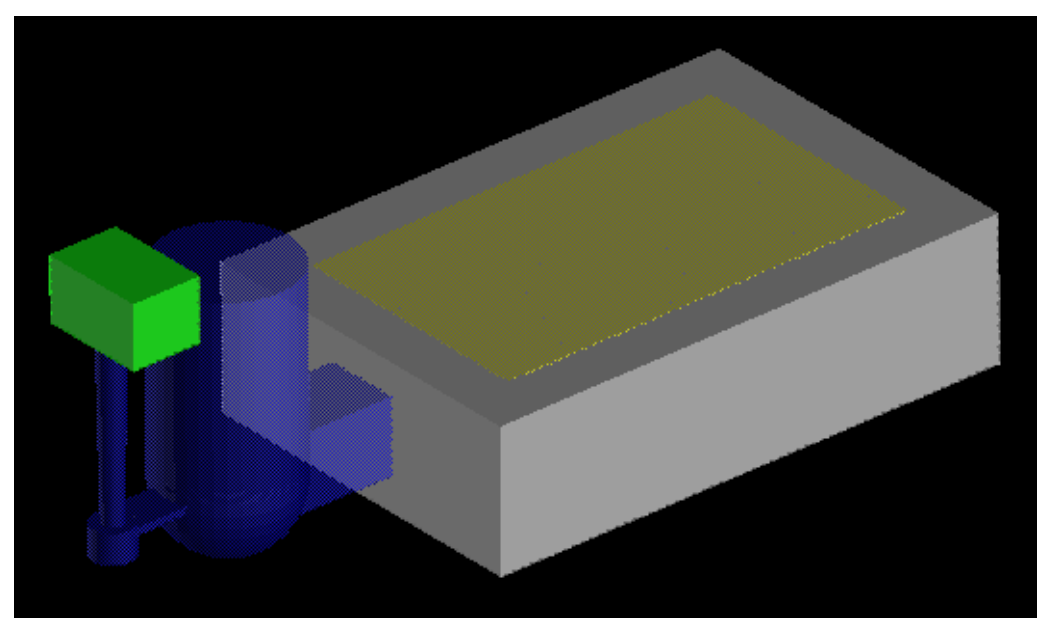

Figure 4.25: Casting model in SOLIDCast using all calculated and user-defined dimensions.

Next, the parameters in the Material List window must be set to represent the casting model. The parameter values in the Casting tab are similar to the settings in the Case Study in Chapter 5, except for the fill time which was calculated to be 24 seconds, as shown in Figure 4.26. In the Mold tab, only silica sand was selected for the mold material to be used in the model. The Curves tab was set to represent this particular casting model using values from the VDG Iron Properties Calculator which was used earlier. The values from the calculator were 77.48 percent of shrinkage time in percent of solidification and 3.72 percent contraction. So, the shrinkage curve was set to start shrinking from pouring down to 4.7 percent contraction (3.7 percent contraction added one percent due to mold dilation) at 77 percent of shrinkage time in percent of solidification, then start expanding with a rate of 0.5 percent expansion for every 10 percent of shrinkage time in percent of solidification. The critical fraction solid point and Niyama point were set at 82 and 87 percent of shrinkage time in percent of solidification respectively. The Curves tab setting is shown in Figure 4.27. 


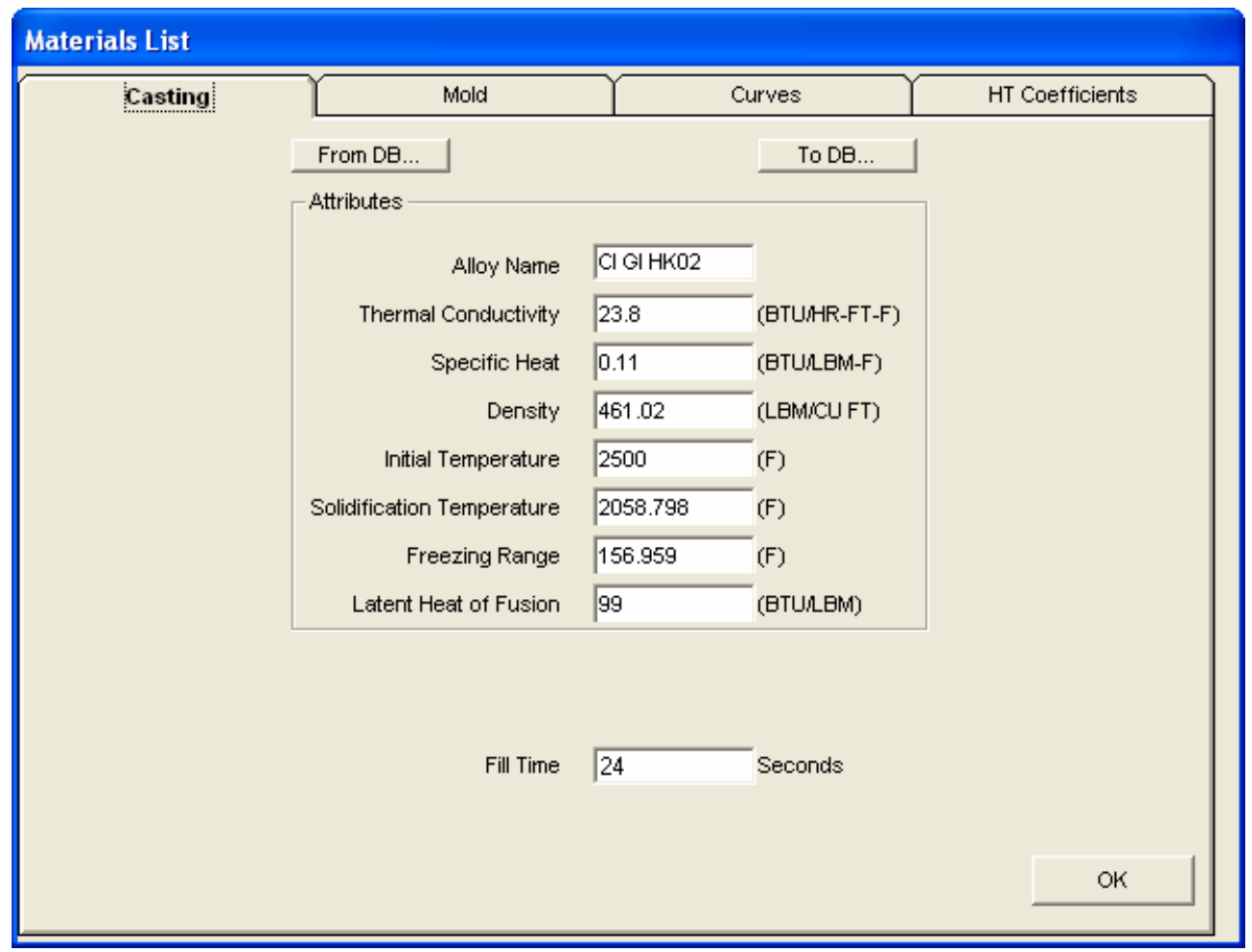

Figure 4.26: The Casting tab set with values representing the casting model.

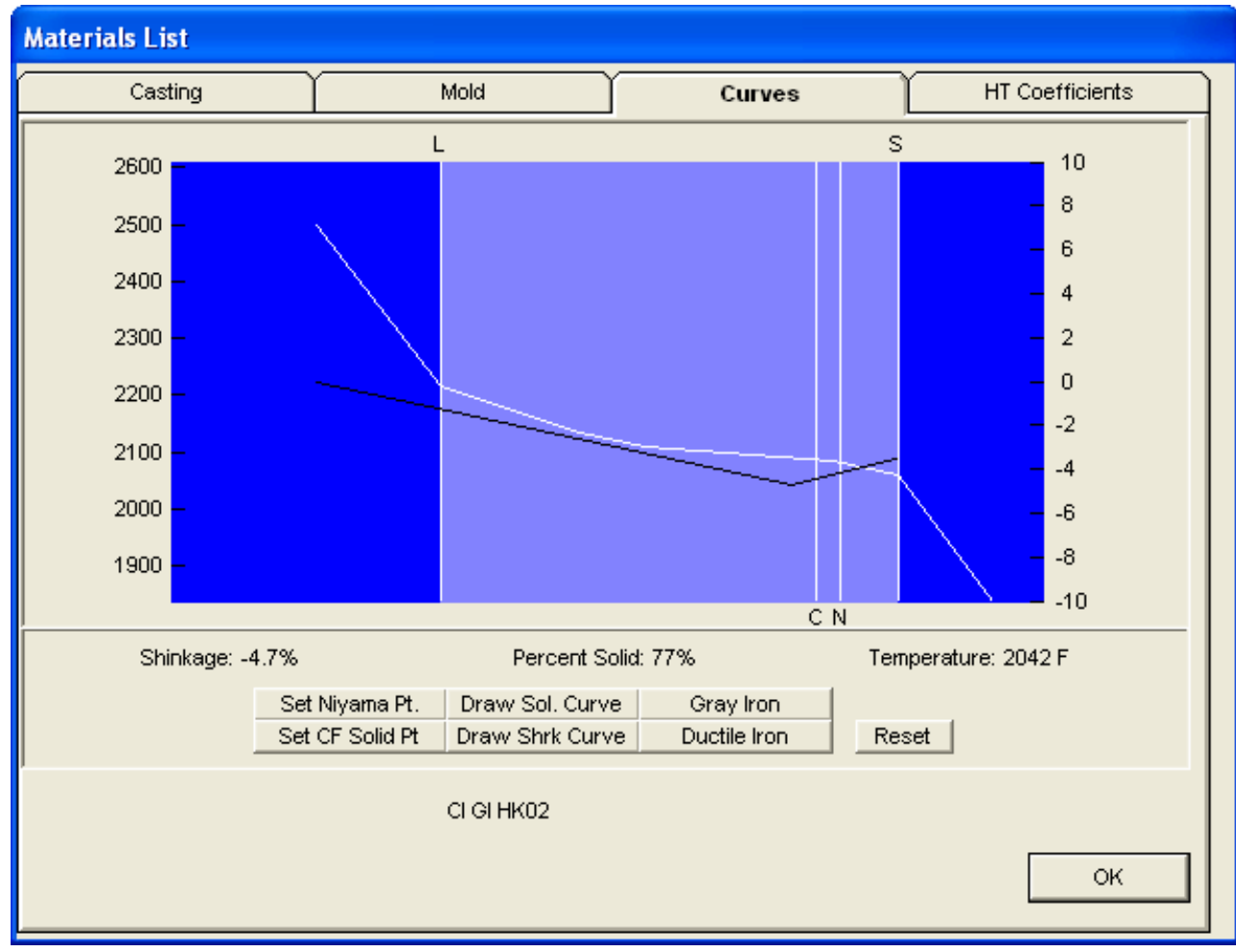

Figure 4.27: The Curves tab set with values representing the casting model. 
The thinnest section of the casting design is the ingate, which is $0.235 \mathrm{inch}$. There should be at least 5 nodes representing a casting section, so, the primary selected node size is 0.047 inch $(0.235 \div 5=0.047)$. But due to the limitations of the program, the number of nodes could not exceed the recommended maximum number of nodes, so, the node size achieved was actually 0.0546 inch. But even though the meshed model was achieved with a node size of 0.0546 inch, the simulation failed twice, so, the final node size achieved in the simulation was 0.078 inch, which gives 3 nodes representing the thinnest section of the casting. Figure 4.28 shows initial mesh creating window and Figure 4.29 shows the calculated weights of the materials in the model after final meshing. The total weight of the casting material is 97.713 pounds from 70.601 pounds of the casting, 24.273 pounds of the "riser material" and 2.839 pounds of the "fill material", which is very close to the estimated 100 pounds of casting material used in the calculation of the optimal fill time or fill time in the Gating Design Wizard.

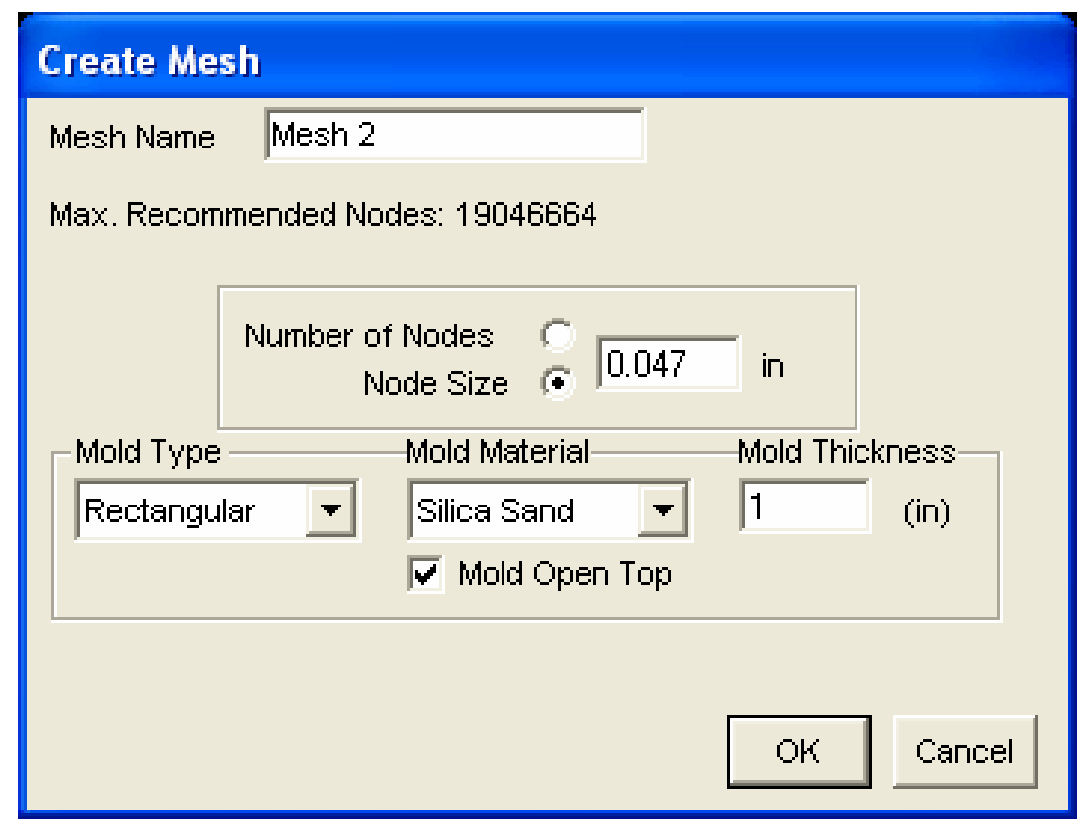

Figure 4.28: The mesh creating window. 


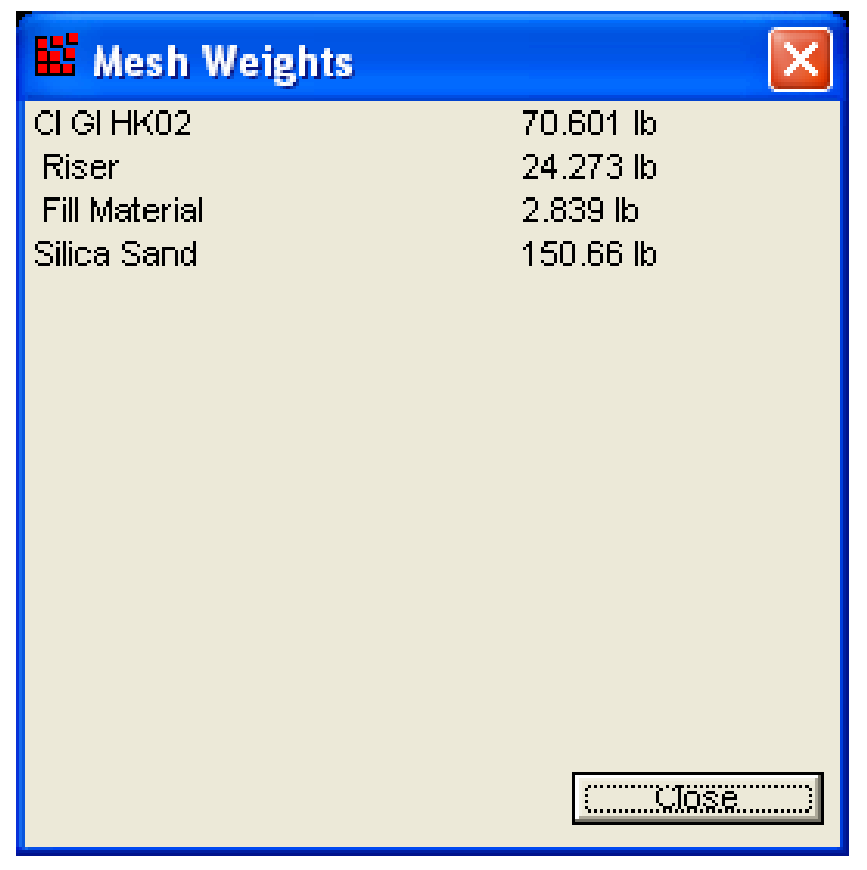

Figure 4.29: The calculated weights of the materials in the model after meshing.

The simulation output criterions that shall be used for analyzing the simulation results for this casting model are the Critical Fraction Solid Time, Material Density Function, FCC Criterion and Hot Spot Criterions. It was found in the Critical Fraction Solid Time plots that the casting started reaching the critical fraction solid temperature at 0.469 minute after the mold is completely filled or pouring. The sprue and the ingate dropped lower than the critical fraction solid temperature at around 2 minutes after pouring. The casting then slowly solidified towards the riser leaving some isolated spots in the inner corners of the far side of the casting across from the sprue and riser. Figure 4.30 shows the Critical Fraction Solid Time plots plotted at 10, 10.5, 11, 11.5, 12 and 12.5 minutes after pouring. Figure 4.31 shows the cut-plane plots of the Critical Fraction Solid Time criterion. It could be seen that the thermal center of the casting is in the riser. 


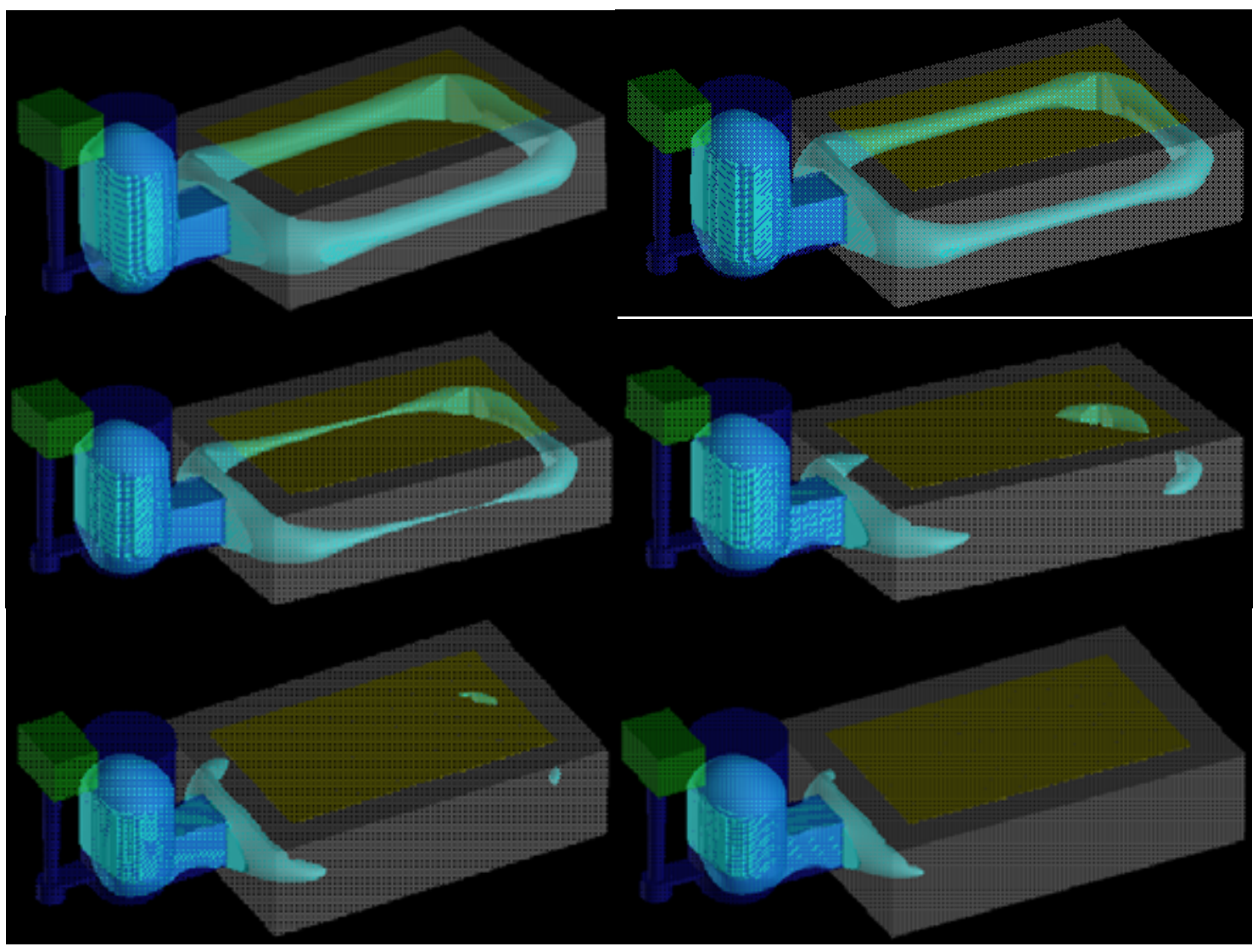

Figure 4.30: Critical Fraction Solid Time plots plotted at 10, 10.5, 11, 11.5, 12 and 12.5 minutes after pouring.

The Material Density Function plots show no signs of macroporosity in the casting at all, as shown in Figure 4.32, but the FCC Criterion plots show possible microporosities or centerline shrinkage in inner corners of the far side of the casting across from the sprue and riser, the centerline of the far side of the casting and the centerline of the sides of the castings, as shown in Figure 4.33. The shrinkages highlighted in the FCC Criterion plots possibly occurred from local hot spots as the highlighted areas are very similar to the Hot Spot Criterions plots shown in Figures 4.34 and 4.35, especially the Hot Spot Criterion calculated from Critical Fraction Solid Time shown in Figure 4.34. 


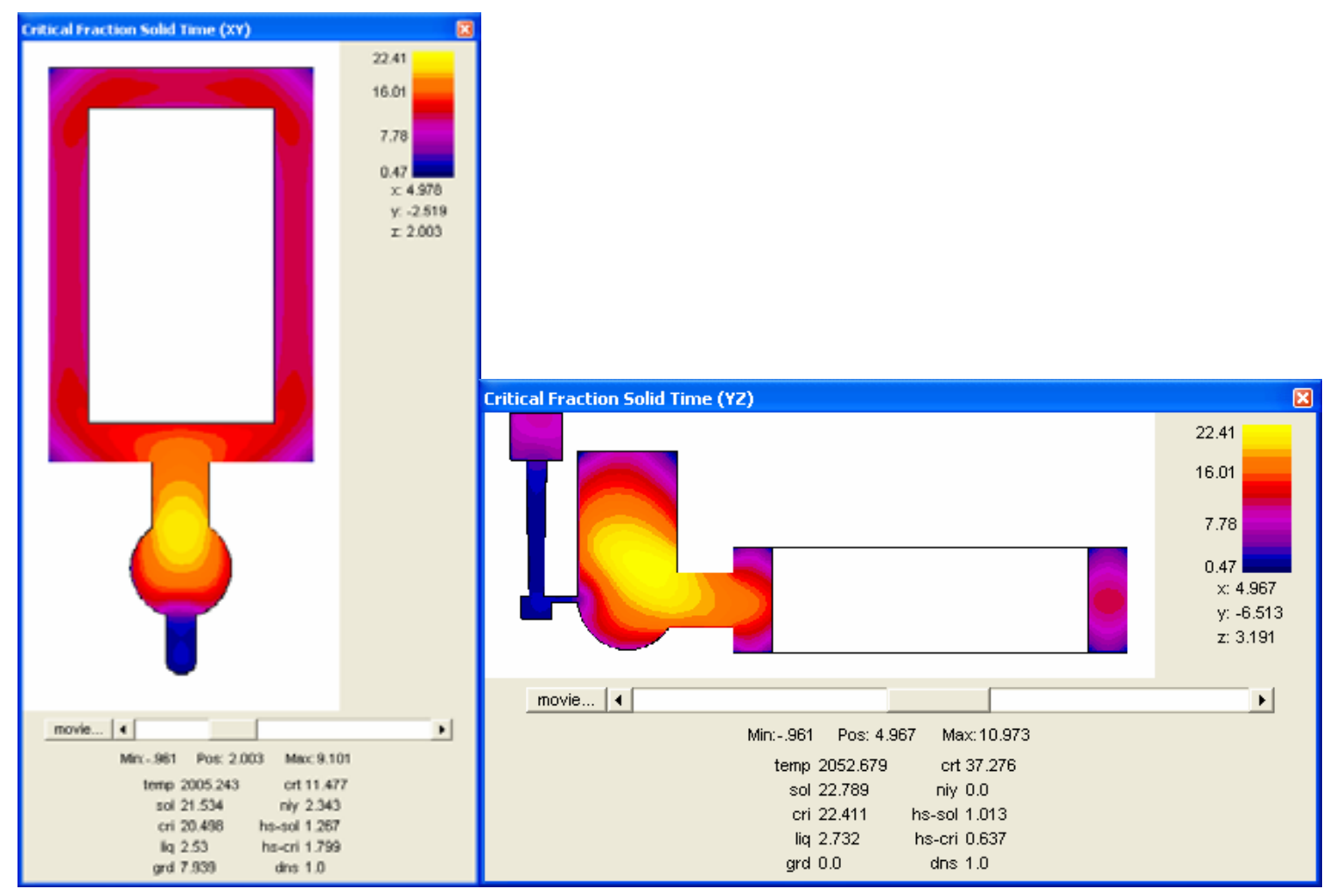

Figure 4.31: Cut-plane plots of the Critical Fraction Solid Time criterion.

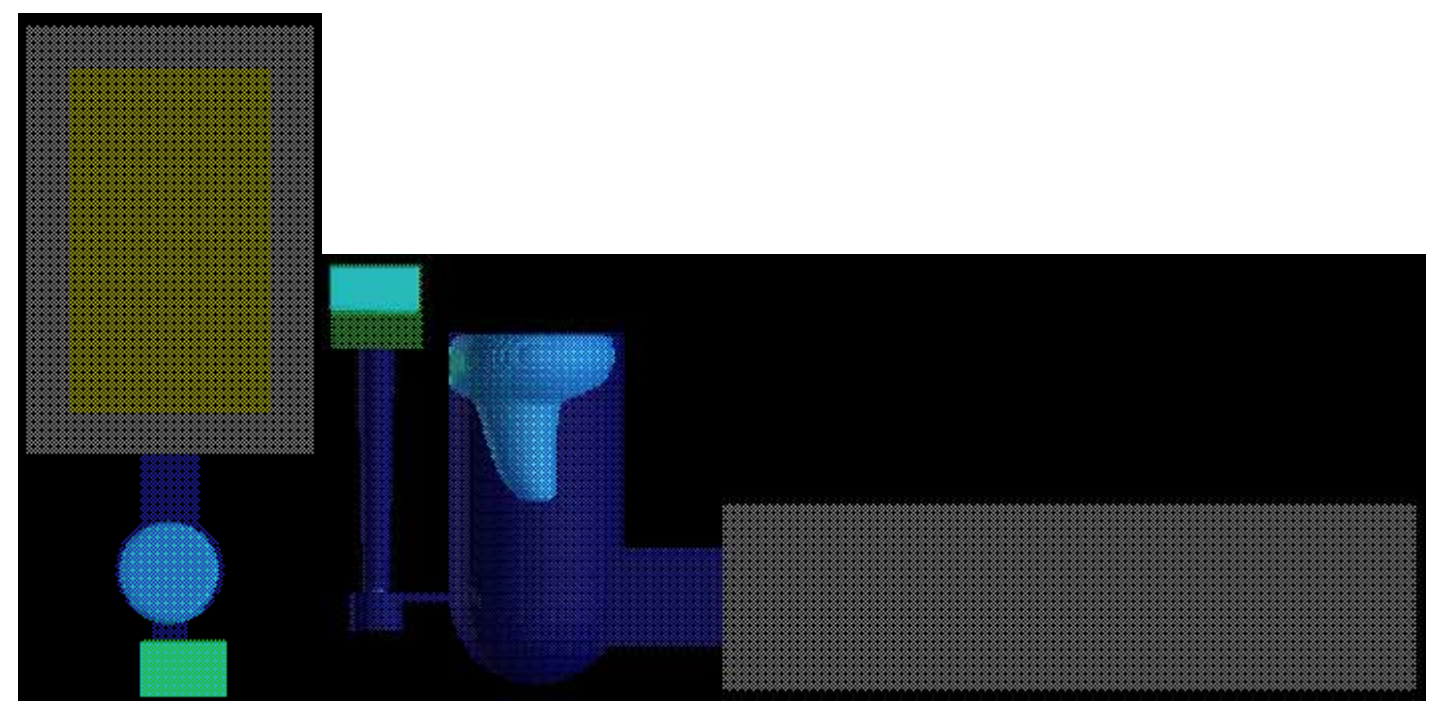

Figure 4.32: Material Density Function plots plotted at 0.995. 


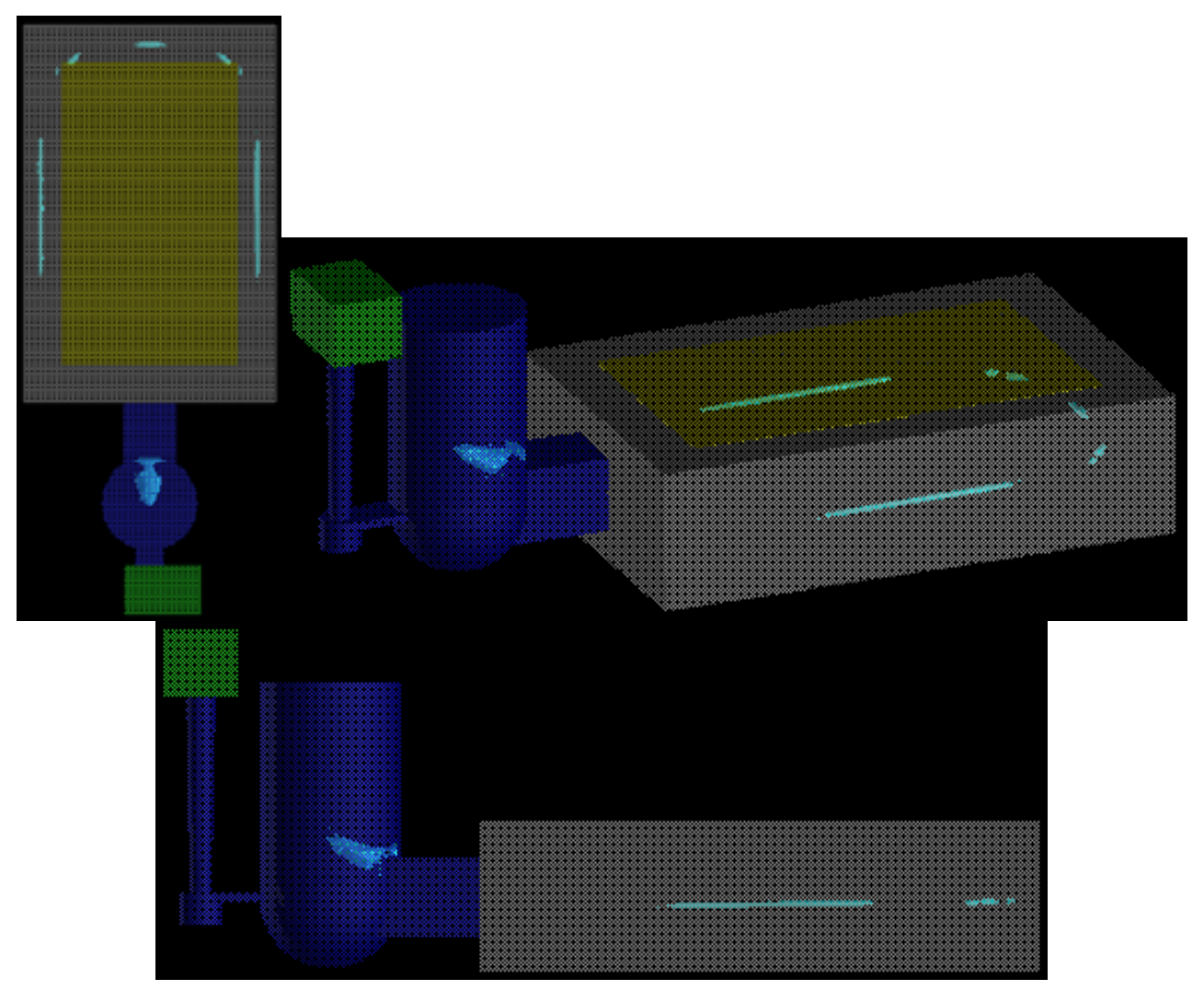

Figure 4.33: FCC Criterion plots.

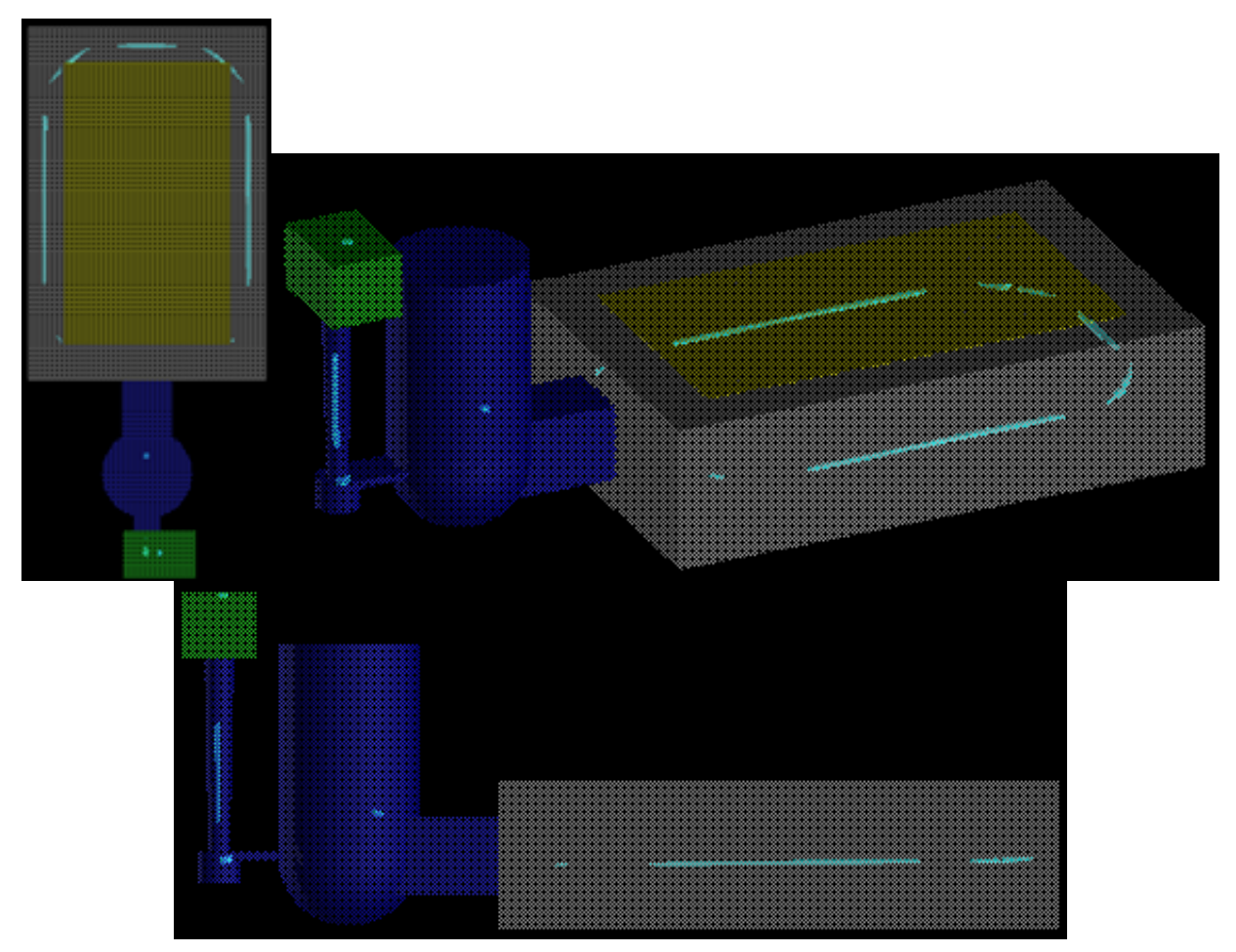

Figure 4.34: Hot Spot Criterion calculated from Critical Fraction Solid Time. 


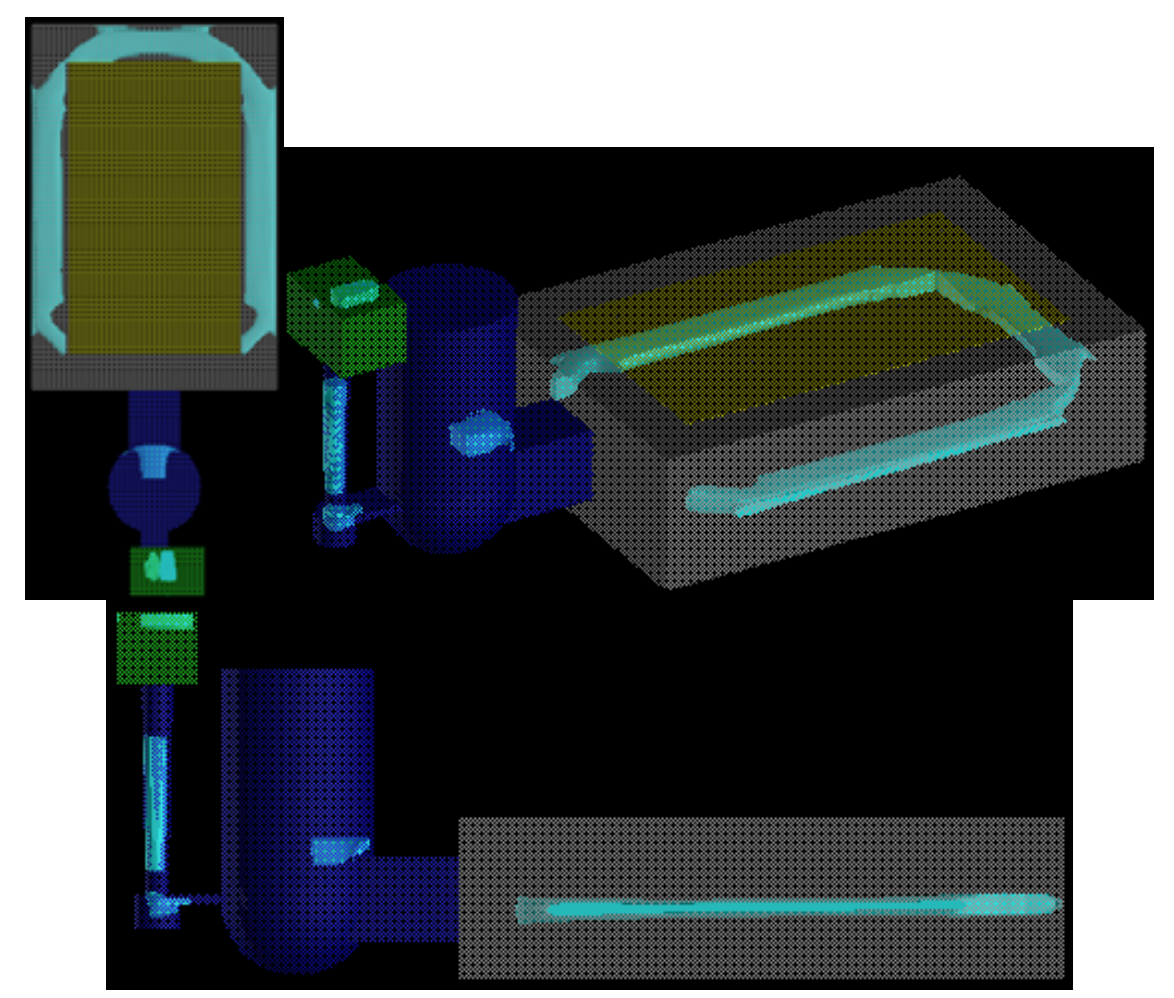

Figure 4.35: Hot Spot Criterion calculated from Solidification Time.

\subsection{Conclusions}

The Riser Design Wizard and the Gating Design Wizard programs are both very useful in designing the initial riser and gating dimensions for a casting, but they do not always provide a flawless casting design, for example, there may be some predicted macroporosity or microporosity problems. The user must use his or her own judgment in improving the casting design, for example, by changing the riser type or its position, redesigning the gating alignment or gating type, adding chills or altering the casting design to not have sharp corners, etc. So, instead of a user having to calculate for the riser and gating sizes by hand for an initial riser and gating design, these two built-in programs can assist the user in designing the initial riser and gating systems. They are also useful in the cases that the user does not know the formulas to calculate for appropriate riser and gating systems dimensions. Not all dimensions for designing the riser and gating systems are given by the program and must be defined by the user, such as the sprue well dimensions, the appropriate sprue height, the dimensions of the pouring basin, the length of the ingate, etc. Positions of laying down the risering or gating system 
are also not provided by the program. The user must decide on the layout of the casting and rigging system with his or her knowledge and past experience.

The method of calculating for the gating section areas from the choke area is wrong. The gating section areas calculated in the program are multiplications of the gating ratio values by the calculated choke area. In cases which none of the gating ratio values are equal to one, the calculated section areas would become wrong. The program also does not consider if the velocity of the liquid metal would be too high or not. The recommended limit of velocity of liquid metal is approximately half a meter per second for aluminum (Ravi, 2005) and also for most metals (Campbell, 2004), and one meter per second for iron (Ravi, 2005). 


\section{Chapter 5 \\ Using SOLIDCast: Case Study}

A case study was conducted to verify the use of SOLIDCast in an industry casting environment. The selected case study was a locomotive piston design made from gray iron by the HK Engine Components Casting Division, HK Engine Components, LLC. (HKEC).

The tests conducted in this case study used SOLIDCast to find potential defects in the casting model with different criterions and compare them with the real casting design and to find possible outcomes to modifications attempted to improve the existing casting design. The Riser Design Wizard and Gating Design Wizard programs in SOLIDCast were also used to try to improve the existing casting design and develop riser and gating systems for the casting from scratch and compare the calculated dimensions and resulting simulations with the existing casting design.

\subsection{Company Profile}

HK Engine Components Casting Division, HK Engine Components, LLC. (HKEC) is located at Weston, West Virginia, founded in 1989. Casting metals produced include ASTM A 48 and 278, Class 30 through 50 gray iron and ASTM A 536 and 395 ductile iron (www.hkec.com).

\subsection{Casting Design}

The casting design studied in this case study is a locomotive piston made from ASTM A48-76 Class 40 gray iron. Figure 5.1 shows a figure of the actual finished piston with machined ring grooves, a figure of a cut open piston from a similar model to the case study and a figure of a cut open view modeled with SOLIDCast. 


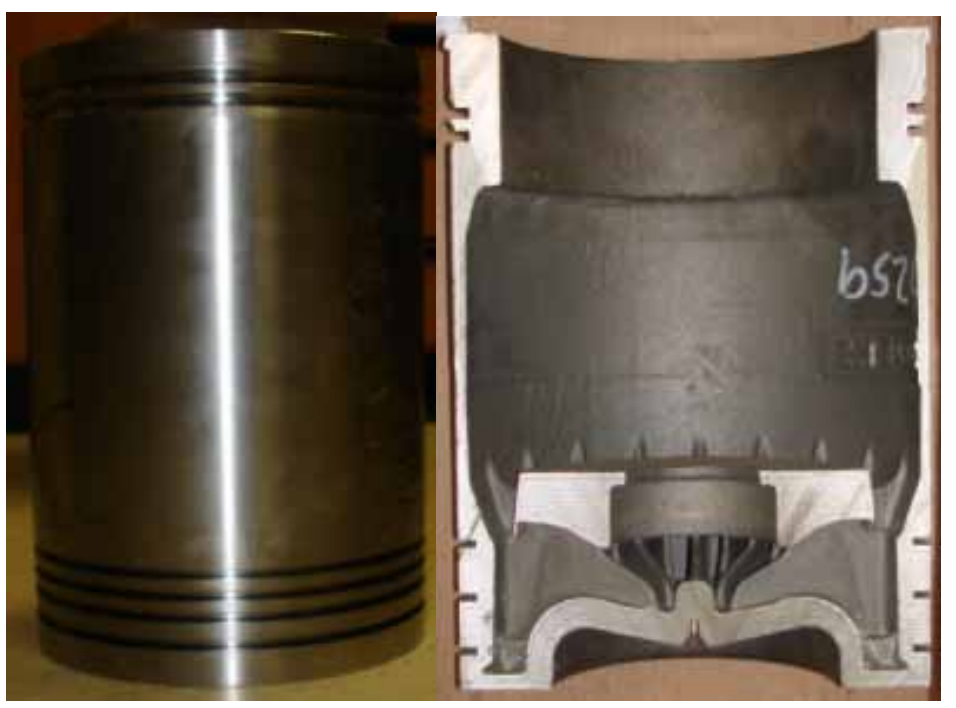

a) Machined piston

b) Sectioned piston

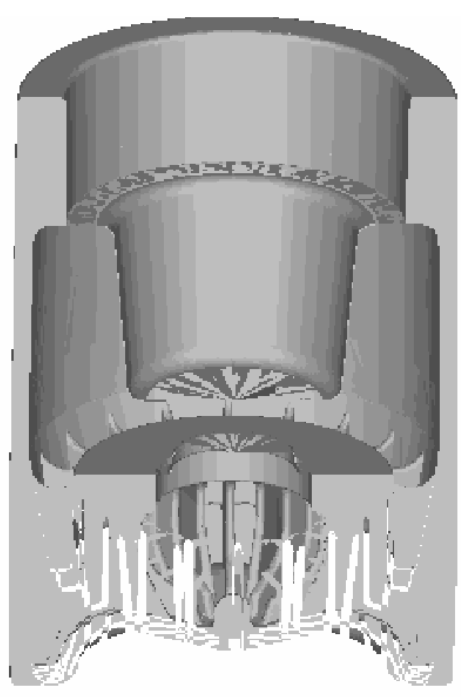

c) Model of section casting

Figure 5.1: Locomotive piston produced by HKEC.

\subsubsection{Pattern and Mold}

Currently, the casting company already has a gating and riser design and is in use for producing this particular locomotive piston casting. The figures of the patterns for the cope and drag are shown in Figure 5.2 and the finished cope and drag molds are shown in Figure 5.3.

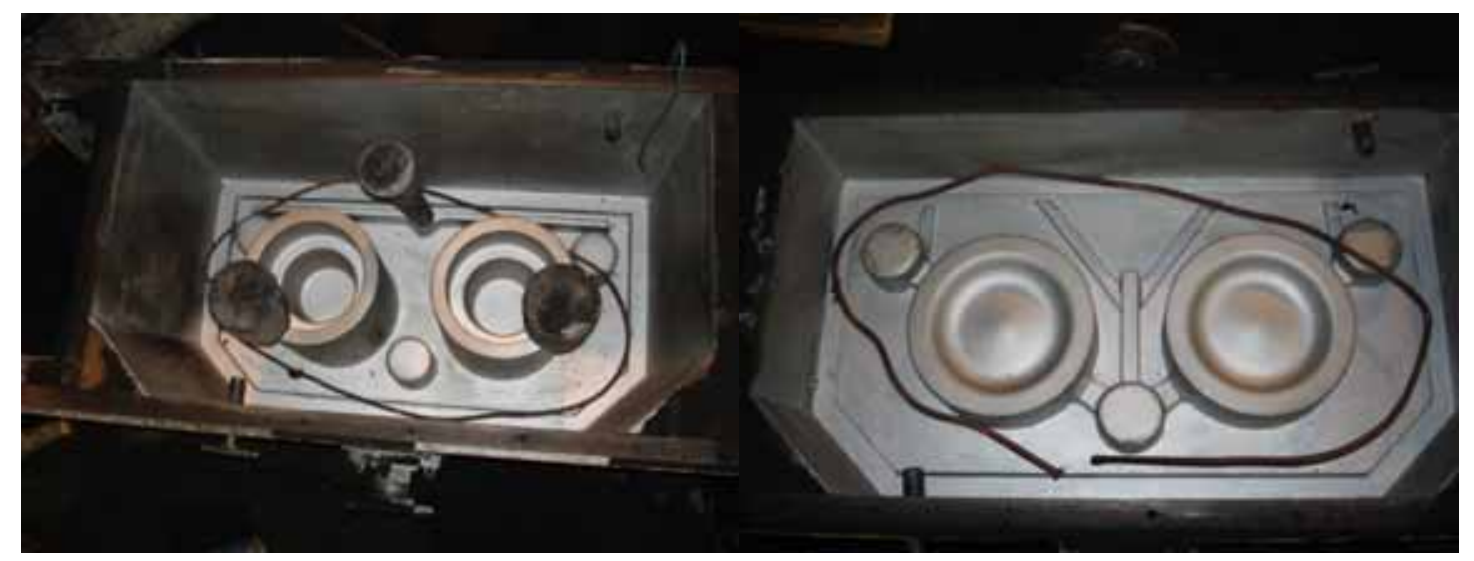

Figure 5.2: The cope pattern (left) and drag pattern (right). 


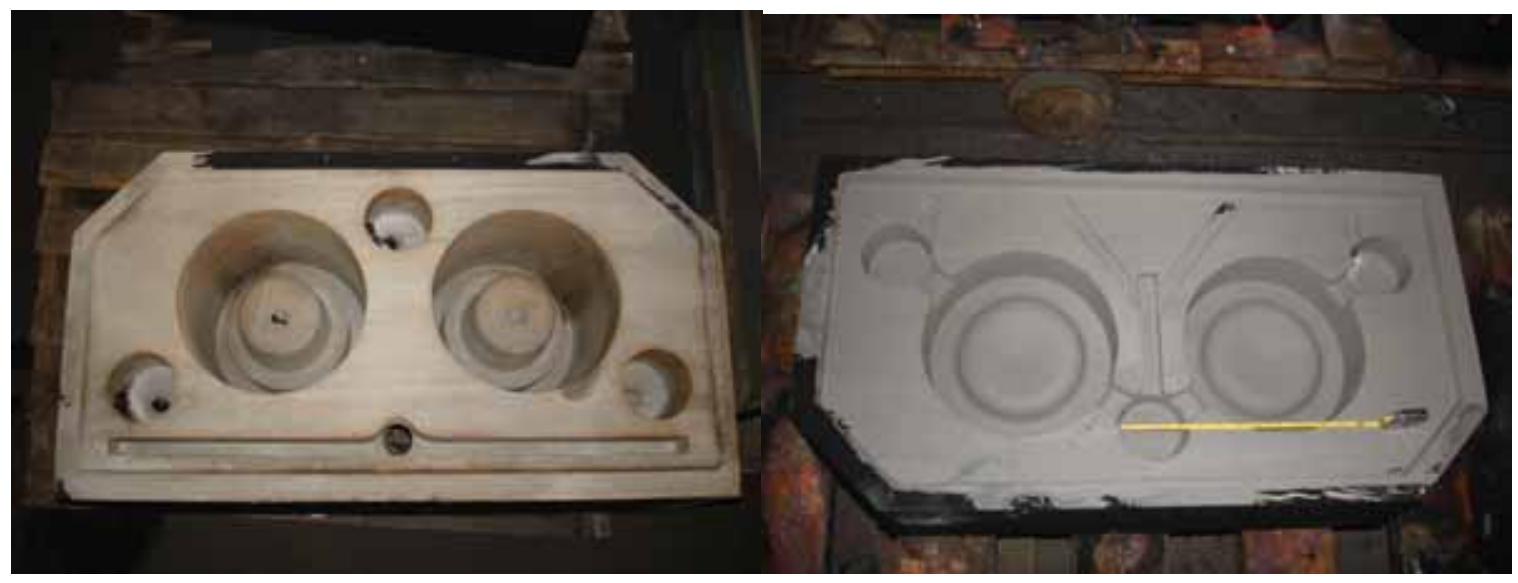

Figure 5.3: The cope mold (left) and drag mold (right).

The cope and drag are flow coated with alcohol based graphite wash before assembly. The blind risers' cavities in the cope would be drilled up to the surface of the cope with a diameter around half an inch so the air inside the risers would be able to escape.

\subsubsection{Core System}

The core system that is used in the casting is actually two cores assembled together with a glue paste. The assembled core is shown in Figure 5.4. From Figure 5.4, the upper core part is made from chromite sand and the lower core part is made from silica sand. They are glued to together and sprayed by water base graphite wash, then the upper core part will be painted with terillium wash which would help chill the casting and facilitate the formation of white cast iron in that particular area. The core would be torched to dry the coating and then carefully aligned and glued up-side-down onto the cope. 


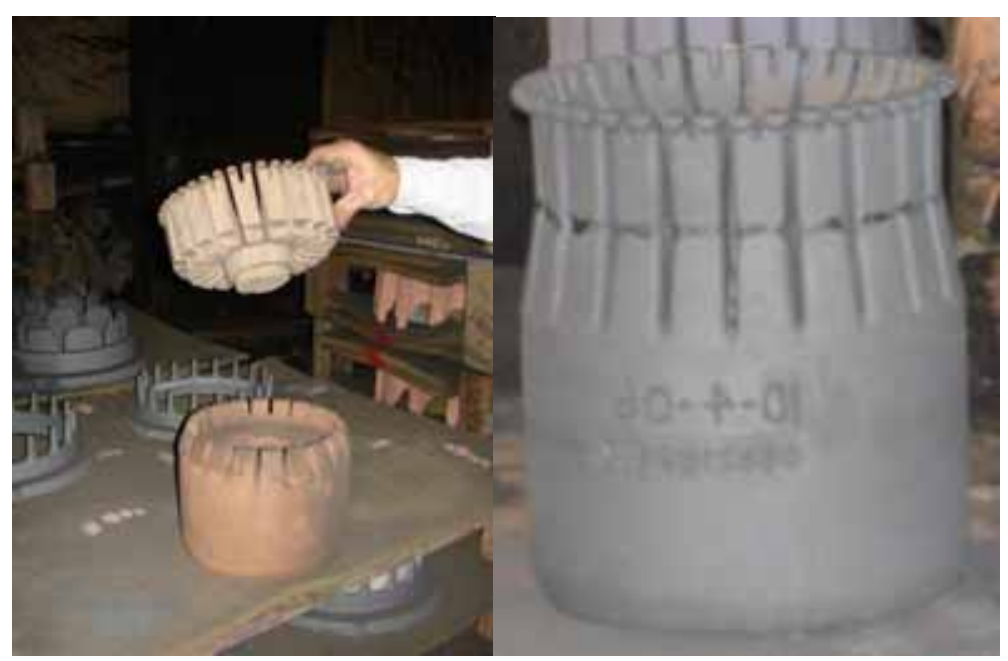

Figure 5.4: Core system.

\subsubsection{Assembled Mold}

After gluing the assembled core onto the cope, the cope will be placed on top of the drag and then the molten metal will be poured into the mold through the sprue. The two top risers are open risers, but were covered with magnesium based exothermic tops to keep the risers hot to feed the casting for an extended period of time. Figure 5.5 shows an assembled mold filled with liquid metal and top risers covered with the exothermic insulation. The exothermic insulation would be approximately 1.25 inches thick.

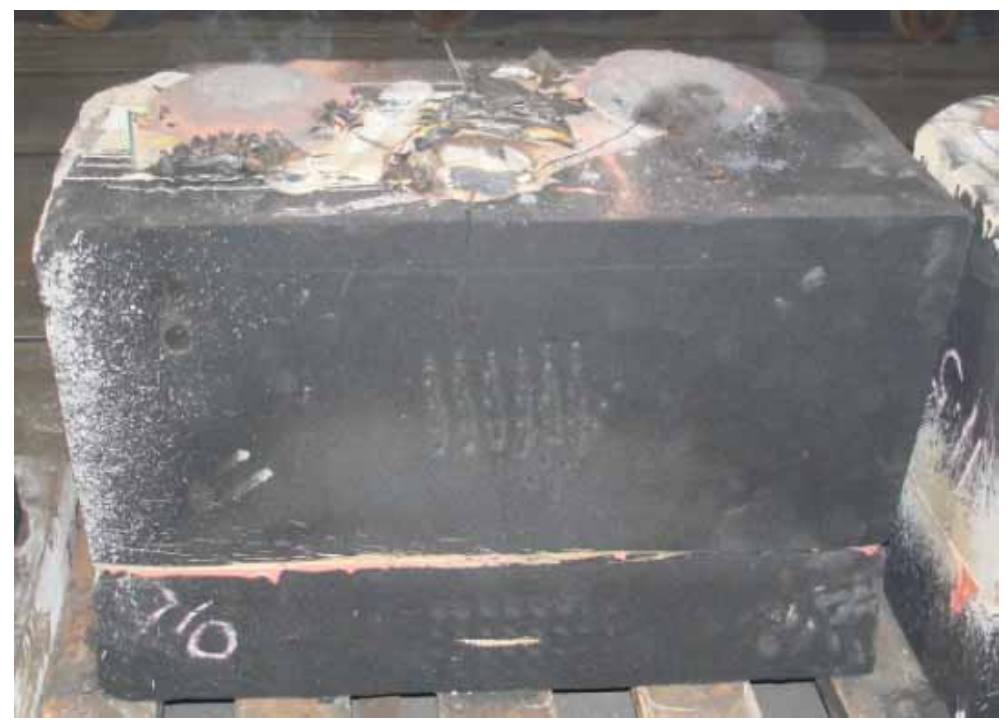

Figure 5.5: Assembled mold with liquid metal and magnesium based insulators covering top risers. 


\subsection{Dimensions of Mold Cavity}

The approximate dimensions of the mold cavity measured from the patterns and the mold are presented in Figures 5.6 and 5.7.

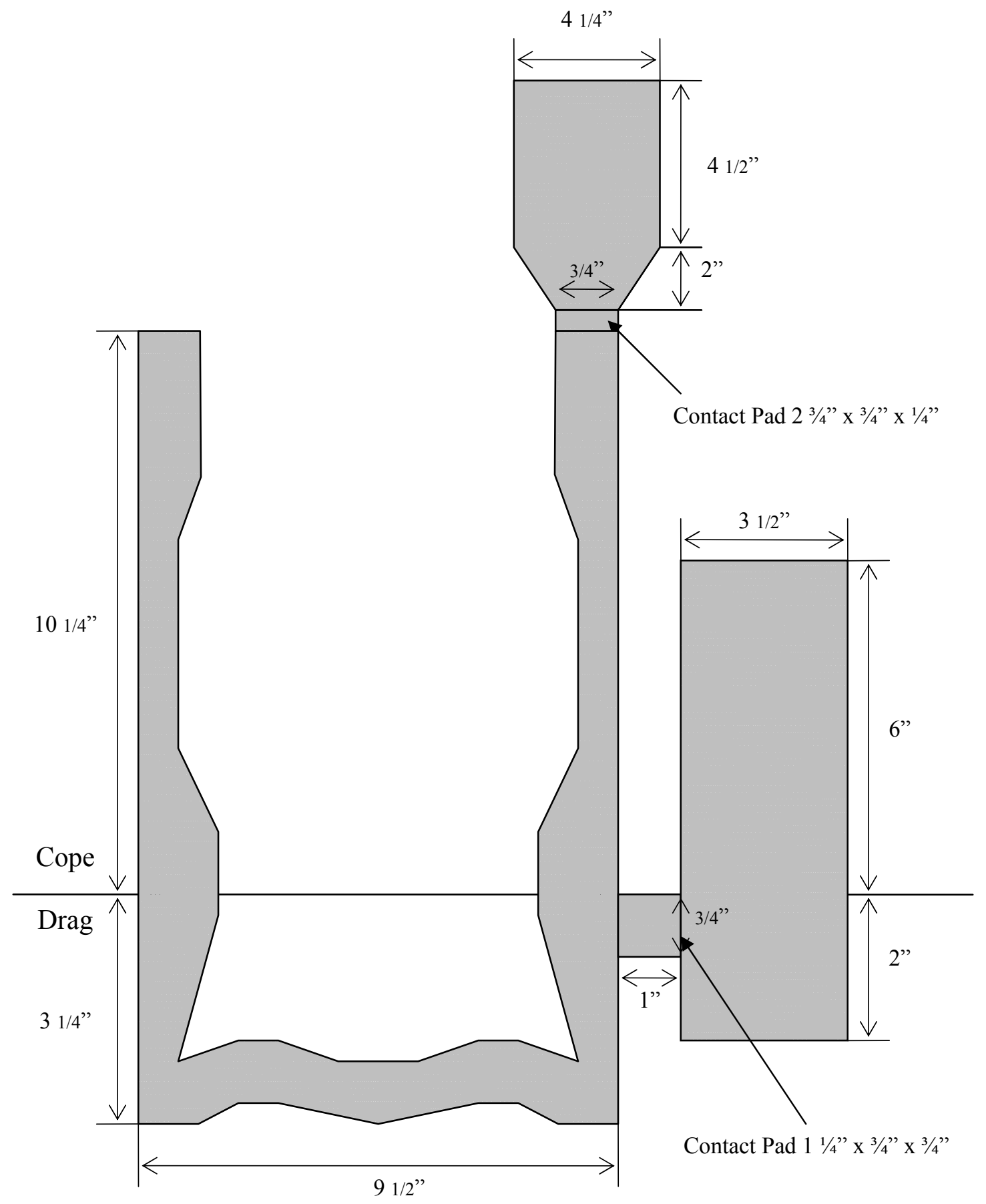

Figure 5.6: Dimensions of top and side risers of casting. 


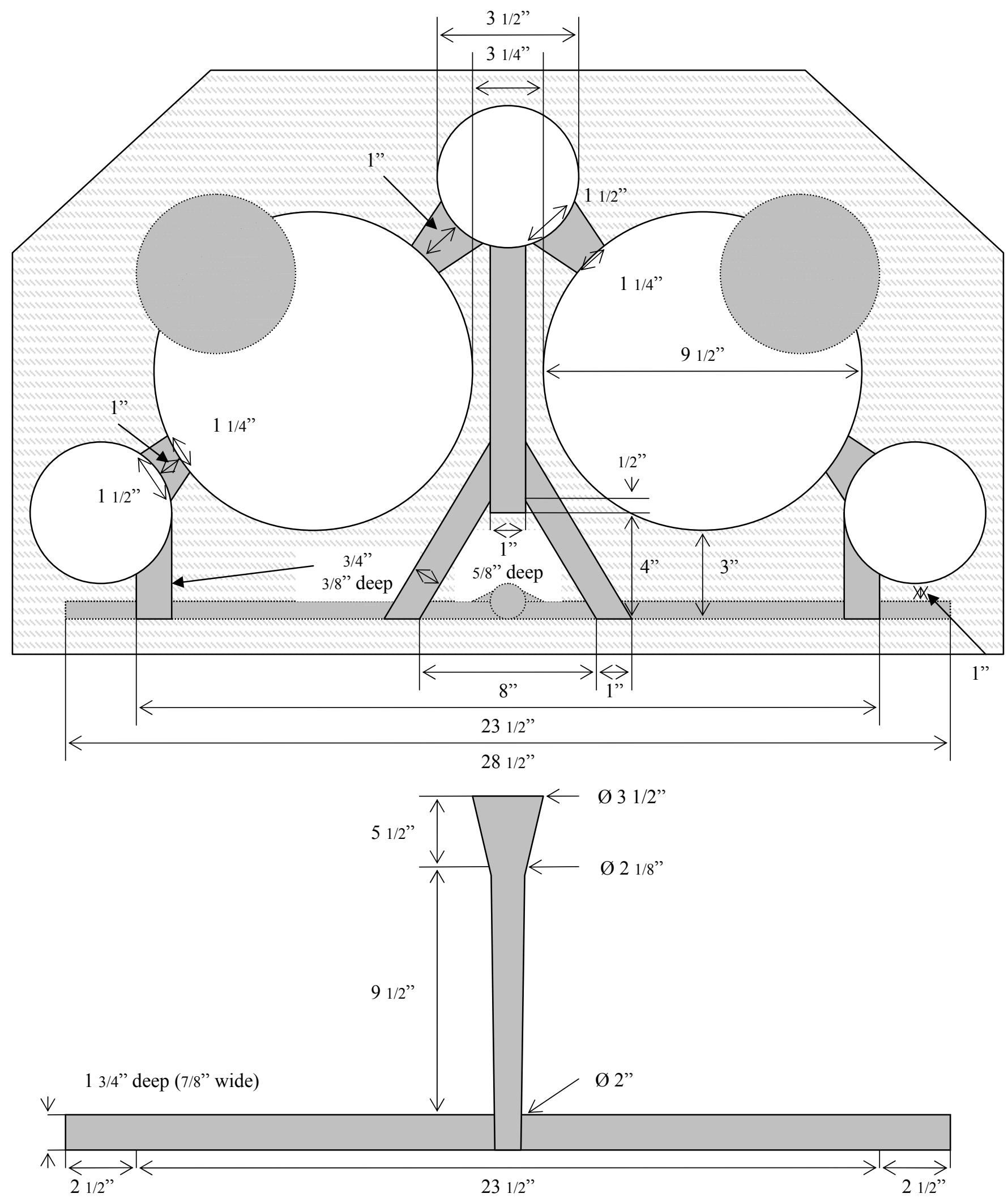

Figure 5.7: Dimensions of the mold cavity and gating system. 
In the upper portion of Figure 5.7, the white circles represent the casting cavities and riser cavities which appear in both the cope and drag molds, the gray shapes with bold lines would only appear in the drag while the transparent gray shapes with dotted lines only appear in the cope. The lower figure shows the dimensions of the sprue and its runner.

\subsection{Discarding a Part}

The defects that would force the company to scrap a part are found mostly in the ring groove areas; more likely in the upper thick ring area of the casting than the lower thick ring area and across the top riser than under it. The company claims that the lower thick ring area must have cooled down more rapidly than the upper thick ring area due to the terillium wash applied to the core placed inside the casting cavity. Also, there may be insufficient feeding from the top riser causing porosities to occur in the thick ring area across from the riser.

Another type of defect that would force the company to scrap a part is surface porosity occurring in the thin section of the casting. The porosities are very small and occasionally disappear between the rough cut and finish cut. The company would not scrap the part if there are no visual porosities showing after the final machining. There may be some internal porosity left in this area not discovered, but since they are considered to not affect the physical properties of the part, and the customer accepts parts with no cosmetic defects, the company finds no need to X-ray or check for internal defects.

The cylindrical surface of the casting would be machined off by almost half an inch, which is near the mid-point of the thin area of the casting. Also, the grooves made by the milling process would approximately reach the mid-point of the thick ring areas and the porosities may be found in these areas. The company believes that these porosities may have occurred from centerline shrinkage.

The rate of scrap is around 10 percent post-machining and the scrap would be remelted and used for producing new castings. Since the scrap rate is not high, the defects detected by SOLIDCast should not be high. 


\subsection{Modeling the Casting Design in SOLIDCast}

A user must model a casting in SOLIDCast which best represents the casting design. Many types of materials were used in this casting design; the gray iron used as the casting material, chemically bonded silica sand used as the primary mold material, the core pieces made from silica sand and chromite sand, graphite and terillium washes, and magnesium based exothermic insulators. Most of the materials in this casting design could be found in SOLIDCast. The gray iron material in SOLIDCast was modified to match the properties of the gray iron used as the casting material, silica and chromite sand were used directly without modifications, the exothermic material in SOLIDCast was adjusted to represent the magnesium based exothermic insulator material, but the graphite and terillium washes were not able to be added to the model due to node sizing limitations.

At first, it seemed possible to increase the thermal conductivity of the silica and chromite sands so they would represent the more rapid cooling effects from the graphite and terillium washes, but it was not appropriate to randomly adjust the thermal properties of a material. After consulting with Mr. David Schmidt of the Finite Solutions Inc., heat transfer is affected mostly by the properties of the sand, so, the graphite wash and terillium wash coatings were neglected in the model. If a model must have a wash

applied to it, the node size must be small enough to represent the very thin layer of the wash and the heat transfer coefficient values between each material must be set in the Heat Transfer Coefficients tab in the Materials List window.

\subsubsection{Modeling of Shapes}

The model of the casting consisted of three .stl CAD files; the casting cavity in the cope and drag, and the two core pieces made from silica and chromite sand. Combined together, they formed the complete casting cavity. The files were provided by the Humtown Products of the HK Engine Components, LLC. The casting was made from the ASTM A48-76 Class 40 gray iron, the upper core piece was made from silica sand and the bottom core piece was made from chromite sand. Each CAD file was added to the model with the appropriate materials and properties. 


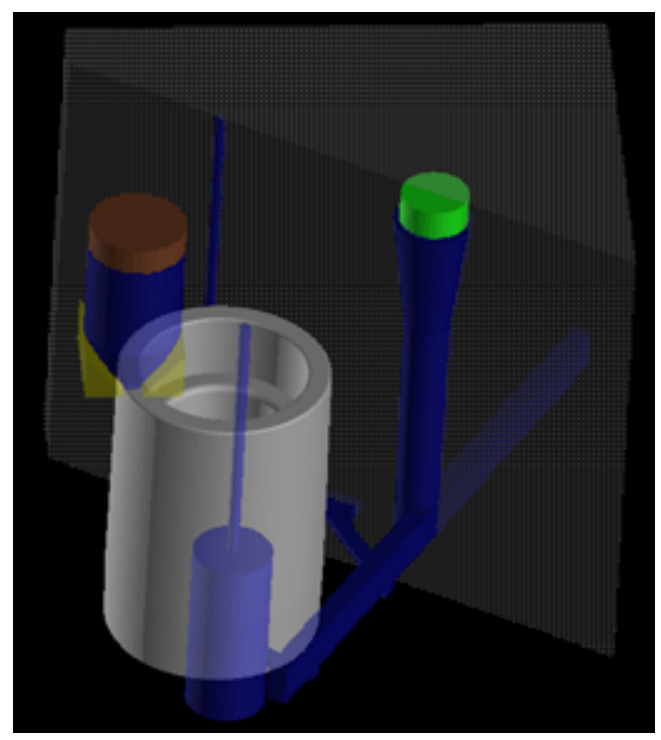

Figure 5.8: Half of the model created in SOLIDCast with Plane of Symmetry function.

After adding the casting and its core parts, the gating and riser systems were added to the model using the dimensions measured at the casting facility, shown in Figure 5.6 and 5.7, added the drilled holes through the blind risers. But since the program had a function called the Planes of Symmetry in the Options tab of the Model menu, this case study used this function to build half of the model. Another advantage to using this function was that smaller nodes could be used, so, the model would be more detailed and simulation results could be more accurate. Figure 5.8 shows the half model created in SOLIDCast. There were slight differences between the model and the casting design, such as, the side risers were tapered at the parting line for easy removal, the ingates were tapered and the total height of metal in the sprue was increased. Modeling tapered risers and ingates in SOLIDCast were difficult and they were considered to not affect the simulation results. The exothermic top was added on top of the top riser, but adding the exothermic top to the model, the total height of the mold would increase due to the meshing method of the program. Extra casting material was added to the top of the sprue to represent the top of the sprue is open to the atmosphere. The extra casting material was modeled as fill material which would represent where liquid metal would enter the mold. Since SOLIDCast is not able to simulate pressure and the extra metal is considered minimal, it was considered that the added height of metal in the sprue would not affect the simulation results. 


\subsubsection{Casting Material}

The next important step to do in a simulation is to set the primary parameters properly, which are the parameters in the Materials List window. The attributes of the casting material in the Casting tab, the mold materials in the Mold tab, the temperature and shrinkage curves along with the CFS and Niyama lines in the Curves tab and the heat transfer coefficients in the Heat Transfer Coefficients tab in the Materials List window were set up. The characteristics of the casting material were researched to find the appropriate values to set the attribute values in the Casting tab in the Materials List window and the graph in the Curves tab.

The casting alloy used was ASTM A48-76 Class 40 gray iron which specifications for the casting alloy for this product in weight percent are:

$\begin{array}{ll}\text { Total Carbon } & \text { between } 3.00 \text { to } 3.50 \text { percent } \\ \text { Silicon } & \text { between } 1.80 \text { to } 2.40 \text { percent } \\ \text { Manganese } & \text { between } 0.60-0.90 \text { percent } \\ \text { Sulfur } & 0.15 \text { percent maximum } \\ \text { Phosphorous } & 0.15 \text { percent maximum } \\ \text { Nickel } & 0.50 \text { to } 1.20 \text { percent maximum } \\ \text { Chromium } & 0.50 \text { percent maximum } \\ \text { Molybdenum } & 0.40 \text { to } 0.70 \text { percent } \\ \text { Copper } & 0.20 \text { to } 0.80 \text { percent } \\ \text { Vanadium } & 0.10 \text { percent maximum }\end{array}$

The grades of gray iron in the SOLIDCast database were CI GI 3.5, 4.0 and 4.4 CE. These alloys were preset to approximately represent cast iron alloys with 3.5, 4.0 and 4.4 percent Carbon Equivalent. Normally, the user should start with selecting the gray iron grade with the Carbon Equivalent closest to the alloy desired. But from tests conducted, the three grades of gray iron had the same temperature curve if input with the same weight percent carbon and silicon using the Gray Iron Calculator button in the Curves tab, so, the temperature curve of the alloy can actually be set with any of the three alloys. The shrinkage curve, critical fraction solid point and Niyama point can be set by 
using the VDG Iron Properties Calculator. As for other attributes in the Casting tab of the Materials List window, the default values of all three gray irons were observed. Table 5.1 shows the default values of each gray iron alloy in the Casting tab in the Materials List window.

Table 5.1: Default values of each attribute of each gray iron alloy in the Casting tab.

\begin{tabular}{|c|c|c|c|c|c|c|c|c|}
\hline $\begin{array}{c}\text { Alloy } \\
\text { Name }\end{array}$ & $\begin{array}{c}\text { Thermal } \\
\text { Cond. } \\
\mathbf{( B t u / h r -} \\
\mathbf{f t - F})\end{array}$ & $\begin{array}{c}\text { Specific } \\
\text { Heat } \\
\mathbf{( B t u / h r -} \\
\mathbf{f t - F})\end{array}$ & $\begin{array}{c}\text { Density } \\
\text { (lbm/cu.ft.) }\end{array}$ & $\begin{array}{c}\text { Initial } \\
\text { Temp. } \\
\mathbf{( F )}\end{array}$ & $\begin{array}{c}\text { Solidification } \\
\text { Temperature } \\
\mathbf{( F )}\end{array}$ & $\begin{array}{c}\text { Freezing } \\
\text { Range } \\
\mathbf{( F )}\end{array}$ & $\begin{array}{c}\text { Liquidus } \\
\text { Temperature } \\
\mathbf{( F )}\end{array}$ & $\begin{array}{c}\text { Latent } \\
\text { Heat } \\
\text { of Fusion } \\
\text { (Btu/lbm) }\end{array}$ \\
\hline CI GI 3.5 CE & 21 & 0.11 & 448 & 2,600 & $2,052.667$ & 229.315 & 2,282 & 99 \\
\hline CI GI 4.0 CE & 25 & 0.11 & 466.6 & 2,500 & $2,051.965$ & 136.285 & 2,188 & 99 \\
\hline CI GI 4.4 CE & 33 & 0.11 & 448 & 2,400 & $2,051.38$ & 75 & 2,126 & 99 \\
\hline
\end{tabular}

It can be seen from Table 5.1 that the values of the specific heat and latent heat of fusion of all three grades of gray iron are the same. It was possible to assume that all gray irons have approximately the same specific heat and latent heat of fusion.

The appropriate values must be assigned to the parameters in order to achieve the most accurate simulation results. In the specifications of the alloy in this case study, the total carbon and silicon percentages are between 3.00 and 3.50 percent and 1.80 and 2.40 percent respectively. The values used to represent the casting alloy were the mean values of the ranges in the specifications, 3.25 weight percent carbon and 2.1 weight percent silicon. From the specifications, the maximum weight percent for phosphorus was 0.15 percent and 0.075 weight percent phosphorus was used to represent the casting alloy.

The Carbon Equivalent value of this alloy was calculated as shown in equation $(5.1)$ :

$$
\begin{aligned}
\mathrm{CE} & =3.25 \%+(2.1 \% / 3)+(0.075 \% / 3) \\
& =3.975 \%
\end{aligned}
$$

The calculated Carbon Equivalent value is very close to 4.0 percent Carbon Equivalent, so, the CI GI 4.0 CE material was used to represent the casting alloy. It was found that the pouring temperature used for this particular casting is between 2,425 and 
2,575 degrees Fahrenheit. A simulation with the actual dimensions and a pouring temperature of 2,500 degrees Fahrenheit was conducted as the base case. Simulations with pouring temperatures of 2,425 and 2,575 degrees Fahrenheit were conducted to test the differences in the results of different pouring temperatures. Simulations with modified dimensions were all conducted with a pouring temperature of 2,500 degrees Fahrenheit.

From a later visit to the company, it was learned that the Carbon Equivalent value of the casting alloy was reduced to approximately 3.85 percent. The weight percent of carbon and silicon were reduced but kept the same weight percent value for phosphorus to achieve this lowered percent Carbon Equivalent value. The new weight percent values of carbon and silicon were calculated as shown in equations (5.2) through (5.6).

$$
\begin{aligned}
& 3.975=3.25+1 / 3(2.1+0.075) \\
& 3.975-0.025=3.25+(2.1 / 3) \\
& 3.95=3.25+(2.1 / 3) \\
& 3.85=\mathrm{C}+1 / 3(\mathrm{Si}+0.075) \\
& 3.85-0.025=\mathrm{C}+(\mathrm{Si} / 3) \\
& 3.825=\mathrm{C}+(\mathrm{Si} / 3) \\
& \mathrm{C} \quad=3.25 \times(3.825 / 3.95) \\
& =3.147 \% \\
& \mathrm{Si} \quad=2.1 \times(3.825 / 3.95) \\
& =2.034 \% \\
& \mathrm{CE} \quad=3.147+1 / 3(2.034+0.075) \\
& =3.85 \%
\end{aligned}
$$

Since the percent Carbon Equivalent value had changed, the density of the material changed as well. The calculations used in calculating the new approximated 
density of the casting alloy is shown in equation (5.7), assuming the density changes linearly.

$448+[(466.6-448) \times(3.85-3.5) /(4.0-3.5)]=461.02$ pounds per cubic foot

For the thermal conductivity, it was calculated in the same manner as equation (5.7), which is shown in equation (5.8).

$21+[(25-21) \times(3.85-3.5) /(4.0-3.5)]=23.8$ Btu per hour-foot- Fahrenheit

The filling time of the casting was claimed by the company to be between 20 and 24 seconds per casting mold. The average time was used in every simulation, which was 22 seconds.

\subsubsection{Setting Up the Materials List Window}

The Materials List Window consists of four input parameter tabs; the Casting, Mold, Curves and Heat Transfer Coefficient tabs. The Casting tab was set up first by selecting the CI GI 4.0 CE as the casting alloy, then modifying the attribute values as calculated in the previous section. The attributes modified in the Casting tab were the thermal conductivity, density, initial temperature and fill time. Figure 5.9 shows the modified Casting tab. The modified alloy and its attributes could be saved with a new name into the database.

Next, the Mold tab in the Materials List window was used for selecting the mold materials in the model. Silica sand and chromite sand were selected without being modified. The "Exothermic Sleeve" (the term for exothermic topping used in SOLIDCast) material in the database was selected and modified according to Mr. David Schmidt of the Finite Solutions Inc., to represent the magnesium based exothermic material used, shown in Figure 5.10. 


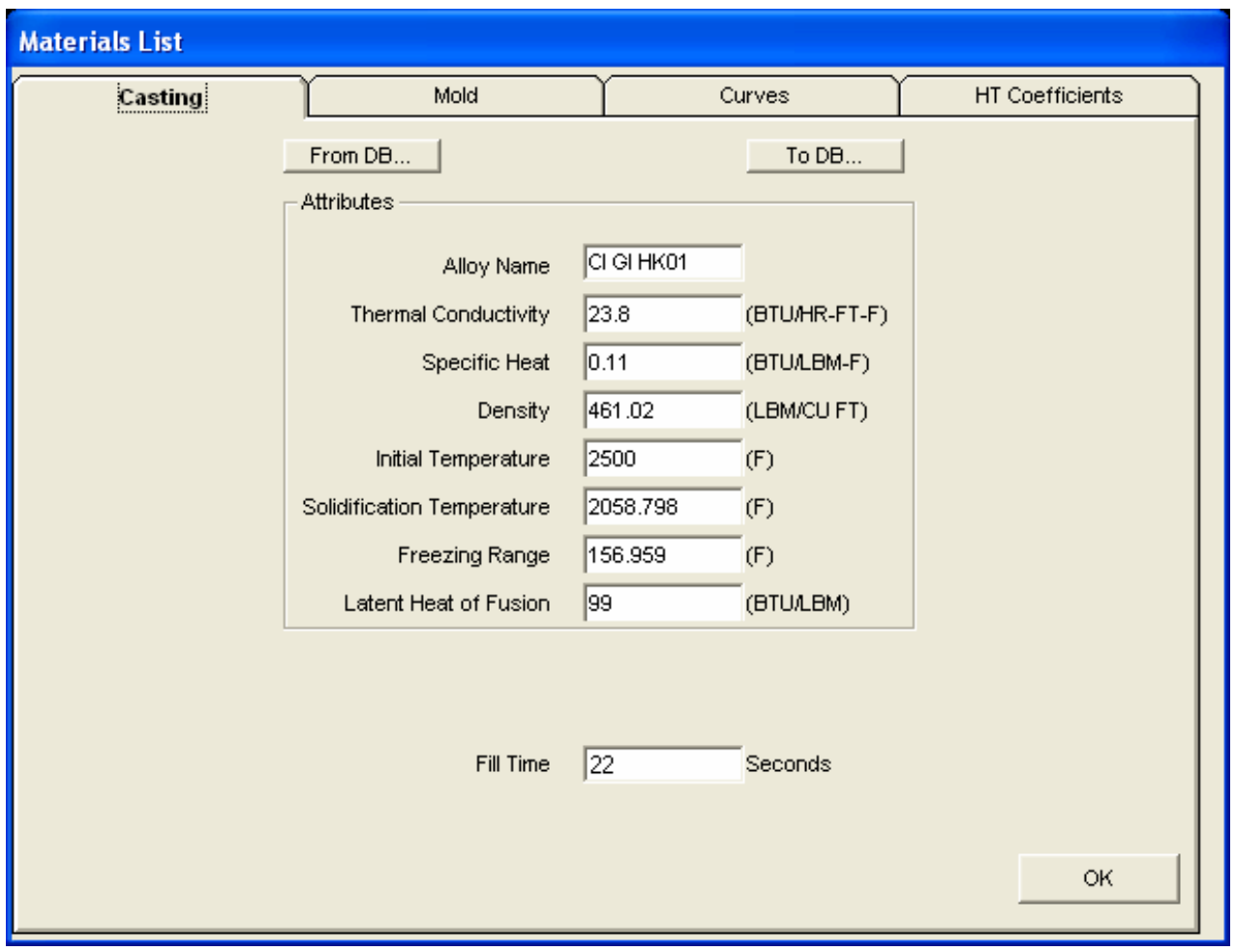

Figure 5.9: The Casting tab.

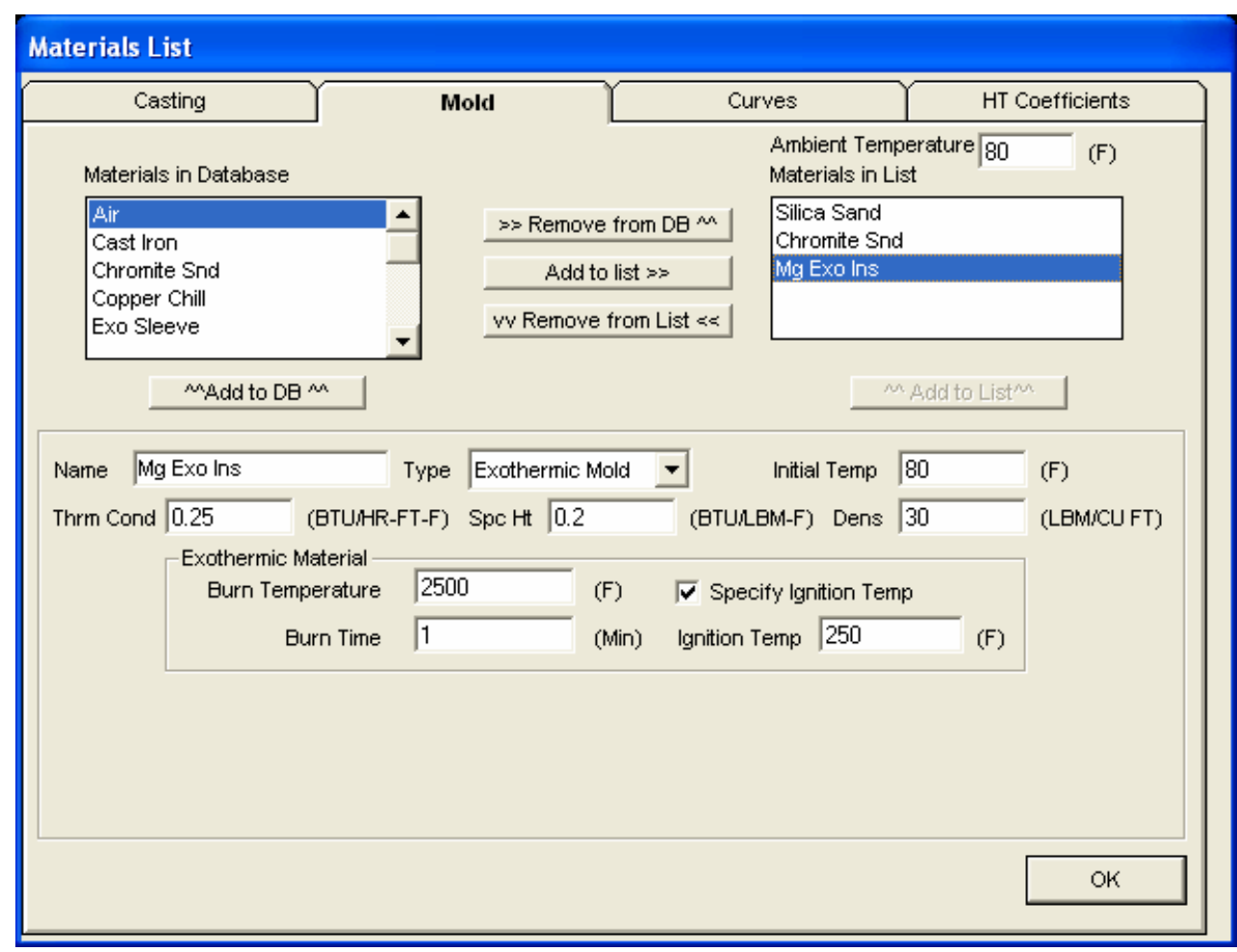

Figure 5.10: The Mold tab showing the attributes of the magnesium based exothermic material. 
The values set in the Curves tab were the temperature curve, the shrinkage curve, the critical fraction solid point and the Niyama point. The temperature curve for this model was set by clicking on the Gray Iron calculator button, and the weight percent carbon and silicon were entered. The mold wall movement was neglected because it would only affect the shrinkage curve which would need another method to modify. The shrinkage curve, critical fraction solid point and Niyama point were set by using the VDG Iron Properties Calculator. In the VDG Iron Properties calculator, the casting modulus was found from a prior simulation using the Riser Design Wizard. One and one-half percent shrinkage was added to the net contraction at the eutectic point to represent the mold wall movement of a chemically bonded silica sand mold. This percentage value was recommended by Mr. David Schmidt of the Finite Solutions Inc. The VDG Iron Properties Calculator is shown in Figure 5.11 and the completed Curves tab is shown in Figure 5.12. No modification was needed for the Heat Transfer Coefficients tab.

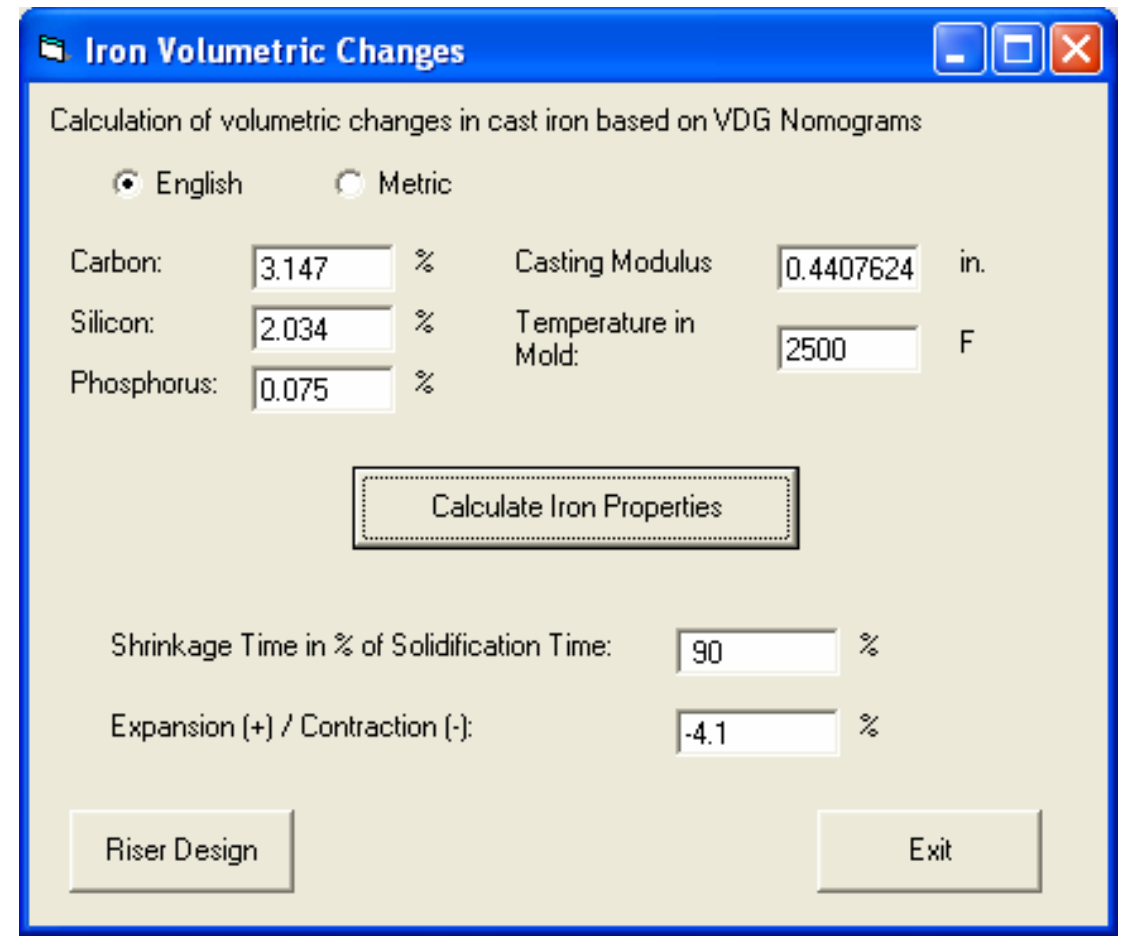

Figure 5.11: The VDG Iron Properties Calculator. 


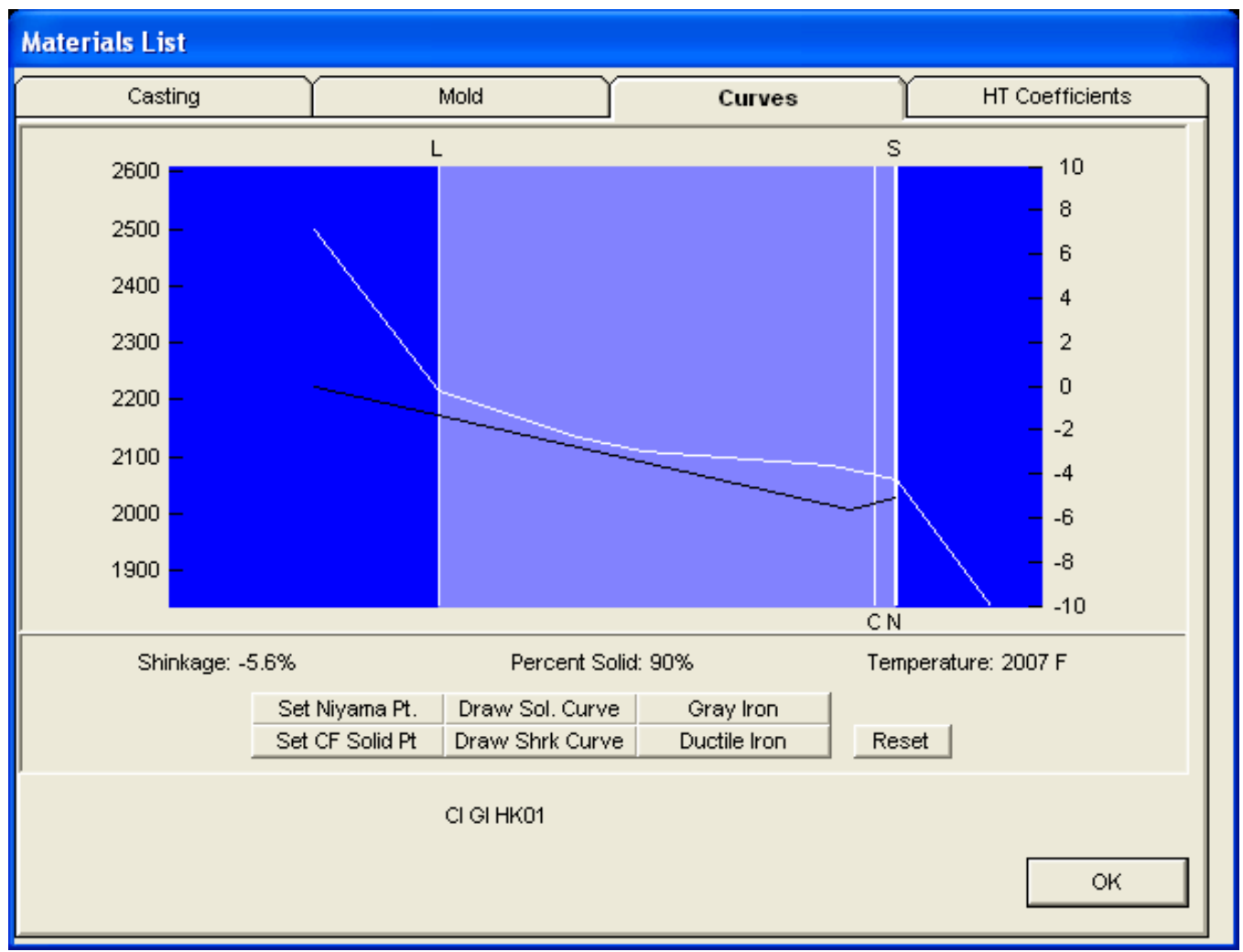

Figure 5.12: The modified Curves tab.

\subsection{Verifying the Simulation Results with the Casting}

The simulation results must be compared to the casting results to determine if the predictions from the program are accurate. The pouring temperature for this particular casting is between 2,425 and 2,575 degrees Fahrenheit, so, three simulations with pouring temperatures of 2,425, 2,500 and 2,575 degrees Fahrenheit were conducted. The settings for each pouring temperature were almost exactly the same. The differences between them were; the pouring temperature and the resulting shrinkage curve, critical fraction solid point, and Niyama point in the Curves tab from the VDG Iron Properties calculator. The results from the VDG Iron Properties Calculator of each pouring temperature are shown in Table 5.2. 
Table 5.2: The results from the VDG Iron Properties Calculator of each pouring temperature.

\begin{tabular}{|c|c|c|c|c|c|c|}
\hline \multicolumn{4}{|c|}{ Inputs } & \multicolumn{2}{c|}{ Outputs } \\
\hline \multirow{2}{*}{$\begin{array}{c}\text { Temperature } \\
\text { in Mold }\left({ }^{\circ} \text { F) }\right.\end{array}$} & $\begin{array}{c}\text { Modulus } \\
\text { (inch) }\end{array}$ & Carbon & Silicon & Phosphorus & $\begin{array}{c}\text { Shrinkage } \\
\text { Time in } \\
\text { Percent of } \\
\text { Solidification } \\
\text { Time }\end{array}$ & $\begin{array}{c}\text { Percent } \\
\text { Contraction }\end{array}$ \\
\cline { 3 - 6 } & & & & & 89.79 & 3.2 \\
\hline 2,425 & 0.4407624 & 3.147 & 2.034 & 0.075 & 90 & 4.1 \\
\hline 2,500 & 0.4407624 & 3.147 & 2.034 & 0.075 & 90 & 4.96 \\
\hline 2,575 & 0.4407624 & 3.147 & 2.034 & 0.075 & & \\
\hline
\end{tabular}

The "Temperature in Mold" used in the VDG Iron Properties Calculator should be the average temperature of the liquid metal in the mold after the mold is completely filled. The SOLIDCast manual (Finite Solutions Inc., 2005) recommends using the pouring temperature less 75 to 100 degrees Fahrenheit as the average temperature. It seems inappropriate to guess for the average temperature. SOLIDCast should develop a calculator to find an appropriate temperature in mold for each casting by taking inputs from the user, such as, the casting weight or volume, the casting modulus, the pouring temperature, etc. It was decided that the pouring temperature be directly used as the temperature in mold for all tests.

From Table 5.2, the shrinkage time in percent of solidification time values are almost the same. As mentioned earlier in Chapter 3, the maximum value for the shrinkage time in percent of solidification time is 90 percent. This was due to the low value of the casting modulus. The percent contractions between each pouring temperature are different due to the difference in the temperatures in the mold (the pouring temperatures).

\subsubsection{Simulation Results of Base Case}

The output criterions selected to analyze the casting model were the Critical Fraction Solid Time, Material Density Function, FCC Criterion and Hot Spot Criterions 
(Solidification Time and Critical Fraction Solid Time). Even though the company highly suspected that the defects occured from centerline shrinkage, the Niyama Criterion is rarely used for predicting cast irons. The best criterion for predicting macroporosity shrinkage in cast irons is the Material Density Function. For predicting microporosity shrinkage, the FCC Criterion was used. Microporosities are small holes of rough surface and usually detected during machining and appearing as a dotted line in the centerlines of long freezing range alloys and occasionally in thick castings of short freezing range alloys. Thus, also were called centerline shrinkage (Ravi, 2005). So, the FCC Criterion may be a good candidate for predicting centerline shrinkage for cast irons. From previous test runs, the highlighted areas in the Niyama Criterion plots were quite large, and probably too large because the defects in the casting were much smaller. It was also found that the highlighted areas of the Hot Spot Criterions and the Niyama Criterion were almost alike in size and positions, so, the Hot Spot Criterions may be used as an aid for predicting areas which may have centerline shrinkages.

The simulation model with original dimensions and average pouring temperature, 2,500 degrees Fahrenheit, was chosen to be the base case. It was compared with the maximum and minimum pouring temperatures and also the modified casting design models. The base case analyses with the selected output criterions are presented.

\section{1) Critical Fraction Solid Time}

This output criterion was used for observing the progression of solidification; showing the areas which reach their critical fraction solid point at a particular time. The Solidification Time output criterion is another criterion used for observing solidification progression, but since the critical fraction solid point and the solidification point are near to each other on the percent of solidification time scale in the Curves tab, and the plots showed very little difference in the simulation runs conducted for comparison, the Critical Fraction Solid Time criterion was the only criterion used for observing the progression of solidification.

In early runs, it was found that there was an un-natural solidification pattern showing in the thick ring area in the bottom part of the casting. Instead of the liquid metal pool between the blind risers separating in the middle from the area between them 
and solidifying towards each riser, the liquid metal pool seemed to separate at the X-axis and solidified towards the risers resulting in a longer path and some isolated areas. So, the model was revolved from the original set up with the runners aligned to the $\mathrm{X}$ and $\mathrm{Y}$ axes to the position which the blind risers are aligned to the Y-axis, or 58.211 degree counterclockwise. The solidification progression appeared more natural with the liquid metal pool separating in the middle from the area between the blind risers. From the calculated mesh weights, the weight of the casting was missing by almost nine pounds (80.645 pounds -72.138 pounds $=8.507$ pounds) with no explainable reason when the whole model was revolved. The weights of the runners and risers were the same. The casting model along with its core pieces were then revolved back to its original alignment and the same weights were achieved. It seemed to be that SOLIDCast is axis dependent, due to it being a Finite Difference Method calculation based casting simulation program. Figure 5.13 shows the Critical Fraction Solid Time plots showing how the liquid metal in the bottom part of the casting solidify towards the blind risers.

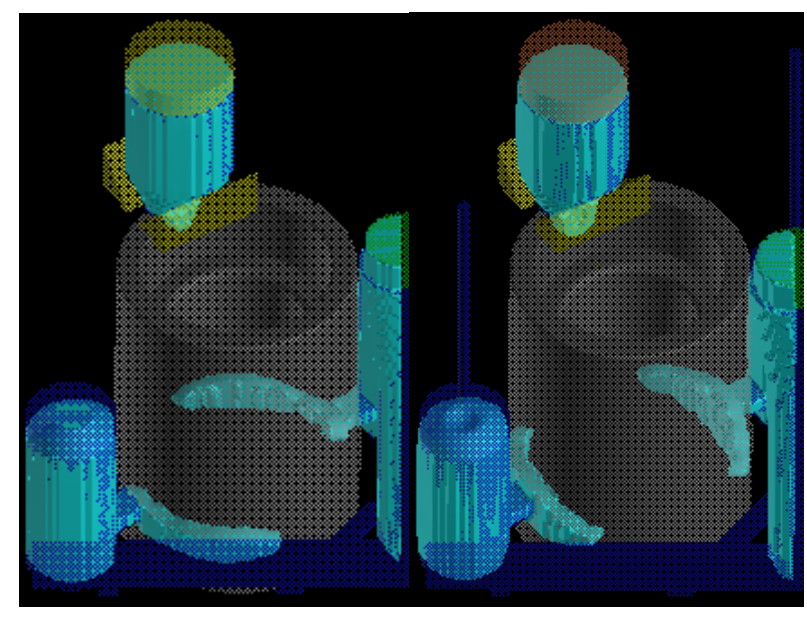

Figure 5.13: Left: Progress of solidification before model re-alignment. Right: Progress of solidification after model re-alignment.

The plots of the Critical Fraction Solid Time Criterion of the base case were plotted from time zero, which is immediately after the mold is filled with molten metal. It was found that at time zero, some areas in the bottom of the casting have already reached their critical fraction solid point. The drilled holes through the blind risers were completely filled, which should be frozen by the time it reaches a height of 4.5 to 6 
inches from the top of the risers in the actual casting. The settings in the Materials List window may not adequately represent the casting material. So, the drill holes in the model were changed to be 5 inches long. It was found that the length of these drill holes in the model had no effect to the simulation results as a whole. Figure 5.14 shows a solidified casting placed upside-down showing the front and back with the misrun drill holes of the single risers and shared riser.

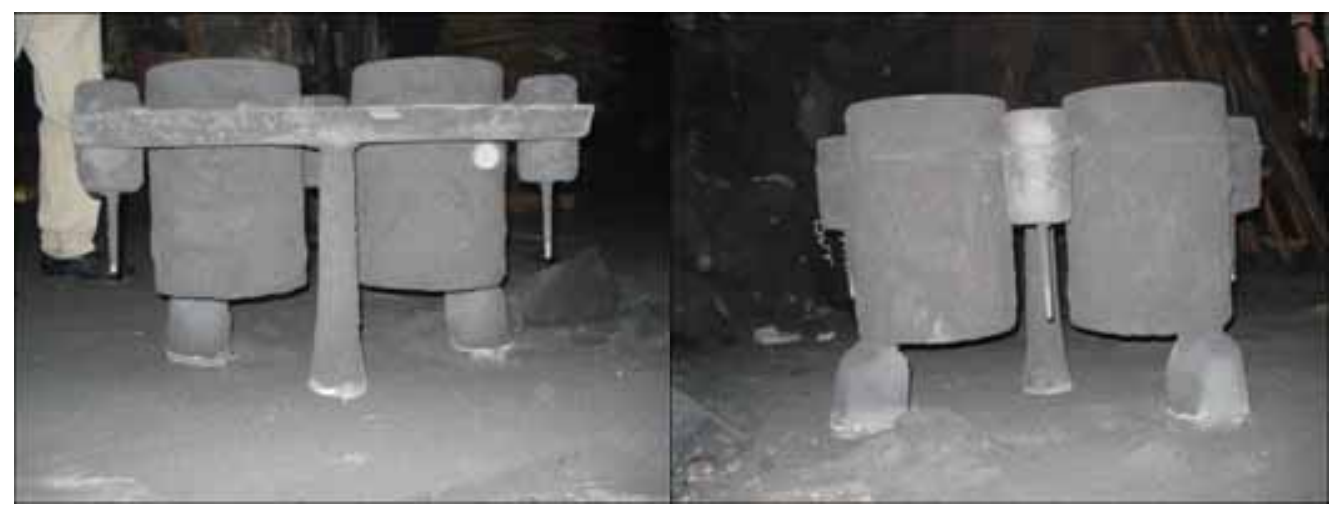

Figure 5.14: A shaken out casting placed upside-down.

The Critical Fraction Solid Time plots showed that the liquid metal in the drill holes cooled down to its critical fraction solid temperature within a little over one minute, as shown in Figure 5.16, and the areas surrounding the core and the bottom of the casting within two minutes after the mold is filled. The knob at the bottom of the casting was the last area to solidify compared to the areas surrounding it. Figure 5.15 shows the progression of cooling in the areas around the core pieces and the bottom of the casting from a top view.

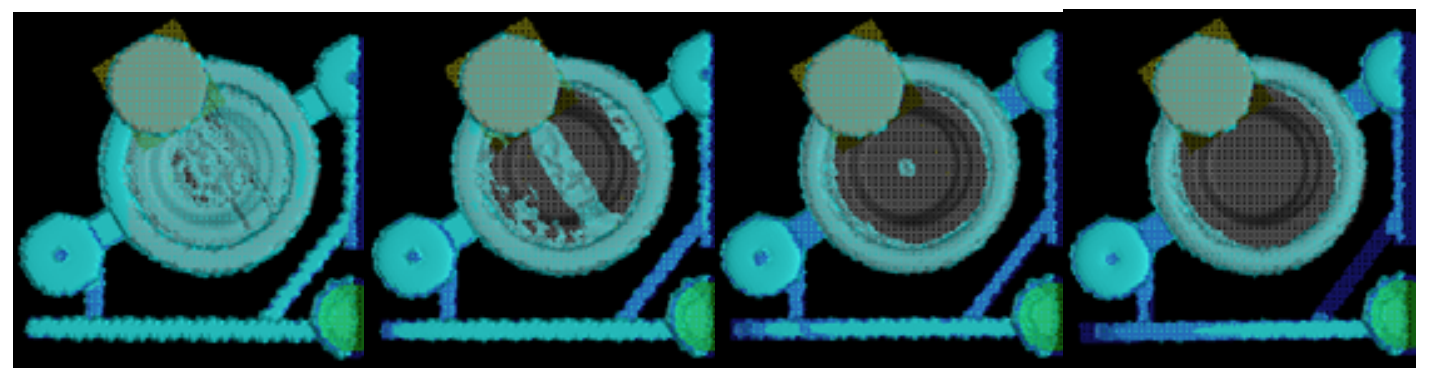

Figure 5.15: Critical Fraction Solid Time criterion plotted at 0, 1.0, 1.5 and 2 minutes after mold is filled. 


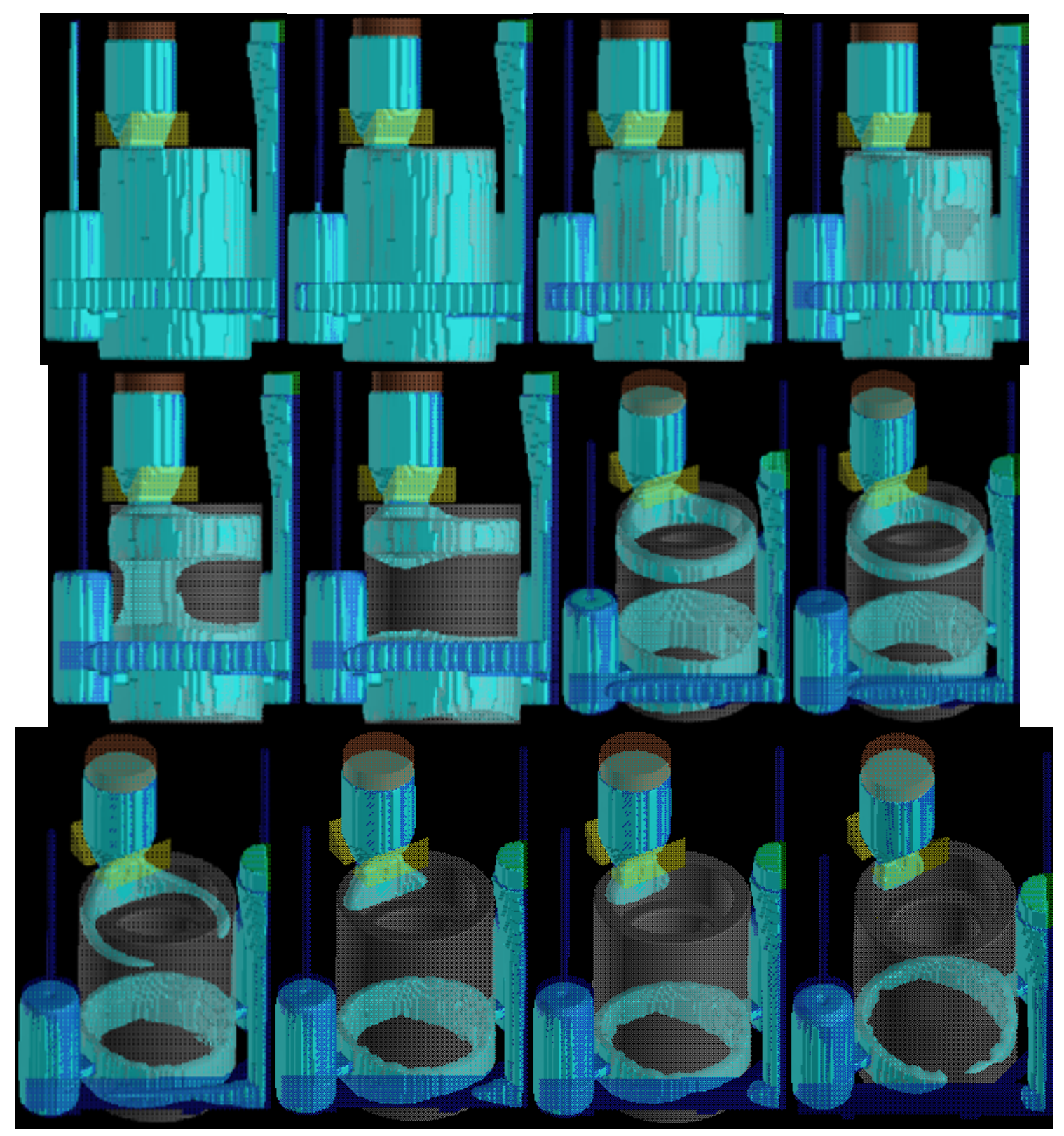

Figure 5.16: Critical Fraction Solid Time criterion plotted at 0, 1.0, 1.5, 2.0, 2.5, 3.0, 3.5, 4.0, 4.5, 5.0, 5.5 and 6.0 minutes after mold is filled. 


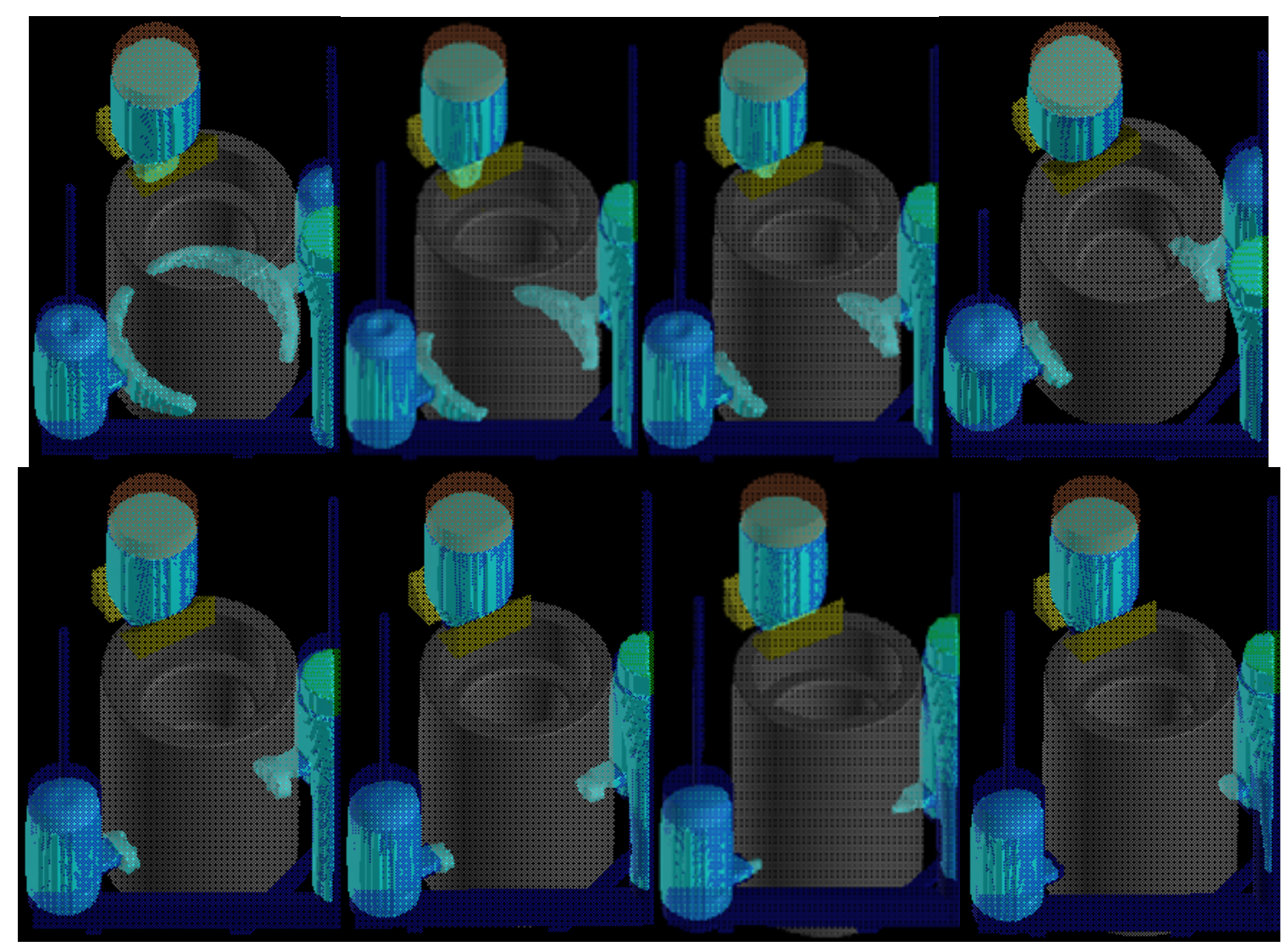

Figure 5.17: Critical Fraction Solid Time criterion plotted at 6.5, 7.0, 7.5, 8.0, 8.5, 9.0, 9.5 and 10.0 minutes after mold is filled.

The thin wall of the casting was next to solidify, starting from the side across from the top riser towards the area under it, separating the liquid metal pools in the top and bottom parts of the casting. The heat from the top riser kept the area under it hotter for a longer time. All other parts of the casting formed shells with liquid metal inside. The thin wall solidified completely separating the top and bottom pools by around 3 minutes after the mold was filled.

The whole casting cooled down further until the upper thick ring solidifed towards the top riser, breaking the ringed pool from the area across the top riser at a little over 4 minutes after the mold is filled. The bottom pool started to separate into the side risers at approximately 6 minutes after the mold was filled starting from the side across from the top riser. It was believed that the side under the top riser solidified slightly later because the temperature of the liquid metal in this area was heated by the top riser. By 8.5 minutes after the mold was filled, the pool of liquid metal under the top riser had 
shrunken into the riser completely out of the casting. At around 10 minutes after the mold was filled, the pools of liquid metal at the bottom ring of the casting had shrunken into both the side risers. Figures 5.16 and 5.17 are the Critical Fraction Solid Time plots showing the progression of solidification.

\section{2) Material Density Function}

This output criterion was used for finding possible areas where macroporosity may occur. The plotting values are between 0 and 1; 0 meaning 0 percent metal density and 1 meaning 100 percent metal density. From the SOLIDCast manual (Finite Solutions Inc., 2005), the critical plotting value may be around 0.995 or 0.99 , which would show the most likely outcome of a casting. If the plotting value is 0.99 , the plot would highlight all areas with less than 99 percent density. Plotting with a value of 1 would show all areas which may be prone to microporosity even though there might not be any. Figure 5.18 shows Material Density Function plots plotted at 1.0, 0.995 and 0.99 respectively from top to bottom.

In all three sets of plots, the common area highlighted in the casting is the bottom of the casting. The plots plotted at 0.995 and 0.99 were almost exactly the same. For the plot plotted with 1.0, an area in the ring between the core pieces was highlighted. It showed a very small possibility of macroporosity occurring in this area.

The company does not experience any macroporosity problems at all. It may be because the highlighted areas at the bottom of the casting are quite small and may have quite a high density percentage value, showing that the macroporosity problem may not be serious and probably does not show on the surface. Also, the bottom of the casting would only be machined off slightly. This type of problem was never detected.

Figure 5.19 and 5.20 shows the front and top views of the casting before fettling of knock-off. The top risers and sprue show some signs of piping quite similar to the plots, but the blind risers do not show piping. Figure 5.21 shows the blind single riser and the blind shared riser. 

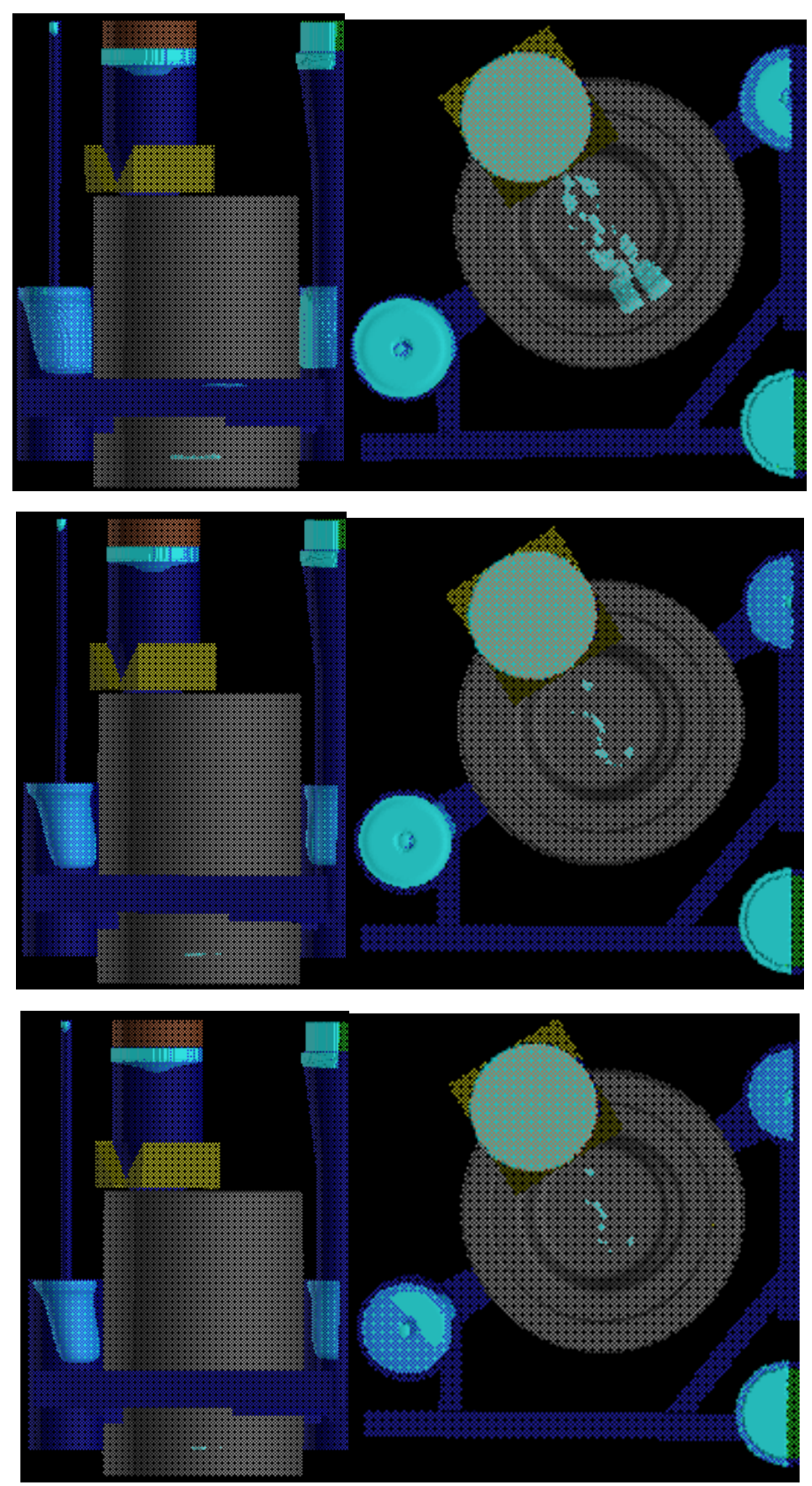

Figure 5.18: Material Density Function plots plotted at 1.0, 0.995 and 0.99 respectively from top to bottom. 


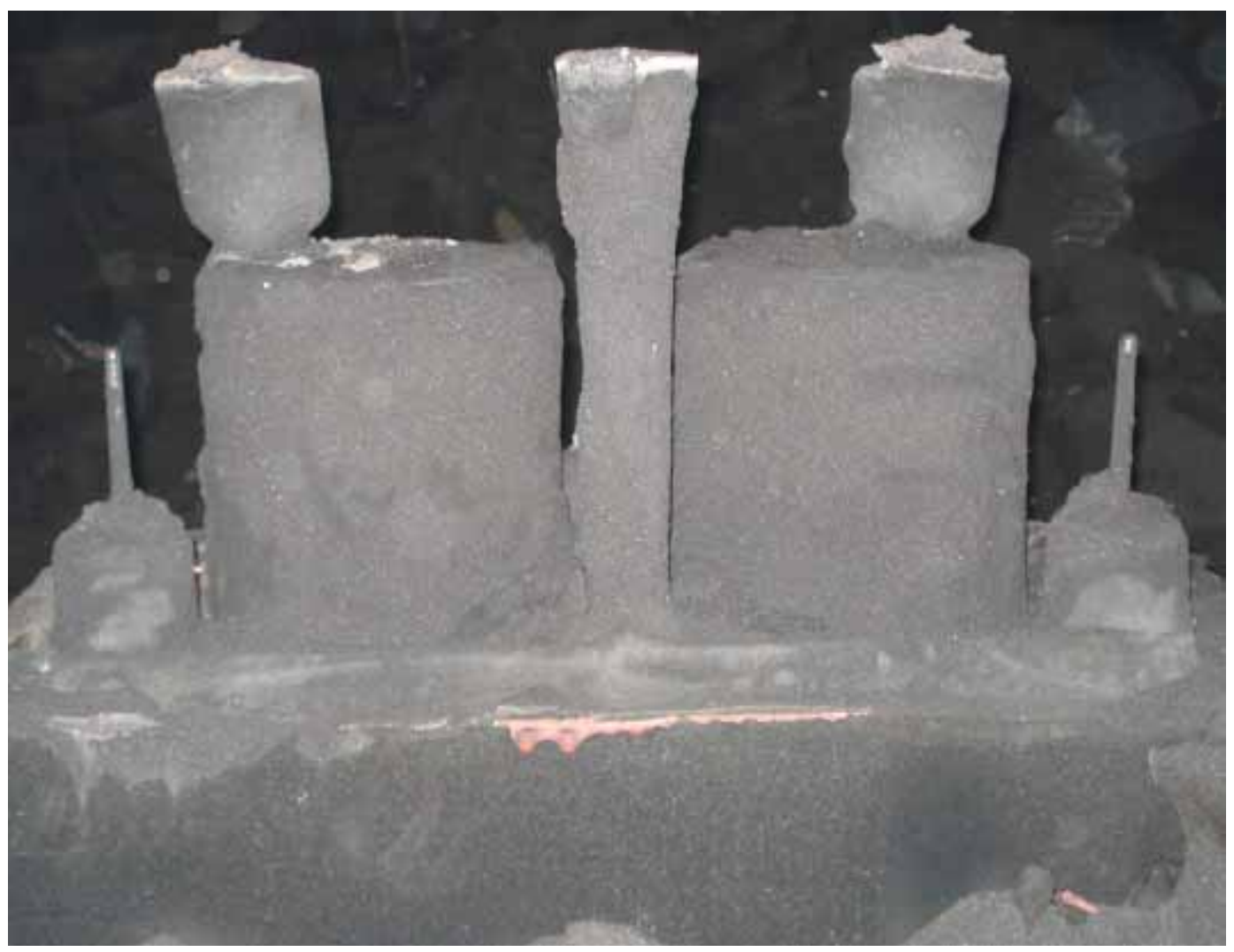

Figure 5.19: Front view of casting before fettling or knock-off.

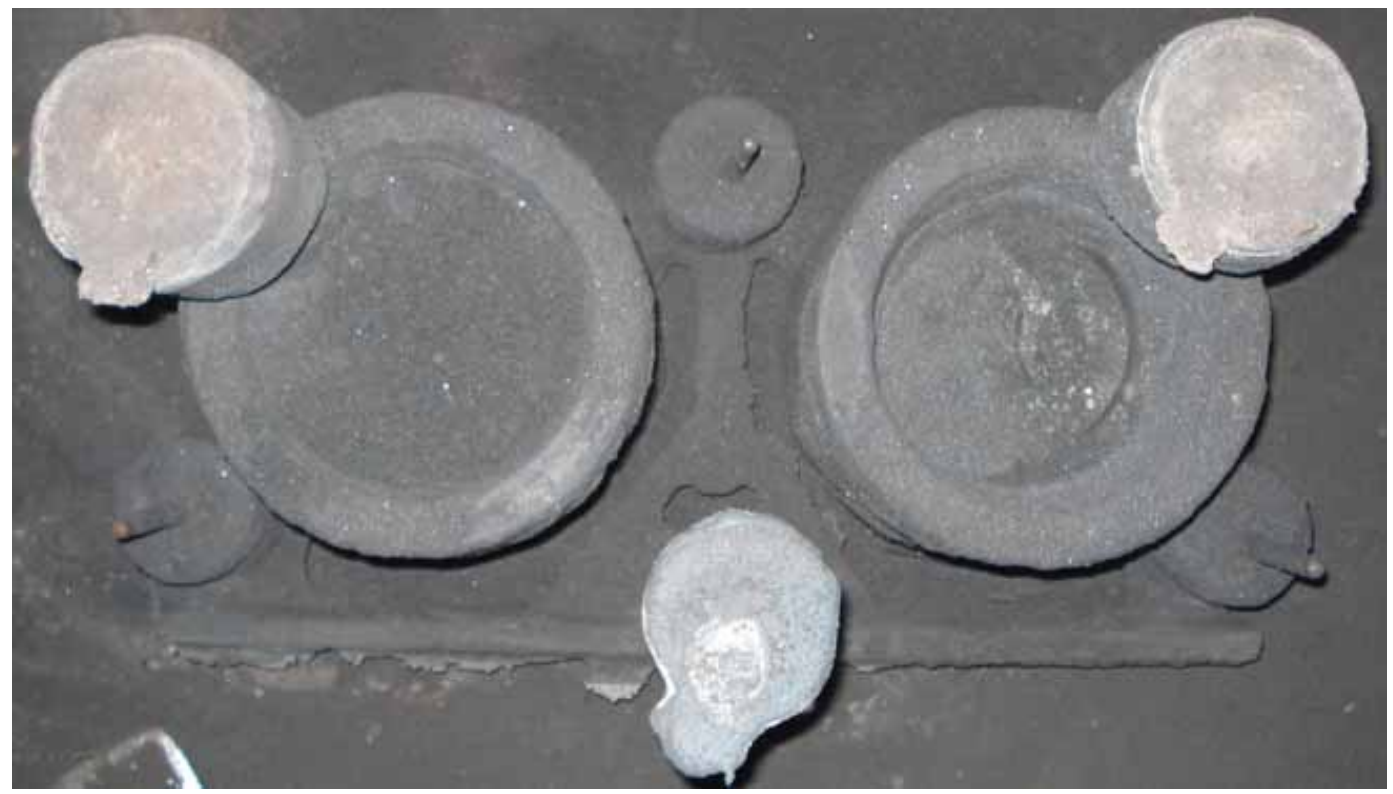

Figure 5.20: Top view of casting before fettling or knock-off. 


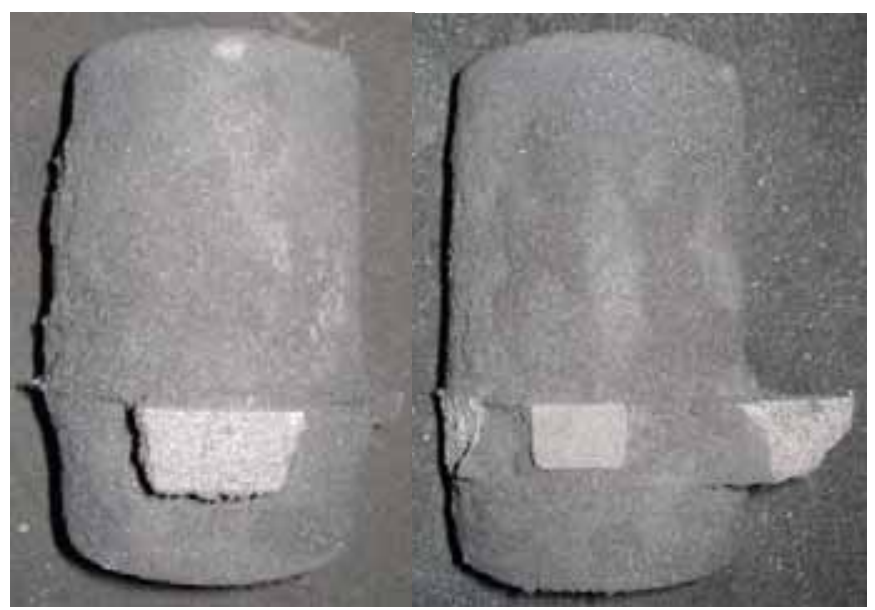

Figure 5.21: Left; blind single riser. Right; blind shared riser.

A Material Density Function cut-plane plot plotting areas with density values from 0 to 1 was plotted as shown in Figure 5.22. It shows a more representative shrinkage figure and the blind risers must have created a shell covering the internal rough-hole porosities represented by plotted areas having darker shades of color showing higher density.

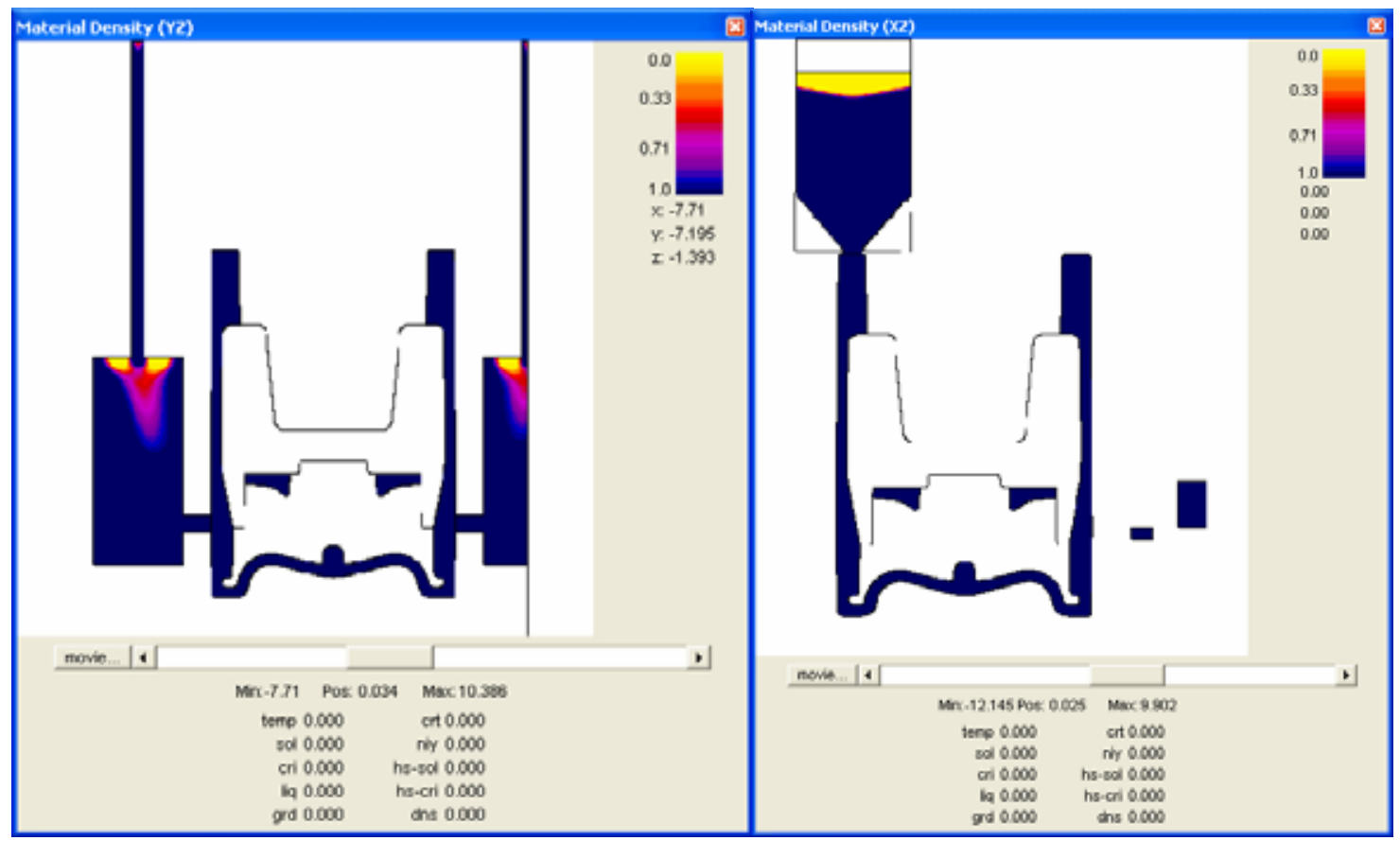

Figure 5.22: Material Density Function cut-plane plot plotting areas with density values from 0 to 1 . 
The plots show that the drilled holes from the blind risers were all filled up. As already mentioned in the Critical Fraction Solid Time criterion, the settings in the Materials List may not represent the casting material as there were no misruns shown in the plots of the drilled holes.

\section{3) FCC Criterion}

The FCC Criterion is a custom criterion provided by SOLIDCast for predicting areas prone to microporosity. The FCC Calculator calculates the values of each node in the casting design through a formula, starting from 0 to the value of the node with the highest calculated value. The recommended plotting value is 40 percent of the maximum calculated value.

As shown in Figure 5.23, the thick ring area at the lower part of the casting shows some possible microporosity occurring near the side risers' necks close to the outer parting line of the two core pieces. The thick ring area at the upper part of the casting also shows some sign of microporosity, mostly in the areas above the side risers and a very small sign in the area across the top riser.

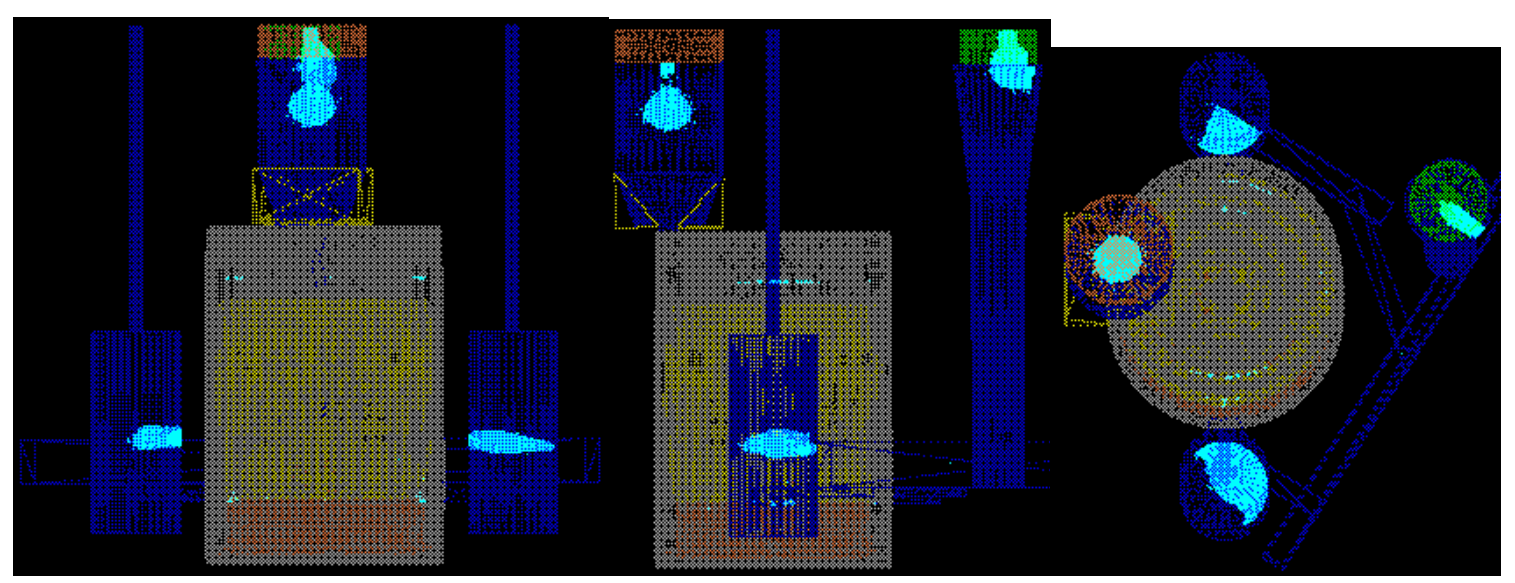

Figure 5.23: FCC Criterion plots.

The company claims that the porosities found in the castings in the upper ring grooves are likely to be found in the area opposite the top riser. This does not match the simulation results. Also, the highlighted areas seem to only be in the areas along the $\mathrm{X}$ and Y axes. No highlighted areas were found in between. This may also be because of 
how SOLIDCast is axis dependent due to being a Finite Difference Method approached casting simulation program.

\section{4) Hot Spot Criterions}

The Hot Spot Criterion plot can be calculated by two methods, comparing the solidification time or the critical fraction solid time of a particular node with its neighbors. A plotted hot spot does not always mean that it will have any problems. It may mean that a particular area is prone to problems, but in some cases, other criterions should be considered as well. For example, the hot spot plot indicating hot spots in the thin wall area plotted all around the casting has a very slight chance of having shrinkage porosities because of rapid cooling occurred from the section being very thin.

The hot spot plots plotted with the solidification times compared to plots plotted with the critical fraction solid times seems slightly larger and has additional highlighted areas. Because the critical fraction solid temperature and the solidification temperature are considered very close to each other, the plots would be almost identical. The differences in the plots may have resulted as the calculated ratios slightly increase. Figure 5.24 shows the hot spot plots plotted with the solidification times and Figure 5.25 shows the hot spot plots plotted with the critical fraction solid times, both plotted at 1.1.

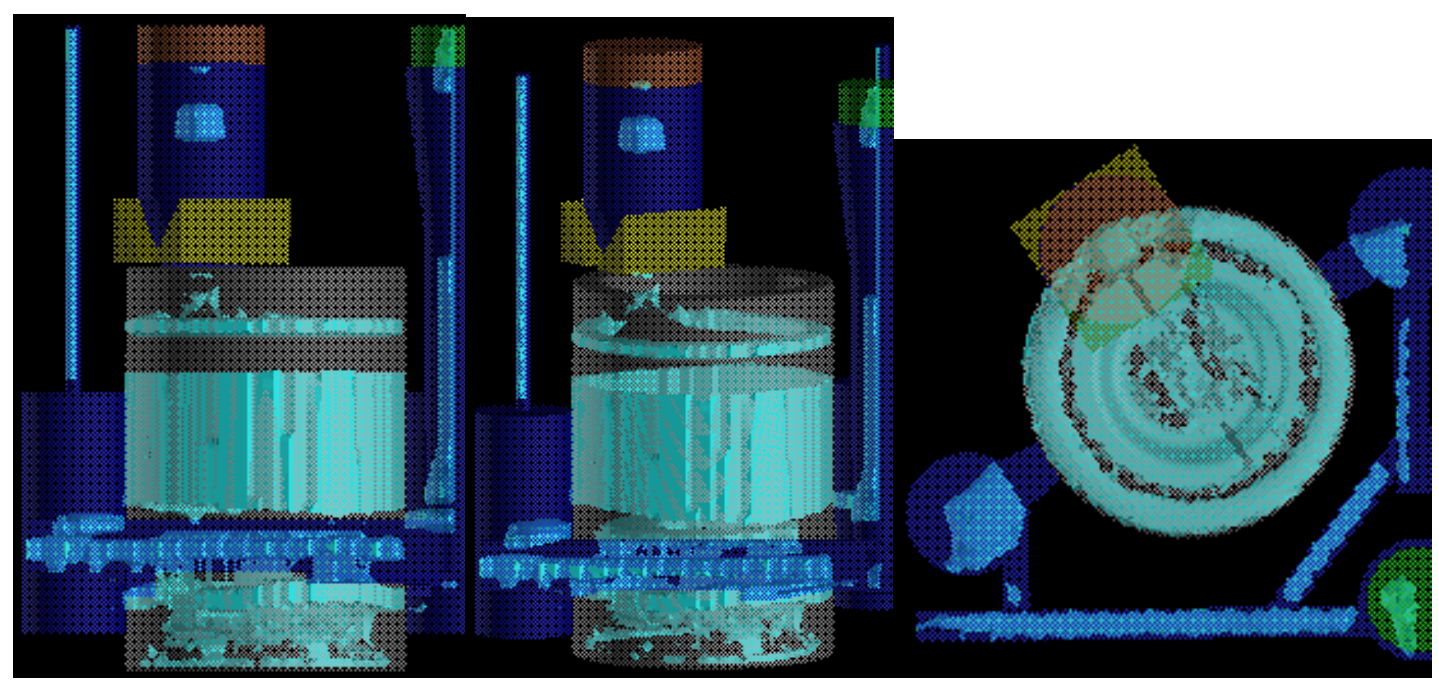

Figure 5.24: Hot Spot Criterion (Solidification Time) plotted at 1.1. 


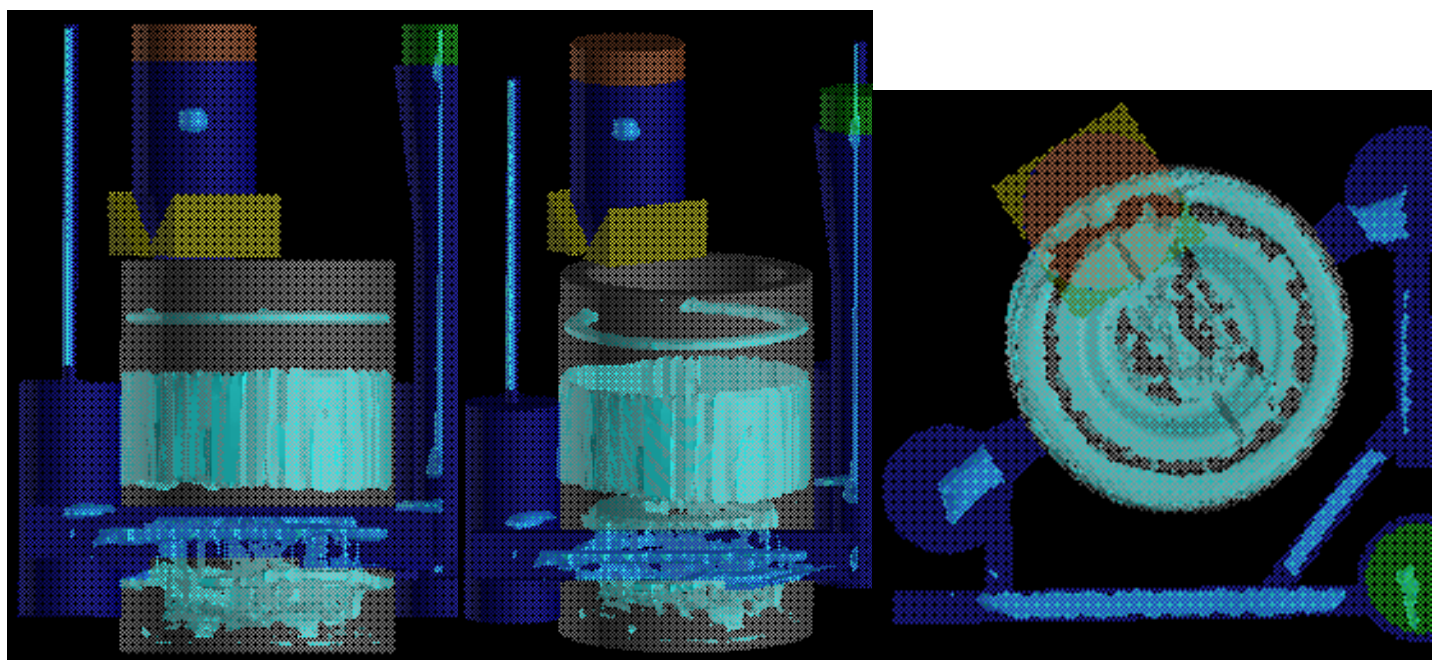

Figure 5.25: Hot Spot Criterion (Critical Fraction Solid Time) plotted at 1.1.

Figure 5.26 and 5.27 are cut-plane plots plotted with values between 1.0 and 1.1 and it was found that the thick ring areas both in the upper and lower part of the casting shows more severity on the inner side. So, the porosities found after milling the ring grooves are probably because they were milled close to the hot spots.

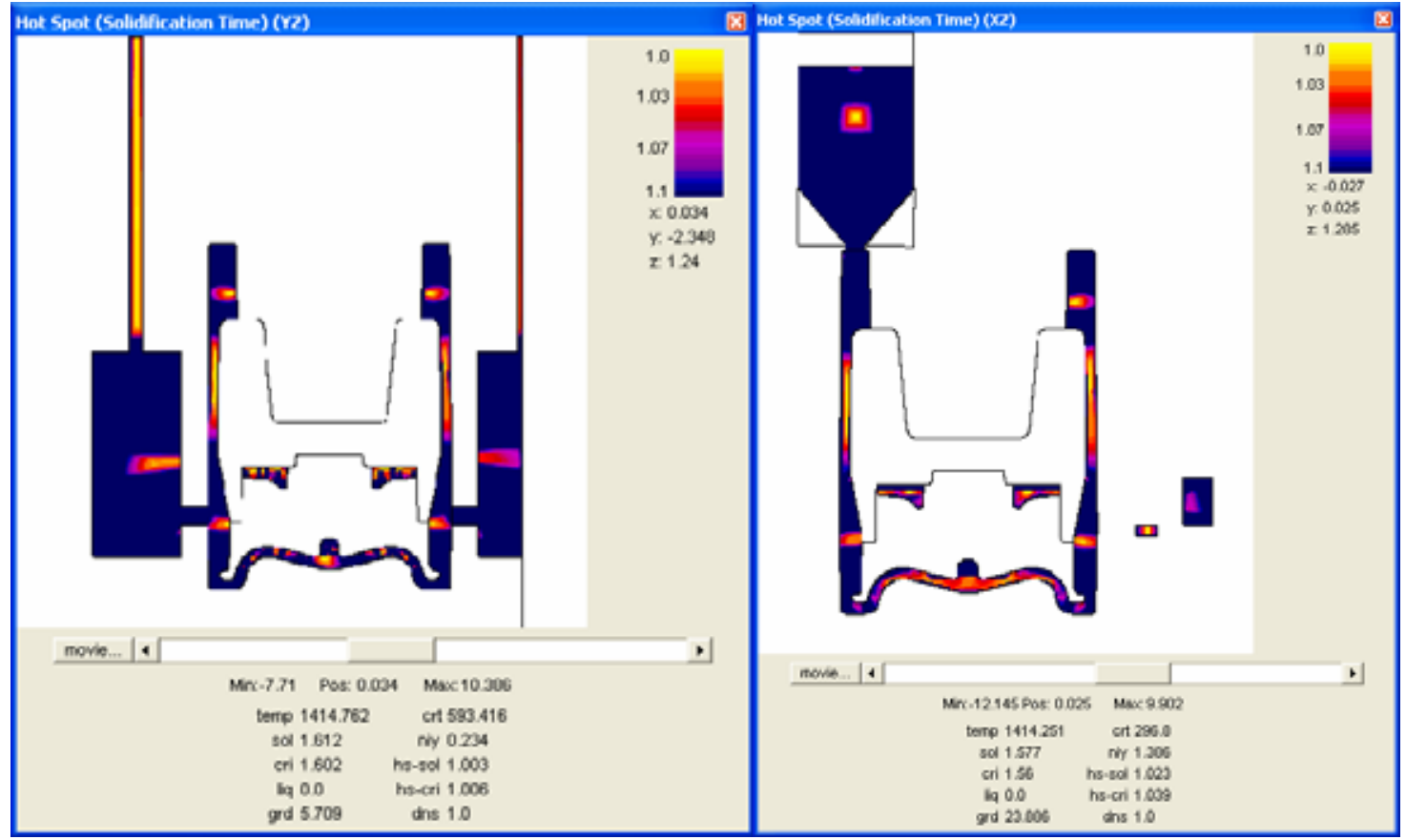

Figure 5.26: Hot Spot (Solidification Time) cut-planes plot plotted between 1.0 and 1.1. 


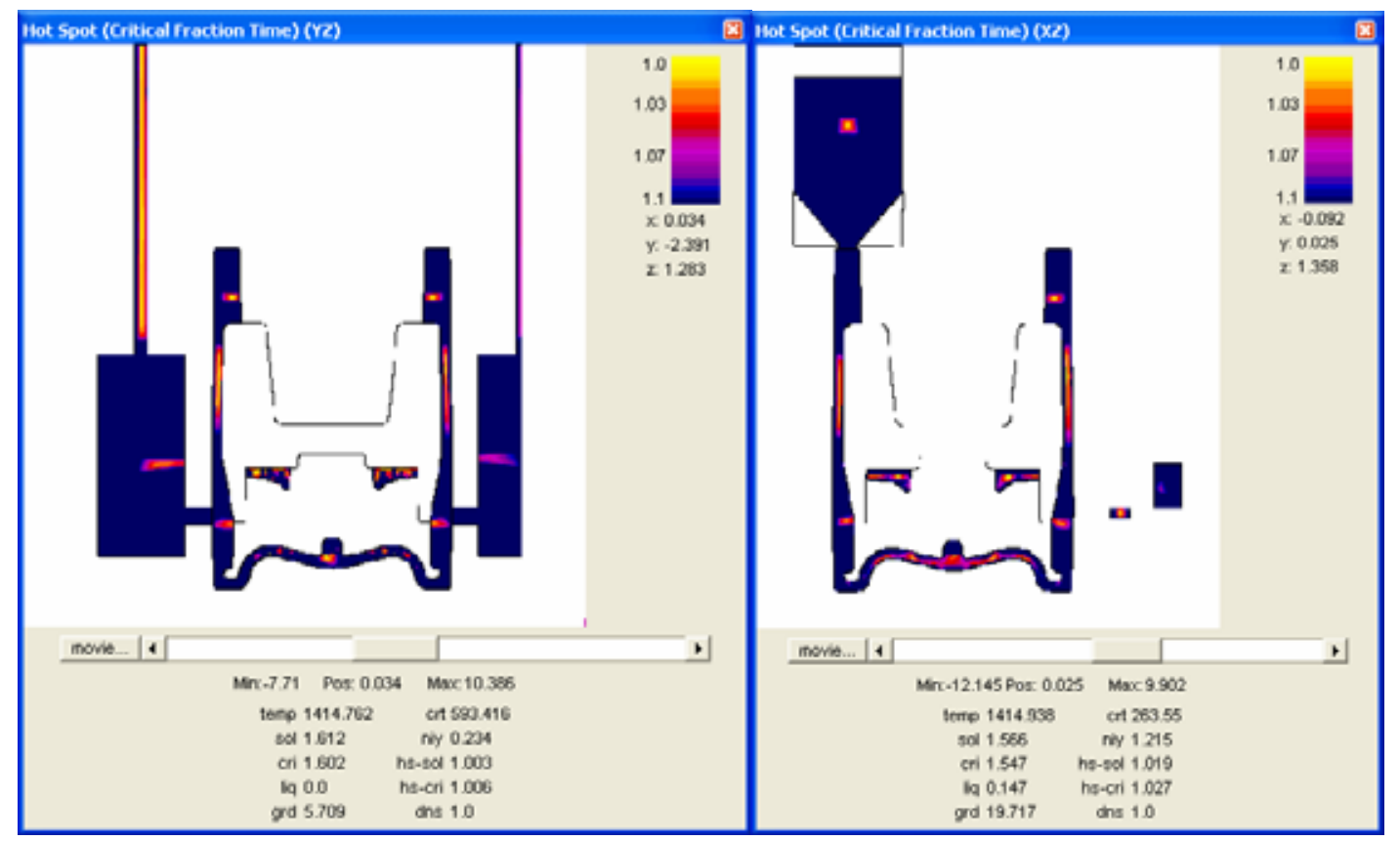

Figure 5.27: Hot Spot (Critical Fraction Solid Time) cut-planes plot plotted between 1.0 and 1.1 .

Plotting a Hot Spot Criterion plot with a smaller value showed the areas with more possible severity. Figure 5.28, 5.29, 5.30 and 5.31 shows hot spot plots plotted with 1.0 and 1.01 showing that the area around the core pieces is the most severe area, then the inner side of the upper thick ring area, the thin wall and the lower thick ring area respectively. But the thin wall and thin fins in the cores may be considered as not severe because of its high cooling rate.

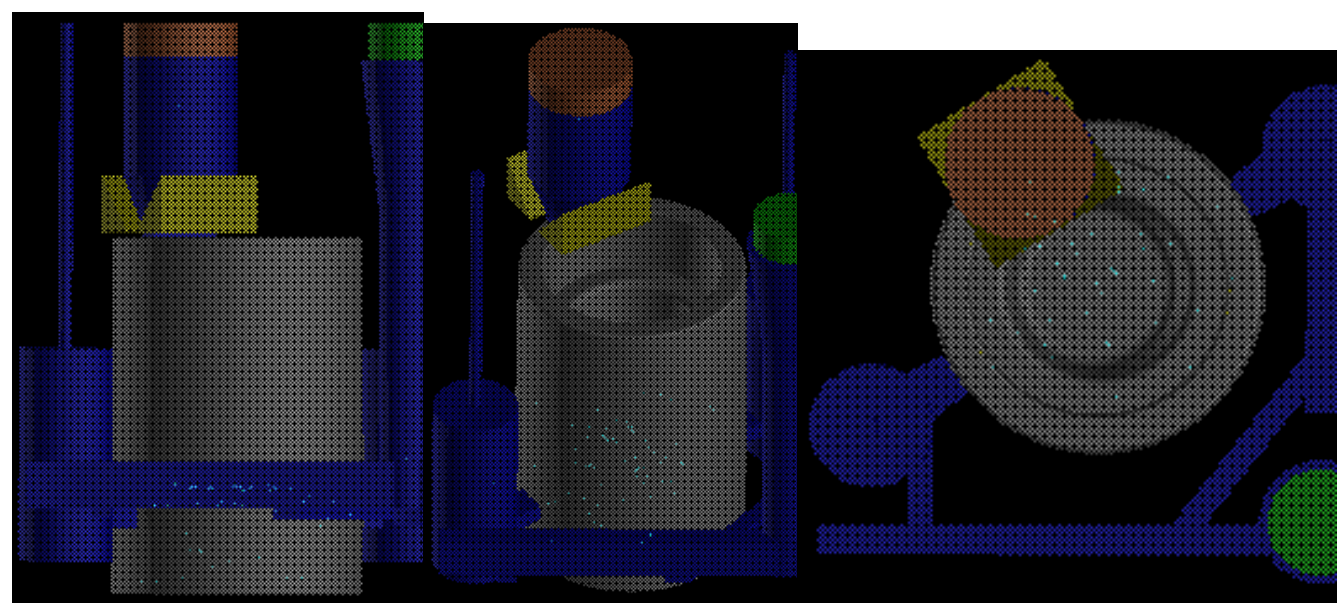

Figure 5.28: Hot Spot (Solidification Time) plotted with 1.0. 


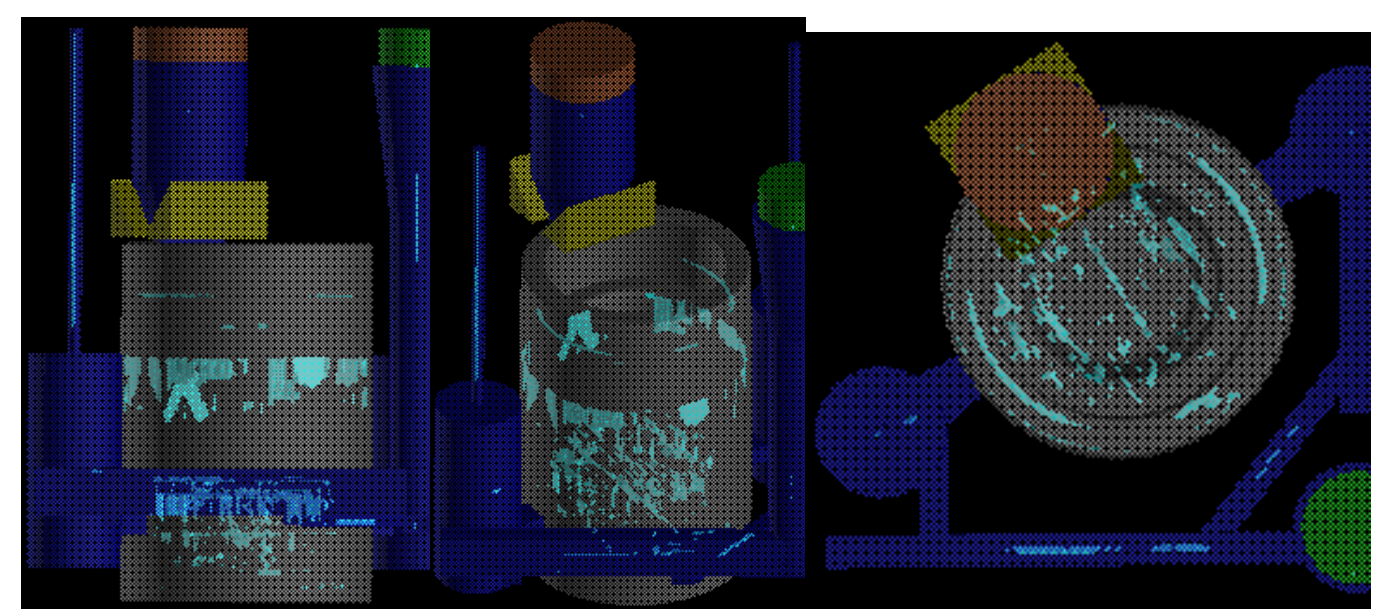

Figure 5.29: Hot Spot (Solidification Time) plotted with 1.01.

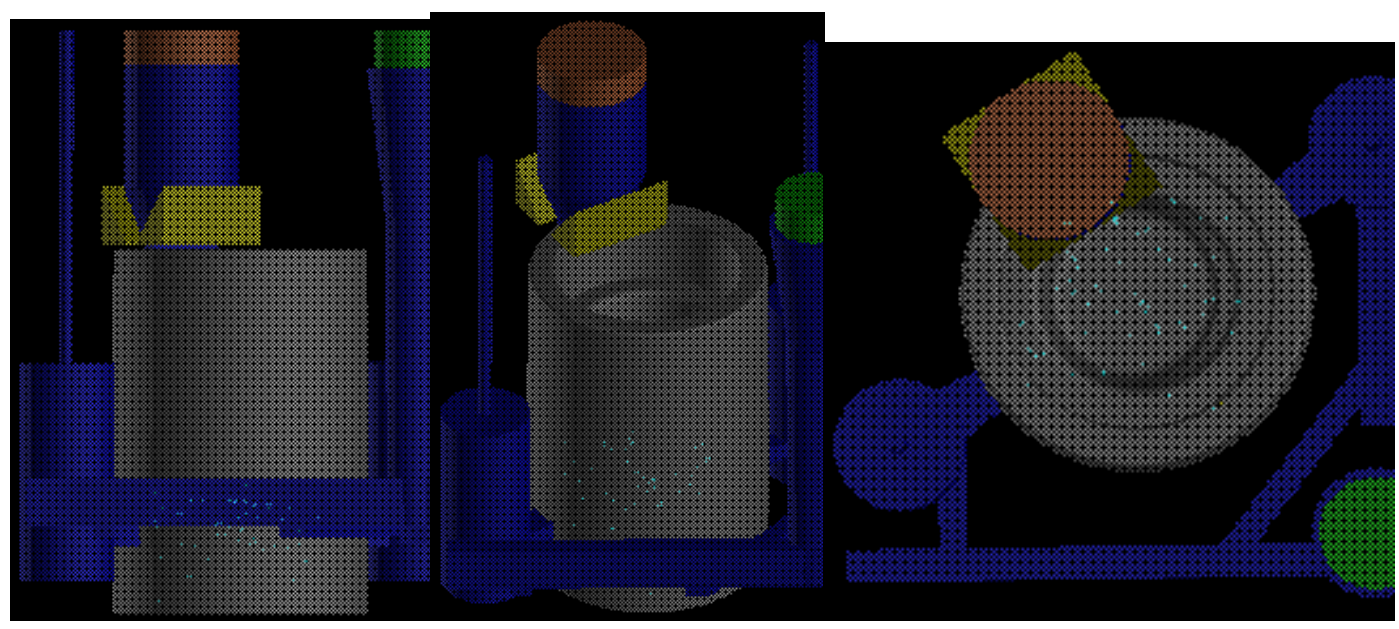

Figure 5.30: Hot Spot (Critical Fraction Solid Time) plotted with 1.0.

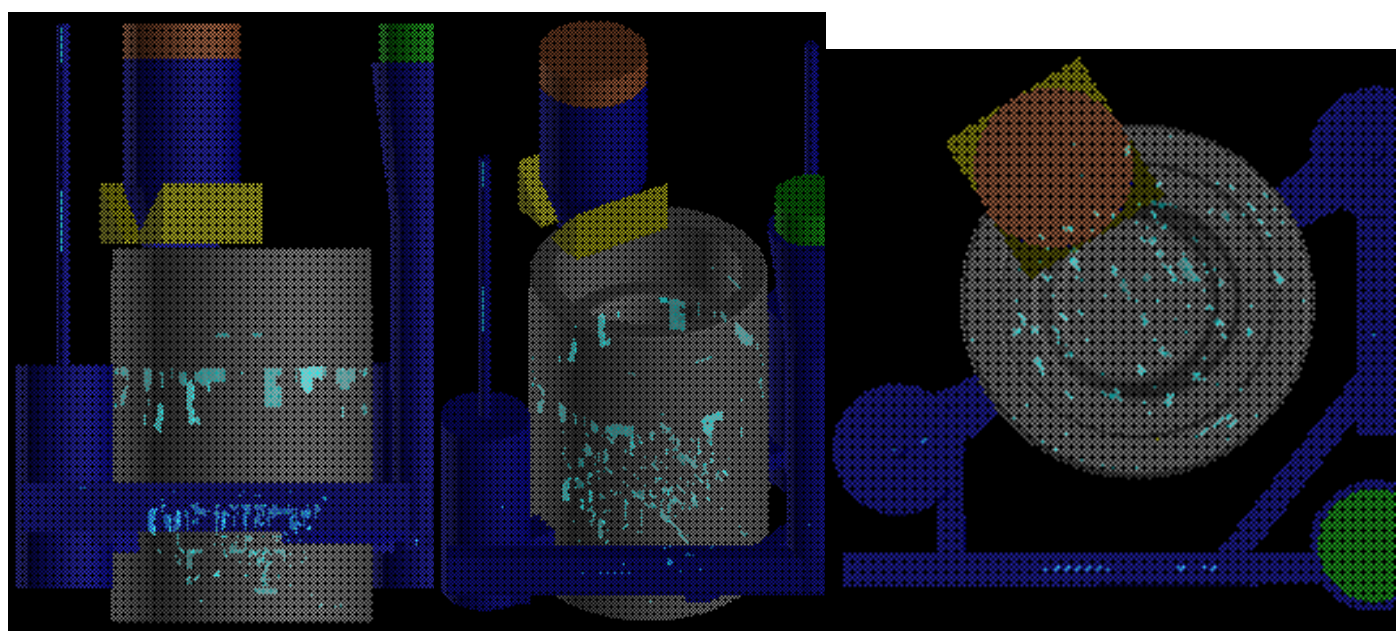

Figure 5.31: Hot Spot (Critical Fraction Solid Time) plotted with 1.01. 


\subsubsection{Conclusions of Base Case}

The simulation results showed many similarities to the casting, such as the microporosities or centerline shrinkage predicted by the FCC Criterion were in the same areas where centerline shrinkage was suspected, Hot Spot Criterions plots showing areas of potential centerline shrinkage and the Material Density Function plots showing no macroporosity problems in the machined surfaces. The biggest difference between the simulation results and the casting was that the simulation did not show any misrun in the drilled holes. It may be because the temperature and shrinkage curves calculated by the program do not represent the characteristics of the casting material well enough.

\subsection{Pouring Temperature Comparison}

The simulation results of the maximum and minimum pouring temperatures were compared with the base case at the average pouring temperature. All three cases were set with the same node size and mold wall thickness, so, the weights of the materials calculated were the same. The three cases having different pouring temperatures resulted in the difference in the Curves tab, as shown earlier in Table 5.2 (the pouring temperatures were presented as Temperature in Mold). The values retrieved from the Simulation Status windows are summarized in Table 5.3.

Table 5.3: Values retrieved from the Simulation Status windows.

\begin{tabular}{|c|c|c|c|c|c|c|}
\hline $\begin{array}{c}\text { Pouring } \\
\text { Temp } \\
\left({ }^{\circ} \mathbf{F}\right)\end{array}$ & $\begin{array}{c}\text { Simulated } \\
\text { Time } \\
\mathbf{( m i n} .)\end{array}$ & $\begin{array}{c}\text { Max } \\
\text { Casting } \\
\text { Temp }\left({ }^{\circ} \mathbf{F}\right)\end{array}$ & $\begin{array}{c}\text { Min } \\
\text { Casting } \\
\text { Temp }\left({ }^{\circ} \mathbf{F}\right)\end{array}$ & $\begin{array}{c}\text { Max Mold } \\
\text { Temp }\left({ }^{\circ} \mathbf{F}\right)\end{array}$ & $\begin{array}{c}\text { Min Mold } \\
\text { Temp }\left({ }^{\circ} \mathbf{F}\right)\end{array}$ & $\begin{array}{c}\text { Time } \\
\text { Steps }\end{array}$ \\
\hline $\mathbf{2 , 4 2 5}$ & 19.739 & $2,057.483$ & 214.122 & $2,029.466$ & 80 & 21,575 \\
\hline $\mathbf{2 , 5 0 0}$ & 21.41 & $2,055.294$ & 206.452 & $2,025.805$ & 80 & 23,400 \\
\hline $\mathbf{2 , 5 7 5}$ & 23.287 & $2,058.777$ & 199.093 & $2,032.052$ & 80 & 25,450 \\
\hline
\end{tabular}

From Table 5.3, it was seen that the higher the pouring temperature, the longer it took the casting to solidify completely (simulated time) and the longer it took to finish the simulation (time steps). The maximum casting temperature was the temperature of the casting material node which solidified last, so, all three cases have nearly the same 
temperatures, and are very close to the solidification temperature, 2,058.798 degrees Fahrenheit from Figure 5.9. The minimum casting temperature of the highest pouring temperature is lowest because the section of the casting which solidified first had more time to cool and wait for the last section of the casting to solidify to finish simulating. As for the maximum mold temperature, the higher the pouring temperature, the higher the maximum temperature of the mold should be.

The results of the simulations were compared by the Critical Fraction Solid Time, Material Density Function, FCC Criterion and the Hot Spot Criterions. The Critical Fraction Solid Time plots of all three cases show the same progressions, but with different speeds. With a difference of 75 degrees Fahrenheit between each step, it was found that the step with a higher pouring temperature compared to the adjacent step would take around less than half a minute later to reach the same progression in solidification in the early stages, and around one minute when the whole casting excluding the risers, runners and sprue passes the critical fraction solid temperature.

Table 5.4: Comparing the severity of the problems predicted by each criterion of the three pouring temperatures.

\begin{tabular}{|c|c|c|c|c|c|c|}
\hline \multirow{2}{*}{$\begin{array}{c}\text { Pouring } \\
\text { Temp }\end{array}$} & \multicolumn{3}{|c|}{$\begin{array}{c}\text { Material Density } \\
\text { Function }\end{array}$} & \multirow{2}{*}{ FCC } & \multicolumn{2}{|c|}{ Hot Spot } \\
\cline { 2 - 4 } & $\mathbf{1 . 0}$ & $\mathbf{0 . 9 9 5}$ & $\mathbf{0 . 9 9}$ & Criterion & $\begin{array}{c}\text { CFS } \\
\text { Time }\end{array}$ & $\begin{array}{c}\text { Solidification } \\
\text { Time }\end{array}$ \\
\hline $\mathbf{2 , 4 2 5}$ & 1 & 1 & 1 & 1 & 1 & 1 \\
\hline $\mathbf{2 , 5 0 0}$ & 2 & 2 & 2 & 1 & 1 & 2 \\
\hline $\mathbf{2 , 5 7 5}$ & 3 & 3 & 3 & 3 & 3 & 3 \\
\hline
\end{tabular}

$1=$ least severe, $2=$ moderate, $3=$ most severe

The highlighted areas in the Material Density Function, FCC Criterion and the Hot Spot Criterions plots of all three cases were almost at the same positions with slightly different intensities. It seemed possible to compare the severity of the problems predicted by each criterion by the volume and size of the plots and additional highlighted areas. The larger the highlighted area or the more highlighted areas, the more severe the 
problems predicted would be. Table 5.4 shows a summary table of the comparison of the three cases with 1 meaning least severe, 2 meaning moderate and 3 meaning most severe compared between the three cases.

It was seen that the higher the pouring temperature, the more possibility of macroporosity may occur. This could be seen from the calculations from the VDG Iron Properties Calculator which set up the shrinkage curve in the Curves tab that the higher the pouring temperature, the more shrinkage would occur. For the FCC Criterion and Hot Spot Criterions, the plots were almost exactly the same with very little difference in the level of severity. The levels of severity shown in Table 5.4 for the FCC Criterion and Hot Spot Criterions among each case were actually very alike and should not be considered significant.

\subsection{Modifying the Casting Design}

The casting design was modified to find ways to improve the casting results and to study some particular outcomes from the modifications. All cases used a pouring temperature of 2,500 degrees Fahrenheit or the mean temperature.

\subsubsection{Remove Top Riser}

The top riser was removed from the base case model to observe the consequences of not having a top riser to feed the thick ring area in the upper part of the casting. The settings in the Materials List window were set exactly the same as the base case, except for the fill time which should be changed due to the missing weight. If both the top risers were removed, the total weight of the casting material would be approximately 45 pounds less. The fill time used in the base case is 22 seconds and the casting weighing around 300 pounds. Back calculating the optimal fill time calculator in the Gating Design Wizard from equation (4.7) would result in a critical section thickness of around threeeights of an inch ( $3 / 8 \mathrm{inch})$, which is approximately the thickness of the ingates of the casting. Using this critical section thickness, the new calculated fill time from the Gating Design Wizard for this particular casting design with no top risers is approximately 19 seconds. 
The Critical Fraction Solid Time plots showed the upper thick ring area is an isolated area. It was separate from the bottom pool of liquid metal when the thin wall solidified. The rest of the casting solidified in the same manner as the base case. The Material Density Function plots showed quite a high possibility of macroporosity occurring inside the upper thick ring area from lack of feed metal, as shown in Figure 5.32 and 5.33 .

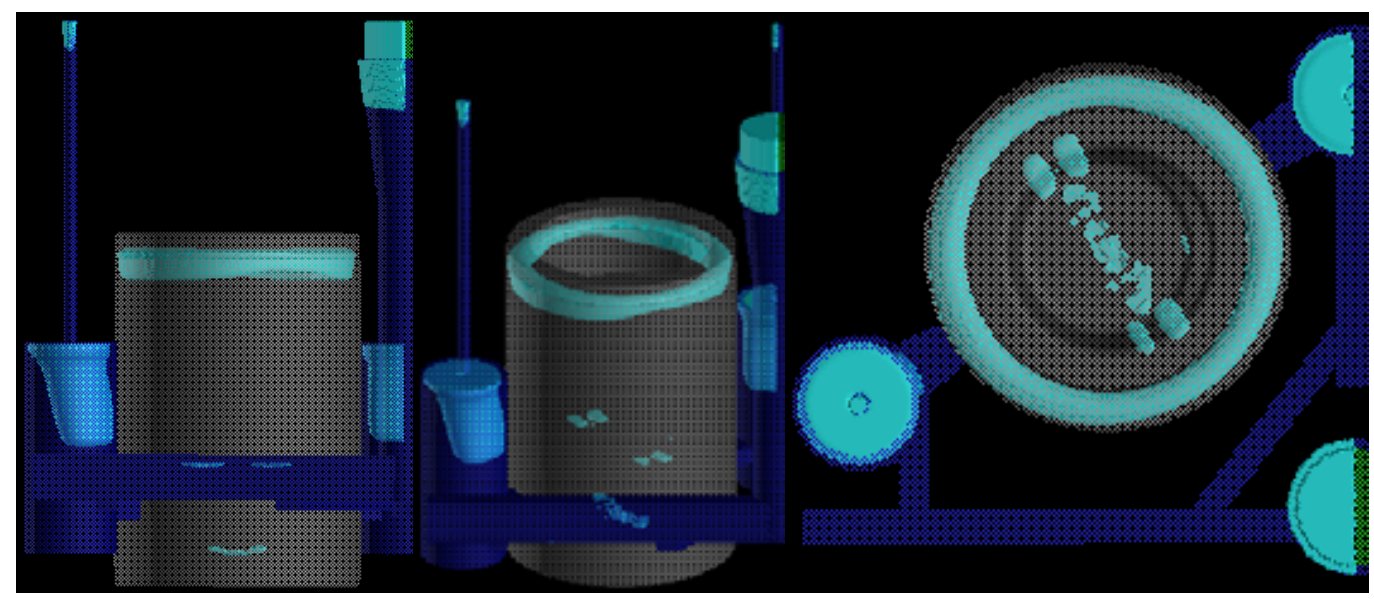

Figure 5.32: Iso-surface plots of the Material Density Function plotted at 0.995.

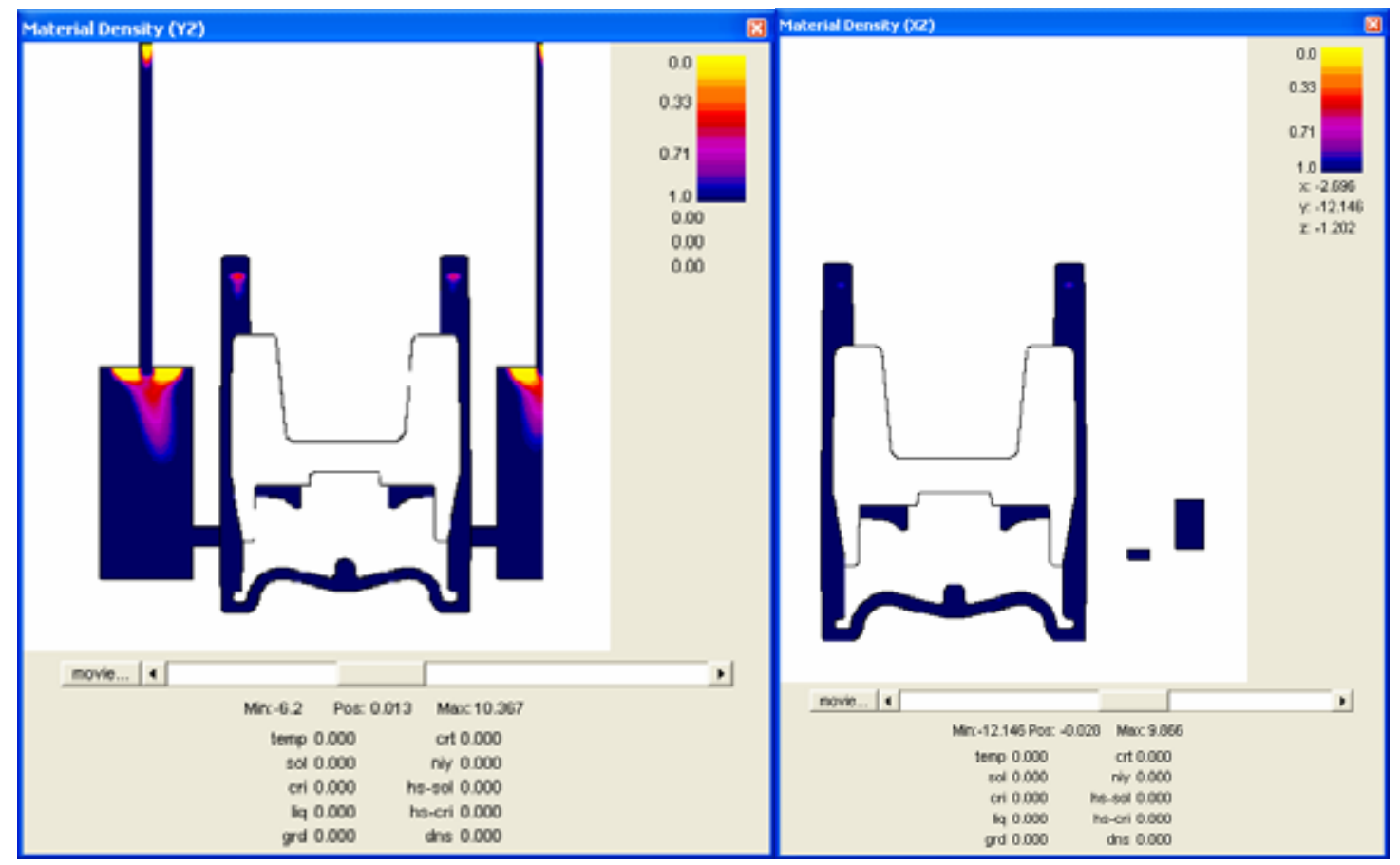

Figure 5.33: Cut-plane plots of the Material Density Function plotted from 0 to 1. 
The FCC Criterion plots showed almost no signs of microporosity. Only some small highlighted pixels showed, which may be considered insignificant. As for the Hot Spot Criterions plots, they were very similar to the base case, except that normally there would be a gap under the top riser, now the upper thick ring area has a full highlighted ring. This test concluded that there should be a riser to feed the upper thick ring area or else macroporosity would occur inside the ring area.

\subsubsection{Reduce Size of Neck of Top Riser}

In this test, the neck connecting the top riser to the casting was reduced to twothirds $(2 / 3)$ of its original width in order to observe if some liquid metal could be trapped in the casting cavity and solidify in isolation instead of directionally solidifying into the riser as in the base case. This test was conducted assuming that if graphite precipitation occurs and causing expansion, it may push the liquid metal back into the riser, and when the metal shrinks, would cause shrinkage porosities. Actually, SOLIDCast would not be able to calculate this type of situation as the nodes cannot move, but the user may be able to see the solidification sequence and predict how the casting would solidify and find out the best time the neck should freeze off in this type of situation.

The Critical Fraction Solid Time plots showed almost no difference between the test and the base case. The pool of liquid in the upper thick ring area solidified into the riser by around less than half a minute faster than the base case. The neck did not freeze off separating the pool of liquid metal. It may have been because the neck was too short or not small enough, so the heat from the casting kept it from freezing off.

The Material Density Function and FCC Criterion plots did not show significant difference from the base case, but the Hot Spot Criterions plots showed that the size of the hot spot directly under the neck in the casting increased. This may mean that the neck trapped a small amount of liquid metal retarding the directional solidification towards the riser even though it did not show in the Critical Fraction Solid Time plots.

\subsubsection{Add a Circular Fin Around Outer Surface of Upper Ring Hot Spot}

A circular fin with a thickness of 0.08 inch (or actually 0.079 inch due to the node size restrictions) and a width of 1 inch was added to the upper thick ring area of the 
casting exactly surrounding the ring shaped hot spot in the upper thick ring area. Even though adding this fin may not be done in the real casting, the purpose of adding this fin in the model was to see if it could cool this ring area faster and reduce the potential hot spots in this area.

From the Critical Fraction Solid Time plots, the fin cooled down lower than the critical fraction solid temperature before the pouring was finished. The Solidification Time plots were also observed and it was found that the fin has totally solidified before the pouring was finished as well, as shown in Figure 5.34.

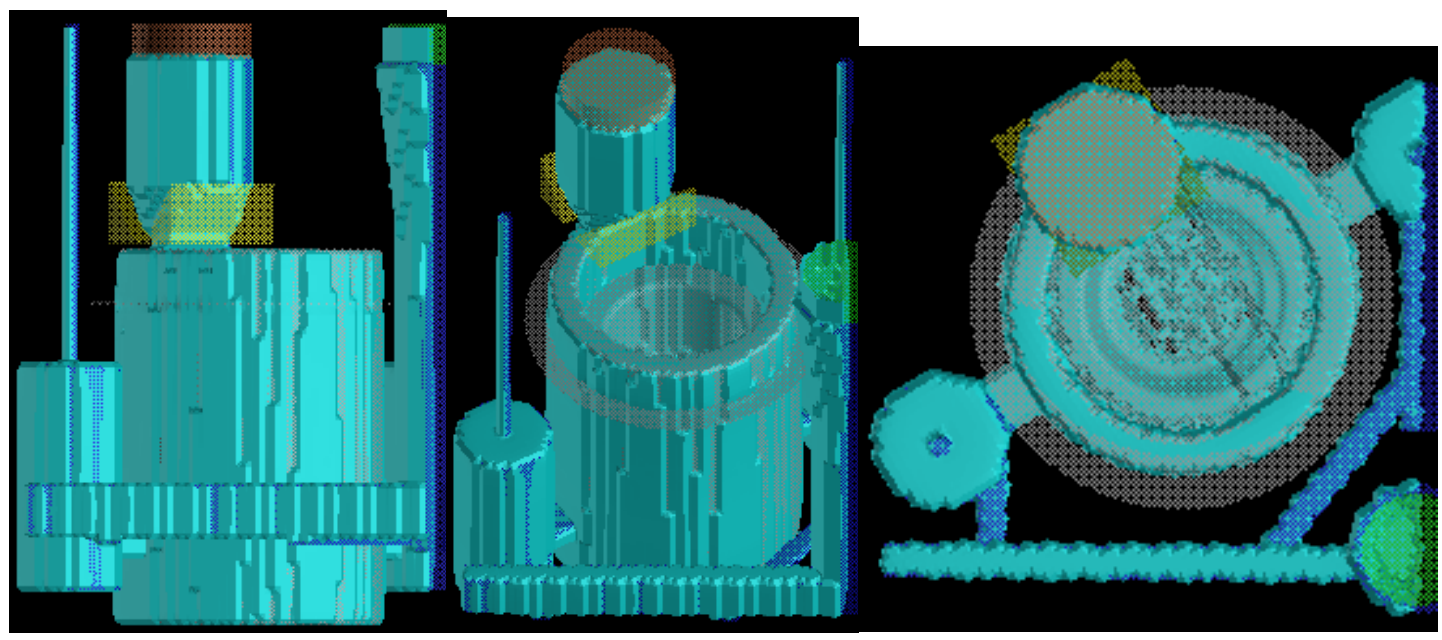

Figure 5.34: Solidification Time plot plotted at 0 minute.

The Critical Fraction Solid Time plots showed that the fin increased the speed of solidification and decreased the solidification time in that area by approximately one and a half minutes. The other parts of the casting solidified at the same speed as the base case. The Material Density Function plots did not show any difference at all compared to the base case, but the FCC Criterion plots showed that adding the fin reduced the possibility of microporosity occurring in this area. The intensity of the highlighted hot spots in the Hot Spot Criterions plots were the same compared to the base case, but it seemed like they were pushed towards the inner side of the ring area. Figure 5.35 shows cut-plane plots of the Hot Spot Criterion calculated by the solidification time. 


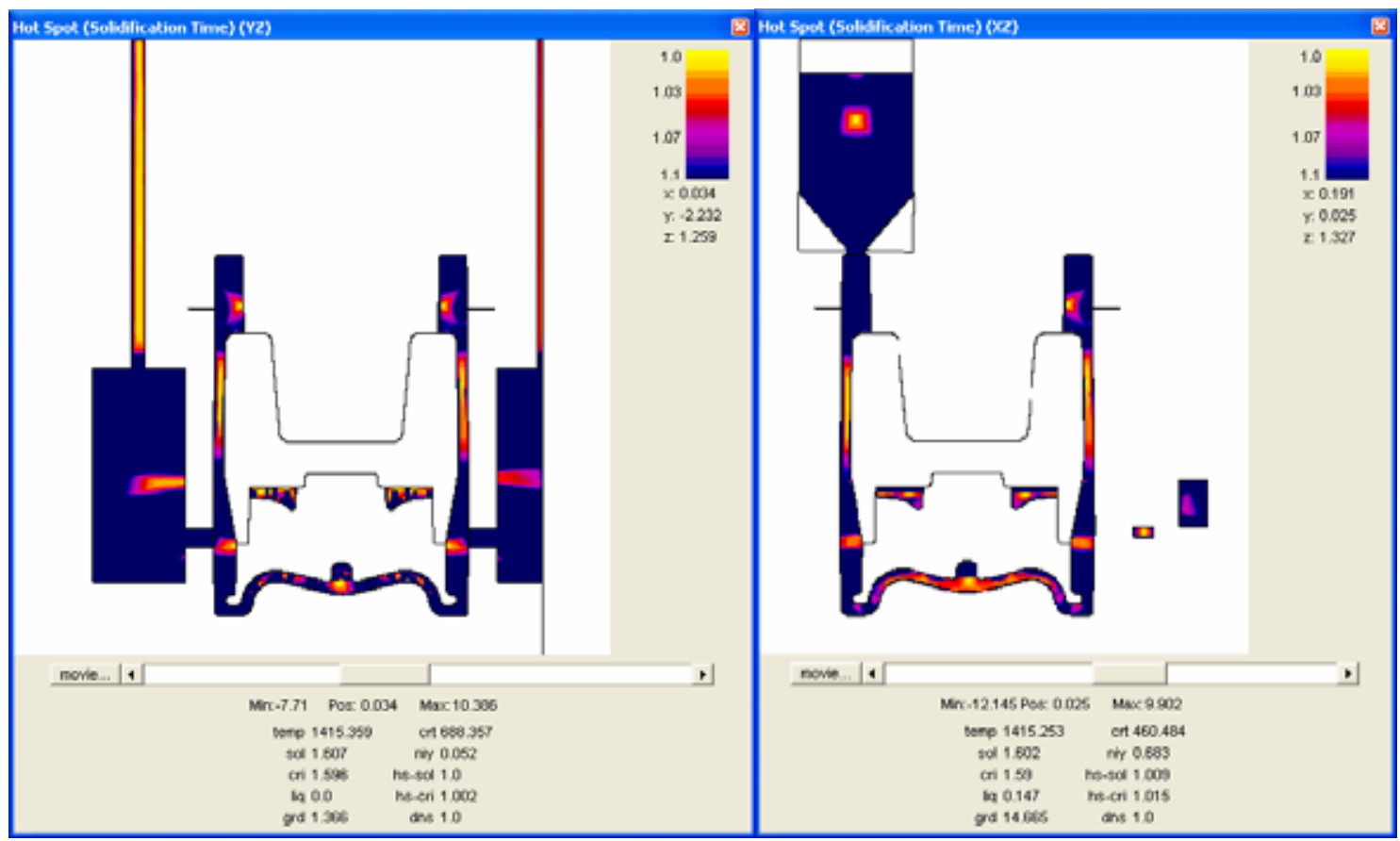

Figure 5.35: Cut-plane plots of Hot Spot (Solidification Time) Criterion.

\subsubsection{Add Circular Fins Around Outer and Inner Surface of Upper Ring Hot Spot}

In this case, an additional fin was added on the inner surface of the upper thick ring area apart from the fin surrounding the outer surface added from the previous section. The thickness and width of this additional fin is the same as the previous fin, only smaller, as it is attached on the inside.

The Critical Fraction Solid Time plots showed that the upper thick ring area cooled down faster than with only the outer ring fin by almost half a minute. The Material Density Function and FCC Criterion plots showed no difference between the two modifications, but the Hot Spot Criterions plots showed that the ringed hot spot seemed to be pushed back into the middle and increased in size, as shown in Figure 5.36.

An additional test was conducted along with this test adding iron chills surrounding the whole upper thick ring area to observe if the hot spots could anyway be eliminated. It was found that they never disappeared because the method of calculating the plots is comparing the time (critical fraction solid or solidification time) of a particular node with its neighbors. So, no matter how rapid the cooling is, if the direction of solidification is still the same, the hot spot plots shall still be in the same positions. "The hot spot plot does not give an indication of the severity of the defect, as it does not 
take contraction or expansion into account. But it does give a good indication of what areas may have problems (Unit 26 of the SOLIDCast manual)." So, even if the hot spots still showed in the plots, there may be no problems in the area at all.

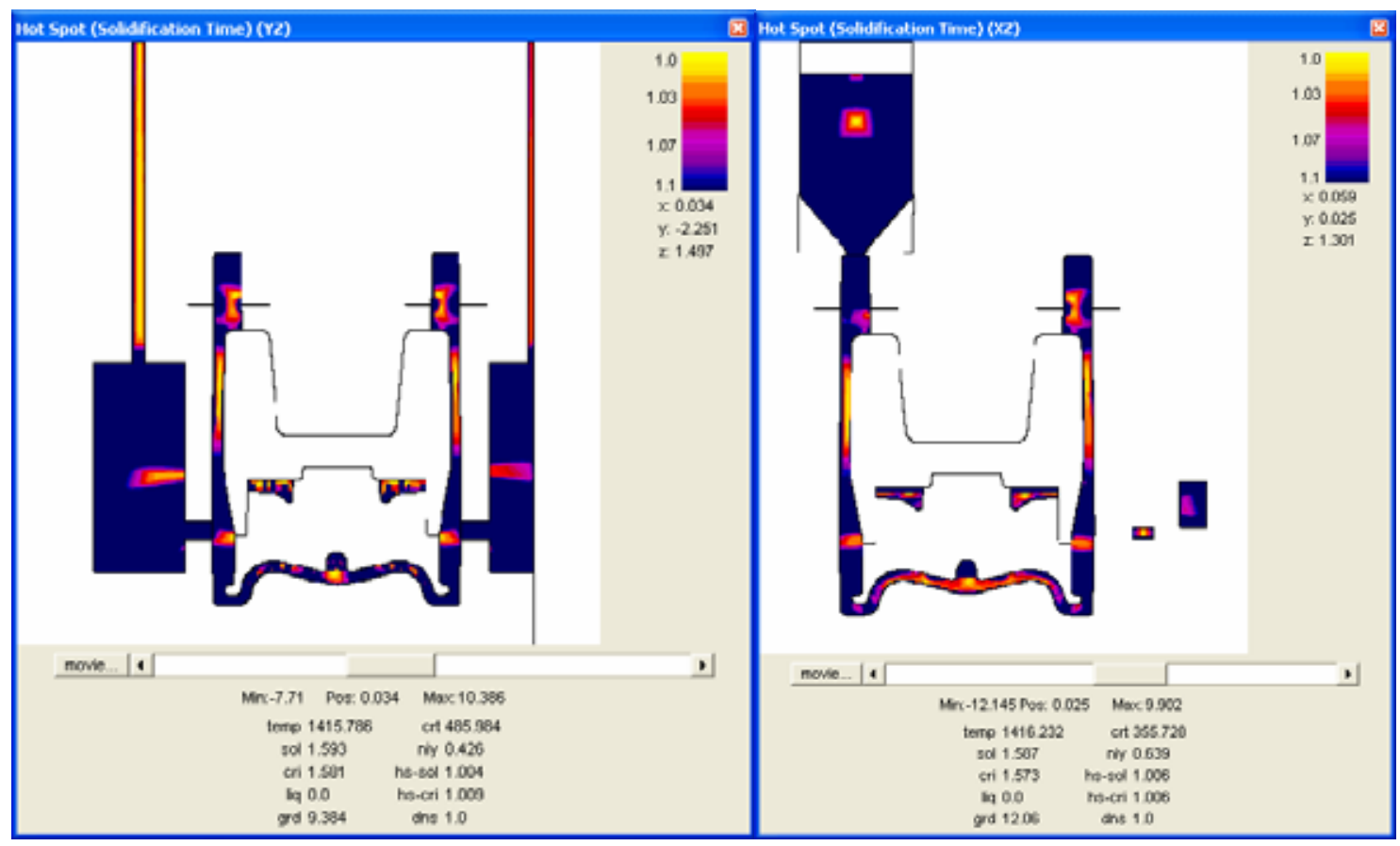

Figure 5.36: Cut-plane plots of Hot Spot (Solidification Time) Criterion.

\subsubsection{Add Fin at Outer Surface of Upper Ring Hot Spot Across from Top Riser}

In this case, a fin with the same thickness as the previous cases, but with 2 inches in width from the outer surface of the upper ring hot spot at the point across from the top riser and tapered down to the mid-point instead of surrounding the whole casting was added. Although this design may not actually be done in a real casting, but its purpose was to see if the design could encourage better directional solidification. In the Critical Fraction Solid Time plots, they showed that the solidification speed at the area across the top riser was relatively faster than the base case, but after mid-point where there was no fin, the solidification speed was the same compared to the base case. The Material Density Function and FCC Criterion plots were at the same levels as the base case. Figure 5.37 shows an example of the design plotted with the Material Density Function at 0.995. As for the Hot Spot Criterions plots, they were somewhat a mixture between the base case and the case which the fin surrounded the outer surface of the hot spot. The hot 
spot was pushed inside in the half across the top riser, and stayed the same on the side of the top riser.

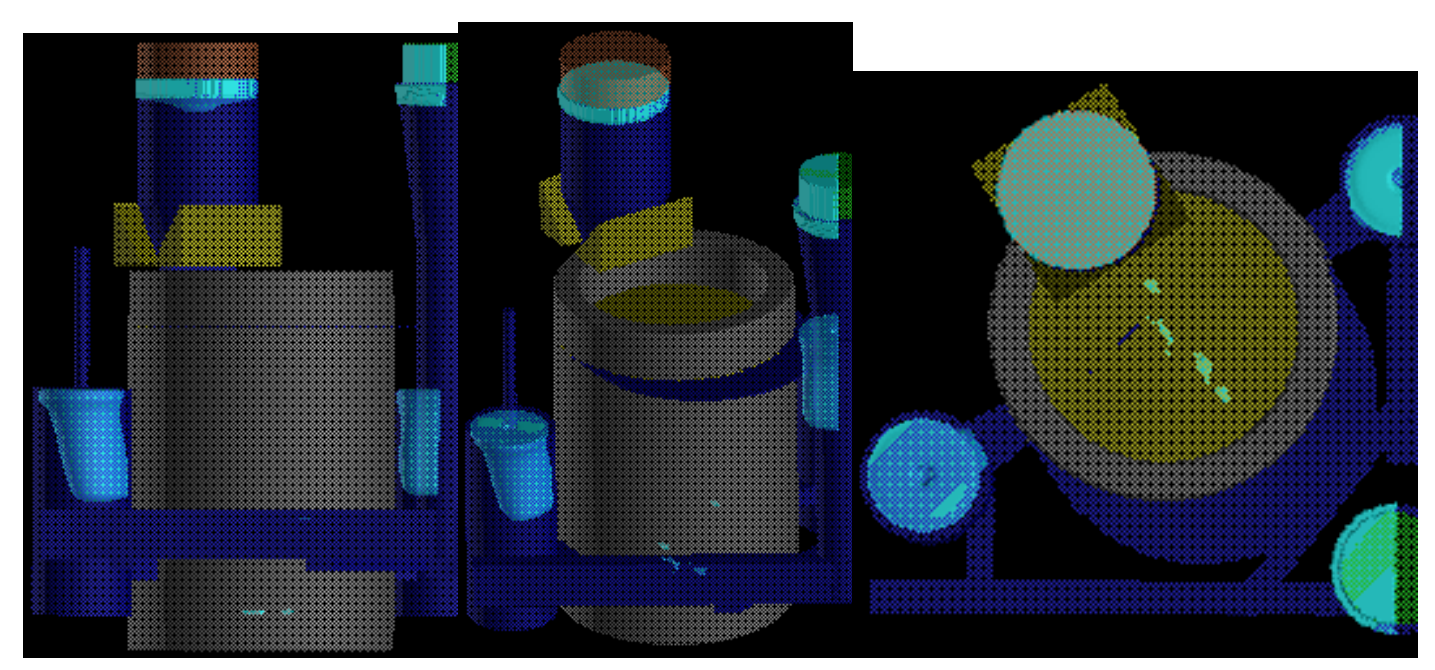

Figure 5.37: Material Density Function plots plotted at 0.995.

\subsubsection{Comparing 3.975 and 3.70 Percent Carbon Equivalent to Base Case}

In this test, the weight percent carbon, silicon and phosphorus were set back to the average percentages of the chemical composition ranges, with 3.975 percent Carbon Equivalent as was calculated in equation (5.1), and decreased to 3.70 percent Carbon Equivalent. The weight percent of carbon, silicon and phosphorus used in this test was 3.25, 2.1 and 0.075 percent respectively for the 3.975 percent Carbon Equivalent and $3.024,1.954$ and 0.075 percent respectively for the 3.70 percent Carbon Equivalent. The calculations for finding the weight percent of carbon and silicon are shown in equations (5.9) through (5.13).

$$
\begin{array}{ll}
3.975 & =3.25+1 / 3(2.1+0.075) \\
3.975-0.025 & =3.25+(2.1 / 3) \\
3.95 & =3.25+(2.1 / 3) \\
3.70 & =\mathrm{C}+1 / 3(\mathrm{Si}+0.075) \\
3.70-0.025 & =\mathrm{C}+(\mathrm{Si} / 3) \\
3.675 & =\mathrm{C}+(\mathrm{Si} / 3)
\end{array}
$$




$$
\begin{array}{ll}
\mathrm{C} & =3.25 \times(3.675 / 3.95) \\
& =3.024 \% \\
& \\
\mathrm{Si} & \\
& =1.1 \times(3.675 / 3.95) \\
\mathrm{CE} & =3.024+(1.954 / 3)+(0.075 / 3) \\
& =3.700 \%
\end{array}
$$

Table 5.5: Comparing the results from the VDG Iron Properties Calculator of 3.70, 3.85 and 3.975 percent Carbon Equivalent.

\begin{tabular}{|c|c|c|c|c|c|c|}
\hline \multicolumn{4}{|c|}{ Inputs } & \multicolumn{2}{c|}{ Outputs } \\
\hline \multirow{2}{*}{$\begin{array}{c}\text { Temperature } \\
\text { in Mold }\left({ }^{\circ} \mathbf{F}\right)\end{array}$} & $\begin{array}{c}\text { Casting } \\
\text { Modulus } \\
\text { (inch) }\end{array}$ & Carbon & Silicon & Phosphorus & $\begin{array}{c}\text { Shrinkage } \\
\text { Time in } \\
\text { Percent of } \\
\text { Solidification } \\
\text { Time }\end{array}$ & $\begin{array}{c}\text { Percent } \\
\text { Contraction }\end{array}$ \\
\hline 2,500 & 0.4407624 & 3.024 & 1.954 & 0.075 & 90 & 4.21 \\
\hline 2,500 & 0.4407624 & 3.147 & 2.034 & 0.075 & 90 & 4.1 \\
\hline 2,500 & 0.4407624 & 3.25 & 2.1 & 0.075 & 87.4 & 4.01 \\
\hline
\end{tabular}

Table 5.6: Comparing the results from the Simulation Status window of 3.70, 3.85 and 3.975 percent Carbon Equivalent.

\begin{tabular}{|c|c|c|c|c|c|c|}
\hline CE (\%) & $\begin{array}{c}\text { Simulated } \\
\text { Time } \\
(\mathbf{m i n} .)\end{array}$ & $\begin{array}{c}\text { Max } \\
\text { Casting } \\
\text { Temp }\left({ }^{\circ} \mathbf{F}\right)\end{array}$ & $\begin{array}{c}\text { Min } \\
\text { Casting } \\
\text { Temp }\left({ }^{\circ} \mathbf{F}\right)\end{array}$ & $\begin{array}{c}\text { Max Mold } \\
\text { Temp }\left({ }^{\circ} \mathbf{F}\right)\end{array}$ & $\begin{array}{c}\text { Min Mold } \\
\text { Temp }\left({ }^{\circ} \mathbf{F}\right)\end{array}$ & $\begin{array}{c}\text { Time } \\
\text { Steps }\end{array}$ \\
\hline $\mathbf{3 . 7 0}$ & 21.255 & $2,056.957$ & 330.531 & $2,059.166$ & 80 & 23,230 \\
\hline $\mathbf{3 . 8 5}$ & 21.41 & $2,055.294$ & 206.452 & $2,025.805$ & 80 & 23,400 \\
\hline $\mathbf{3 . 9 7 5}$ & 21.666 & $2,057.252$ & 208.027 & $2,027.919$ & 80 & 24,577 \\
\hline
\end{tabular}


Table 5.5 and 5.6 shows the results from the VDG Iron Properties Calculator and from the Simulation Status window of 3.70, 3.85 and 3.975 percent Carbon Equivalent respectively. The calculations do not seem to differ much from each other, except for the minimum casting temperature and maximum mold temperature of the 3.70 percent Carbon Equivalent. Actually the casting model built for this particular case had a reduction of the drill holes' lengths down to 5 inches, which is the length of what the metal in the drill holes should be if misrun. Additional tests were conducted and showed that the length of the drill hole does not affect the model in a whole. So, the minimum casting temperature measured was probably from the metal in the drill hole, i.e., the further away from the riser, the cooler the metal would be. But for the maximum mold temperature, it normally should not exceed the maximum casting temperature, unless it was measured from the exothermic top which was slowly cooling down. The clearest trends which were considered were the percent contraction and the simulated time. It seems that the higher the percent Carbon Equivalent, the smaller the net contraction, and that more time was needed for the casting to solidify.

The Critical Fraction Solid Time plots showed no difference in the progression of solidification, but slightly different in the timing, as a higher percent Carbon Equivalent took a slightly longer time. The Material Density Function plots were considered to be the same, but the FCC Criterion plots, although almost identical, showed that the case with 3.85 percent Carbon Equivalent had the highest chance of having microporosities, then the 3.70, and the 3.975 percent Carbon Equivalent respectively. As for the Hot Spot Criterions plots, all three cases seemed to be the same.

\subsubsection{Add Hemispheric Bottoms to Side Risers}

The single and shared blind risers were added with hemispheric shaped bottoms. The rectangular shaped mold was slightly enlarged due to the extended bottom resulting in a slightly larger node size. The Critical Fraction Solid Time plots showed the same solidification progression compared to the base case. The Material Density Function plots showed slightly more possible macroporosities occurring in the area between the core pieces and the bottom of the casting but in the FCC Criterion plots showed almost no highlighted areas of possible microporosity. As for the Hot Spot Criterions, the hot 
spot plots calculated by the solidification time seemed the same compared to the base case but the hot spot plots calculated by the critical fraction solid time showed that the hot spot under the top riser disappeared. The reason why the hemispheric shaped bottoms were added was to see if the thermal centers in the risers showing in the hot spot plots would move down towards the necks or not, which they did not. Actually, in a real casting, the thermal center should move down because of the level of the liquid metal in the risers should drop due to feeding, but because the nodes in SOLIDCast cannot move, the thermal centers do not move as well.

\subsubsection{Move Side Risers Down}

The single and shared blind risers were moved lower until the middle of the risers connected to the necks. The purpose was to move the thermal centers in the risers towards the necks. Normally the thermal center should move down because of the level of the liquid metal in the risers should drop due to feeding. The Critical Fraction Solid Time plots showed the same solidification progression compared to the base case. The Material Density Function plots showed slightly more possible macroporosities occurring in the area between the core pieces and the bottom of the casting, and when plotted with 1.0 , an area in the thin wall under the top riser was highlighted. The FCC Criterion plots showed almost no highlighted areas of possible microporosity. The Hot Spot Criterions plots were almost exactly the same as the model with risers with hemispheric shaped bottoms.

\subsubsection{Conclusions of Modifying the Casting Design}

SOLIDCast is helpful for users to predict the outcomes of a new casting design. A user may use SOLIDCast to help predict outcomes and potential problems in deciding on an option of improving the design of a casting design before casting a real casting. It would help prevent loss in the investment on trial castings. But the results from SOLIDCast have limitations due to the software, such as axis alignment, node size restrictions and node movement and limitations in the physics of metallurgy such as gravity, head pressure, etc. 


\subsection{Using the Riser and Gating Design Wizard Programs}

The Riser and Gating Design Wizard programs are sub-programs in SOLIDCast which may help a user design the riser and gating systems for a particular casting design. They may be used to improve an existing casting design or design the riser and gating system from scratch. The following sections show the calculated dimensions from the Riser Design Wizard accessed from the Simulation tab and accessed from the VDG Iron Properties Calculator and the Gating Design Wizard. The calculated dimensions shall be used for improving and re-designing the casting design.

\subsubsection{Riser Design Wizard}

There are two Riser Design Wizard programs in SOLIDCast; one can be accessed from the VDG Iron Properties Calculator and the other can be accessed from the Simulation tab in the menu. From past observations, the two programs may have different approaches, but the methods of calculating for the riser dimensions are quite similar. The Riser Design Wizard program from the Simulation tab shall be used for improving the currently used casting design, and the Riser Design Wizard program from the VDG Iron Properties Calculator shall be used for redesigning all the risers and their necks from scratch.

\subsubsection{Riser Design Wizard: Simulation Tab}

The piston including the core pieces excluding all risers and gating system were simulated once in order to use this Riser Design Wizard program. The settings in the Materials List window were set exactly the same as the base case, except for the Curves tab which uses the new calculated maximum modulus of the casting, from Figure 5.38 to calculate for the shrinkage curve using the VDG Iron Properties Calculator. The net shrinkage after adding a 1.5 percent mold wall movement at the eutectic point was 5.4 percent contraction. When entered the program, selecting the "Calculate and Display Casting Modulus" option, as shown in Figure 5.38, would let the user plot the suggested modulus for determining the number of feeding areas. The plots showed two feeding areas, but the bottom feeding area shows a narrowing area which may be two separate 
feeding areas. The modulus plot set up window is shown in Figure 5.39 and the resulting plot is shown in Figure 5.40.

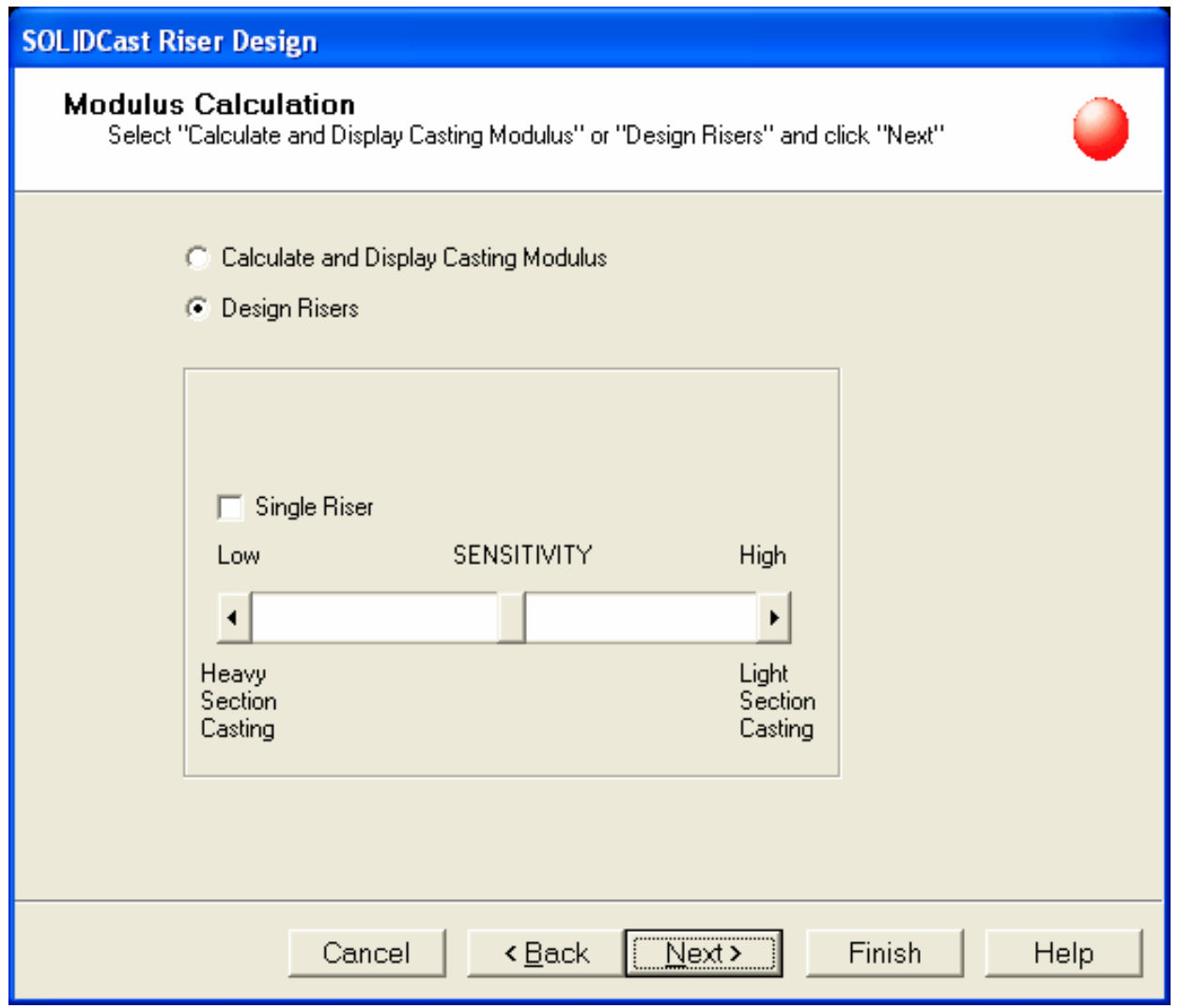

Figure 5.38: Options of "Calculate and Display Casting Modulus" and "Design Risers".

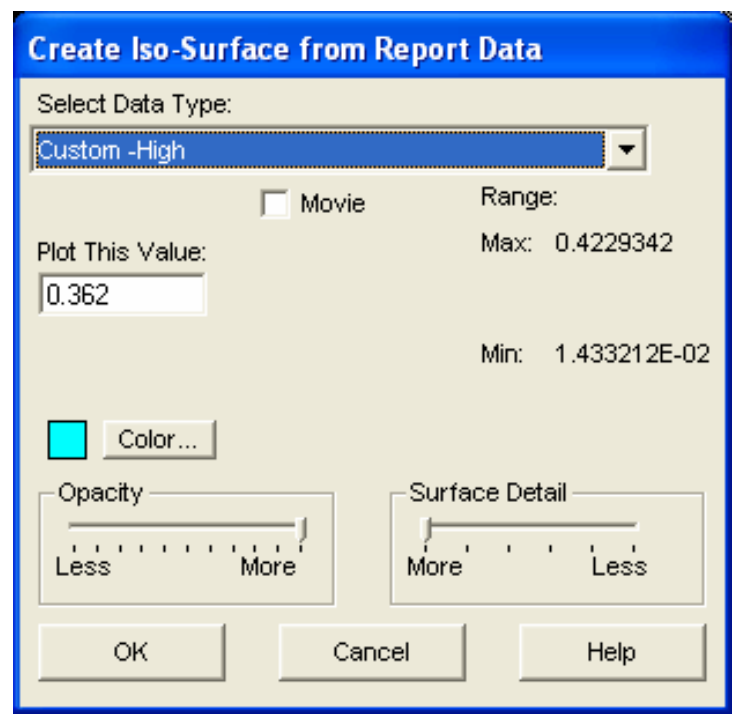

Figure 5.39: Modulus plot set up window. 


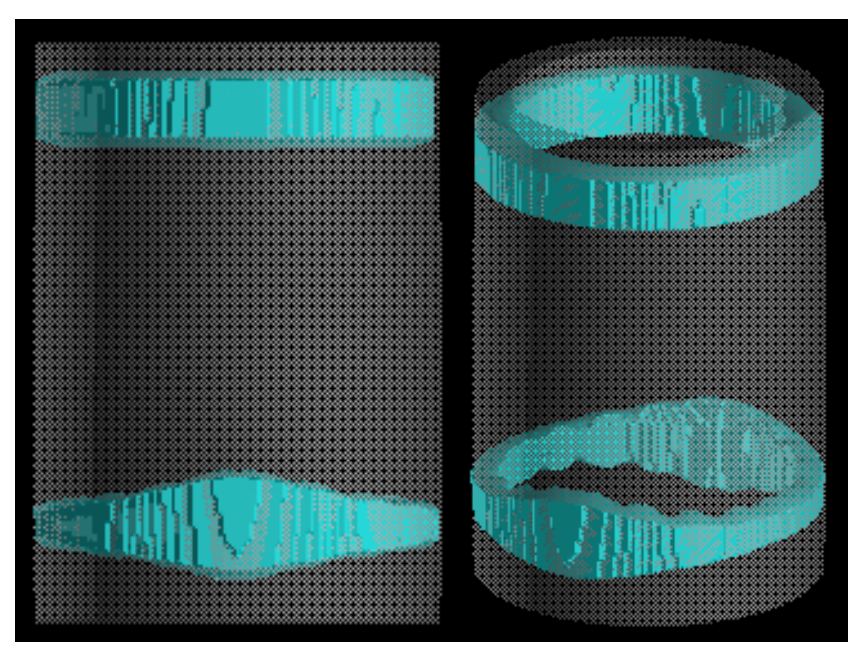

Figure 5.40: The resulting plots from the modulus plot set up window in Figure 5.39.

Next, returning to the Riser Design Wizard again, selecting the "Design Risers" option would let the user select a single riser for the casting or a sensitivity level for designing multiple risers, as shown in Figure 5.38. From observation, the numbers of risers calculated for a medium sensitivity to the lowest sensitivity was three risers, but as the level of sensitivity in the sliding bar increased, the calculated numbers of risers were 4, 5 and 6. When plotted the areas which each riser fed, the additional risers were placed inside the casting or fed very small areas which did not seem practical, so, the sensitivity level of the sliding bar was set at the middle and resulted in three feeding areas, as shown in Figure 5.41. Selecting the option "Plot feed area" would plot the areas of the calculated feeding areas, as shown in Figure 5.41. These areas were identified from a calculated modulus value of 0.39 , which is shown in Figure 5.42. This value was plotted by going back to select the option "Calculate and Display Casting Modulus" in Figure 5.38, and the resulting plots are shown in Figure 5.43. 


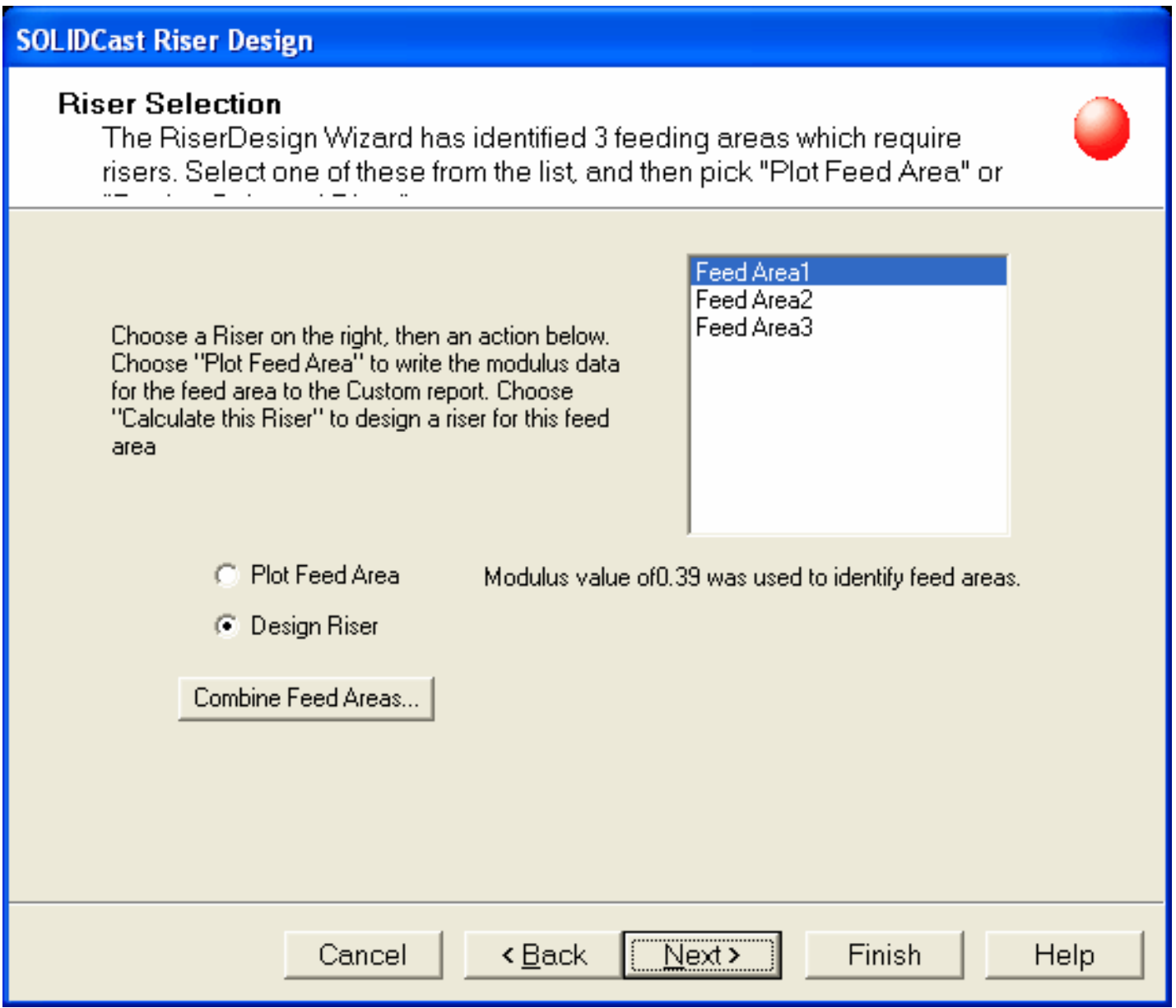

Figure 5.41: Calculated feeding areas.

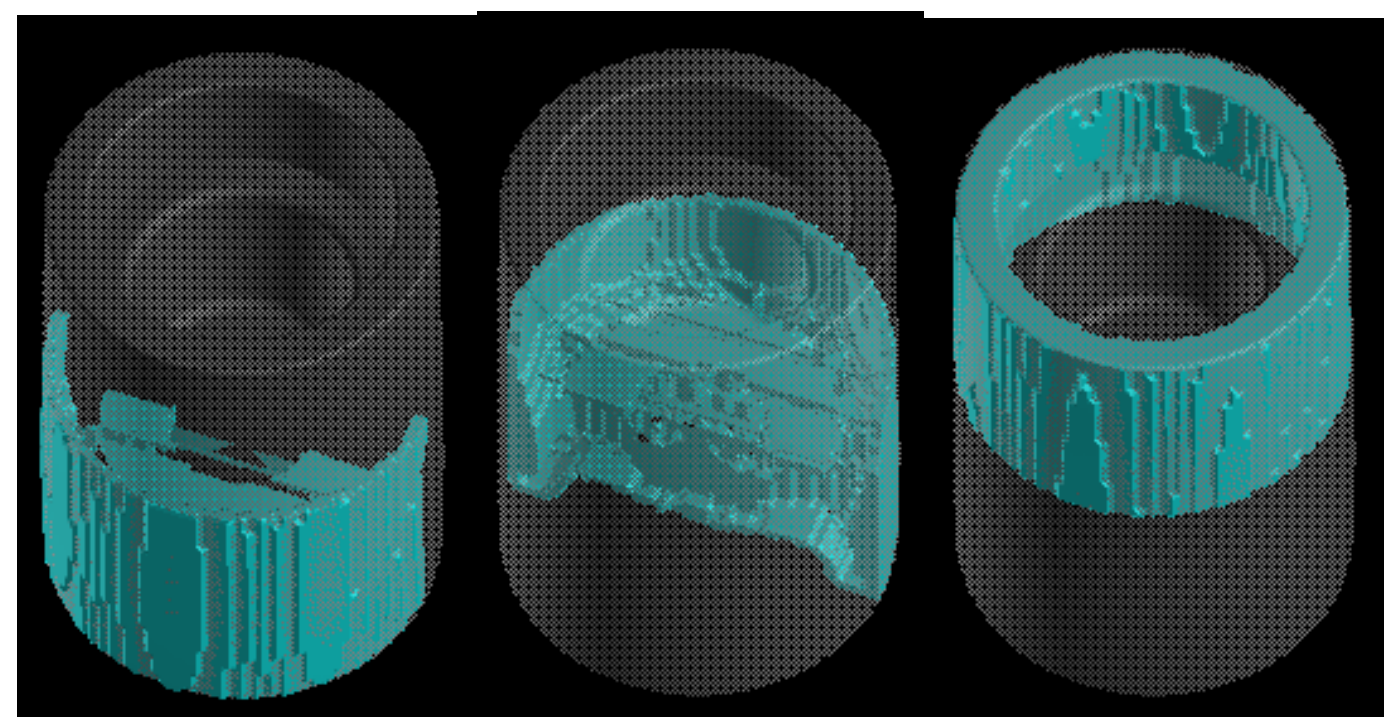

Figure 5.42: Plotted feeding areas; from left to right, Feed Area 1, Feed Area 2 and Feed Area 3. 


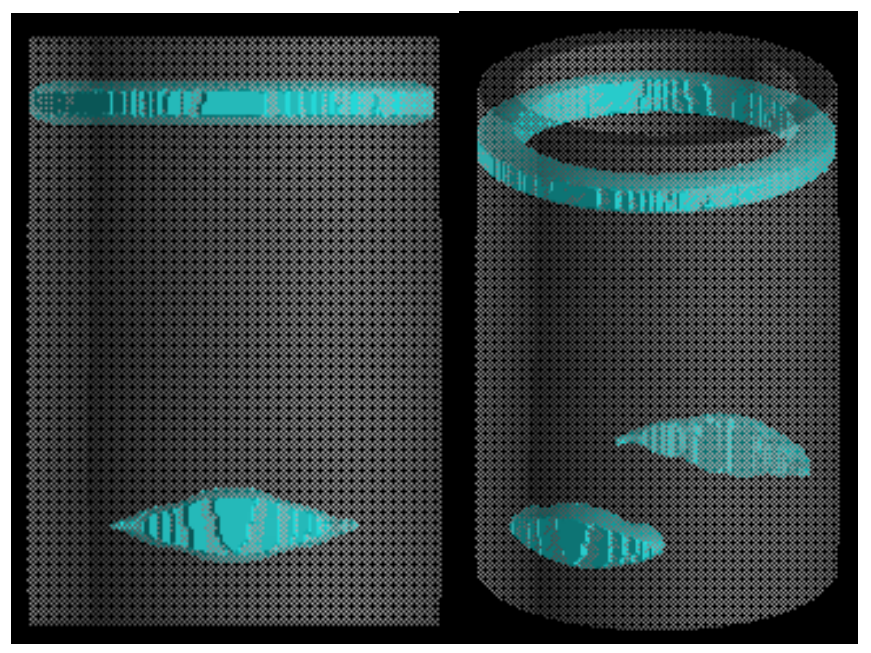

Figure 5.43: Plots plotted from feeding area identification modulus value of 0.39 showing 3 feeding areas.

Selecting a feeding area and selecting the option "Design Riser" in Figure 5.41 would appear a window as shown in Figures 5.44, 5.45, 5.46 from selecting Feed Area 1, 2 and 3 respectively. They would automatically retrieve the modulus of that casting area, the casting volume or actually the volume of the feed area from the simulation and calculate the required riser modulus according to the riser per casting modulus ratio, which default value is 1.2. This value means that the modulus of a riser must be 20 percent more than the casting area it feeds (Finite Solutions Inc., 2005).

The riser could be selected to have no sleeve, an insulting sleeve or an exothermic sleeve which would have a "riser modulus increase factor" of $1,1.25$ and 1.33 respectively. The riser modulus increase factor would be multiplied by the calculated riser modulus and displayed in the "Actual Riser Modulus" box. The shape of the riser in this Riser Design Wizard is cylindrical. The modulus of a riser in this case is the volume of the cylindrical shape divided by the surface area of the whole cylindrical shape. As could be seen, this Riser Design Wizard does not calculate the neck dimensions.

In the calculator box, four calculator buttons with four calculation methods could be chosen to calculate the riser's dimensions, which could be summarized in Table 5.7. 


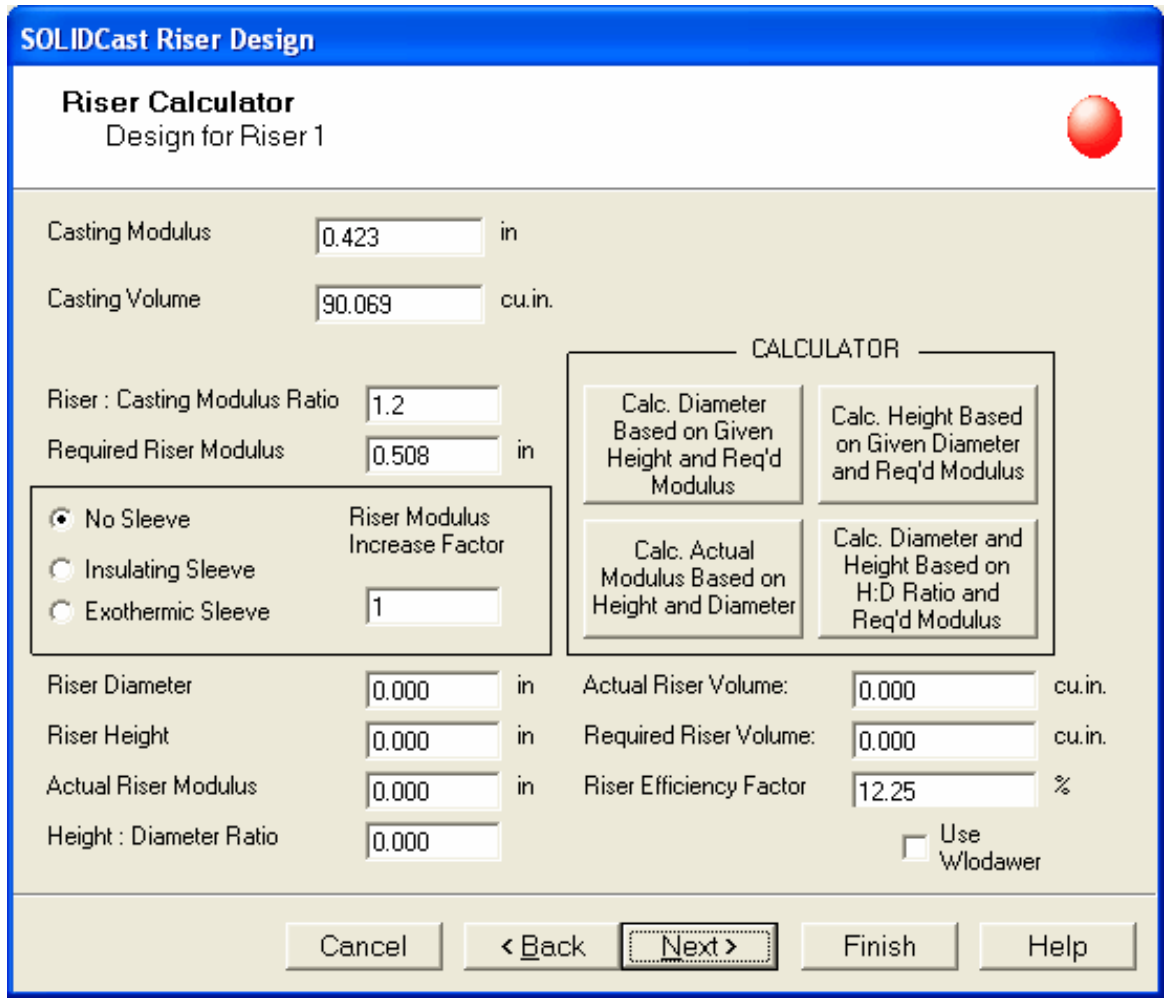

Figure 5.44: Riser calculator for Feed Area 1.

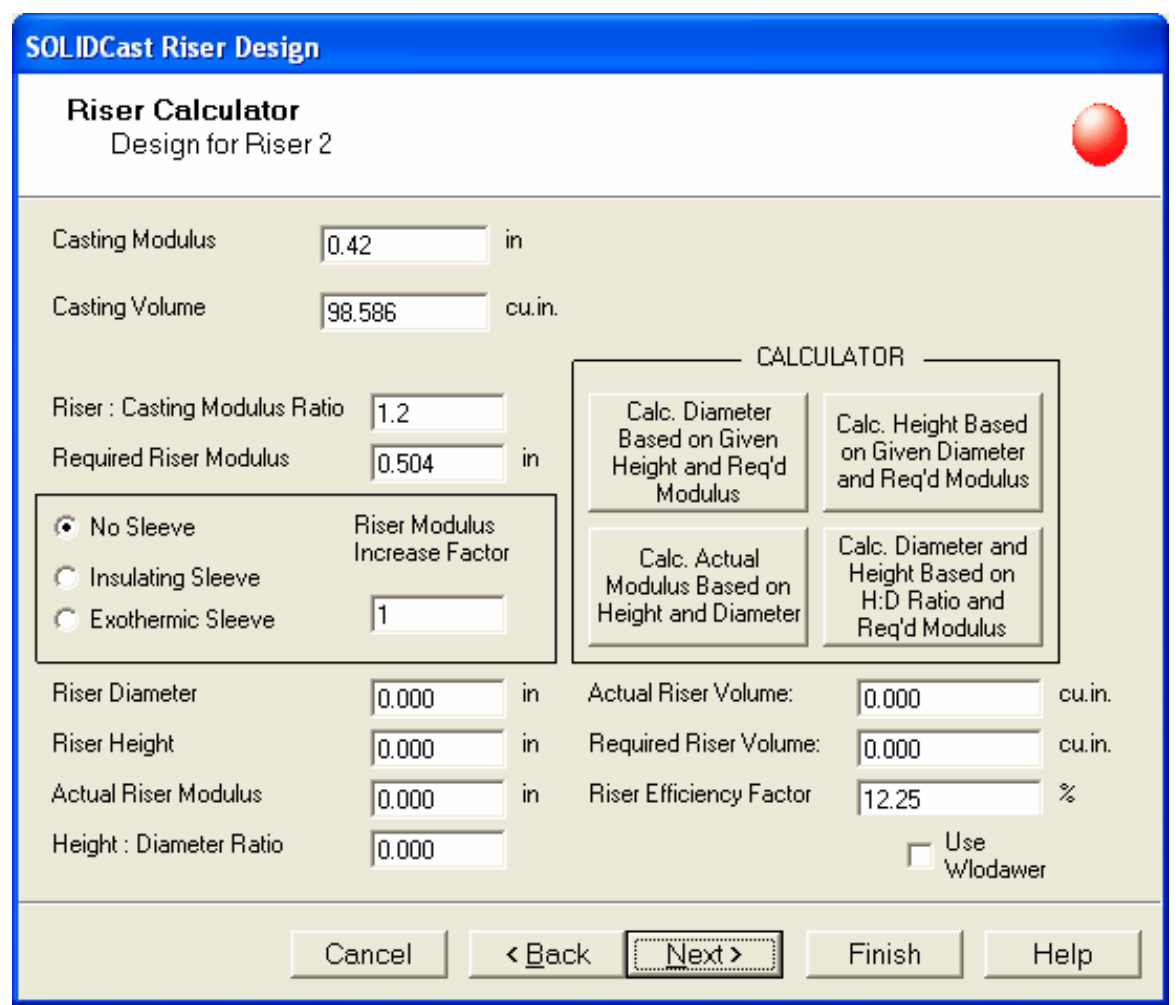

Figure 5.45: Riser calculator for Feed Area 2. 


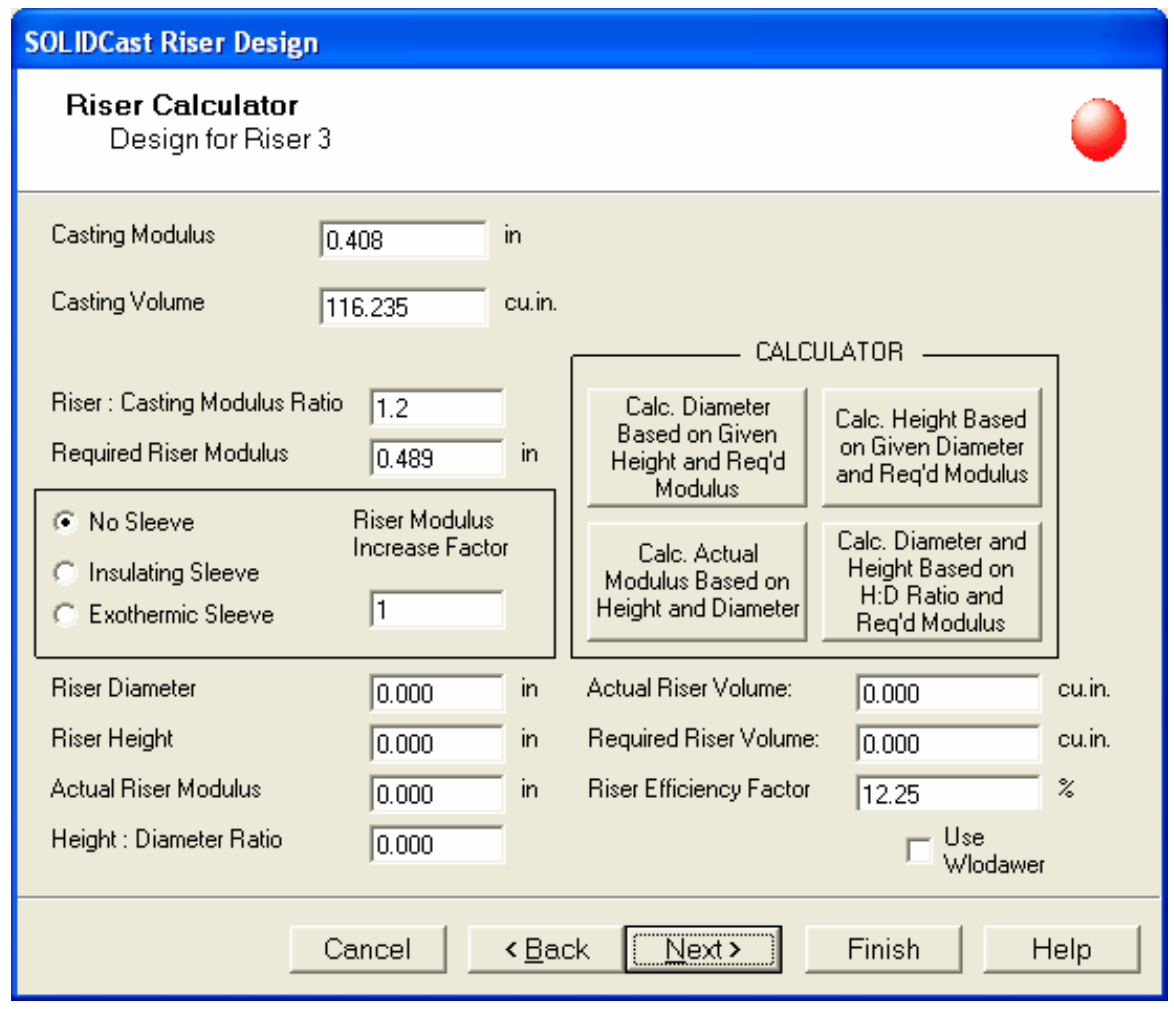

Figure 5.46: Riser calculator for Feed Area 3.

Table 5.7: The inputs needed and outputs provided by each calculator button in the calculator box.

\begin{tabular}{|c|c|c|}
\hline Calculator & Inputs & Outputs \\
\hline 1 & $\begin{array}{ll}\text { - } & \text { Height } \\
\text { - } & \text { Required riser modulus }\end{array}$ & $\begin{array}{ll}\text { - } & \text { Diameter } \\
\text { - } & \text { Actual riser volume }\end{array}$ \\
\hline 2 & $\begin{array}{ll}\text { - } & \text { Diameter } \\
\text { - } & \text { Required riser modulus }\end{array}$ & $\begin{array}{ll}\text { - } & \text { Height } \\
\text { - } & \text { Actual riser volume }\end{array}$ \\
\hline 3 & $\begin{array}{ll}\text { - } & \text { Height } \\
\text { - } & \text { Diameter }\end{array}$ & $\begin{array}{ll}\text { - } & \text { Actual riser modulus } \\
\text { - } & \text { Actual riser volume }\end{array}$ \\
\hline 4 & $\begin{array}{ll}\text { - } & \text { Height per diameter ratio } \\
\text { - } & \text { Required riser modulus }\end{array}$ & $\begin{array}{ll}\text { - } & \text { Diameter } \\
\text { - } & \text { Height } \\
\text { - } & \text { Actual riser volume }\end{array}$ \\
\hline
\end{tabular}


There is a checkbox shown in Figures 5.44, 5.45 and 5.46 which says "Use Wlodawer". Without checking the checkbox, the riser efficiency factor value would be retrieved from a chart kept in the database of the SOLIDCast program. It would take the riser per casting modulus ratio and riser type into consideration and produce the "riser efficiency factor" value. This is referred as the AFS Method according to the SOLIDCast manual (Finite Solutions Inc., 2005). But from various simulation runs on this piston casting, even though the riser per casting modulus ratio was always set at 1.2 and the same riser types selected, the riser efficiency factor value would change between simulation runs. It seemed more likely that the riser efficiency factor value would increase as the modulus of the whole casting increases, as shown in Table 5.8.

Table 5.8: Riser efficiency factor values resulting from different casting modulus values.

\begin{tabular}{|c|c|c|c|}
\hline $\begin{array}{c}\text { Casting } \\
\text { Modulus }\end{array}$ & $\begin{array}{c}\text { Riser:Casting } \\
\text { Modulus }\end{array}$ & Type of Riser & $\begin{array}{c}\text { Riser Efficiency } \\
\text { Factor (\%) }\end{array}$ \\
\hline 0.423 & 1.2 & No sleeve, no top & 12.25 \\
\hline 0.426 & 1.2 & No sleeve, no top & 12.45 \\
\hline 0.441 & 1.2 & No sleeve, no top & 13.64 \\
\hline
\end{tabular}

If the checkbox was checked, the riser efficiency factor value would be retrieved from the Wlodawer method (Finite Solutions Inc., 2005). The riser efficiency factor value would be 15 percent for a non-sleeved riser, 32 percent for a riser with an insulating sleeve and 35 percent for a riser with an exothermic top. Both the methods would follow equation (5.14). Rearranging the items in equation (5.14), the required riser volume may be calculated with equation (5.15).

$$
\begin{array}{ll}
\left(\mathrm{V}_{\mathrm{c}}+\mathrm{V}_{\mathrm{r}}\right) \times \mathrm{s} & =\mathrm{V}_{\mathrm{r}} \times \mathrm{E} \\
\mathrm{V}_{\mathrm{r}} & =\mathrm{V}_{\mathrm{c}} /(\mathrm{E} / \mathrm{s}-1)
\end{array}
$$

Where,

$$
\begin{array}{ll}
\mathrm{V}_{\mathrm{c}} & =\text { Volume of feed area, cubic inch } \\
\mathrm{V}_{\mathrm{r}} & =\text { Required riser volume, cubic inch } \\
\mathrm{E} & =\text { Riser efficiency factor, percent }
\end{array}
$$


$\mathrm{s} \quad=$ Shrinkage of alloy at the critical fraction solid point, percent

The procedure this Riser Design Wizard follows may be summarized as follows:

1) Calculating the required riser modulus by multiplying the casting modulus (modulus of the feeding area) by the riser per casting modulus ratio.

2) Calculating the required riser volume by using the formula in equation (5.15).

3) Enter the input values required for using the desired calculator button.

4) Calculating the actual riser modulus by multiplying riser modulus increase factor with the riser modulus calculated from the volume and surface area of the calculated riser dimensions.

The dimensions of the currently used risers were entered into the Riser Design Wizard. Table 5.9 shows the actual volume of each riser compared to the calculated riser volume required for each feeding area. For Riser 3, even though the actual riser has a funnel shaped bottom, the effective volume of the riser would be very close to a cylindrical riser with the same diameter and height.

Table 5.9: Comparing the actual riser volumes and the calculated riser volume required for each feeding area.

\begin{tabular}{|c|l|c|c|c|c|c|}
\hline \multirow{2}{*}{ Riser } & \multirow{2}{*}{ No. } & \multicolumn{1}{|c|}{$\begin{array}{c}\text { Type of } \\
\text { Riser }\end{array}$} & $\begin{array}{c}\text { Diameter } \\
\text { (inch) }\end{array}$ & $\begin{array}{c}\text { Height } \\
\text { (inch) }\end{array}$ & $\begin{array}{c}\text { Riser } \\
\text { Volume } \\
\text { (inch }\end{array}$ & \multicolumn{2}{|c|}{$\begin{array}{c}\text { Actual } \\
\text { (inch }\end{array}$} & \multicolumn{2}{|c|}{$\begin{array}{c}\text { Required Riser Volume } \\
\text { Method }\end{array}$} & $\begin{array}{c}\text { Wlodawer } \\
\text { Method }\end{array}$ \\
\hline 1 & $\begin{array}{l}\text { No sleeve, } \\
\text { no top }\end{array}$ & 3.5 & 8 & 76.969 & 69.591 & 49.78 \\
\hline 2 & $\begin{array}{l}\text { No sleeve, } \\
\text { no top }\end{array}$ & 3.5 & 8 & 76.969 & 76.17 & 54.487 \\
\hline 3 & $\begin{array}{l}\text { Exothermic } \\
\text { top }\end{array}$ & 4.25 & 6.5 & 92.211 & 22.749 & 20.924 \\
\hline 3 & $\begin{array}{l}\text { No sleeve, } \\
\text { no top }\end{array}$ & 4.25 & 6.5 & 92.211 & 89.806 & 64.242 \\
\hline
\end{tabular}


It could be seen from Table 5.9 that the actual riser volumes of the currently used risers are only slightly more than the required riser volumes calculated by the AFS method considering all risers to have no insulating sleeves and no exothermic tops. For Riser 3, or the top riser, the currently used riser is actually covered with an exothermic top, so, it seemed that this riser was initially calculated to not have an exothermic top. From the calculations, the top riser was over designed.

This Riser Design Wizard considers the mold to have a single casting, so, Riser 2 , the shared riser, may not be large enough to feed two feeding areas of two castings. But according to the simulation results, there were no potential problems occurring from the size of the shared riser.

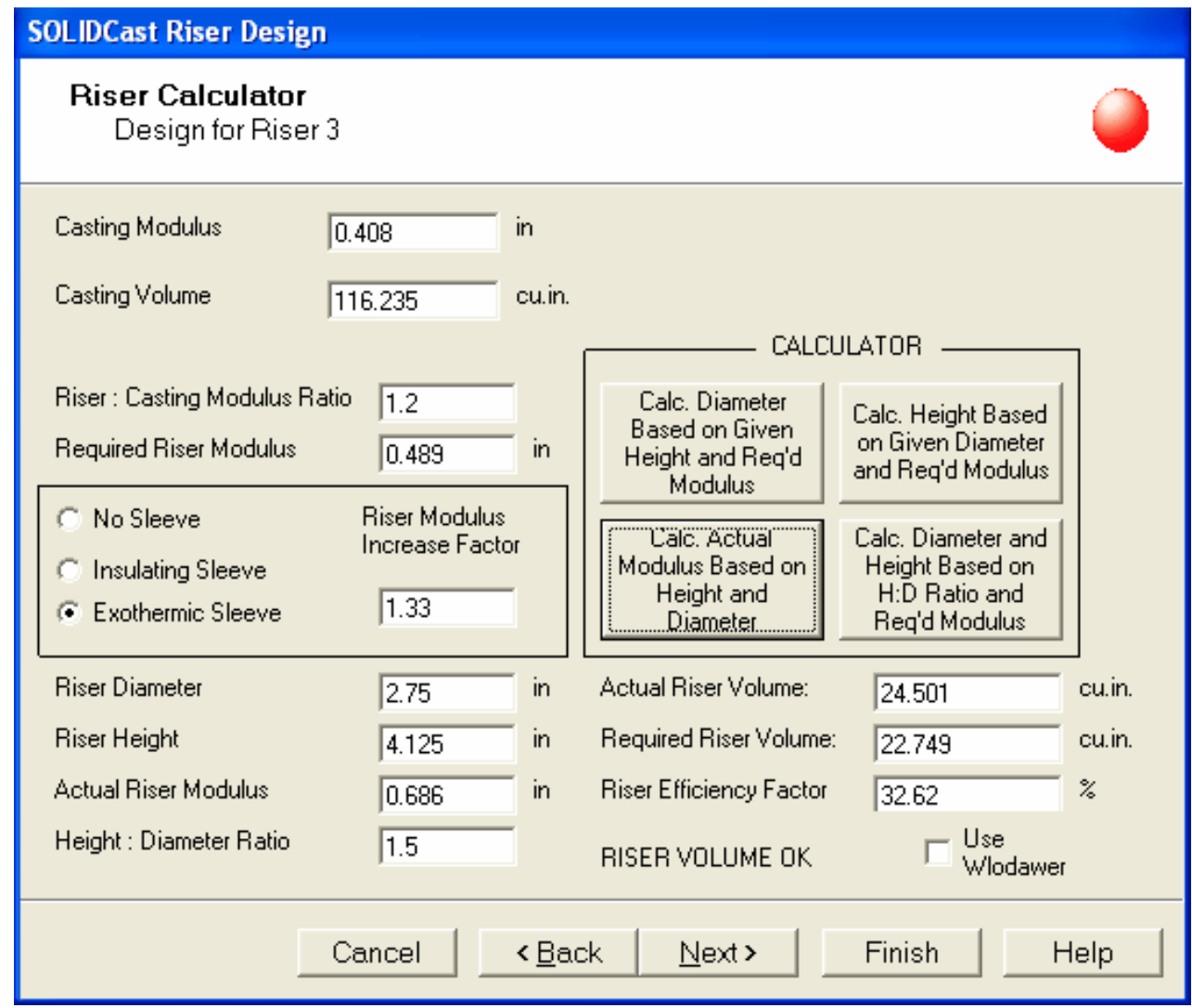

Figure 5.47: Calculated dimensions for Riser 3; the top riser.

It seemed possible that the size of the top riser could be reduced to increase the yield and use less casting material in casting the piston castings. From Table 5.9, the riser sizes were very close to the sizes of the calculated risers calculated with the AFS 
method, so, it seemed appropriate to calculate for a top riser with an exothermic top in the same manner. Figure 5.47 shows the calculated riser dimensions with a 1.5 height per diameter ratio for the exothermic top riser. The calculated riser is 2.75 inches by diameter and 4.125 inches by height.

Even though the neck dimensions cannot be calculated by this Riser Design Wizard, the neck modulus and the neck dimensions could be calculated by adopting equations (4.6) and (4.5) respectively.

The length of the necks of Riser 1 and 2 were each 1 inch, which cannot be considered as short necks, but the length of the neck of Riser 3, which was 0.25 inch, can be considered as a short neck. So, 0.6 must be multiplied to the normal neck modulus resulting in a smaller neck. Since this top riser was tapered, both neck dimensions shall be calculated. The neck dimensions for Riser 1,2 and 3 was calculated as shown in equations (5.16) through (5.23).

Neck dimensions for Riser 1 were calculated as;

$$
\begin{aligned}
\mathrm{M}_{\mathrm{n}} & =\mathrm{M}_{\mathrm{c}} \times \sqrt{ } \%_{\mathrm{ST}} \\
& =0.423 \times \sqrt{ } 0.90 \\
& =0.4013 \mathrm{inch} \\
\mathrm{L} & =4 \mathrm{M}_{\mathrm{n}} \\
& =4 \times 0.4013 \\
& =1.605 \mathrm{inch}
\end{aligned}
$$

Neck dimensions for Riser 2 were calculated as;

$$
\begin{aligned}
\mathrm{M}_{\mathrm{n}} & =\mathrm{M}_{\mathrm{c}} \mathrm{x} \sqrt{ } \%_{\mathrm{ST}} \\
& =0.420 \times \sqrt{ } 0.90 \\
& =0.3984 \mathrm{inch}
\end{aligned}
$$


$\mathrm{L} \quad=4 \mathrm{M}_{\mathrm{n}}$

$$
\begin{aligned}
& =4 \times 0.3984 \\
& =1.594 \text { inch }
\end{aligned}
$$

Neck dimensions of a short neck for Riser 3 were calculated as;

$$
\begin{aligned}
\mathrm{M}_{\mathrm{n}} & =0.6 \times \mathrm{M}_{\mathrm{c}} \times \sqrt{ } \% \mathrm{sT} \\
& =0.6 \times 0.408 \times \sqrt{ } 0.90 \\
& =0.2322 \mathrm{inch} \\
\mathrm{L} & =4 \mathrm{M}_{\mathrm{n}} \\
& =4 \times 0.2322 \\
& =0.929 \text { inch }
\end{aligned}
$$

Neck dimensions of a normal neck for Riser 3 were calculated as;

$$
\begin{aligned}
\mathrm{M}_{\mathrm{n}} & =\mathrm{M}_{\mathrm{c}} \times \sqrt{ } \% \mathrm{sT} \\
& =0.408 \times \sqrt{ } 0.90 \\
& =0.3871 \mathrm{inch} \\
\mathrm{L} & =4 \mathrm{M}_{\mathrm{n}} \\
& =4 \times 0.3871 \\
& =1.548 \text { inch }
\end{aligned}
$$

The connecting surface areas of the necks of the three risers were calculated as shown in equations (5.24) through (5.27).

$$
\begin{aligned}
\text { Neck area for riser } 1 & =1.605^{2} \\
& =2.576 \text { square inches }
\end{aligned}
$$




$$
\begin{aligned}
\text { Neck area for riser } 2 & =1.594^{2} \\
& =2.541 \text { square inches }
\end{aligned}
$$

$$
\begin{aligned}
\text { Short-neck neck area for riser } 3 \quad & 0.929^{2} \\
& =0.863 \text { square inches }
\end{aligned}
$$

Normal-neck neck area for riser $3=1.548^{2}$

$$
=2.397 \text { square inches }
$$

From the casting design dimensions shown in Figures 5.6 and 5.7, the actual surface areas of the necks of the three risers connected to the casting were calculated as shown in equations (5.28) through (5.30). The calculated and actual surface areas of the necks connecting the three risers to the casting are summarized and shown in Table 5.10.

$$
\begin{aligned}
\text { Neck area of riser } 1 & =0.75 \times 1.25 \\
& =0.9375 \text { square inches } \\
\text { Neck area of riser } 2 & =0.75 \times 1.25 \\
& =0.9375 \text { square inches } \\
\text { Neck area of riser } 3 & =0.75 \times 2.75 \\
& =2.0625 \text { square inches }
\end{aligned}
$$

Table 5.10: The actual and calculated surface areas of the necks connecting the three risers to the casting.

\begin{tabular}{|c|c|c|c|}
\hline \multirow{2}{*}{ Riser No. } & \multicolumn{3}{|c|}{ Surface Areas of the Necks Connected the Casting (square inch) } \\
\cline { 2 - 4 } & \multirow{2}{*}{ Actual } & \multicolumn{2}{|c|}{ Calculated } \\
\cline { 3 - 4 } & & Normal neck & Short neck \\
\hline 1 & 0.9375 & 2.576 & - \\
\hline 2 & 0.9375 & 2.571 & - \\
\hline 3 & 2.0625 & 2.397 & 0.863 \\
\hline
\end{tabular}


The actual surface areas of the necks connected to the casting area were smaller than the calculated neck dimensions, except for the short neck condition. Normally, a small neck is preferred so it has a low modulus and will freeze off before the expansion in the casting could push the liquid metal back into the riser. Since the original neck dimensions were working well and changing the neck sizes would not significantly help increase the yield, the neck dimensions were kept at their original sizes.

From Table 5.9, Riser 1 and 2 have approximately the same actual and calculated riser sizes but Riser 3 was quite different when calculated with this Riser Design Wizard accessed from the Simulation tab. Riser 3 was redesigned with the dimensions calculated from this Riser Design Wizard. The dimensions of the redesigned riser can be found in Figure 5.47. For the neck dimensions, the thickness and width was kept the same as the original design, so, the neck was considered a short neck. The resulting surface area of the connecting neck can be calculated as shown in equation (5.31). A summary of the dimensions which shall be used in designing Riser 3 or the exothermic top riser are shown in Table 5.11.

$$
\begin{array}{ll}
\text { Connecting area of neck } & =0.863 \text { inch }^{2} \\
\text { Length of neck } & =0.863 \div 0.75 \\
& =1.151 \text { inch }
\end{array}
$$

Table 5.11: Dimensions for designing Riser 3.

\begin{tabular}{|c|c|c|c|c|}
\hline \multicolumn{2}{|c|}{ Riser Dimensions (inch) } & \multicolumn{3}{c|}{ Neck Dimensions (inch) } \\
\hline Diameter & Height & Width & Length & Thickness \\
\hline 2.75 & 4.125 & 0.75 & 1.151 & 0.25 \\
\hline
\end{tabular}

\subsubsection{Riser Design Wizard: VDG Iron Properties Calculator}

The Riser Design Wizard accessed from the Simulation tab can design multiple risers for a single casting but does not calculate for the dimensions of the necks. The Riser Design Wizard accessed from the VDG Iron Properties Calculator can design one riser for a single feeding area casting and the neck dimensions. From analyzing the methods of calculating the riser dimensions of both the Wizard programs, they are very 
similar to each other. It seemed appropriate that the Riser Design Wizard accessed from the VDG Iron Properties Calculator can calculate the dimensions of a single riser feeding a single feeding area by entering the volume and modulus of the feeding area instead of the whole casting. The modulus and volumes of the feeding areas from Figures 5.44, 5.45 and 5.46 are summarized in Table 5.12.

Table 5.12: The modulus and volumes of the three feeding areas of the casting.

\begin{tabular}{|c|c|c|}
\hline Riser No. & Modulus of Feeding Area (inch) & Volume of Feeding Area (inch ${ }^{\mathbf{3}}$ ) \\
\hline 1 & 0.423 & 90.069 \\
\hline 2 & 0.420 & 98.586 \\
\hline 3 & 0.408 & 116.235 \\
\hline
\end{tabular}

\section{1) Design For Riser 1}

Riser 1 represents the single blind side riser in the actual casting design. The gating system is gated through the riser. The mold dilation is 1.5 percent. If the riser height per diameter ratio is 1.5 , by using the formula in equation (4.2), the diameter of the riser can be calculated as shown in equation (5.32) and the results in the Riser Design Wizard shown in Figure 5.48.

$$
\left[\pi \times\left(D^{2} / 4\right) \times(D \times r)\right] \times \% \%_{p} \quad=V_{c} \times\left(\%{ }_{V D G}+\%_{M D}\right) \quad \text { from }
$$

Where,

$\mathrm{D} \quad=$ Diameter of side riser, inch

$\mathrm{r} \quad=$ Riser height per diameter ratio, 1.5

$\mathrm{V}_{\mathrm{c}} \quad=$ Volume of casting (feeding area) from Table 5.12, 90.069 cubic inches

$\%_{\mathrm{p}} \quad=$ Proportion of liquid metal removed from riser, 20 percent

$\%_{\mathrm{VDG}}=$ Percent shrinkage calculated from the VDG Iron Properties Calculator, 4.1 percent

$\%_{\mathrm{MD}}=$ Mold dilation, 1.5 percent

$$
\begin{aligned}
{\left[\pi \times\left(\mathrm{D}^{2} / 4\right) \times(\mathrm{D} \times 1.5)\right] \times 0.2 } & =90.069 \times(0.041+0.015) \\
\mathrm{D} & =2.777 \mathrm{inch}
\end{aligned}
$$




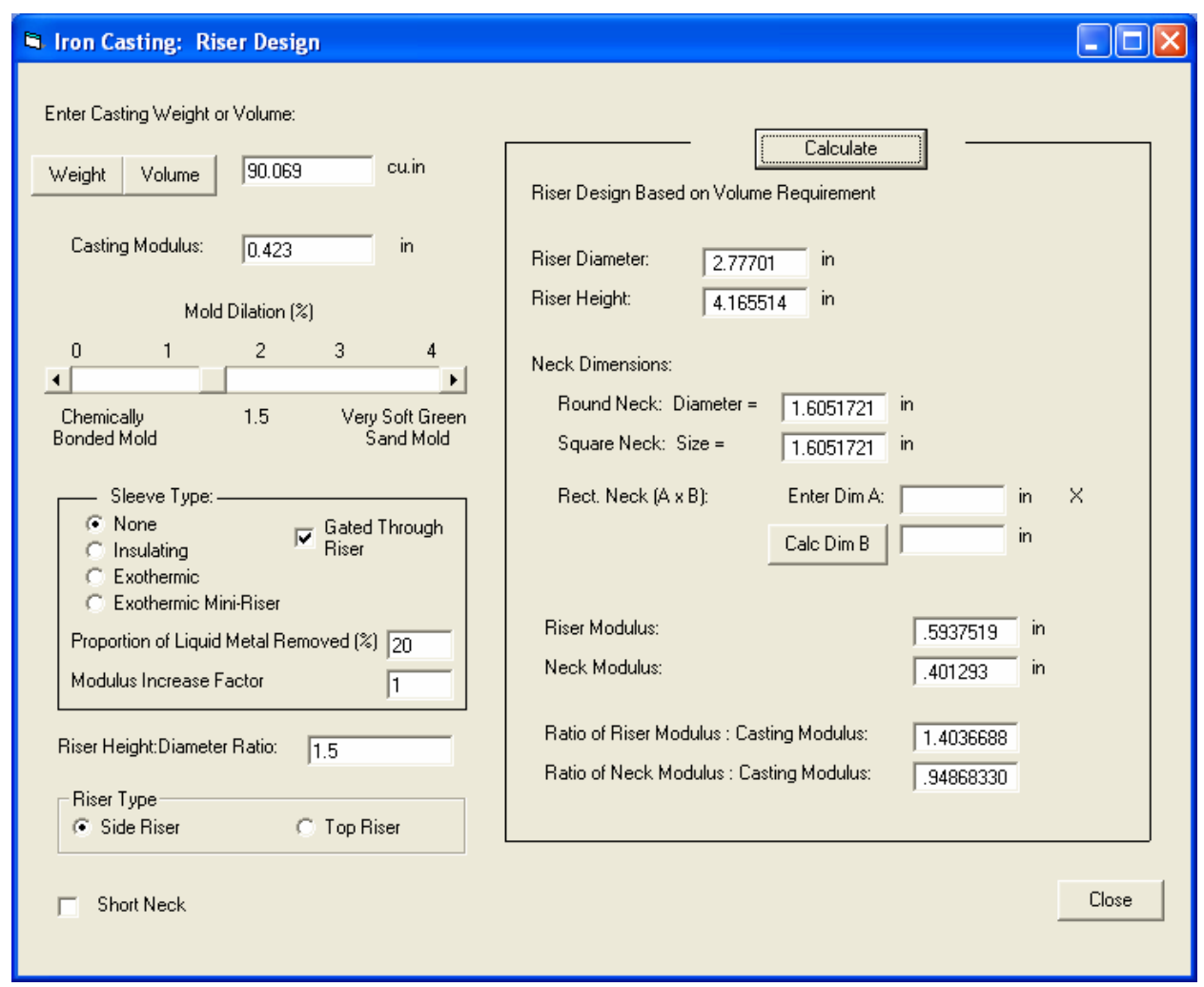

Figure 5.48: Resulting calculations for Riser 1 in Riser Design Wizard.

\section{2) Design For Riser 2}

Riser 2 represents the shared blind side riser in the actual casting design. The gating system is gated through the riser. The mold dilation is 1.5 percent. If the riser height per diameter ratio is 1.5 , by using the formula in equation (4.2), the diameter of the riser can be calculated as shown in equation (5.33) and the results in the Riser Design Wizard shown in Figure 5.49.

$$
\left[\pi \times\left(D^{2} / 4\right) \times(D \times r)\right] \times \%_{p} \quad=V_{c} \times\left(\% v_{V G}+\%_{M D}\right) \quad \text { from }
$$

Where,

$$
\begin{aligned}
& \mathrm{D} \quad=\text { Diameter of side riser, inch } \\
& \mathrm{r} \quad=\text { Riser height per diameter ratio, } 1.5 \\
& \mathrm{~V}_{\mathrm{c}} \quad=\text { Volume of casting (feeding area) from Table 5.12, } 98.586 \text { cubic inches } \\
& \%_{\mathrm{p}} \quad=\text { Proportion of liquid metal removed from riser, } 20 \text { percent } \\
& \% \text { VDG }=\text { Percent shrinkage calculated from the VDG Iron Properties Calculator, } \\
&
\end{aligned}
$$


$\%_{\mathrm{MD}}=$ Mold dilation, 1.5 percent

$$
\begin{aligned}
{\left[\pi \times\left(\mathrm{D}^{2} / 4\right) \times(\mathrm{D} \times 1.5)\right] \times 0.2 } & =98.586 \times(0.041+0.015) \\
\mathrm{D} \quad & =2.862 \mathrm{inch}
\end{aligned}
$$

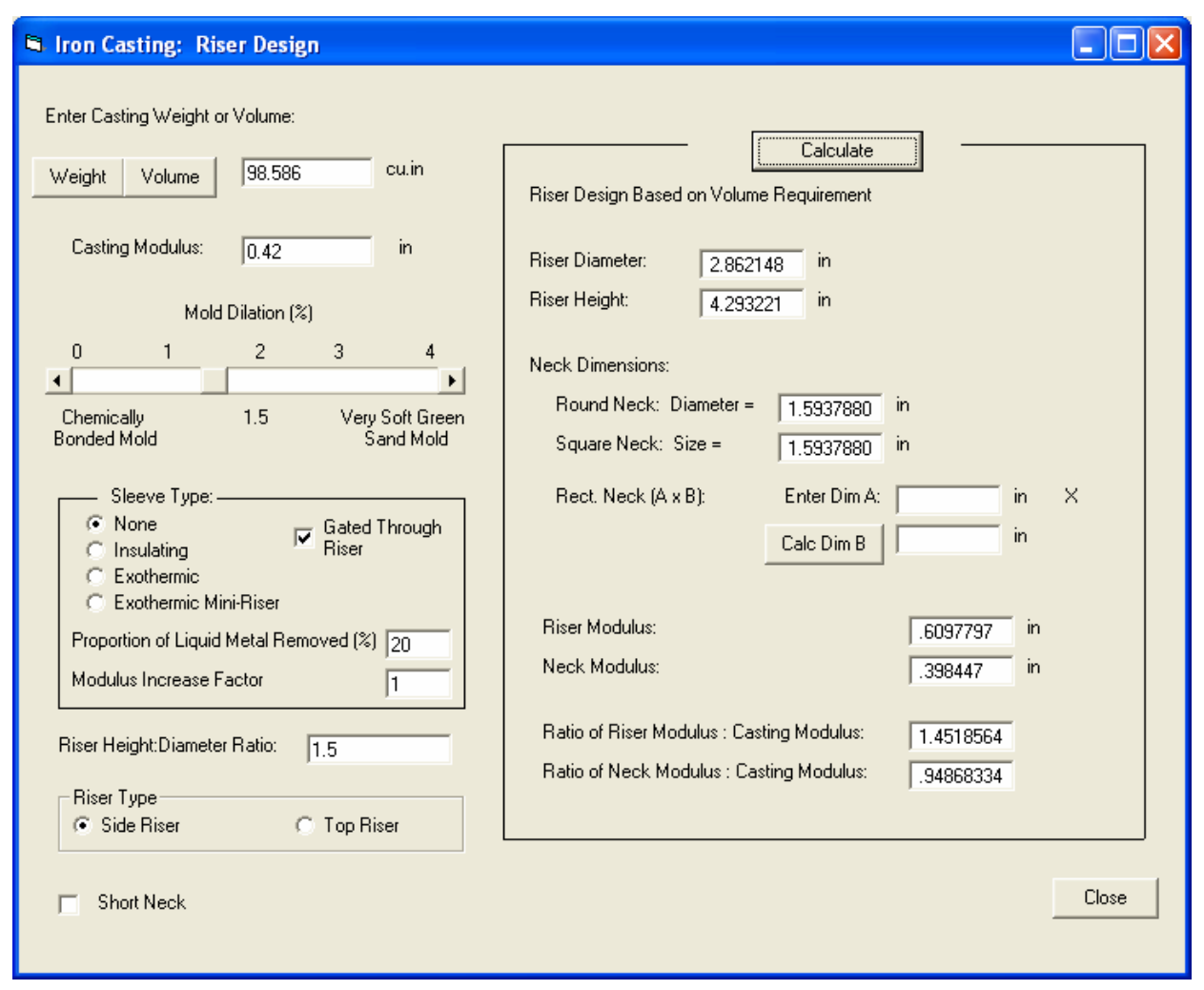

Figure 5.49: Resulting calculations for Riser 2 in Riser Design Wizard.

Riser 2 is the shared riser in the casting design, so, actually it must feed two feeding areas. A test shall be conducted by making the riser size large enough to feed both feeding areas considering them to be one whole feeding area. The feeding areas would have the same modulus even when combined $((\mathrm{V}+\mathrm{V}) /(\mathrm{A}+\mathrm{A})=\mathrm{V} / \mathrm{A})$, but since the Riser Design Wizard was designed for risers feeding one feeding area with one connecting neck, the dimensions needed to make two necks cannot be found. At first, dividing the neck connecting area seems possible, but it would affect the neck modulus, so, both necks shall have the dimensions of the calculated neck dimensions. The total volume of the two feeding areas is 197.172 cubic inches $(2 \times$ 98.586). By using the 
formula in equation (4.2), the diameter of the riser can be calculated as shown in equation (5.34) and the results in the Riser Design Wizard shown in Figure 5.50.

$$
\left[\pi \times\left(D^{2} / 4\right) \times(D \times r)\right] \times \%_{p} \quad=V_{c} \times\left(\%{ }_{V D G}+\% \mathrm{MD}\right) \quad \text { from }
$$

Where,

$$
\begin{aligned}
& \mathrm{D}=\text { Diameter of side riser, inch } \\
& \mathrm{r} \quad=\text { Riser height per diameter ratio, } 1.5 \\
& \mathrm{~V}_{\mathrm{c}} \quad=\text { Volume of casting (feeding area), } 197.172 \text { cubic inches } \\
& \%_{\mathrm{p}} \quad=\text { Proportion of liquid metal removed from riser, } 20 \text { percent } \\
& \% \text { VDG }=\text { Percent shrinkage calculated from the VDG Iron Properties Calculator, } \\
& 4.1 \text { percent } \\
& \%_{\mathrm{MD}}=\text { Mold dilation, } 1.5 \text { percent } \\
& {\left[\pi \times\left(D^{2} / 4\right) \times(D \times 1.5)\right] \times 0.2=197.172 \times(0.041+0.015)} \\
& \mathrm{D}=3.606 \text { inch }
\end{aligned}
$$



Figure 5.50: Resulting calculations for Riser 2 feeding two feeding areas in Riser Design Wizard. 


\section{3) Design For Riser 3}

Riser 3 represents the top riser with exothermic topping in the actual casting design. The gating system was not gated through the riser. The mold dilation is 1.5 percent. If the riser height per diameter ratio is 1.5 , by using the formula in equation (4.2), the diameter of a normal side riser can be calculated as shown in equation (5.35) but the volume of a top riser must be 20 percent more than the volume of a side riser without a hemispheric bottom, so, the diameter of this top riser must be calculated as shown in equation (5.36).

$$
\left[\pi \times\left(D^{2} / 4\right) \times(D \times r)\right] \times \% p \quad=V_{c} \times\left(\%{ }_{v D G}+\% M D\right) \quad \text { from }
$$

Where,

$$
\begin{aligned}
& \text { D }=\text { Diameter of side riser, inch } \\
& \mathrm{r} \quad=\text { Riser height per diameter ratio, } 1.5 \\
& \mathrm{~V}_{\mathrm{c}} \quad=\text { Volume of casting (feeding area) from Table 5.12, } 116.235 \text { cubic inches } \\
& \%_{\mathrm{p}} \quad=\text { Proportion of liquid metal removed from riser, } 35 \text { percent } \\
& \% \text { VDG }=\text { Percent shrinkage calculated from the VDG Iron Properties Calculator, } \\
& 4.1 \text { percent } \\
& \%_{\mathrm{MD}}=\text { Mold dilation, } 1.5 \text { percent } \\
& {\left[\pi \times\left(D^{2} / 4\right) \times(D \times 1.5)\right] \times 0.35=116.235 \times(0.041+0.015)} \\
& \mathrm{D} \quad=2.509 \mathrm{inch} \\
& \pi \times\left(D^{2} / 4\right) \times(D \times 1.5) \\
& =\left[\pi \times\left(2.509^{2} / 4\right) \times(2.509 \times 1.5)\right] \times 1.20 \\
& \mathrm{D}=2.666 \mathrm{inch}
\end{aligned}
$$

Figure 5.51 shows the resulting dimensions for the top riser with exothermic topping with normal neck dimensions. In the current casting design, the top riser has a neck length of a quarter of an inch and is considered to be a short neck. The new riser shall also have the same neck length of 0.25 inch and a connecting surface width of 0.75 inch. Figure 5.52 shows the resulting dimensions for a top riser with exothermic topping with short neck dimensions. 


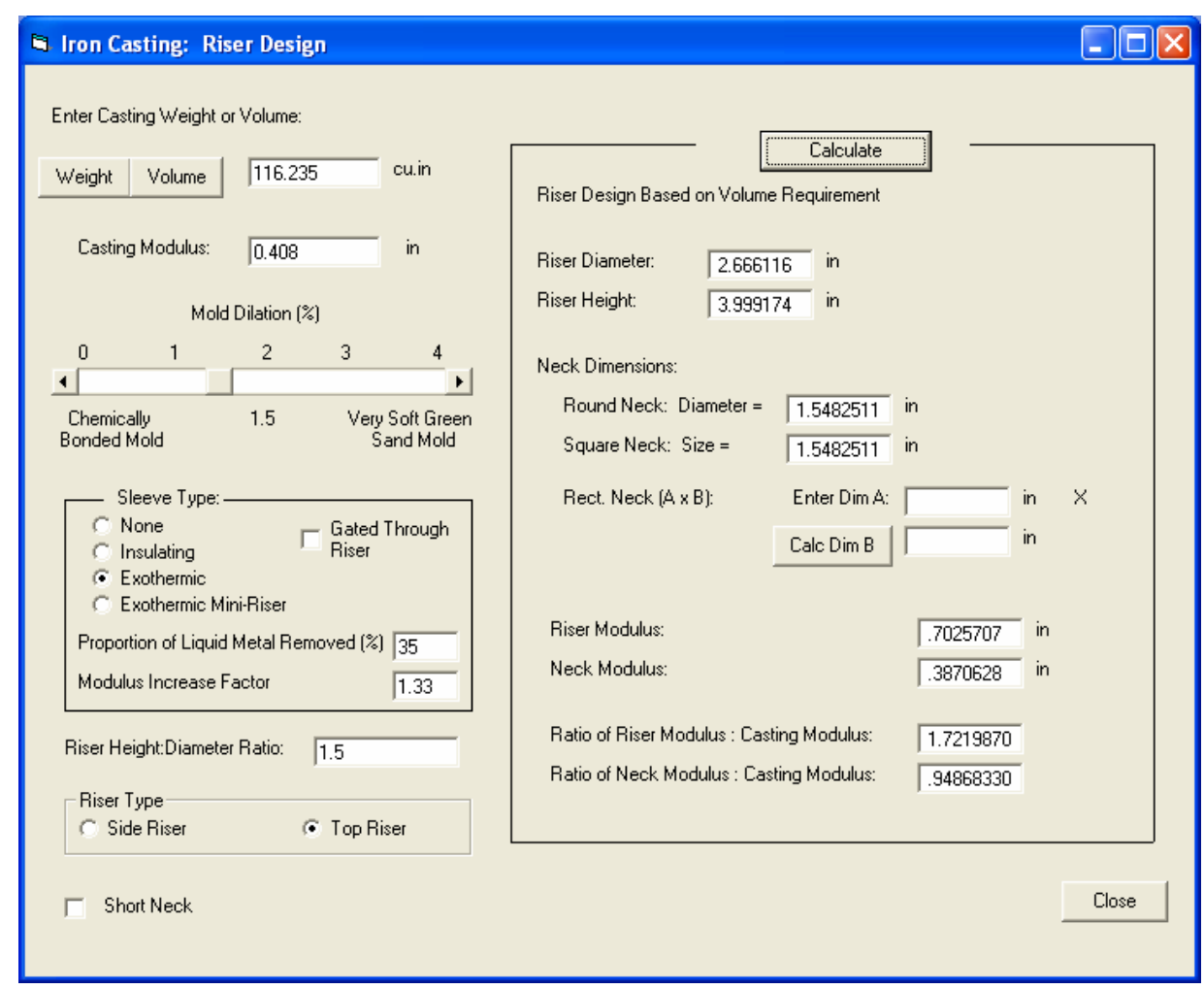

Figure 5.51: Resulting calculations for Riser 3 in Riser Design Wizard with normal neck.

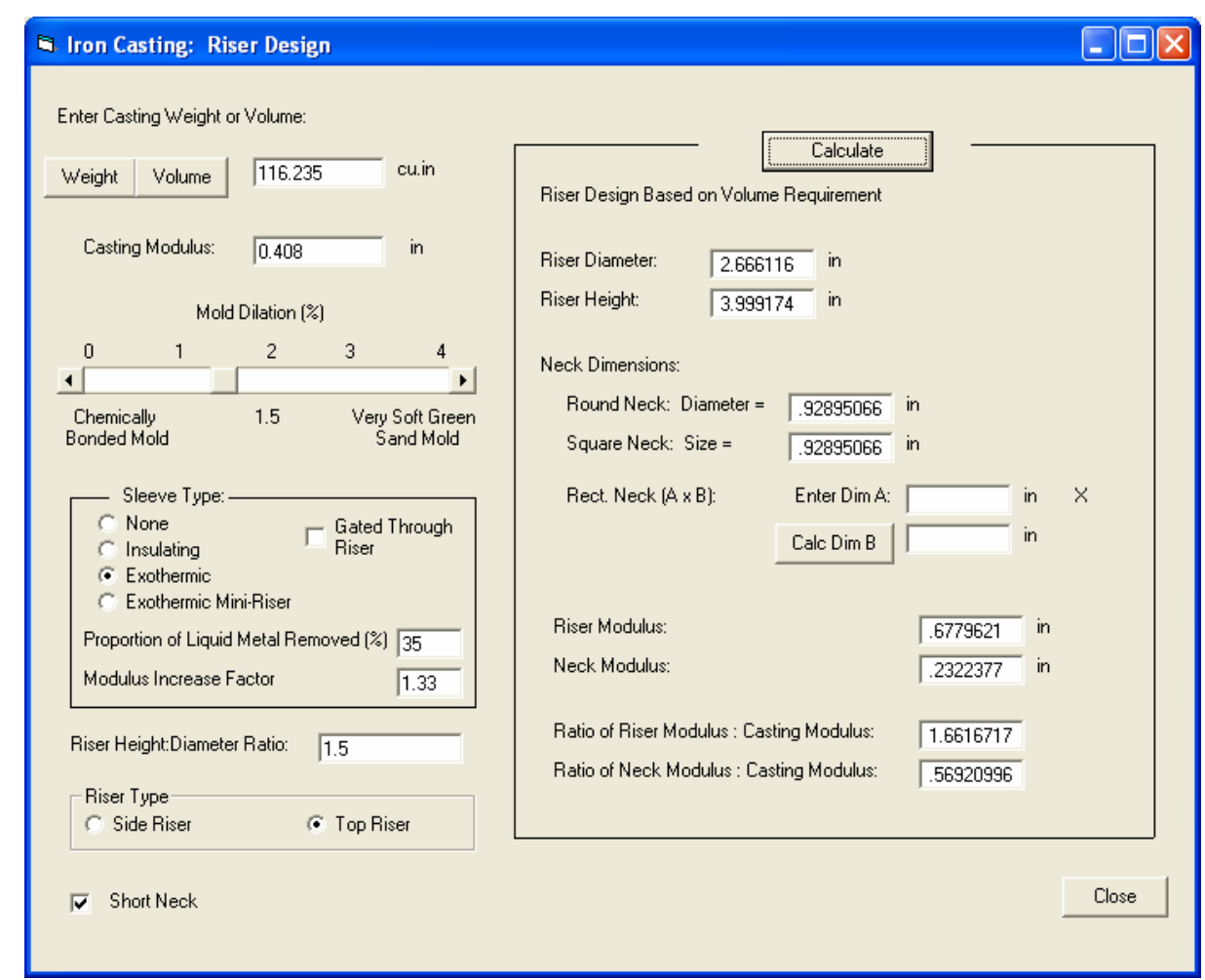

Figure 5.52: Resulting calculations for Riser 3 in Riser Design Wizard with short neck. 
The side risers would have a hemispheric bottom added while the top riser shall be a normal cylindrical shape. The calculated diameters, heights and volumes of the riser and the neck dimensions of Riser 1, 2 and 3 are summarized in Table 5.13.

Table 5.13: The calculated diameters, heights and volumes of the risers and the neck dimensions of Riser 1, 2 and 3.

\begin{tabular}{|c|c|c|c|c|c|c|}
\hline \multirow{3}{*}{$\begin{array}{c}\text { Riser Number and } \\
\text { Descriptions }\end{array}$} & \multicolumn{3}{|c|}{ Riser Dimensions } & \multicolumn{3}{|c|}{ Neck Dimensions (inch) } \\
\hline & \multirow{2}{*}{$\begin{array}{c}\text { Diameter } \\
\text { (inch) }\end{array}$} & \multirow{2}{*}{$\begin{array}{l}\text { Height } \\
\text { (inch) }\end{array}$} & \multirow{2}{*}{$\begin{array}{l}\text { Volume } \\
\text { (inch }^{3} \text { ) }\end{array}$} & \multicolumn{2}{|c|}{$\begin{array}{c}\text { Connecting } \\
\text { Surface }\end{array}$} & \multirow{2}{*}{$\begin{array}{l}\text { Neck } \\
\text { Length }\end{array}$} \\
\hline & & & & Width & Length & \\
\hline Riser 1 & 2.777 & 4.166 & 30.839 & 1.605 & 1.605 & 1.605 \\
\hline Riser 2 with 1 feed area & 2.862 & 4.293 & 33.755 & 1.594 & 1.594 & 1.594 \\
\hline Riser 2 with 2 feed areas & 3.605 & 5.408 & 67.465 & 1.594 & 1.594 & 1.594 \\
\hline Riser 3 with normal neck & 2.666 & 3.999 & 22.323 & 1.548 & 1.548 & 1.548 \\
\hline Riser 3 with short neck & 2.666 & 3.999 & 22.323 & 0.75 & 1.151 & 0.25 \\
\hline
\end{tabular}

\subsubsection{Gating Design Wizard}

The gating dimensions calculated from the Gating Design Wizard used the current casting design's layout and dimensions as guidelines. The gating system would start from the sprue down to the sprue well, and then three runners shall separate from the sprue well. Two of the runners shall go left and right to the ingates into the single side risers. The other runner shall lead into the shared riser with no ingate.

This casting design has a horizontal gating system. The castings including the risers and gating system has a weight of approximately 300 pounds, found from adding the mesh weights of all material which are casting material. The Mesh Weights window of the base case is shown in Figure 5.53. The pouring time used for this casting design was 22 seconds. This pouring time could be directly entered into the optimal fill time or fill time calculation box in the Gating Design Wizard as shown in Figure 5.54. The weight and pouring time was used to calculate the volumetric feed rate. 


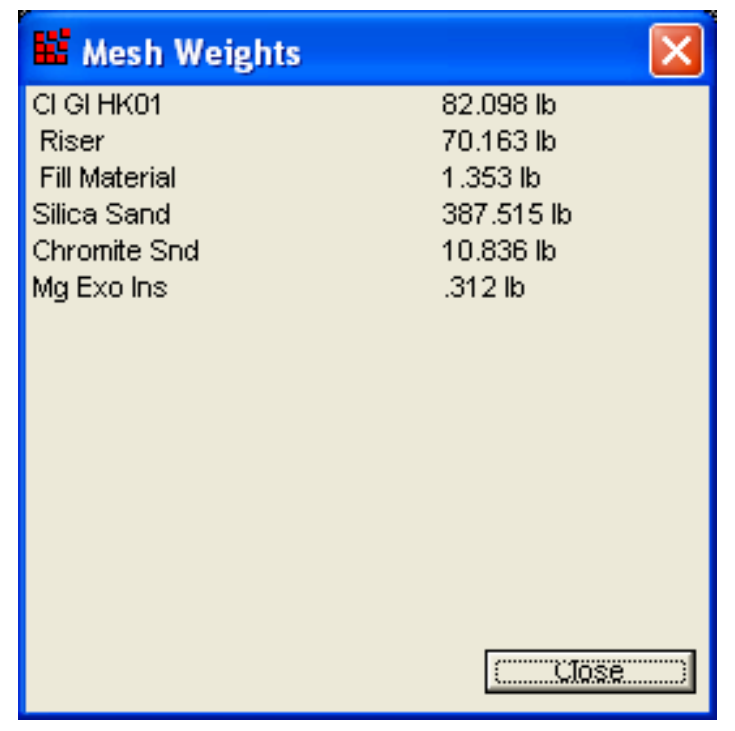

Figure 5.53: Mesh weights of base case.

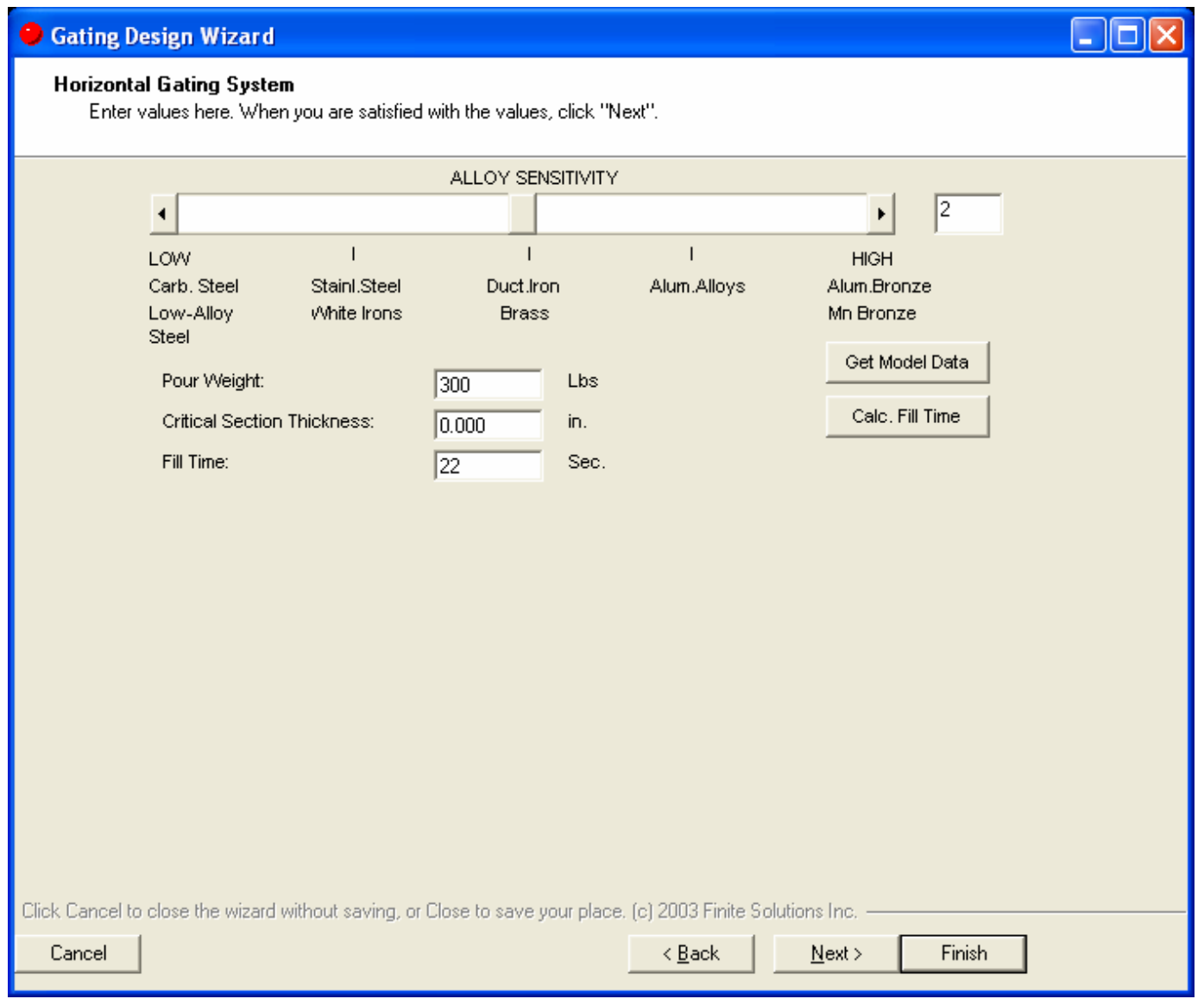

Figure 5.54: Entering the pour weight and fill time. 
Next, the Gate Position window was set up. The casting design has a horizontal gating system with parting line gating. It has a conical basin, so, the molten metal is poured directly into the sprue. Conical basins are probably responsible for the production of more casting scrap than any other single feature of the filling system and are not recommended (Campbell, 2004). The metal enters the mold at an unknown, high and unchecked velocity. Slag or dross may enter the mold cavity with the molten metal. Entrainment of air may occur and may most likely form a vortex.

The height of the current sprue is 16.75 inches with no sprue well. The height of the casting is 13.5 inches and the height of the casting measured from the parting line is 10.25 inches. The height of the ladle exit is approximated to be 6 inches from the top of the sprue, which shall be added to the Effective Sprue Height, which was 12.859 inches, so, the new Effective Sprue Height is 18.859 inches. The gating ratio was set at 1:1.3:1.1 for gray iron pressurized castings. The number of runners was 3 ; two to each single riser and one to the shared riser. Even though the ingate into the shared riser was neglected, the number of gates entered shall still be 3 . The completed Gate Position window is shown in Figure 5.55.

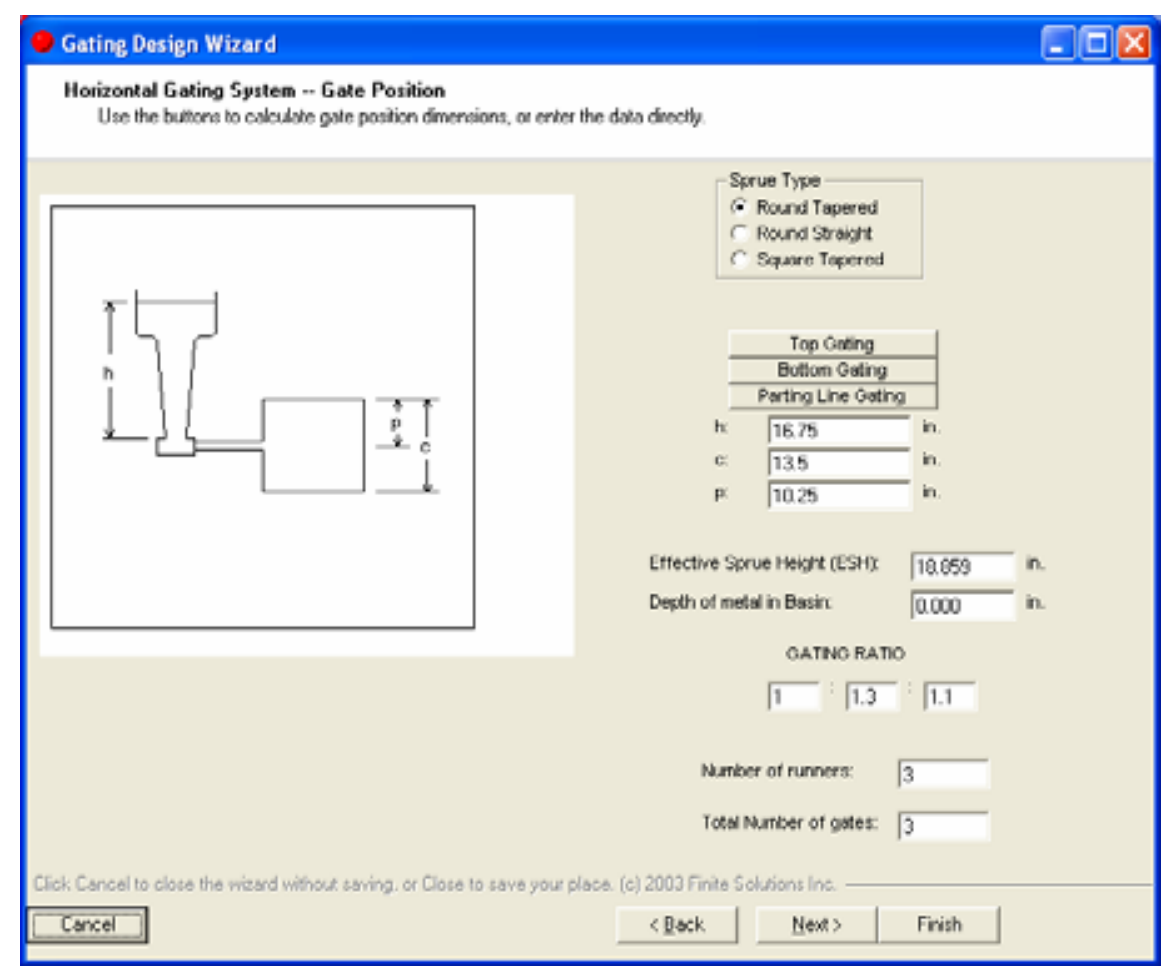

Figure 5.55: The Gate Position window. 


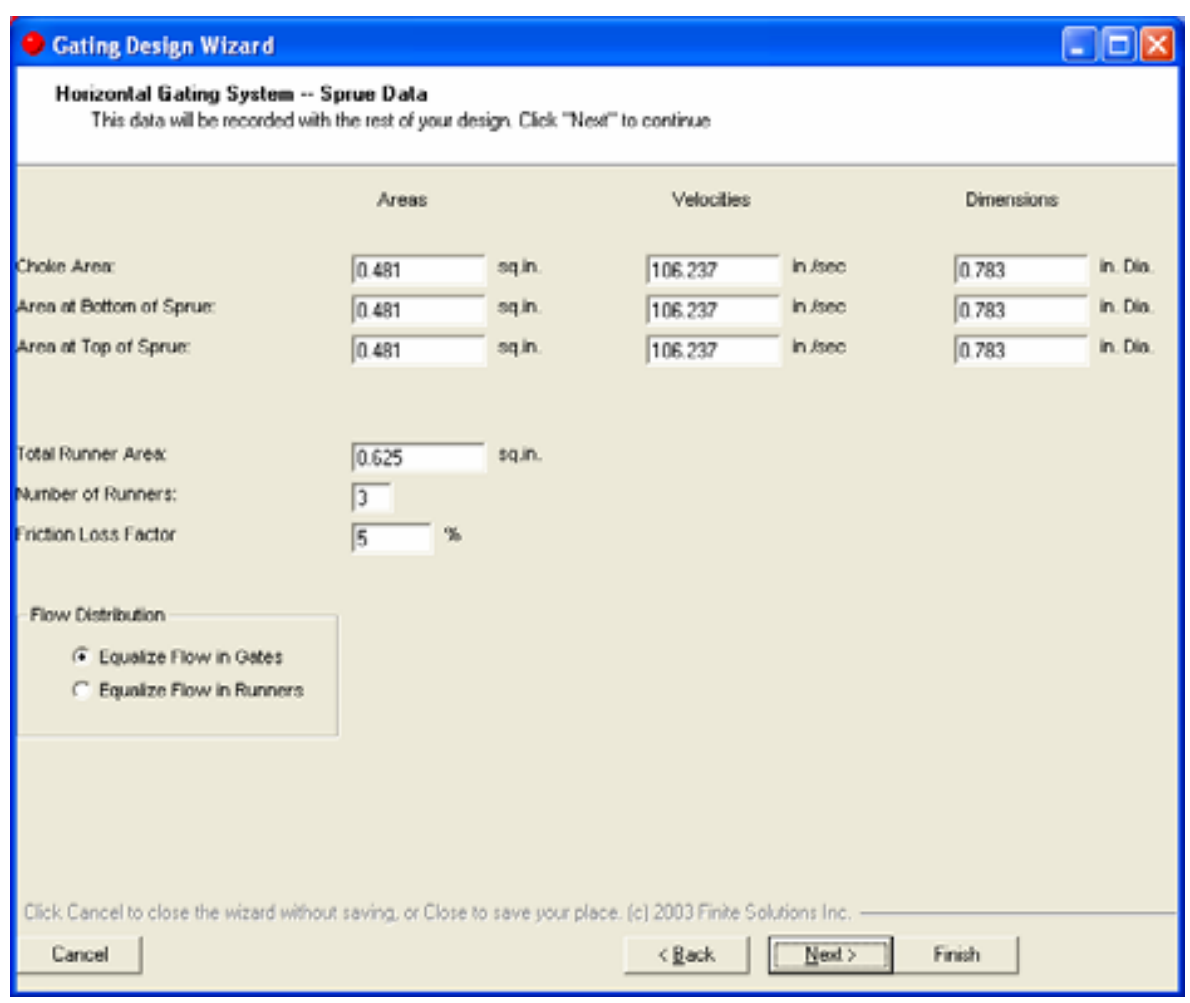

Figure 5.56: Calculated sprue dimensions.

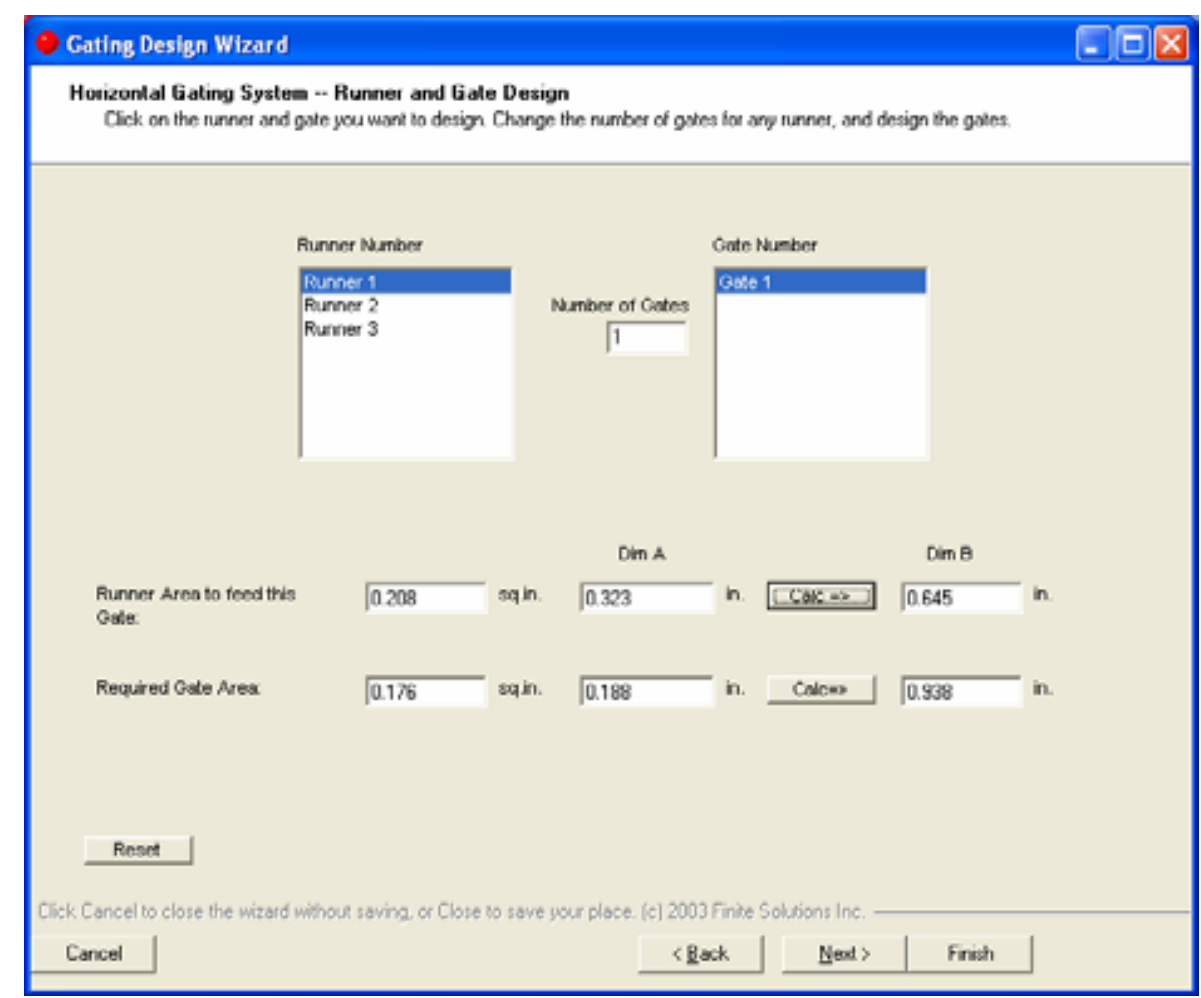

Figure 5.57: Calculated gate and runner areas and dimensions. 
Clicking the Next button in Figure 5.55, the window shown in Figure 5.56 would appear, and clicking the Next button in Figure 5.56, the window shown in Figure 5.57 would appear. Figure 5.56 shows the calculated sprue dimensions and Figure 5.57 shows the calculated gate and runner areas and dimensions. In Figure 5.56, the velocity of the liquid metal seems to be very high compared to the critical maximum velocity for most liquid metals of 0.5 meters per second (approximately 20 inches per second) (Campbell, 2004). In Figure 5.57, the runner areas for all runners and the required gate area for all the gates are the same. The runners were set to have a width per height ratio of 0.5 and the gates were set to have a width per length ratio of 0.2 for the connecting surface. The calculator buttons were used for finding the length of the other side of the rectangular shaped runner or gate with the same area. From Figures 5.56 and 5.57, the dimensions of the sprue well can be calculated. The sprue well should have a diameter of twice the diameter of the sprue exit, which is 1.566 inch, and a depth of 1.5 times the height of the runner, which is 0.968 inch. Table 5.14 shows the dimensions of the currently used sprue, runners and ingates compared to the calculated ones.

Table 5.14: Dimensions of the current gating system and the proposed gating system.

\begin{tabular}{|l|c|c|c|c|c|c|}
\hline \multirow{2}{*}{ Gatings and Descriptions } & \multicolumn{2}{|c|}{ Current Gating System } & \multicolumn{2}{c|}{ Proposed Gating System } \\
\cline { 2 - 7 } & Width & Depth & Area & Width & Depth & Area \\
\hline $\begin{array}{l}\text { Runner from sprue to gates } \\
\text { into single side risers }\end{array}$ & 0.875 & 1.75 & 1.53125 & 0.323 & 0.645 & 0.208 \\
\hline $\begin{array}{l}\text { Two runners to middle } \\
\text { runner }\end{array}$ & 0.75 & 0.375 & $\begin{array}{c}2 \times 0.28125 \\
=0.5625\end{array}$ & - & - & - \\
\hline $\begin{array}{l}\text { Middle runner into shared } \\
\text { riser }\end{array}$ & 1 & 0.625 & 0.625 & 0.323 & 0.645 & 0.208 \\
\hline Ingate into a single side riser & 0.75 & 0.375 & 0.28125 & 0.938 & 0.188 & 0.176 \\
\hline $\begin{array}{l}\text { Top of sprue } \\
\text { Bottom of sprue }\end{array}$ & 2.125 & - & 3.547 & 0.783 & - & 0.481 \\
\hline
\end{tabular}


The calculated diameter of the top and bottom of the sprue are the same (round straight sprue), which is not practical and not recommended (Campbell, 2004). The sprue should have a tapered shape, so, the diameter of the top of the sprue may be increased and have a conical basin or maybe a pouring basin at the top of the sprue.

It was seen that the velocity of the liquid metal exiting the sprue exit is extremely high (106.237 inches per second) compared to the critical maximum velocity of liquid metal (20 inches per second) (Campbell, 2004). It seems that SOLIDCast does not consider if the velocity of liquid metal may be too high and may damage the casting. An experienced user may consider the dimensions calculated from the Gating Design Wizard to be a guideline in designing the gating system and then modify the dimensions to reduce the velocity of the liquid metal himself or herself.

SOLIDCast has an extension program called FLOWCast used for simulating the flow of liquid metal during pouring. Since SOLIDCast cannot simulate the affect of the speed of flow of the liquid metal, FLOWCast should be used along side SOLIDCast to help the user modify the gating dimensions calculated from the Gating Design Wizard. SOLIDCast may also need to be improved so it may recognized and warn the user if velocities of liquid metal may be too high.

\subsection{Simulation Results of Re-designed Casting Design}

Three simulation tests were conducted. The first test was the casting design with a smaller top riser calculated from the Riser Design Wizard accessed from the Simulation tab. The second and third tests were the casting design with riser dimensions calculated from the Riser Design Wizard from the VDG Iron Properties Calculator and gating dimensions calculated from the Gating Design Wizard, but in the second test, the shared riser was larger than the third test because it was considered to have a volume to feed two feeding areas of the two castings inside the mold.

\subsubsection{Simulation Results: Test 1}

The casting design was a smaller top riser with a smaller neck calculated from the Riser Design Wizard accessed from the Simulation tab. The single side risers and their necks, the shared riser and its neck, and the gating system had the same dimensions as the 
original design. The settings in the Materials List window was exactly the same as the base case except for the fill time which was reduced from 22 seconds to 21 seconds due to the new weight of total casting.

Because the top riser was designed with a height per diameter ratio of 1.5 , the height of the riser was reduced. The sprue was shortened to match the height of new top riser with exothermic topping. This would result in a smaller flask, which is not practical. In order to be able to use the same flask size, the height of the top riser should be kept the same and the diameter should be reduced but having the same volume. For this test, the dimensions were taken directly from the program to observe its true usefulness.

The Critical Fraction Solid Time plots showed that the thin wall and the upper ring area solidified slightly faster than the base case. The plots also showed that some areas in the upper ring area may have been isolated as shown in Figure 5.58. Since the solidification rate in the ring is quite high, they can be considered to cool down almost at the same time. The bottom ring area of the casting solidified at the same rate as the base case, because the dimensions of Riser 1 and 2 were not modified and the bottom part of the casting is isolated from the top. The Material Density Function plots showed slightly larger highlighted areas in the areas between the core pieces and at the bottom of the casting compared to the base case, as shown in Figure 5.59. But since the areas highlighted are not the main problem and the level of porosity is not high, they were considered to not affect the final casting results.

The FCC Criterion plots showed no highlighted areas in the casting at all, as shown in Figure 5.60. This shows a remarkable improvement in the casting design. The Hot Spot Criterions iso-surface plots were very much the same as the base case except the area under the top riser seems to have a larger highlighted spot compared to the base case, but since the solidification rate in that area was quite high, possible problems occurring in that area may be low. 


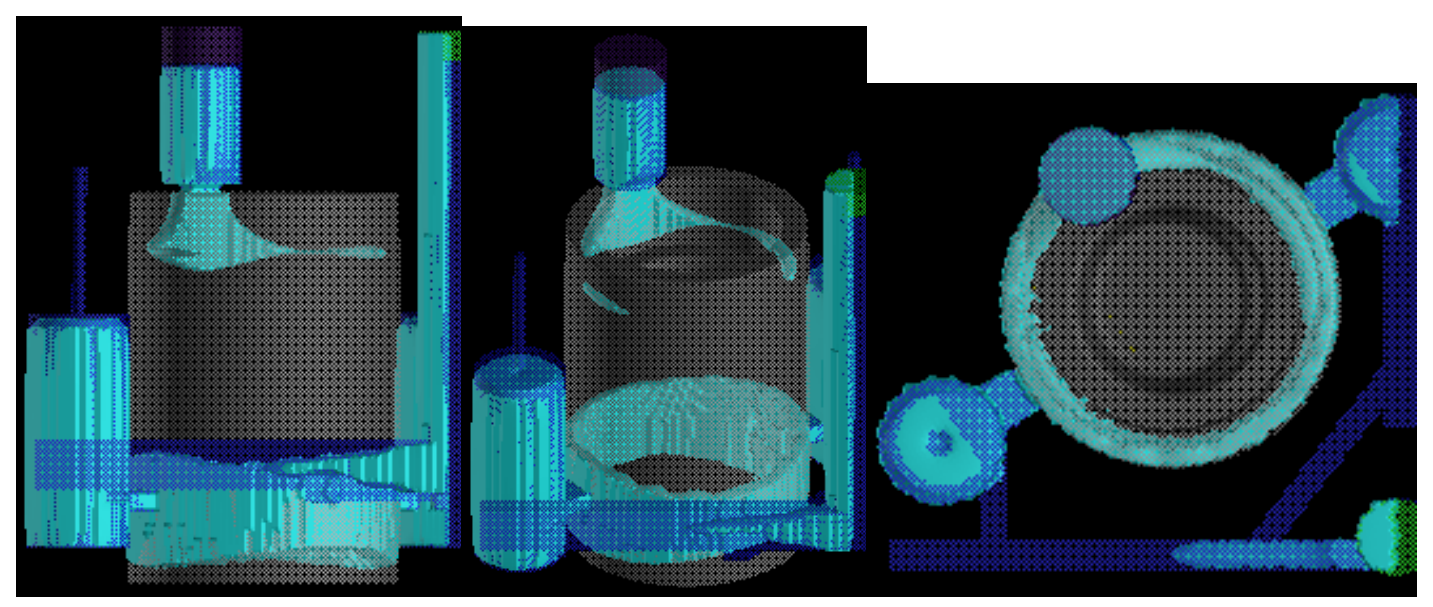

Figure 5.58: Critical Fraction Solid Time plots plotted at 4.5 minutes show possible isolated areas.

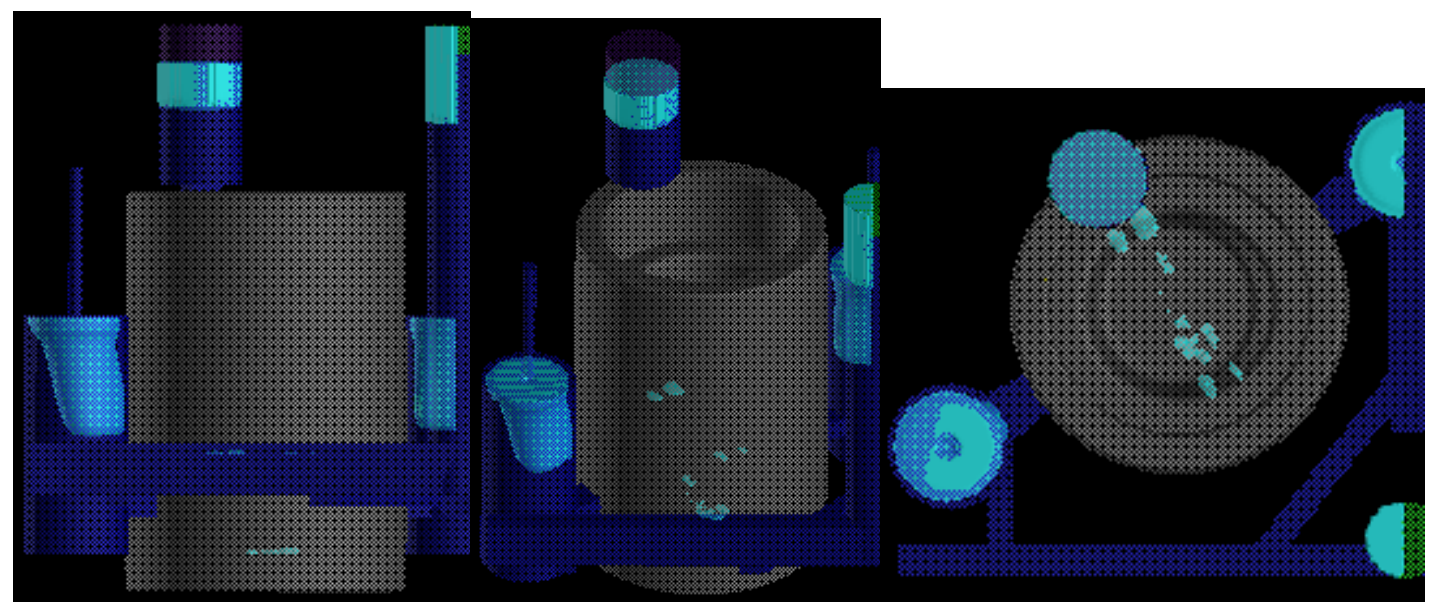

Figure 5.59: Material Density Function plots plotted at 0.995.

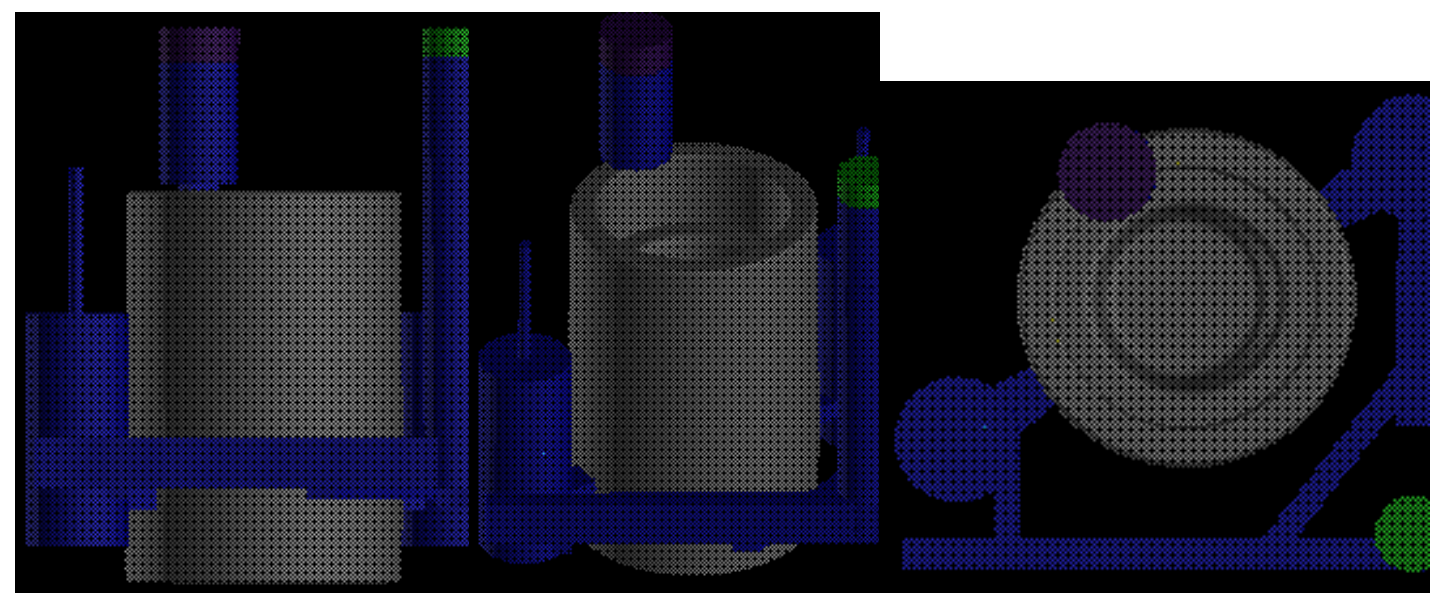

Figure 5.60: FCC Criterion plots showing no highlighted areas. 
The simulation results showed a remarkable improvement in the level of predicted microporosity. Other criterions may show slightly different predicted plots compared to the base case but still at very much the same levels. Some minor adjustments may be made to further improve the casting design, but if this design was used instead of the currently used design, the casting yield may be increased. The weights of the materials in the model are shown in the Mesh Weights window, shown in Figure 5.61. The total weight of the casting material in this model can be calculated as shown in equation (5.37).

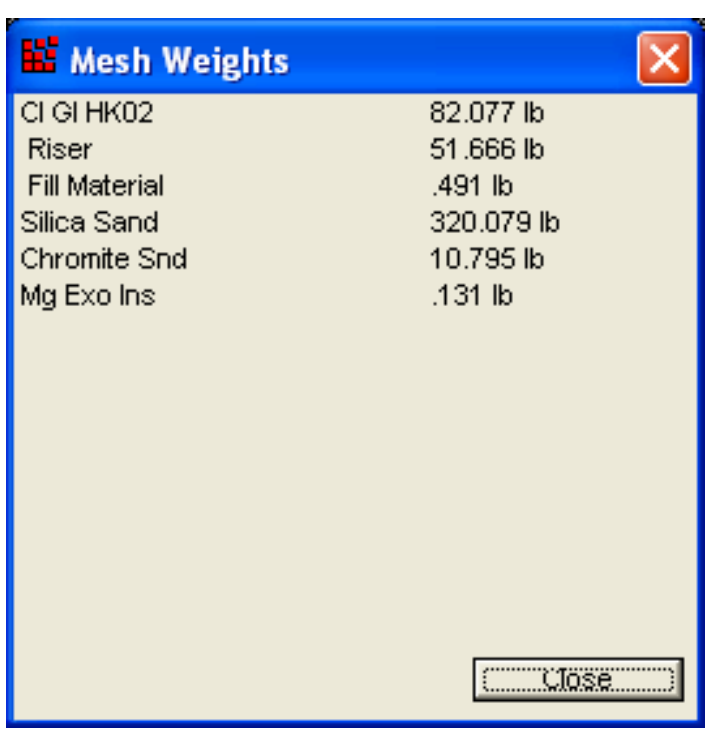

Figure 5.61: The weights of the materials in Test 1.

$$
2 \times(82.077+51.666+0.491) \quad=268.468 \text { pounds }
$$

The weights of the materials of the base case is shown in Figure 5.53 and the total weight of the casting material in the base case can be calculated as shown in equation (5.38).

$$
2 \times(82.098+70.163+1.353) \quad=307.228 \text { pounds }
$$

The weight of the casting material was reduced by 38.76 pounds per mold or approximately 12.62 percent. This can be considered a significant savings in the materials cost. The weight reduced was from the reduction in size of the top risers and 
the sprue. If the height of the sprue was kept the same and the risers were modified to be open risers to fit the same flask size, less casting material would actually be reduced.

\subsubsection{Simulation Results: Test 2}

The dimensions of the risers in this test were calculated from the Riser Design Wizard accessed from the VDG Iron Properties Calculator and the dimensions of the gating system were calculated from the Gating Design Wizard. The shared riser was considered to have a volume which could feed two feeding areas in both the castings in the mold. The top riser was considered to have a short neck. The dimensions used for building this model was retrieved from Table 5.12 and 5.13. The model built with these dimensions is shown in Figure 5.62.

The total height of the model was reduced due to the reduction in size of the top riser. The sprue height was also modified to match the new top riser. Reducing the size of the flask is not practical, so, the dimensions of the top riser may need to be modified to use the same flask size. The sprue shape calculated from the Gating Design Wizard was a round straight sprue, which is not pratical. The user may modify the sprue dimensions for the real casting, but because SOLIDCast cannot calculate the flow and friction loss in the simulation, and the sprue would be considered full during filling, the gating dimensions shall be kept as is for the simulation.

A sprue well was added to the model. The gating design was slightly changed due to the methods for calculating for the gating dimensions in the Gating Design Wizard. The runner that runs to the shared riser would have two smaller runners connected from the side runners in the original model. In this case, the runner would run directly from the sprue well into the shared riser. If this design was applied to a real casting, there may be defects occurring from slag and dirt. The side runners have the same length as the original model. 


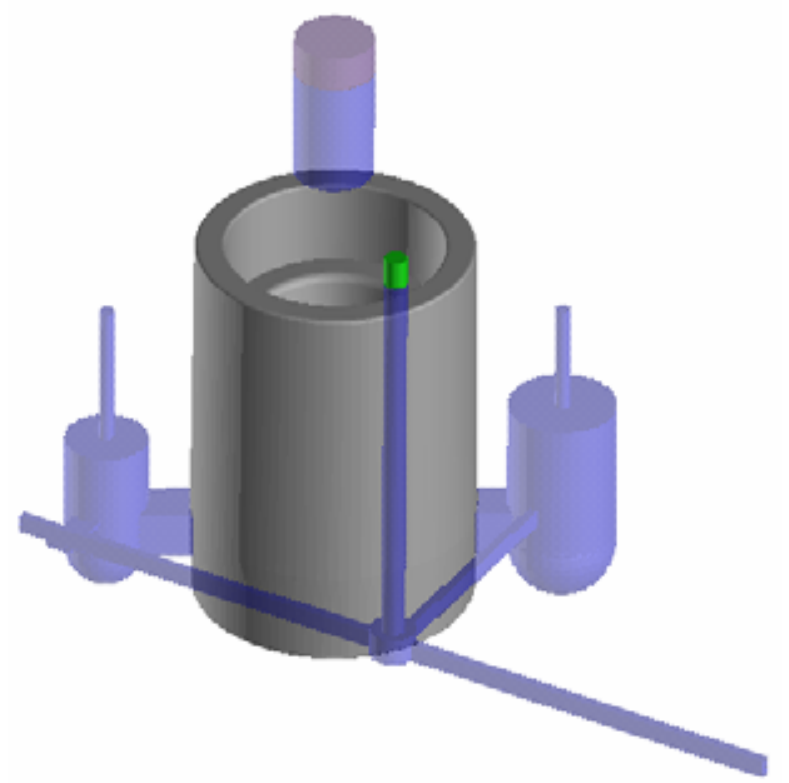

Figure 5.62: Casting model built from calculated dimensions for Test 2.

The settings in the Materials List window were kept the same as the base case, but the fill time was reduced to 20 seconds due to the reduced weight of the casting model. The fill time used in the base case was 22 seconds and the casting weighing around 300 pounds. Back calculating the optimal fill time calculator in the Gating Design Wizard from equation (4.7) would result in a critical section thickness of around three-eights of an inch (3/8 inch), which is approximately the thickness of the ingates of the casting. Using this critical section thickness, the new calculated fill time from the Gating Design Wizard for this particular casting design was approximately 20 seconds. The weights of the materials in the Mesh Weights window are shown in Figure 5.63. The total weight of the casting material was 217.614 pounds. The weight of the casting material was reduced by 89.614 pounds per mold or approximately 29.17 percent. The weight reduced was from the reduction in size of all the risers and the gating system. 


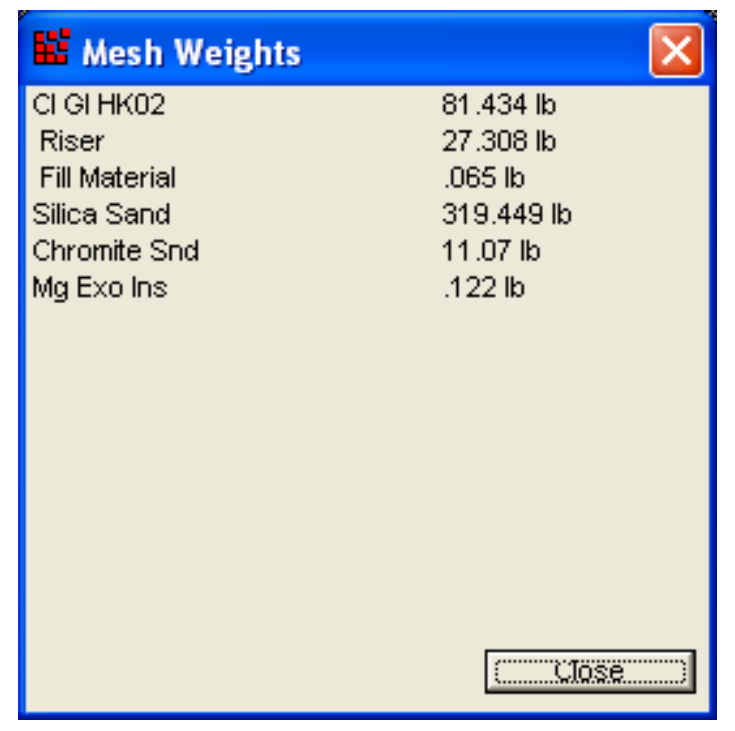

Figure 5.63: The weights of the materials in Test 2.

The solidification progression shown in the Critical Fraction Solid Time plots showed that the upper ring area solidified at a faster rate than the base case. For the bottom ring area, the shared riser seemed to feed a larger area of the bottom ring area compared to the single riser, and also took a longer time to solidify towards the riser. An example is shown in Figure 5.64. It took around 12 minutes for the casting to cool down lower than the critical fraction solid temperature.

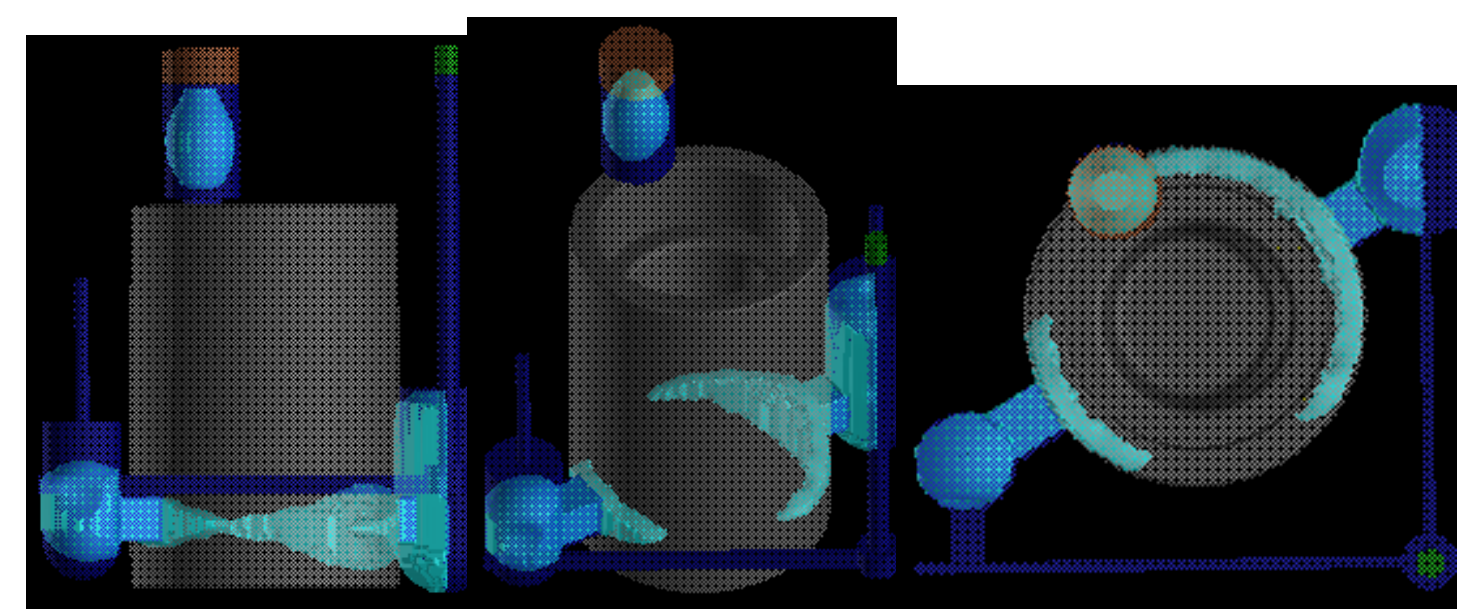

Figure 5.64: Critical Fraction Solid Time plot plotted at 7.5 minutes. 
The predicted macroporosity levels shown in the Material Density Function plots were very similar to the base case, with slightly more highlight levels in the area between the core pieces, as shown in Figure 5.65. The FCC Criterion plots showed the same predicted microporosity level compared to the base case, but more dispersed, as shown in Figure 5.66.

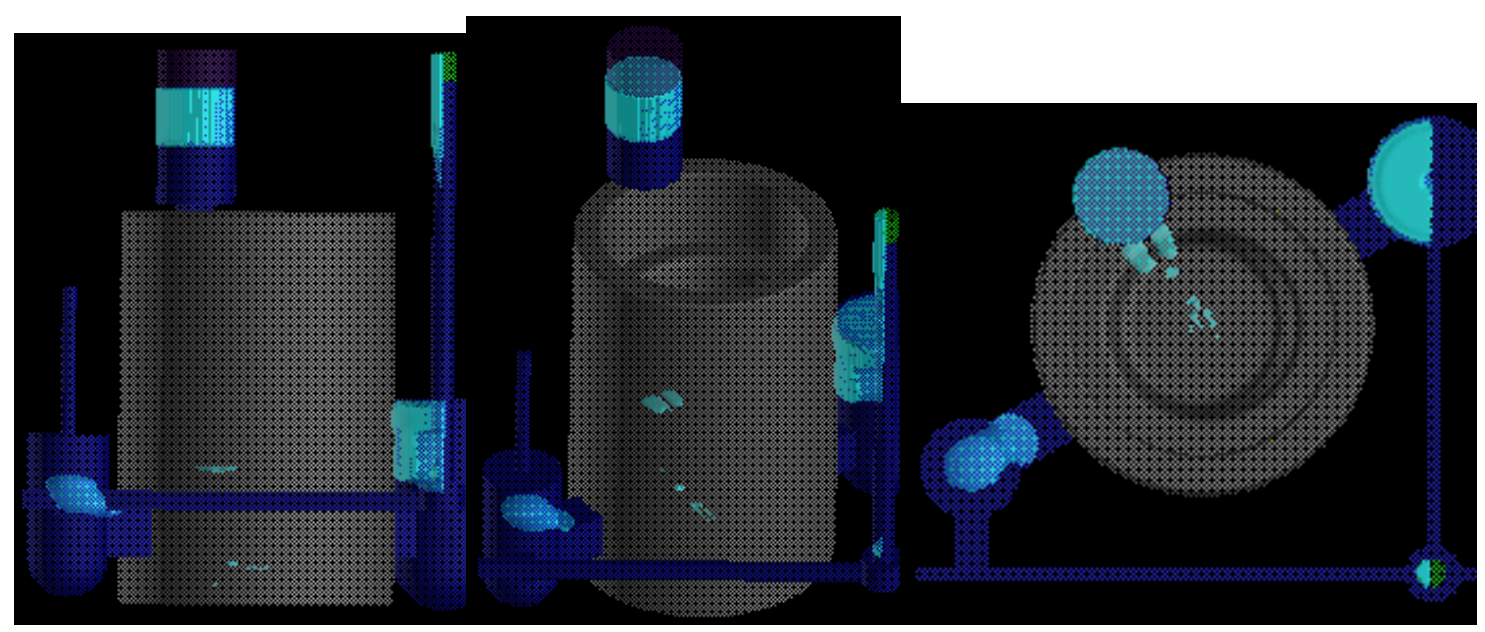

Figure 5.65: Material Density Function plots plotted at 0.995.

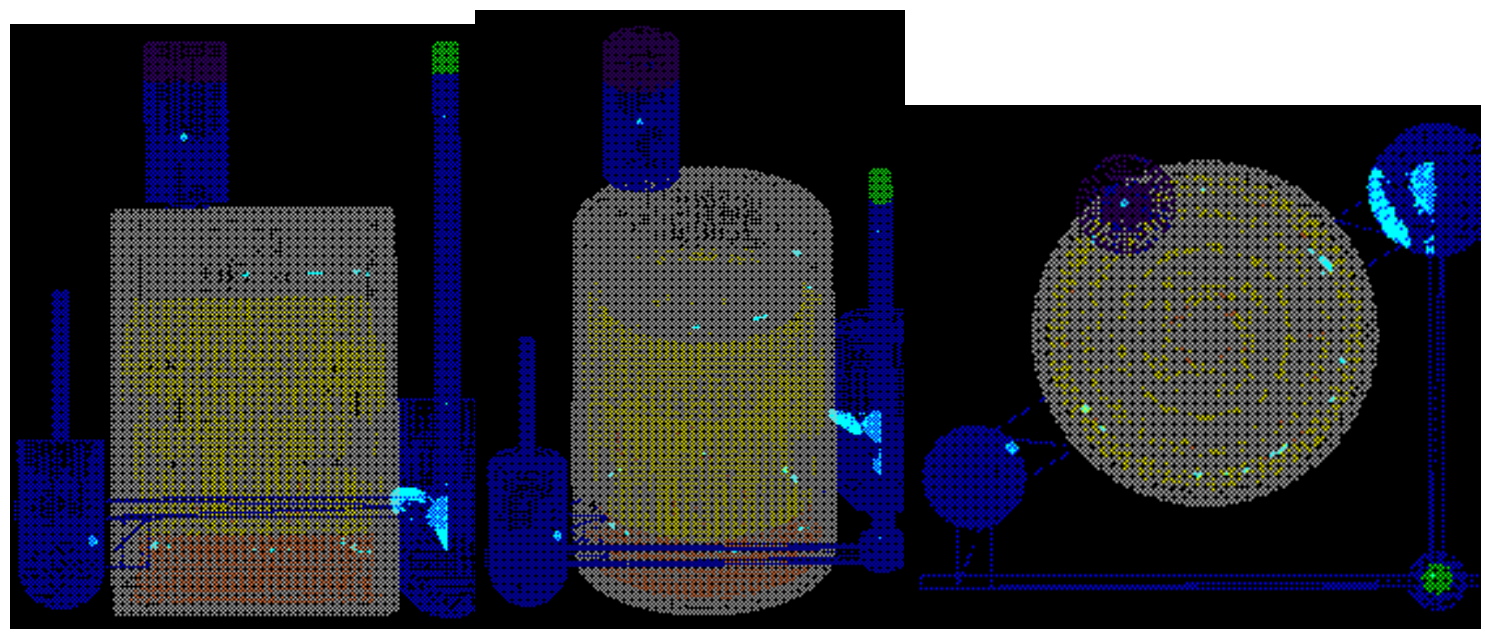

Figure 5.66: FCC Criterion plots.

The Hot Spot Criterions plots were quite similar to the base case, but with more highlighted intensity, especially under the top riser and in the upper ring area, as shown 
in Figure 5.67 and 5.68. There may not be any problems or may be very minor because this area has a high cooling rate.

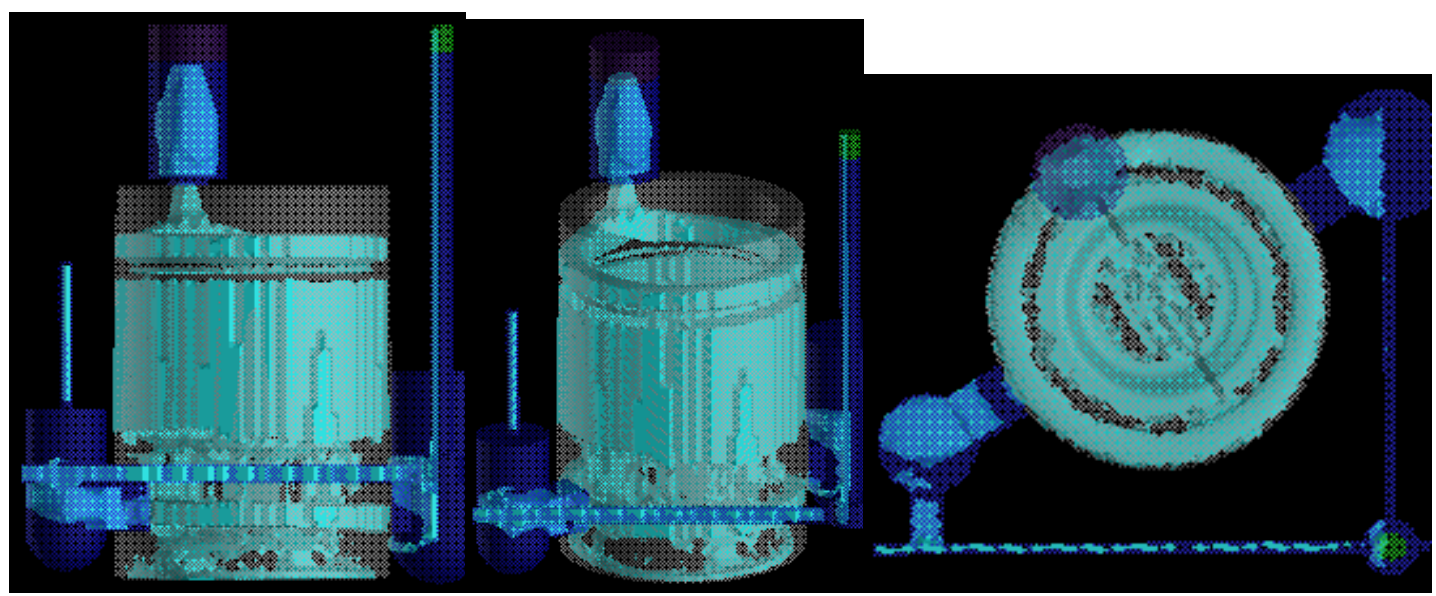

Figure 5.67: Hot Spot (Solidification Time) plotted at 1.1.

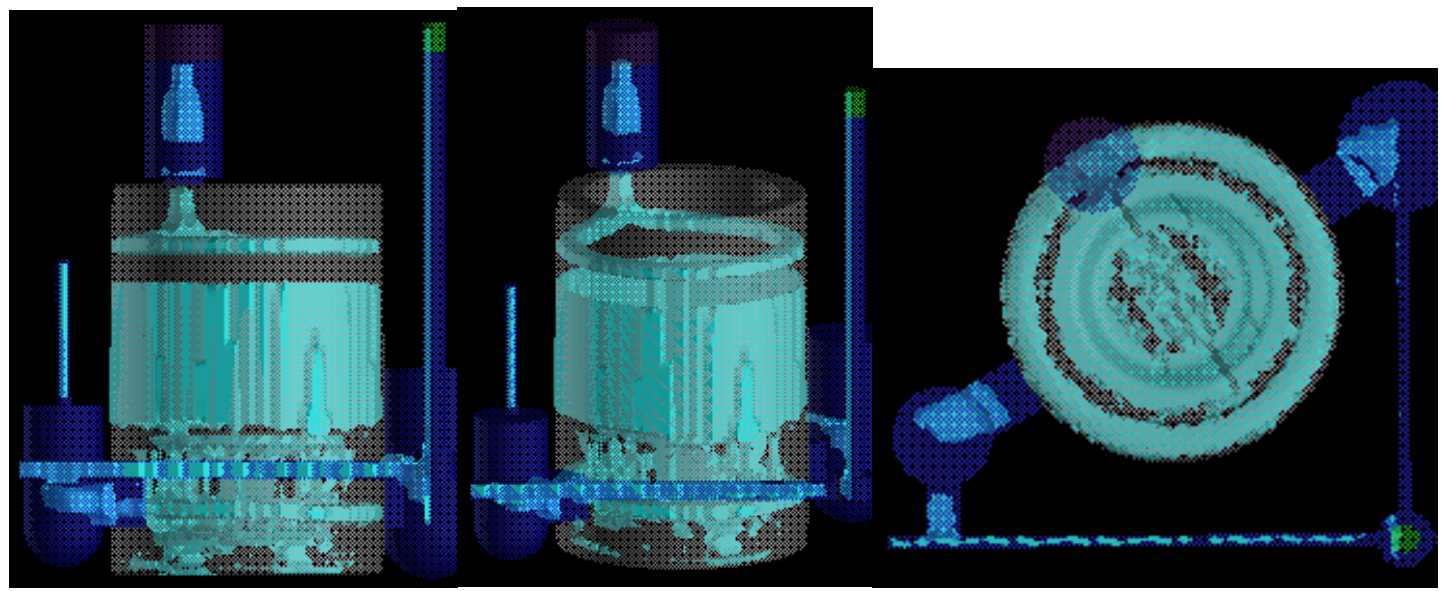

Figure 5.68: Hot Spot (Critical Fraction Solid Time) plotted at 1.1.

The simulation results of this model has slightly more predicted problems than the base case, but the need for casting material has decreased by around 29.17 percent. From the Critical Fraction Solid Time plots, it seems that the shared riser is too big and can be reduced. In the base case, the shared riser has the same dimensions as the single riser, so, it may be possible to consider as if the shared riser only needs to feed one feeding area. 


\subsubsection{Simulation Results: Test 3}

This model is almost exactly the same as Test 3 , but the size of the shared riser was considered to feed only one feeding area of one casting. The size of the shared riser was almost the same size as the single side riser, similar to the base case which the single side riser and shared riser have the same dimensions. The model is shown in Figure 5.69. The weights of the materials in the Mesh Weights window are shown in Figure 5.70. The total weight of the casting material is 210.374 pounds. The weight of the casting material was reduced by 96.854 pounds per mold or approximately 31.53 percent. The weight reduced was from the reduction in size of all the risers and the gating system.

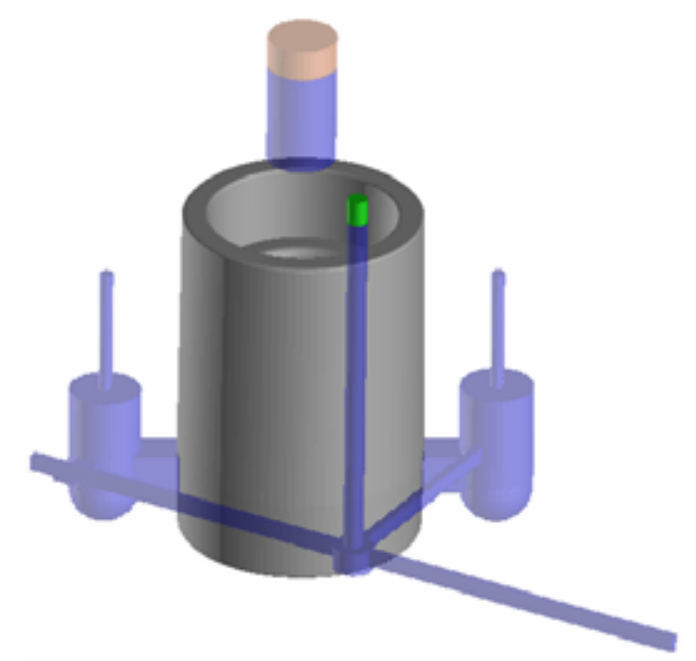

Figure 5.69: Casting model built from calculated dimensions for Test 3.

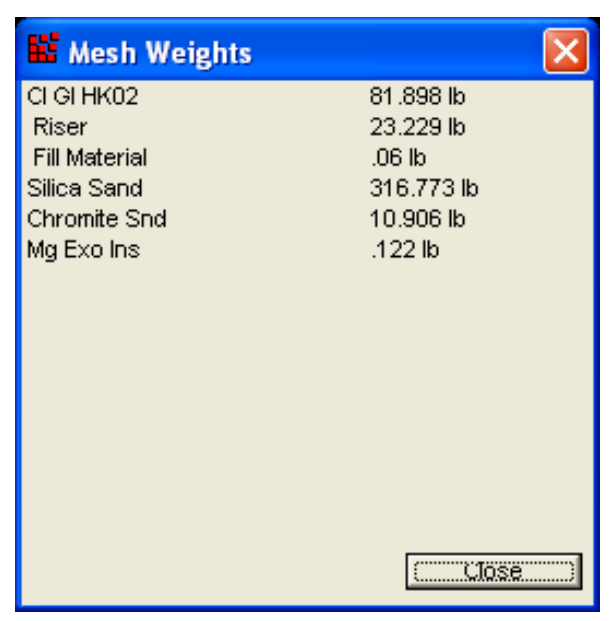

Figure 5.70: The weights of the materials in Test 3. 
The Critical Fraction Solid Time plots showed almost exactly the same solidification progression compared to Test 2. The shared riser still seemed to feed a larger portion of the lower ring area compared to the single riser and still took more time for the liquid metal to solidify towards the shared riser than the single riser, but this test took slightly less time compared to Test 2. In the Material Density Function plots plotted with 1.0, the section at where the thin wall and the lower thick ring are connected is highlighted, as shown in Figure 5.71, but when plotted with 0.995 would disappear, and almost no predicted macroporosities are shown, as shown in Figure 5.72. The critical value for plotting a Material Density Function plot is between 0.99 and 0.995 . The highlighted areas disappeared when plotted with 0.995 showing that there is less than 0.5 percent possibility of macroporosity occurring in the highlighted areas, which means there may only be a very slight possibility to have this particular shrinkage.

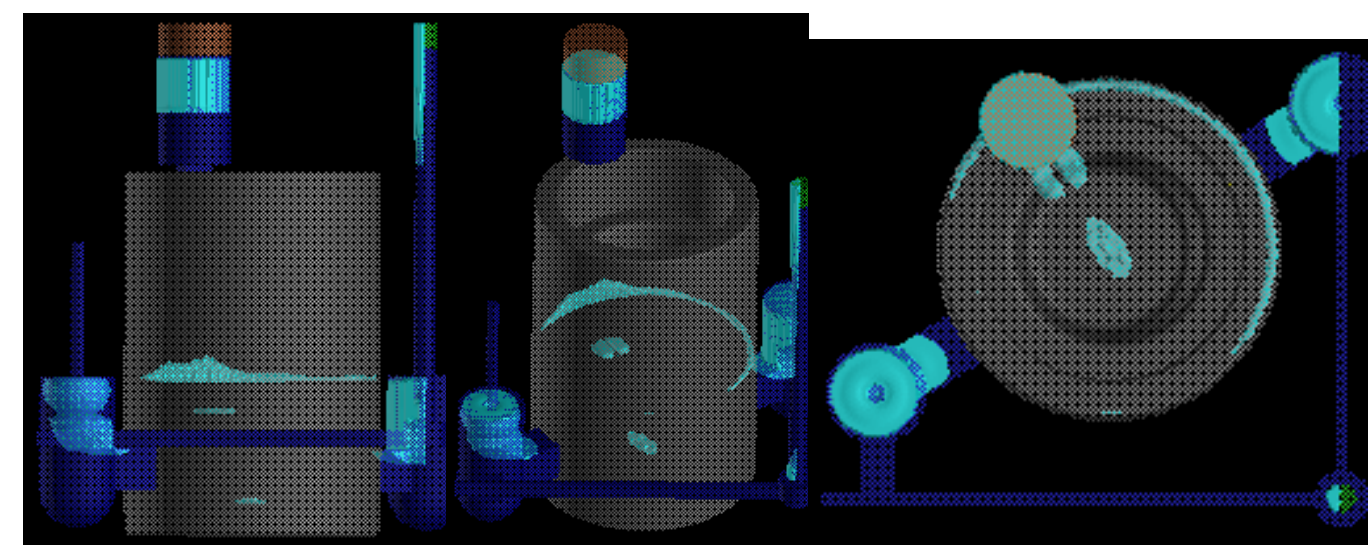

Figure 5.71: Material Density Function plots plotted at 1.0.

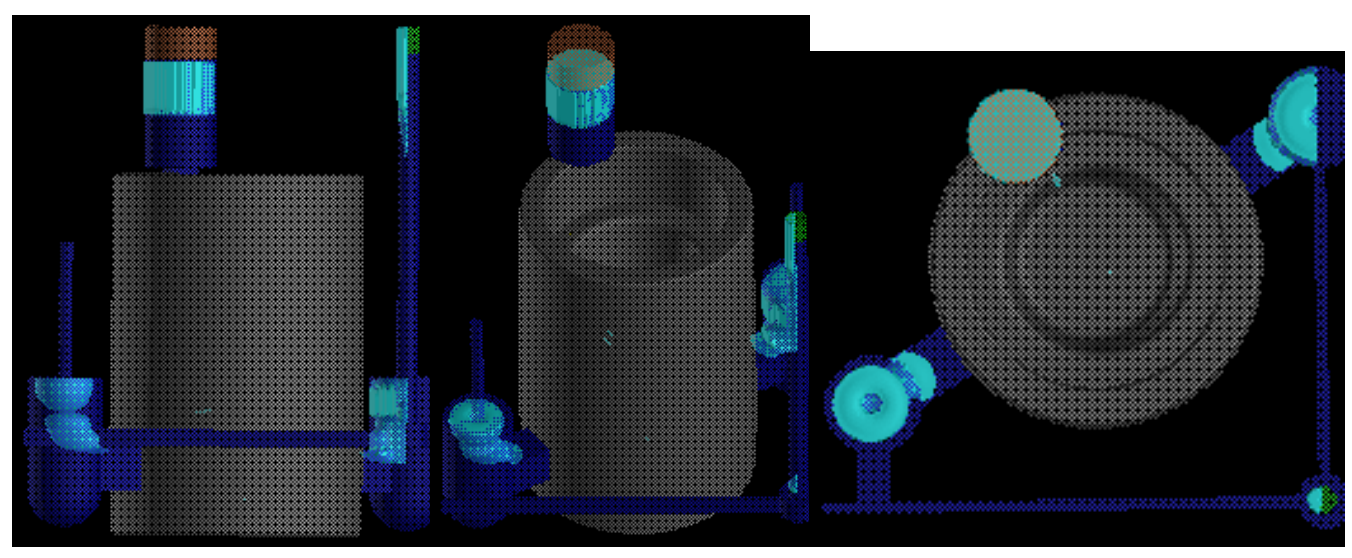

Figure 5.72: Material Density Function plots plotted at 0.995. 
The FCC Criterion plots were almost the same as Test 2, only with less highlighted areas in the upper ring area. For the Hot Spot Criterions plots, they showed a high similarity compared to Test 2 , but with less highlighted intensity, as shown in Figure 5.73 and 5.74. Compared to Test 2, Test 3 showed less predicted possible defects.

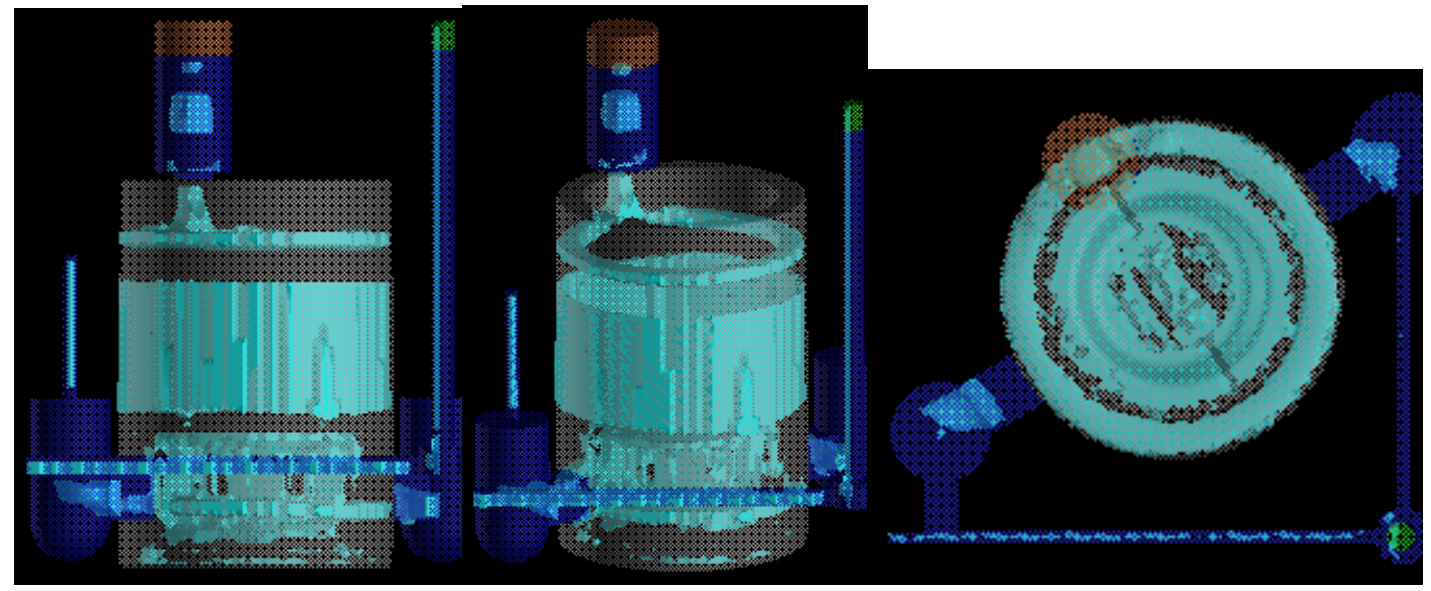

Figure 5.73: Hot Spot (Solidification Time) plotted at 1.1.

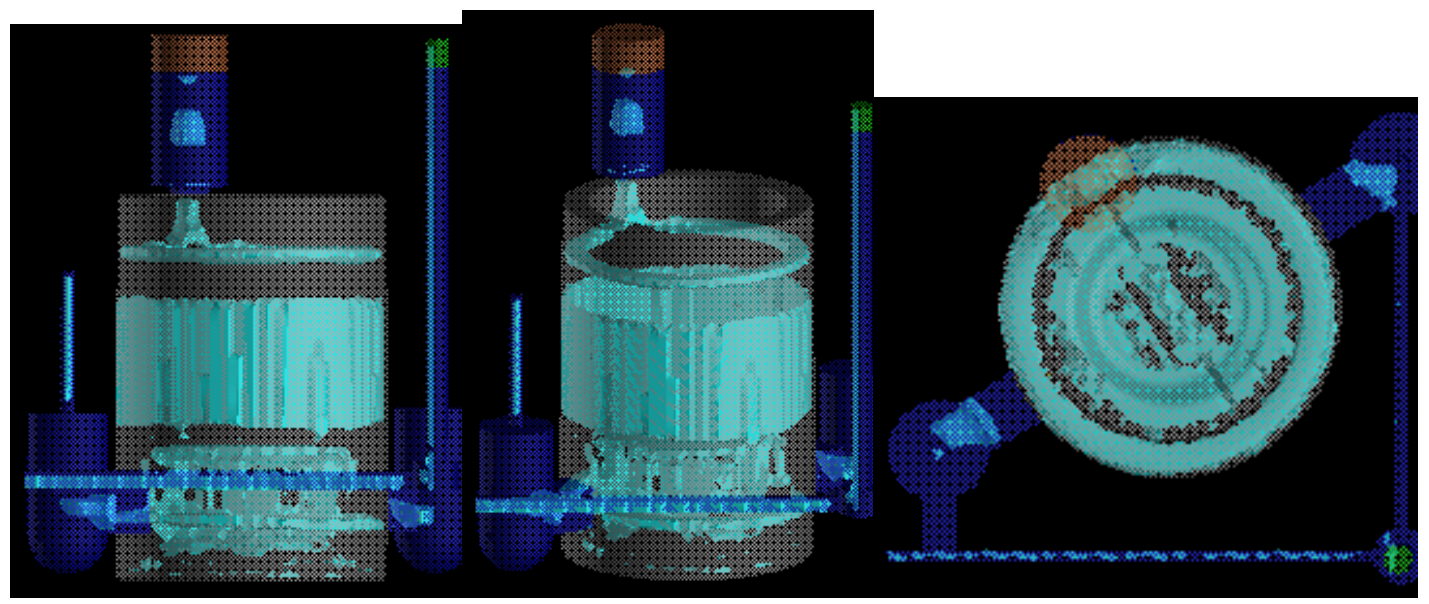

Figure 5.74: Hot Spot (Critical Fraction Solid Time) plotted at 1.1.

\subsubsection{Conclusions of Simulation Results}

The Riser and Gating Design Wizard programs were useful for designing the riser and gating system for a casting design. The results showed that the reduction in riser sizes and gating system would increase the yield. The percent decrease in casting 
material weight compared to the base case are shown in Table 5.15 and the casting yield of each case including the base case are shown in Table 5.16.

Table 5.15: The percent decrease in casting material weight compared to the base case.

\begin{tabular}{|c|c|c|c|c|}
\hline Test No. & $\begin{array}{c}\text { Casting } \\
\text { Material Mesh } \\
\text { Weight of Base } \\
\text { Case (lbs) }\end{array}$ & $\begin{array}{c}\text { Calculated } \\
\text { Casting } \\
\text { Material Mesh } \\
\text { Weight (lbs) }\end{array}$ & $\begin{array}{c}\text { Decrease in } \\
\text { Casting } \\
\text { Material (lbs) }\end{array}$ & $\begin{array}{c}\text { Decrease in } \\
\text { Casting } \\
\text { Material (\%) }\end{array}$ \\
\hline Test 1 & 307.228 & 268.468 & 38.76 & 12.62 \\
\hline Test 2 & 307.228 & 217.614 & 89.614 & 29.17 \\
\hline Test 3 & 307.228 & 210.374 & 96.854 & 31.53 \\
\hline
\end{tabular}

Table 5.16: The casting yield of each case including the base case.

\begin{tabular}{|c|c|c|c|c|}
\hline $\begin{array}{c}\text { Simulation } \\
\text { Case }\end{array}$ & $\begin{array}{c}\text { Weight of } \\
\text { Casting } \\
\text { Material (lbs) }\end{array}$ & $\begin{array}{c}\text { Weight of riser } \\
\text { and gating } \\
\text { system (lbs) }\end{array}$ & $\begin{array}{c}\text { Total Weight } \\
\text { of Model (lbs) }\end{array}$ & $\begin{array}{c}\text { Casting Yield } \\
\text { (\%) }\end{array}$ \\
\hline Base Case & 164.196 & 143.032 & 307.228 & 53.44 \\
\hline Test 1 & 164.154 & 104.314 & 268.468 & 61.14 \\
\hline Test 2 & 162.868 & 54.746 & 217.614 & 74.84 \\
\hline Test 3 & 163.796 & 46.578 & 210.374 & 77.86 \\
\hline
\end{tabular}

Both Table 5.15 and 5.16 show that the current casting design could be modified and a higher yield is possible to achieve. Even though the riser and gating dimensions produced from the Wizard programs do not produce castings with zero possible defects, or with acceptable liquid metal velocity levels, but they are a good starting point for designing a casting design. The design may then be modified or additional materials may be added with the knowledge and experience of the user to eliminate or minimize the defects. 


\subsection{Conclusions}

No castings were able to be made to prove if the modified designs would result in the same way as predicted, but the simulation results are good estimations of how a casting may come out. The calculations of an outcome could be predicted without calculating by hand or just from experience. The calculations for dimensions for risers and gating system in the Riser and Gating Design Wizard programs are based on casting knowledge and could be useful even to a user who may not know the calculations behind them. SOLIDCast was useful for modifying a casting's riser and gating system dimensions, for helping the user in designing the whole riser and gating system and for predicting the design outcomes. 


\section{Chapter 6 \\ Summary and Conclusions}

SOLIDCast is one of the casting simulation software programs that can be used to help a user visualize the solidification of a casting and forecast the outcome of a casting design. The focus of this thesis was to observe the usefulness, the capabilities and the limitations of SOLIDCast in simulating cast iron castings cast by the sand casting method. Tests were conducted on some functions of SOLIDCast which determined the important capabilities and limitations of the software. A simple casting model was created to study the usefulness of the Riser Design Wizard and Gating Design Wizard in helping the user design the risering and gating systems for a casting. SOLIDCast was used in simulating and analyzing the case study design, a casting design of a locomotive piston made from gray iron. The Riser Design Wizard and Gating Design Wizard programs were also used to improve the casting design's risering and gating designs respectively.

\subsection{Basic Capabilities and Limitations of the Simulation Function}

There are various types of defects that may occur in a casting. Different casting simulation software programs and modules may predict some types of defects that may occur in the casting. SOLIDCast is a casting simulation software program which can simulate thermal changes and heat transfer in the solidification process of a casting. It assists the user to visualize the solidification process of a particular casting. The program offers functions to produce visual outputs showing possible problem areas and possible defects that may occur in a casting. The output criterions available in SOLIDCast are:

1) Solidification Time

2) Critical Fraction Solid Time

3) Material Density Function

4) Temperature Gradient

5) Cooling Rate

6) Niyama Criterion

7) Hot Spots

- Solidification Time

- Critical Fraction Solid Time 
8) Custom Criterion

- $\quad$ FCC Custom Criterion

9) Temperature

10) Liquidus Time

The predictions are limited to the output criterions. SOLIDCast would simulate and collect temperature and time data, starting from when the metal is poured into the mold until the last node of casting material is completely solidified. The program could calculate an approximate flow and the heat loss during the flow but it cannot calculate the turbulence from the flow.

Casting simulation softwares currently do not predict the porosities occurred from first principles, i.e., the pressure drop which may occur in various parts of the casting. Many researchers found that there are other parameters which are easier to calculate and can be used for assessing the porosity formation (Campbell, 2003). From all criterions available in SOLIDCast and the custom criterion, it was found that all output criterions are functions of temperature, time and distance, except for the Material Density Function that also takes gravity into consideration.

The function of time in SOLIDCast would be restricted to the program's "time zero"; the time at which pouring ends. For example, when pouring is still in progress, some parts of the casting may lose heat and solidify before pouring is finished. There may be areas which the solidification process may not be observed because of this limitation, especially castings with very thin sections.

The accuracy of the predictions from the output criterion functions depends upon the knowledge and opinions of the user. The plots of the output criterions may need further inspection to achieve the most accurate predictions, for example, areas highlighted in the Hot Spot Criterions plots may not have any problems if a high cooling rate was achieved in that area, etc.

Tests and observations were conducted to study some of the basic functions in the SOLIDCast program that are used for simulating a cast iron casting model. The tests and their brief conclusions are presented. 


\section{1) Basic Functions for Casting Cast Irons}

This set of tests consisted of observations on the Materials List window, the Gray Iron and Ductile Iron Calculator buttons in the Curves tab and the VDG Iron Properties Calculator. It was found that only the Casting tab and the Curves tab in the Materials List window have some relationships between each other. This was found from altering the parameter values in each tab and observing the changes occurred from the alterations. Only the specific heat, the initial temperature, the solidification temperature, the freezing range and the latent heat of fusion in the Casting tab would affect the temperature curve in the Curves tab.

The Gray Iron and Ductile Iron buttons were found to achieve the same temperature curves in the Curves tab when entered with the same weight percent carbon and silicon. The slight difference found was that the temperature curve produced from the Gray Iron Calculator button slightly curved when the steepness of the temperature curve changed and had an "S" shape, whereas the Ductile Iron Calculator button did not and had a "Z" shape. As for the VDG Iron Properties Calculator, it is based on the VDG nomograms as published by the German Iron Society (Finite Solutions Inc., 2005).

The VDG Iron Properties Calculator takes five inputs; the weight percent carbon, silicon and phosphorus, casting modulus and temperature in the mold and give two outputs; the shrinkage time in solidification and the expansion or contraction rate for the user to modify the shrinkage curve and set the critical fraction solid line and the Niyama line. The temperature in mold or the average temperature in the mold was recommended in the SOLIDCast manual (Finite Solutions, 2005) to be 75 to 100 degrees Fahrenheit less than the pouring temperature. It seems inappropriate to presume the temperature. The pouring temperature was used in all tests as the temperature in mold. SOLIDCast should develop a calculator to find an appropriate temperature in mold for each particular casting by taking inputs from the user, such as the casting weight or volume, the casting modulus and the pouring temperature, etc.

The conclusions from this set of tests were that the information in the database of the program and the calculators built into the program were derived from metallurgy knowledge arranged and applied into the program. To achieve the most accurate results, 
the user must enter the correct data collected from the materials used in the casting process.

\section{2) Modifying the Curves Tab}

In SOLIDCast, the amount of shrinkage of metal at any time would equal to the volumetric difference of the mold cavity and casting. The shrinkage curve in the Curves tab is actually the shrinkage of the metal added the shrinkage occurred from the expansion of the mold or the percent mold wall movement. Modifying the shrinkage curve would not affect the weight of the casting because the weight of the casting is calculated from the size of the nodes, the total number of nodes and the density of the material. The calculation of the weight of a casting could only be found from meshing and not from simulation. It was also found that SOLIDCast does not simulate the dimensional shrinkage or expansion of the casting.

Modifying the shrinkage curve in the Curves tab only affected the Material Density Function output criterion plots. It was also found that the shrinkage occurred before the liquid metal reaches its liquidus point would form a flat shape pipe. The shrinkage that occurred after the liquidus point would form a cone shape pipe. Contraction or expansion was not significant after the liquid metal passes its critical fraction solid point.

\section{3) Other Tests}

It was found that SOLIDCast would allow liquid metal to flow until it reaches its solidification point instead of the critical fraction point where it should lose the ability to flow. The user must use his or her own judgment in identifying misruns and coldshuts. The program may need improvement to allow the liquid metal to flow until it reaches its critical fraction solid point, not its solidification point.

The maximum number of nodes which could be created by this version of SOLIDCast was 19,046,664 nodes. The Planes of Symmetry function was a useful function which can help reduce the use of nodes in a simulation. It reduced the time used for simulating a casting model using the same node size or could achieve more detailed simulation results using a smaller node size for a symmetrical casting design. It was 
found that the meshing starts from the edge of the casting model, so, the symmetrical plane may not actually be at the symmetrical line dividing the symmetrical model. The user must select a node size which would divide the model symmetrically or select the smallest node size possible in order to achieve the most accurate results.

A test was also conducted to observe the meshing function. A portion of the material would be considered a whole node if it is larger than half the size of the node size and neglected if smaller. The node size could not exceed the size of the thinnest section of any material used in the mold. Because the weights of each material in the model were calculated from the number of nodes, the node size and the density of the material, the only situation where the calculated weights of the model would be exactly correct is if the model intersects perfectly with the nodes. For intricate shaped models, the more detailed the meshes could represent the model or the smaller the nodes could possibly be, the better approximation of the weights of the model.

\subsection{Usefulness of the Riser Design Wizard and Gating Design Wizard Programs}

The Riser Design Wizard and the Gating Design Wizard were programs built into SOLIDCast to help a user develop risering and gating designs. Using the simple hollow rectangular box shaped casting case and the case study, the calculation methods behind the programs were analyzed and the formulas used in the programs were uncovered.

SOLIDCast has two separate Riser Design Wizard programs. One was accessed from the VDG Iron Properties Calculator and the other from the Simulation tab in the menu. The one accessed from the VDG Iron Properties Calculator would draw the results from the calculator into the program to calculate for the riser and neck dimensions. This Riser Design Wizard program would only be good for calculating a riser for a single feeding area casting. The other Riser Design Wizard accessed from the Simulation tab in the menu was able to calculate dimensions for multiple risers, but does not provide the neck dimensions for the risers.

The Riser Design Wizard and the Gating Design Wizard programs provide only some information in designing the risering and gating systems. The output dimensions from the program and the dimensions which must be determined by the user are shown in the following: 


\section{1) Riser Design Wizard Accessed from the VDG Iron Properties Calculator}

This Riser Design Wizard used two methods to calculate the riser design; a calculation based on riser volume requirement and a calculation based on the riser modulus being at least 20 percent more than the calculated neck modulus. The latter method of calculation would only be used if the calculation based on volume requirement does not satisfy the rule that the riser modulus has to be at least 20 percent larger than the calculated neck modulus. The output values from the wizard program are as follows:

- Riser diameter and height

The program assumes the shape of a side riser would have a cylindrical shape with the calculated diameter and height added a hemispheric bottom, so, the true height per diameter ratio would not be the same as entered primarily. For a top riser, the program would calculate a riser size with twenty percent more volume than the side riser without the hemispheric bottom.

- Neck dimensions

- Diameter of neck

- Neck dimensions as a cubic shape

- Neck dimensions with a rectangular connecting face with same area as the cubic neck

The neck dimensions were calculated from the calculated neck modulus and had a cubic shape, i.e., the width, thickness and length of the calculate neck had the same length. If the user would want to change the connecting surface to a different shape, such as a rectangular shape, the true modulus of the neck would change and the solidification rate of the neck would change as well. The program provides a built-in calculator to calculate for a rectangular shape connecting surface with the same area as the calculated square shape connector, but this would change the modulus of the neck.

The Riser Design Wizard does not locate the position where the user should attach the riser nor what type of riser should be used for the casting. The user must use his or her own judgment to position the riser. 


\section{2) Riser Design Wizard Accessed from the Simulation Tab}

This Riser Design Wizard program can help the user design multiple risers for a casting with multiple feeding areas determined by the program. The calculations for the riser dimensions are based on the method that the riser to casting modulus ratio is 1.2. The output values from the wizard program are as follows:

- Riser diameter and height

The program assumes that the shape of either a side or a top riser would have a cylindrical shape, which is different from the other Riser Design Wizard. The height per diameter ratio of the calculated riser dimensions would have the same ratio as entered primarily.

This wizard program does not provide neck dimensions. They must be determined by the user. This wizard program also does not provide the position where the user should attach the riser nor what type of riser should be used for the casting.

\section{3) Gating Design Wizard}

When entered the Gating Design Wizard, the flow rate of the liquid metal must be calculated. The user must enter the alloy sensitivity and the pour weight (including casting and rigging). The alloy sensitivity value must be approximated by the user without exact rules of which alloy must have what certain value. The critical section thickness must be approximated by the user to calculate the fill time or the user may enter the fill time from past experience. The approximate sprue height added the liquid metal in the basin and the casting dimensions for the selected gating system must be determined by the user. The user must also determine the gating ratio for the casting design from casting handbooks according to the alloy used.

The Gating Design Wizard program would provide the user with the calculated areas, velocities and diameters of the choke area, the area at the bottom of the sprue and the area at the top of the sprue. It also provides the total runner area and required ingate area. The areas of the bottom of the sprue, the runner and the ingate would fall in the gating ratio set by the user, but their calculated values are the results of its ratio value multiplied by the calculated choke area instead of the smallest of the ratio being the 
choke. For example, the ingate area for a gating ratio of 4:8:3 would have three times the area of the calculated choke area. This would permit the pouring time to be reduced up to one third of its original value and thus this calculation needs further investigation.

It seems that SOLIDCast does not consider the velocity of liquid metal and it may be higher than the critical maximum velocity of liquid metal (Campbell, 2004) and may damage the casting. An experienced user must consider the dimensions calculated from the Gating Design Wizard to be a guideline in designing the gating system and modify the dimensions or otherwise to reduce the velocity of the liquid metal.

SOLIDCast has an extension program called FLOWCast used for simulating the flow of liquid metal during pouring. Since SOLIDCast cannot simulate the affect of the velocity of liquid metal, FLOWCast should be used along side SOLIDCast to help the user modify the gating dimensions calculated from the Gating Design Wizard. SOLIDCast may also need to be improved so it may recognized and warn the user if velocities of liquid metal may be too high.

The program provides calculators for calculating dimensions for rectangular runners and ingates. The program does not recommend what should the width per depth ratio for the runners or width per thickness ratio for the ingate be. It is only recommended in the SOLIDCast manual (Finite Solutions Inc., 2005) that the width per thickness ratio of the ingate should be 5 to encourage high cooling rate so it may freeze off quickly. As for the runners, a width per depth ratio of 0.5 is practical. The program is also able to calculate the "step down" calculation of the runner, meaning the runner areas after each ingate.

The program does not provide the length of the runners or the ingates, but the length must be larger than the width or thickness of the ingate or runner. The user must determine the dimensions of the pouring basin, the height of the sprue and calculate the dimensions of the sprue well.

\section{4) Conclusions for Riser Design Wizard and Gating Design Wizard}

Designing the risering and gating systems for a casting design, the user must design the layout. For example, the orientation of the casting, where the risers should be attached to the casting and where the gating systems are laid, etc. The dimensions of the 
risers and gating system calculated from Riser Design Wizard and Gating Design Wizard programs may not produce the best solution or defect free casting, but would produce a good starting point for the user to modify and achieve good castings.

\subsection{Further Capabilities and Limitations Found from the Case Study}

It was found early in the testing of the case study that the orientation of the casting in the model significantly affected the simulation process. Because the program is based on the Finite Difference Method, the program is axis critical. Revolving the casting and using the same node size resulted in different casting weights and different simulation results.

In the case study, the metal in the drill holes would freeze and misrun, but the simulation showed that the drill holes were completely filled. This shows that the calculation for the shrinkage curve may not be correct and the methods for calculating for the shrinkage curve may need to be improved.

The simulation results showed very positively that the defects detected from the simulation matched with the defects found in the casting. But the simulation results seemed to show signs of axis dependence, such as the highlighted plots were denser near the $\mathrm{X}$ and $\mathrm{Y}$ axes.

SOLIDCast is a useful tool for forecasting the outcomes of a modified casting design. So, instead of trial casting modified designs, the modified design could be tested by SOLIDCast to see its possible outcomes to reduce defects and improve yield.

\subsection{Future Recommendations}

Since SOLIDCast is a Finite Difference Method based casting simulation program, the orientation of the casting is important in the solution. Guidelines must be developed to indicate proper orientation to give better solutions more rapidly. The impact of the orientation difference should be determined to determine preventatively the effect of orientation.

The maximum number of nodes is a restriction reducing the use of an effective node size for the thinnest part of the casting. Either the program should be able to have 
more nodes along with faster calculation methods or the meshing method should be improved.

The use of different node sizes, like the Finite Element Method, must be investigated to reduce the simulation times. Thick sections must be able to use larger nodes than thin sections. A possible suggestion method to achieve a larger node size is to combine $\mathrm{x}^{3}$ number of nodes $(8,27,64$, etc.) into a large single node.

\subsection{Conclusions}

The accuracy of the simulation depends highly on the input parameters while the accuracy of the predictions from the output criterion functions depends highly on the knowledge and opinions of the user. Although, SOLIDCast may have many limitations, it still is a good tool for verifying the solidification process in a casting. In the future, metallurgists and software developers may produce more precise casting simulation software programs that would be user friendly to users with a minimum metallurgical background. Modules may be developed to find the best design for a casting for casting quality, yield improvement, and scrap reduction. 


\section{REFERENCES}

1. Alonso, Arnaldo and Franco, Luis, Foundry Management and Technology, Penton Publishing Co., v 133, n 10, October, 2005, p. 22 - 24.

2. Andersen, B., "Temperature management [Casting Process]", Die Casting Engineer, v. 50, n 1, January, 2006, p. $42-46$.

3. Callister, William, D., "Material Science and Engineering: An Introduction", $7^{\text {th }}$ Edition, John Wiley \& Sons, Inc., 2006.

4. Campbell, John, "The New Metallurgy of Cast Metals: Casting", $2^{\text {nd }}$ Edition, Butterworth-Heinemann, 2003.

5. Campbell, John, "Castings Practice - The 10 Rules of Castings", 2004.

6. Creese, Robert C., "Introduction to Manufacturing Processes and Materials", 1999.

7. Charoenvilaisiri, Sombun, Ph.D., Faculty of Engineering, Production Engineering Department, King Mongkut's University of Technology Thonburi, Bangkok, Thailand, 2006, Personal communication.

8. Danzur, Wynn, "The Casting and Molding Processes", Wynn Danzur Marketing, www.wynndanzur.com.

9. De Looze, G., "Effect of die temperature and melt quality on a commercial low pressure die casting", Shape casting, The John Campbell Symposium, Proceedings of a Symposium Sponsored by the Aluminum Committee of the Light Metals Division (LMD) and the Solidification Committee of the Materials Processing and Manufacturing Division of TMS, held at the 2005 TMS Annual Meeting, 2005, p. $423-432$.

10. Finite Solutions Inc., "SOLIDCast", Training Course Workbook, Copyright $\mathbb{C} 2005$, Version 6.3.39.

11. Finite Solutions Inc., "Training Overview 6.3.39”, PowerPoint slides, January 15, 2005.

12. Guharaja, S., Noorul Haq, A. and Karuppannan, K. M., "Optimization of Green Sand Casting Process Parameters by Using Taguchi's Method", International Journal of Advanced Manufacturing Technology, v. 30, n 11 - 12, October, 2006, p. 1,0401,048 . 
13. Heine, Richard W., Loper, Carl R. and Rosenthal, Philip C., "Principles of Metal Casting”, TMH Edition 1976, Tata McGraw-Hill Publishing Company Limited, India, 1995.

14. Herman, Edmund, "Casting cycle rate by design", Die Casting Engineer, v. 48, n 5, September, 2004, p. $46-52$.

15. Iron Castings Society, "Iron Castings Handbook", 1981.

16. Jakumeit, J., Laqua, R., Iyas, T., Scheele, J., Braun, M., Mukhopadhya, A., Pelzer, M., "Multidisciplinary coupled simulations of investment casting processes using CASTS-FLUENT", Proceedings of Modeling, Control and Optimization in Ferrous and Nonferrous Industry Symposium, 2003, p. $333-342$.

17. Lewis, R. W., Ransing, R. S., Pao, W. K. S., Kulasegaram, K. and Bonet, J., Civil and Computer Engineering Centre, University of Wales Swansea, UK, "Alternative Techniques for Casting Process Simulation", International Journal of Numerical Methods for Heat \& Fluid Flow, v. 14, n 2, 2004, p. 145 - 166.

18. Liu, Wenhui, Liu, Yangai, Xiong Shoumei, Liu, Baicheng, Matsumoto, Y., Murakami, M., "Influences of casting pressure conditions on the quality and properties of a magnesium cylinder head cover die casting", Journal of Materials Science \& Technology, v. 21, n 2, March 2005, p. 170 - 174.

19. Moreira, Jose and Ribeiro, C.A. Silvia, "Confrontation of two solidification simulation software to a particular use into foundry industry", Material Science Forum, v 455 - 456, Advanced Materials Forum II: Proceedings of the II International Materials Symposium: Materials 2003 and XI Encontro Sociedade Portugesa de Materials, 2003 ATERIAIS, 2004, p. 690 - 693.

20. Pan, Weihua, Shen, Yunfu and Zhang, Wu, "Grid-based simulation system of casting solidification process", $8^{\text {th }}$ International Conference on Computer Supported Cooperative Work in Design (IEEE Cat. No. 04EX709, 2004, pt. 1, 692 - 697 Vol. 1.

21. Pearce, John T. H., Dr., Tanasombat, Bancha, Dr. and the METALS Group, "Casting Defects", National Metal and Materials Technology Center (MTEC) of Thailand, 2001. 
22. Pernicka, E., G.A. Wagner, et al. "Early Bronze Age Metallurgy in the Northeast Aegean.”, Troia and the troad: scientific approaches, Berlin, London: Springer; 2003, p. $143-172$.

23. Pongsukijwat, Suwanchai, Lortongkum, Kobbun, Nisaratanaporn, Aekasit, Lueangwaranunt, Thachai, Supradit Na Ayutthaya, Mawin and Wisuthpitakkul, Patama, "Materials Science and Engineering: An Introduction", Top Publishing Co., Ltd., 2005.

24. Pongsukijwat, Suwanchai, "Computer Simulation in Metal Forming Processes", Research Group of Solidifications of Liquid Metals, Department of Metallurgy, Faculty of Engineering, Chulalongkorn University, Thailand, 2006.

25. Pongsukijwat, Suwanchai, Department of Metallurgy, Faculty of Engineering, Chulalongkorn University, Thailand, 2006, Personal communication.

26. Prasertsakul, Supachai, Assistant Professor, "Foundry Technology Vol. 2 Standard Edition”, B \& K Science \& Engineering Publisher.

27. Ravi, B., "Metal Casting - Computer Aided Design and Analysis", Prentice Hall of India Private Limited, New Delhi, 2005.

28. Sarfaraz, Ahmad Reza, "Computer Simulation and Experimental Analysis of Fin Effect in L Shaped Casting", Dissertation, College of Engineering of West Virginia University, 1988.

29. Society of Manufacturing Engineers, "Fundamental Manufacturing Processes: Nearnet Shape - Casting".

30. Wang, Huei-Sen, Tseng, Hua-Ling, Hwang, Weng-Sing, Weng, Ruey-Jer, Yeh, Jiunn-Lin, "Measurements of interfacial heat transfer coefficients during the casting of high temperature alloys in sand mold and ceramics mold", Modeling of Casting, Welding and Advanced Solidification Process - X. Proceedings of the Tenth International Conference, 2003, p. $693-700$.

31. Webster, P. D., "Fundamentals of Foundry Technology", Portcullis Press Ltd., 1980.

32. Wong, Chen-Chieh, "Applications of Campbell's casting rules on high quality aluminum castings", JOM, v. 56, n 11, November, 2004, p. $301-302$.

33. Wright, Frank, "Walker die casting finds new ways to compete", Die Casting Engineer, v. 48, May, 2004, p. $32-38$. 
34. Yang, L. J., "The effect of casting temperature on the properties of squeeze cast aluminum and zinc alloys", Journal of Materials Processing Technology, v. 140, n 1 3 SPEC, September 22, 2003, p. $391-396$.

35. Zanchuk, V., "ZA-12 alloy casting with graphite molds: economical precision parts, reduced time-to-market", Die Casting Engineer, North American Die Casting Association, USA, v. 50, n 1, Jan 2006, p. 38 - 41.

36. www.alphacast-software.co.uk

37. www.calcom.ch

38. www.castech.fi

39. www.ekkinc.com

40. http://en.wikipedia.org/wiki/Rapid_prototyping

41. www.hkec.com

42. http://www.key-to-steel.com/Articles/Art63.htm.

43. www.magmasoft.com

44. www.metal-technologies.com, "History of metal casting".

45. http://www.moderncasting.com/MoreInfo/0804/MoreInfo_06_0804.pdf

46. http://www.mrl.ucsb.edu/ edkramer/LectureVGsMat100B/99Lecture14VGs/FeCPha seDiagramVG.html

47. http://www.msm.cam.ac.uk/phase-trans/2001/adi/cast.iron.html, University of Cambridge.

48. www.novacast.se

49. www.technalysis.com

50. http://www.twi.co.uk/j32k/protected/band_3/jk25.html.

51. www.simtec-inc.com

52. Wikipedia, The Free Encyclopedia, http://en.wikipedia.org. 